\title{
Third language acquisition
}

Age, proficiency and multilingualism

Edited by

Camilla Bardel

Laura Sánchez

Eurosla Studies 3 


\section{EuroSLA Studies}

\section{Editor: Gabriele Pallotti}

Associate editors: Amanda Edmonds, Université de Montpellier; Ineke Vedder, University of Amsterdam

In this series:

1. Pérez Vidal, Carmen, Sonia López-Serrano, Jennifer Ament \& Dakota J. Thomas-Wilhelm (eds.). Learning context effects: Study abroad, formal instruction and international immersion classrooms

2. Saturno, Jacopo. Utterance structure in initial L2 acquisition.

3. Bardel, Camilla \& Laura Sánchez (eds.). Third language acquisition: Age, proficiency and multilingualism. 


\section{Third language acquisition}

Age, proficiency and multilingualism

Edited by

Camilla Bardel

Laura Sánchez 
Bardel, Camilla \& Laura Sánchez (eds.). 2020. Third language acquisition: Age, proficiency and multilingualism (Eurosla Studies 3). Berlin: Language Science Press.

This title can be downloaded at:

http://langsci-press.org/catalog/book/268

(C) 2020, the authors

Published under the Creative Commons Attribution 4.0 Licence (CC BY 4.0):

http://creativecommons.org/licenses/by/4.0/@ @

ISBN: 978-3-96110-280-8 (Digital)

978-3-96110-281-5 (Hardcover)

ISSN: $2626-2665$

DOI: 10.5281/zenodo. 4138753

Source code available from www.github.com/langsci/268

Collaborative reading: paperhive.org/documents/remote?type=langsci\&id=268

Cover and concept of design: Ulrike Harbort

Typesetting: Carla Bombi Ferrer, Felix Kopecky

Proofreading: Amir Ghorbanpour, Andreas Hölzl, Edalat Shekari, Elen Le Foll, Eliane Lorenz, Ivelina Stoyanova, Jeroen van de Weijer, Daniela Kolbe-Hanna, Lotta Aunio, Sean Stalley, Tom Bossuyt

Fonts: Libertinus, Arimo, DejaVu Sans Mono

Typesetting software: $\mathrm{X}_{\mathrm{H}} \mathrm{AT} \mathrm{T} \mathrm{X}$

Language Science Press

xHain

Grünberger Str. 16

10243 Berlin, Germany

langsci-press.org

Storage and cataloguing done by FU Berlin

Freie Universität 


\section{Contents}

1 Introduction

Camilla Bardel \& Laura Sánchez

2 Multilingualism from a language acquisition perspective Laura Sánchez

3 The conceptualisation of knowledge about aspect: From monolingual to multilingual representations

Rafael Salaberry

4 The mental lexicon of multilingual adult learners of Italian L3: A study of word association behavior and cross-lingual semantic priming Anna Gudmundson

5 The acquisition of clitic pronouns in complex infinitival clauses by German-speaking learners of Italian as an L3: The role of proficiency in target and background language(s)

Sandro Sciutti

6 Cognate recognition by young multilingual language learners: The role of age and exposure

Carmen Muñoz

7 Age meets multilingualism: Influence of starting age on L3 acquisition across different learner populations

Simone E. Pfenninger

8 From L2 to L3, verbs getting into place: A study on interlanguage transfer and L2 syntactic proficiency

Laura Sánchez

9 L1 Dutch vs L2 English and the initial stages of L3 French acquisition Rosalinde Stadt, Aafke Hulk \& Petra Sleeman 



\title{
Chapter 1
}

\section{Introduction}

\author{
Camilla Bardel
}

Stockholm University

Laura Sánchez

Stockholm University

This book is concerned with how languages are learned by someone who already speaks at least two languages. Hence, the authors of the different chapters look beyond the classical second language acquisition perspective, according to which the researcher, traditionally, is interested in how people with monolingual backgrounds learn a second language (L2) or how bilingual speakers use and process their two languages. Research into third language (L3) acquisition or learning, ${ }^{1}$ a branch of multilingualism that studies how multilinguals learn an additional language, has grown strong during the last decades. In this research area, we reserve the term bilingualism for cases where two languages coexist in the mind of the individual, a first language (L1) and an L2, or two L1s.

When two or more languages are present in the speaker's mind, no perfect balance among these languages can be expected. Variation and dynamics concerning use, style and proficiency of the different languages an individual knows are characteristic for the multilingual language system.

In this volume, the L3 is viewed in the light of three factors: age, language proficiency and multilingualism itself. Age can be considered in different ways. Both the age of onset of learning the target language and that of previously acquired languages (as in simultaneous vs. sequential bilinguals) are of interest (see e.g., the empirical studies of Muñoz, Pfenninger and Sánchez in this volume). Age

${ }^{1}$ For the sake of convenience, the terms acquisition and learning will be used interchangeably in this introduction. 
and its interaction with multilingualism is focused on in the chapters by Carmen Muñoz and Simone Pfenninger, both conducted in instructed settings, and it is also discussed in depth in the first chapter of the volume, a conceptual paper written by Laura Sánchez. Proficiency in the target language has been held as one of the key factors for the intricate crosslinguistic influence in L3 learning and use ever since the seminal paper from Williams \& Hammarberg (1998) was published. The proficiency level in the L2 has also been suggested to play a role for L3 development and for transfer from the background languages (i.e., L1 and L2, see e.g., Bardel \& Lindqvist 2007; Sánchez \& Bardel 2017). In this volume, an empirical study by Sánchez pursues the subject of proficiency in the L2, while Sandro Sciutti, in his study, investigates proficiency in the L3 as well as in the L2 in the understudied area of clitic pronouns in L3 acquisition. In a study on the multilingual lexicon, Anna Gudmundson investigates how an L2 in which learners have high proficiency can play a role in word associations in the L3, and finds that the L2 can mediate semantic access for L3 words.

One basic assumption in research on L3 learning is that multilingualism per se (bilingualism included) enhances both further language learning and the potentially achieved proficiency in additional languages. It has been suggested that both L1 and L2 knowledge (Flynn et al. 2004; Berkes \& Flynn 2016), and the experience of second or foreign language learning (Hufeisen 2005; Jessner 2006), will benefit the learning of subsequent languages. Possible explanations of such positive effects of multilingualism would be the cognitive advantages in terms of language awareness and high degrees of metalinguistic knowledge and communicative skills that multilingual learners may have developed while learning and using multiple languages. Cummins' $(1976 ; 1991)$ interdependence hypothesis concerning the role of literacy skills in L1 for L2 development and threshold hypothesis for the positive effects of proficiency have been adopted by several L3 researchers (e.g., Cenoz 2003), who suggest that proficiency in the L1 and in the L2 may affect the learning of an L3 positively. However, that multilingual language learning is complex and depends on a number of interacting factors becomes clear in Muñoz' chapter in this volume, where age is shown to play an important role for young learners' capacity to draw on cognates in the languages they know, and in Pfenninger's study, which emphasizes the role of social and educational factors for successful multilingual development. To diverse degrees, all the papers in the volume deal with the complex relationship between age, proficiency and multilingualism in additional language learning.

Two linguistic areas that have a longstanding tradition in the L3 field are lexis and syntax. Among the six empirical papers in this volume we have included two chapters that specifically deal with lexical aspects (Gudmundson; Muñoz) 
and three studies on syntax (Sánchez, Sciutti and Stadt et al.). As for the biological age of the participants, two of the chapters are concerned with adult learners (Gudmundson; Sciutti) and four with young multilinguals learning an additional language in school contexts (Muñoz; Pfenninger; Sánchez and Stadt et al.). The volume starts with two conceptual papers. The first chapter, Multilingualism from a language acquisition perspective, by Laura Sánchez, is a state of the art of research into multilingualism with a special focus on the respective roles of age and proficiency in L3 acquisition. As such it offers a theoretical background to the content in the rest of the volume. Moreover, it presents a brief overview of research on crosslinguistic influence in L3 acquisition. The chapter draws an important distinction between two types of multilingual language learning. One is third or additional language learning by people who have previous experience of one or more non-native languages learned as adults, or at least after the critical period $(\mathrm{CP})$. The other type is third or additional language learning by bilinguals from an early age. Especially the age factor, but also the proficiency factor, can be expected to come into play differently in these two types of multilingualism considering that in the first case, the L2 has been learned after the $\mathrm{CP}$ and in the second, two languages have been acquired before this phase in the individual's cognitive and linguistic development. This can be assumed to be an important distinction to make when it comes to different conditions for processing, development and ultimate attainment of the languages that constitute the background knowledge and potential transfer sources in L3 learning.

In the second chapter, also essentially theoretical, The conceptualization of knowledge about aspect: From monolingual to multilingual representations, Rafael Salaberry looks into the grammatical category of aspect from the L3 perspective. The queries posed in this chapter concern the roles of the background languages and the differences in processing mechanisms used for implicit versus explicit knowledge (Ellis 2005), or implicit competence versus explicit knowledge (Paradis 2009), that may determine crosslinguistic influence. According to the author, the complex construct of aspect, with its semantic, syntactic and discursive facets, lends itself ideally for evaluating the potential effect of the L1 and the L2 on the developing L3, and for assessing two dimensions that have been identified in recent theoretical L3 models: typological proximity, on the one hand, and the processing mechanisms applied in implicit competence versus explicit knowledge, on the other. The range of linguistic representations of the perspective-driven notion of aspect and its prototypical and non-prototypical conceptualisations related to context make it a complex part of language to grasp in an L2, let alone in multilingual learning. As pointed out by Salaberry, this complexity and the fact that the temporal-aspectual systems differ to various degrees between groups 
of languages, for instance when comparing Romance languages and Germanic languages, render aspect an interesting test case for the effect on the L3 of prior knowledge of and about languages that are similar to or different from the new language in this respect.

The few available empirical studies on L3 learning of aspect and a few recent L2 studies are reviewed in the chapter. These are interpreted as support for the claim that processing constraints associated with L2/L3 learning are distinct from those linked to the L1. According to the author, L3 data on aspect learning indicate that the L3 will mainly rely on the same processing mechanisms as those used in the L2. It is acknowledged that recent L2 studies point to an influence from the L1 in learning aspect in the new language and that there is an L1 effect across all subsequently acquired languages, at least when it comes to non-prototypical meanings of aspect, and as mentioned, there are few L3 studies on aspect. This may be related to its inherent semantic, syntactic and morphological complexity, a complexity which makes it hard to set up rigorous designs for comparison when multiple languages are involved. More empirical studies of this particular linguistic area are needed and consequently the paper ends with a call for more studies on aspect in multilingual learning.

The two conceptual papers summarized above are followed by two chapters presenting empirical studies on adult L3 learners, one on the multilingual lexicon (Gudmundson) and one on L3 syntax (Sciutti). Chapter 3, The mental lexicon of multilingual adult learners of Italian L3: A study of word association behaviour and cross-lingual semantic priming, by Anna Gudmundson, is a partial replication of a study of bilingual speakers conducted by Fitzpatrick \& Izura (2011), who found differences in types of bilinguals' word associations in their L1 and L2. Widening the scope to three languages, Gudmundson investigated the mental lexicon of multilingual speakers of Swedish L1, English L2 and Italian L3. All participants were unbalanced trilinguals in terms of proficiency, having started with Italian as adults and with relatively high proficiency in English and lower proficiency in Italian.

The aim of the study was to identify how word associations differ, in terms of association type and response time, in the native and the non-native languages. The effect of language status (L1, L2 or L3) and association category on reaction time and on the distribution of associations in different categories was measured in word association tasks in all three languages. Results showed a difference between the languages regarding the association distribution; for example, the proportion of equivalent meaning associations was larger in the L1 than in the L2, and larger in the L2 than in the L3. The proportion of non-equivalent meaning 
associations showed the opposite pattern, indicating a switch in the type of associations related to proficiency. Collocational associations were mainly made in the L1 and form-based associations were mainly made in the L3. There was also a difference regarding the speed of association, that is, participants associated faster in the L1 than in the L2 and in the L2 than in the L3, generally. As regards the speed related to the different association categories, though, the pattern was similar across all languages; reaction times were fast for collocational associations and equivalent meaning associations, and slower for non-equivalent meaning associations. Results suggest that the differences are due to differences in proficiency levels but that the basic mechanisms related to lexical representation and access are similar in all languages.

The study also investigated the effect of long-term semantic priming and lexical mediation between L2 and L3, that is, whether the activation of conceptual information of L3 words was mediated by corresponding word forms in the L2. The primes were English translation equivalents of stimulus words from the prior Italian word association task. The translation equivalents obtained shorter reaction times compared to control words, indicating that L2 English words were activated during the L3 Italian word association task. This result from trilingual speakers is interesting in relation to the one obtained by Fitzpatrick \& Izura (2011), who found a semantic mediation effect in L2 from L1 word forms in bilingual speakers. Gudmundson's results from multilinguals contribute by recognizing that an L2 in which a learner has high proficiency can take on a similar role as the L1 in that it can mediate semantic access for L3 word forms in a similar way.

In the next chapter, The acquisition of clitic pronouns in complex infinitival clauses by German-speaking learners of Italian as an L3: The role of proficiency in target and background language(s), Sandro Sciutti reports findings from a study on the acquisition of clitic pronouns in Italian as an L3 by L1 speakers of German with L2 knowledge of either French or Spanish. Whereas Romance languages like Italian, French and Spanish display different series of clitic pronouns, these are not present in German. The participants in this study, 20 German-speaking learners aged between 20 and 47, were grouped on the basis of their proficiency level in Italian (intermediate or advanced) and categorized according to their L2, either French or Spanish. The learners who had French as L2 $(n=10)$ were further divided into a low and a high proficiency group (5 in each group), with respect to their self-assessed knowledge of French. The same distinction was not applicable for the group with Spanish as L2 $(n=5)$, whose self-assessed proficiency was generally high. The learners' performances in three experimental tests in Italian - one elicited production, one grammaticality judgment and correction task, and 
one written translation task - were analysed to determine whether the acquisition of clitics in clauses with infinitives was affected by the proficiency level in L3 Italian, by the specific L2 (French or Spanish) or by the proficiency level in the L2 (because the learners of Spanish had all self-assessed their L2 proficiency level as high, this was only applicable for the learners with French as L2). The analysis focused on overall production and avoidance of clitic pronouns as well as on their forms and placement. Results show that the degree of proficiency in both L2 and L3 seems to be of importance for the acquisition of clitics. They are generally difficult to acquire and their many morpho-syntactic properties are generally not completely mastered at an intermediate level of Italian, where they are often omitted or replaced with lexical determiner phrases. Learners with advanced proficiency in the target language showed a better mastery of all the properties of clitisation than those with intermediate proficiency. This was true across all the experimental tasks. Furthermore, an examination of clauses containing an infinitive governed by a causative verb (e.g., lo faccio lavare in lavanderia - 'I will have it washed in the laundry'), revealed that difficulties with the multifaceted phenomenon of Italian clitics may remain at advanced levels. As for proficiency in French or Spanish, high proficiency in a Romance L2 seems to play a positive role for the production of clitics and the reduction of their omissions in Italian as an L3. The higher the proficiency in the L2, the more prone the learners seemed to be to transfer their knowledge about the existence of clitics from one Romance language to another. Especially for the Italian partitive and locative clitics ne and $c i$, high proficiency in French, where similar forms that correspond syntactically to the Italian ones exist, seems to foster their production in L3 Italian and to reduce the number of omissions. Omission was, otherwise, a common strategy of avoidance in the case of other learners. Also for the position of clitics, proficiency in L2 French played a role. When comparing learners with high versus low proficiency in L2 French, it was found that higher proficiency in French generally led to more target-like instances in Italian. Generally, it can be concluded that a high proficiency in both French L2 and Spanish L2 may have the general effect of enhancing the acquisition of clitics in Italian L3.

Shifting the focus to young learners, Chapter 5 presents a study by Carmen Muñoz, Cognate recognition by young multilingual language learners. The role of age and exposure. In this study, trends already observed in previous work by Muñoz (2006; 2014) are confirmed: age is an important factor for language learning, in the sense that older learners have cognitive advantages over younger learners and that metalinguistic skills that develop with age support language learning. Muñoz investigates the recognition of cognates by two groups of young bilingual learners of English as their first foreign language (EFL), one group of 
7 year-olds and one of 9 year-olds. The study fills a gap concerning the role of cognateness in vocabulary recognition by bilingual children learning a foreign language to which they have limited exposure. As the author points out, it is commonly acknowledged that lexical similarity between known and new languages will facilitate additional language learning (Ringbom 2007) and that cognates between L1 and L2 are relatively easy to recognise and learn (e.g. Ellis \& Beaton 1993; De Groot \& van Hell 2005). Moreover, this facilitative effect has been observed more often in older than in younger learners. The role of cognates in young learners' foreign language learning has not been considered much in previous research, with noteworthy exceptions such as Otwinowska (2016) and Goriot et al. (2018). With this study, gathering evidence from learners of English as an L3 in the Spanish-Catalan context, new light is shed on young learners' ability to recognise cognates in an additional language. The study explores phonological cognates and, in particular, the role that age and amount of exposure to the target language play in the ability to recognise them.

The research questions that guided the study concerned the extent to which bilingual EFL learners recognise cognate words over non-cognate words and the respective roles of age and amount of exposure to English in cognate word recognition and non-cognate word recognition. In order to answer the research questions, the study examined how often young learners - 170 Spanish-Catalan bilingual children - recognised cognates and non-cognates in the Peabody picture vocabulary test (Dunn \& Dunn 2007) in its oral form, which categorises the words based on their etymology. The participants, evenly distributed in terms of age (7 vs. 9 year-olds in grades 2 and 4, respectively) and gender (males vs. females), had received different amounts of curricular exposure at school. Indeed, some of them were even attending a school that taught CLIL (content and language integrated learning), which increased their amount of instruction hours in English. Following the methodology employed in previous studies (as in Muñoz et al. 2018), the analysis of the data relied on the total number of words heard, the total number of cognates and non-cognates, and the indexes of cognate and noncognate recognition. The results indicated that cognates were more frequently recognised than non-cognates in both the examined age groups. Furthermore, the results conceded an advantage to the older children in benefitting from the facilitation of cognates, which may turn into an asset in foreign language classrooms. Thus, older learners, benefitting from positive transfer, were shown to better use their L1 vocabulary knowledge to identify and use target language vocabulary. While age was the strongest determinant of cognate recognition, hours of exposure was a stronger predictor of non-cognate recognition. The significant age effect on the ability to recognise cognates, which is in line with findings 
from previous research from Muñoz with young bilinguals and young foreign language learners, suggests that cognate awareness develops substantially between the ages 7 and 9. The possibility to dissociate age and contact hours in this study yielded evidence that the age effect was stronger for cognate recognition. As Muñoz concludes, both age groups showed a large and significant difference in the proportion of correct answers to cognate items and non-cognate items. However, the older group outperformed the younger one in both types. The explanation of the advantage of the older group, as suggested by the author, may be that with age they have developed a higher level of metalinguistic skills.

In order to obtain a deeper understanding of the age factor, Simone Pfenninger investigates age effects on additional language learning by comparing early bilinguals on the one hand and later bilinguals and monolinguals on the other when learning EFL in the German-speaking area of Switzerland. In this study the heterogeneity of bilingual populations and the importance of distinguishing between different types of bilinguals are highlighted. In her chapter, Age meets multilingualism: Influence of starting age on L3 acquisition across different learner populations, Pfenninger approaches two questions related to age: first whether early bilinguals are more successful than later bilinguals and monolinguals when learning a new language at school, and second how literacy skills in the home language (or languages), affect the development of literacy in the foreign language. In order to answer these questions, Pfenninger conducted a longitudinal study in Switzerland, in which the English proficiency development of 636 secondary school students was assessed through a series of oral and written tests of receptive as well as productive language skills. All students learned standard German and French at primary school, but only half of them had studied English from the third grade; the others had started with English five years later. Home languages in the bilingual groups were Spanish, Portuguese, Croatian, Serbian, Albanian, Arabic or Italian. All participants were between 13 and 14 at the first data collection time and in the range 18-19 at the second time, which occurred five years later. The findings suggest that age of onset played a different role in the different groups: monolinguals, simultaneous bilinguals, and sequential bilinguals were affected differently by age of onset effects, due to individual differences and socio-contextual factors. The results of the analyses revealed that an earlier age of onset was only beneficial, across a range of measures of productive and receptive EFL skills, for one specific learner group: simultaneous biliterate bilinguals who received substantial parental support. Monolinguals and non-biliterate bilinguals did not display benefits from earlier age of onset in the same way. For early bilinguals, the importance of sociolinguistic and educational factors for success, such as parents' support and positive attitudes towards 
language learning and multilingualism, use of both languages at home, and sustainment of L1 literacy skills in early school years, is clearly highlighted by the results.

The two final chapters of the volume investigate the L3 syntax of learners of foreign languages in middle and secondary school. In the chapter From L2 to L3, verbs getting into place: A study on interlanguage transfer and L2 syntactic proficiency, by Laura Sánchez, the participants are early bilinguals (that is, with two L1s) who learn two foreign languages (L2 and L3) in parallel. With a difference of at least three years in the age of onset of the L2 and the L3, the study explores the role of L2 proficiency for transfer into the L3. Relatively few studies have focused on the L2 proficiency factor, which however appears to condition transfer from one non-native language to another; see for example also Sciutti's study in this volume. Nonetheless, whereas Sciutti addressed the effects of general selfperceived proficiency, the study by Sánchez focuses on the effects of proficiency at the level of syntax, which was measured on the basis of the learners' written productive knowledge of a set of structural properties related to the V2 (verb second) rule present in German. Data were retrieved using a story-telling task (Sánchez \& Jarvis 2008) from a data set of 280 Spanish/Catalan learners of L3 English with knowledge of L2 German, aged 9-13. While learning German and English simultaneously at school, the participants used Spanish and/or Catalan, to varying degrees, in their everyday lives. They had started learning German when they were 5 years old in a programme that integrated language and content in some subjects. At the time of testing, both their overall proficiency in German (as determined by the German placement test) and their syntactic proficiency in the structures tested were still generally low. Subsequently, at the age of 8, or later, the participants had started learning English. Differences in age and L3 overall proficiency, measured by means of a cloze test, were controlled in the tests used for the statistical treatment of the data.

The study examined whether syntactic proficiency in German had an effect on the timing, extent and type of transfer from L2 to L3. The research is innovative in that it analyses analogous structures used in the L3 and the L2. As mentioned, the study looks into a cluster of structural properties related to the V2 (verb second) rule. The V2 rule yields three characteristic word orders in German that differ from English, namely subject-verb inversion, discontinuous verb placement and verb final. Results show that two of these structures chosen for examination, discontinuous verb placement and verb final, transferred from the L2 into the L3. Transfer of these structures was found at low levels of syntactic proficiency, but also when syntactic proficiency in the L2 was high, which suggests that the specific structural properties that may be transferred to the L3 may either be fully 
acquired in the L2 or in the process of being acquired. Methodologically, this study highlights the necessity, in research on interlanguage transfer of syntax, to test and determine learners' knowledge of particular structures in the L2. In fact, low syntactic proficiency in the L2 seemed to favour activation and negative transfer from the L2, participants having difficulties inhibiting unintended activation of a previously built up interlanguage. This finding aligns with the claim in the chapter by Pfenninger that unstable knowledge of the L2 has an effect on the learning of the L3. Furthermore, the results lend further support to the extension of Cummins' (1991) interdependence hypothesis to L3 learning and multilingualism.

Partly similar age groups participate in the study reported in the final chapter, and syntactic problems closely related to those of the previous chapter are also investigated in L1 Dutch vs L2 English in the initial stages of L3 French acquisition: The case of verb placement, by Rosalinda Stadt, Aafke Hulk and Petra Sleeman. The general aim of this study was to define the role of native and nonnative background languages in the very initial stages of learning an L3 in the classroom. The setting was Dutch secondary school and the first weeks of study of French, a suitable scene for investigating the potential influence of Dutch as L1 and English as L2 on French L3, which the participants were also acquiring in parallel under two different input conditions. The number of participants, $1^{\text {st }}$ year learners of English, was 23 (selected out of 118 possible candidates on the basis of a language background questionnaire and the Anglia placement test). Learners were classified into two groups depending on whether they were enrolled in the mainstream Dutch curriculum $(n=11)$ or in a bilingual stream programme $(n=12)$ where they were exposed to English more intensively. Two syntactic error types were analysed in order to detect transfer either from Dutch or from English: errors based on V2 surface structures in sentences containing a sentence initial adverb (which would stem from the L1 Dutch) and errors based on the Adv-V word order in the middle field of the sentence (which would stem from the L2 English word order). A considerable amount of transfer from the L1 was found in both reception data from a grammaticality judgement task and production data from a gap-filling task designed by the authors. In previous studies (Stadt et al. 2016; 2018), the authors had found a stronger transfer effect from the L2 English on the L3 French, which could be explained with a higher amount of L2 exposure compared to the current study. Differently from the previous studies, the participants had not been exposed to English in the daily school context at the time when the study was conducted.

In the previous studies, the preferred role for the L2 as transfer source had been identified in later stages of $\mathrm{L} 3$ development with $3^{\text {rd }}$ and $4^{\text {th }}$ year students. 
Such a strong L2 effect was not found in the beginners participating in this study. In order to explain the predominant role of the L1 here, it is argued that in the initial state, the learners were unable to make assumptions about word order in French L3, but resorted to their L1 Dutch, hypothesizing that Dutch and French share the same word order. Furthermore, it is suggested that the L2 needs to be activated, through exposure, for the L2 to override the L1 as transfer source. Moreover, it is argued that the grammatical judgement task might have been too difficult for the learners, having to cope with reading skills and morphosyntactic knowledge in the target language that they did not possess yet.

In summary, the chapters of this volume present together a wide range of theoretical positions and empirical evidence that represent important aspects of current directions in the field of L3 research, touching upon different age groups and proficiency levels, looking into diverse linguistic phenomena and language combinations, and studying additional language learning from a perspective where all background languages potentially play a role. Research into third or additional language learning by young learners or adults who have previous experience of one or more languages learned as children or adults adds to our knowledge about non-native language acquisition. In fact, as testified in this volume, much L3 research is about reviewing old knowledge about second language acquisition in the light of factors that are of importance for the complex multilingual mind: the age of onset of the additional language and that of previously acquired languages, social and affective factors, instruction, language proficiency and literacy, as well as the typology of the background languages and the role they play in shaping the syntax and the lexicon and other components of a third language. These factors and others are intertwined in an intricate way and the L3 research area continues to call for more studies. It is our hope that the variety of ideas and results presented here will contribute to the development of the field.

\section{References}

Bardel, Camilla \& Christina Lindqvist. 2007. The role of proficiency and psychotypology in lexical cross-linguistic influence: A study of a multilingual learner of Italian L3. In Marina Chini, Paola Desideri, Maria Elena Favilla \& Gabriele Pallotti (eds.), Atti del VI congresso internazionale dell'Associazione Italiana di Linguistica Applicata, 123-145. Perugia: Guerra Edizioni.

Berkes, Éva \& Suzanne Flynn. 2016. Multi-competence and syntax. In Vivian Cook \& Li Wei (eds.), The Cambridge handbook of linguistic multi-competence, 183-205. Cambridge: Cambridge University Press. 
Cenoz, Jasone. 2003. The additive effect of bilingualism on third language acquisition: A review. International fournal of Bilingualism 7(1). 71-87. DOI: 10.1177/ 13670069030070010501.

Cummins, Jim. 1976. The influence of bilingualism on cognitive growth: A synthesis of research findings and explanatory hypotheses. Working Papers on Bilingualism 9. 1-43. https://eric.ed.gov/?id=ED125311.

Cummins, Jim. 1991. Interdependence of first- and second language proficiency. In Ellen Bialystok (ed.), Language processing in bilingual children, 70-89. Cambridge: Cambridge University Press. DOI: 10.1017/CBO9780511620652.006.

De Groot, Annette M. B. \& Janet G. van Hell. 2005. The learning of foreign language vocabulary. In Judith F. Kroll \& Annette M. B. De Groot (eds.), Handbook of bilingualism: Psycholinguistic approaches, 9-29. Oxford: Oxford University Press.

Dunn, Lloyd M. \& Douglas M. Dunn. 2007. Peabody picture vocabulary test. 4th edn. Bloomington, MN: NCS Pearson.

Ellis, Nick C. 2005. At the interface: Dynamic interactions of explicit and implicit language knowledge. Studies in Second Language Acquisition 27(2). 305-352.

Ellis, Nick C. \& Alan Beaton. 1993. Factors affecting the learning of foreign language vocabulary: Imagery keyword mediators and phonological short-term memory. Quarterly fournal of Experimental Psychology 46(3). 533-558. DOI: 10.1080/14640749308401062.

Fitzpatrick, Tess \& Cristina Izura. 2011. Word association in L1 and L2: An exploratory study of response types, response times, and interlingual mediation. Studies in Second Language Acquisition 33(3). 373-398. DOI: 10 . 1017 / S0272263111000027.

Flynn, Suzanne, Claire Foley \& Inna Vinnitskaya. 2004. The cumulativeenhancement model for language acquisition: Comparing adults' and children's patterns of development in first, second and third language acquisition of relative clauses. International fournal of Multilingualism 1(1). 3-15.

Goriot, Claire, Roeland van Hout, Mirjam Broersma, Vanessa Lobo, James M. McQueen \& Sharon Unsworth. 2018. Using the Peabody picture vocabulary test in L2 children and adolescents: Effects of L1. International fournal of Bilingual Education and Bilingualism. Advanced online publication. DOI: 10.0050.2018. 1494131.

Gudmundson, Anna. 2020. The mental lexicon of multilingual adult learners of Italian L3: A study of word association behavior and cross-lingual semantic priming. In Camilla Bardel \& Laura Sánchez (eds.), Third language acquisition: Age, proficiency and multilingualism, 67-109. Berlin: Language Science Press. DOI: $10.5281 /$ zenodo.4138739. 
Hufeisen, Britta. 2005. Multilingualism: Linguistic models and related issues. In Britta Hufeisen \& Robert J. Fouser (eds.), Introductory readings in L3, 31-45. Tübingen: Stauffenburg.

Jessner, Ulrike. 2006. Linguistic awareness in multilingualism: English as a third language. Edinburgh: Edinburgh University Press.

Muñoz, Carmen. 2006. Age and the rate of foreign language learning. Clevedon: Multilingual Matters.

Muñoz, Carmen. 2014. Complexities and interactions of age and second language learning: Broadening the research agenda. Applied Linguistics 35(4). 369-373.

Muñoz, Carmen, Teresa Cadierno \& Isabel Casas. 2018. Different starting points for English language learning: A comparative study of Danish and Spanish young learners. Language Learning 68(4). 1076-1109.

Muñoz, Carmen. 2020. Cognate recognition by young multilingual language learners: The role of age and exposure. In Camilla Bardel \& Laura Sánchez (eds.), Third language acquisition: Age, proficiency and multilingualism, 145165. Berlin: Language Science Press. DOI: 10.5281/zenodo.4138743.

Otwinowska, Agnieszka. 2016. Cognate vocabulary in language acquisition and use: Attitudes, awareness, activation. Clevedon: Multilingual Matters.

Paradis, Michel. 2009. Declarative and procedural determinants of second languages. Amsterdam: John Benjamins.

Pfenninger, Simone E. 2020. Age meets multilingualism: Influence of starting age on L3 acquisition across different learner populations. In Camilla Bardel \& Laura Sánchez (eds.), Third language acquisition: Age, proficiency and multilingualism, 167-207. Berlin: Language Science Press. DOI: 10.5281/zenodo. 4138745.

Ringbom, Håkan. 2007. Cross-linguistic similarity in foreign language learning. Clevedon: Multilingual Matters.

Salaberry, Rafael. 2020. The conceptualisation of knowledge about aspect: From monolingual to multilingual representations. In Camilla Bardel \& Laura Sánchez (eds.), Third language acquisition: Age, proficiency and multilingualism, 43-65. Berlin: Language Science Press. DOI: 10.5281/zenodo.4138737.

Sánchez, Laura \& Camilla Bardel. 2017. Transfer from an L2 in third language learning: A study on L2 proficiency. In Tanja Angelovska \& Angela Hahn (eds.), L3 syntactic transfer: Models, new developments and implications, 223250. Amsterdam: John Benjamins.

Sánchez, Laura \& Scott Jarvis. 2008. The use of picture stories in the investigation of crosslinguistic influence. TESOL Quarterly 42(2). 329-333. 
Sánchez, Laura. 2020a. From L2 to L3, verbs getting into place: A study on interlanguage transfer and L2 syntactic proficiency. In Camilla Bardel \& Laura Sánchez (eds.), Third language acquisition: Age, proficiency and multilingualism, 209-235. Berlin: Language Science Press. DOI: 10.5281/zenodo. 4138747.

Sánchez, Laura. 2020b. Multilingualism from a language acquisition perspective. In Camilla Bardel \& Laura Sánchez (eds.), Third language acquisition: Age, proficiency and multilingualism, 15-41. Berlin: Language Science Press. DOI: 10. 5281/zenodo.4138735.

Sciutti, Sandro. 2020. The acquisition of clitic pronouns in complex infinitival clauses by German-speaking learners of Italian as an L3: The role of proficiency in target and background language(s). In Camilla Bardel \& Laura Sánchez (eds.), Third language acquisition: Age, proficiency and multilingualism, 111-144. Berlin: Language Science Press. DOI: 10.5281/zenodo.4138741.

Stadt, Rosalinde, Aafke Hulk \& Petra Sleeman. 2016. The influence of L2 English and immersion on L3 French in the Netherlands. In Jenny Audring \& Sander Lestrade (eds.), Linguistics in the Netherlands, 152-165. Amsterdam: John Benjamins.

Stadt, Rosalinde, Aafke Hulk \& Petra Sleeman. 2018. The role of L2 exposure in L3A: A comparative study between third- and fourth-year secondary school students in the Netherlands. In Janine Berns, Haike Jacobs \& Dominique Nouveau (eds.), Romance languages and linguistic theory 13: Selected papers from “Going Romance" 29, Nijmegen, 279-296. Amsterdam: John Benjamins.

Stadt, Rosalinde, Aafke Hulk \& Petra Sleeman. 2020. L1 Dutch vs L2 English and the initial stages of L3 French acquisition. In Camilla Bardel \& Laura Sánchez (eds.), Third language acquisition: Age, proficiency and multilingualism, 237261. Berlin: Language Science Press. DOI: 10.5281/zenodo.4138749.

Williams, Sarah \& Björn Hammarberg. 1998. Language switches in L3 production: Implications for a polyglot speaking model. Applied Linguistics 19(3). 259-333. DOI: 10.1093/applin/19.3.295. 


\section{Chapter 2}

\section{Multilingualism from a language acquisition perspective}

\section{Laura Sánchez}

\section{Stockholm University}

This chapter conceptualizes and discusses two subtypes of multilingualism, namely, (a) third language acquisition in learners who have prior experience in acquiring one or more non-native languages, and (b) subsequent language acquisition in learners who are bilingual from an early age. The chapter also discusses the roles played by age (both biological age and age of onset) and proficiency in multilingual acquisition. As regards age, the discussion focuses primarily on two aspects, namely, differential effects in instructed and naturalistic contexts, and the apparent superiority of older learners and late starters against younger learners and early starters. It is stressed that further research is necessary in order to identify and single out the particularities of L3 acquisition for learners with prior experience in the concurrent or consecutive learning of one or more non-native languages. Likewise, the chapter highlights the need to obtain a deeper understanding of how age-related differences in the level of linguistic entrenchment in multilinguals constrain L3 learning after exposure to additional languages. With respect to the proficiency factor, it is argued that it is important to consider proficiency thresholds and to tease apart the distinctive effects of proficiency in the target language (the L3) and in the background languages when exploring linguistic development among multilinguals. These distinctive effects are also relevant for understanding crosslinguistic influence in L3 acquisition, above all in determining the potential source languages and the direction of this influence.

The art of language learning may lie not in the acquisition of an individual language but in the mastery of the learning process itself.

(Tonkin 2009: 201) 


\section{Definitions of multilingualism and third (or additional) language acquisition}

In present days, to claim that "multilingualism is no longer the exception but the rule" (Sánchez 2019a: 113) may seem uncontroversial. From a terminological point of view, however, defining the term multilingualism and distinguishing it from other language contact and learning situations such as bilingualism or second language (L2) acquisition is a different and more complicated matter (Cenoz 2013). A common misconception stems from the lack of clarity when it comes to distinguishing bilingualism and multilingualism and the interchangeable use of the two terms made sometimes in the literature. For example, some authors have defined multilingualism as "the acquisition and use of two or more languages" (Aronin \& Singleton 2008: 2; emphasis added). By the same token, the term second language is sometimes viewed as a "cover term for any language other than the first language learned by a given learner or group of learners irrespective of the type of learning environment and irrespective of the number of other nonnative languages possessed by the learner" (Sharwood Smith 1994: 7), and the term bilingual is used when referring to those "who use two or more languages in their everyday life" (Grosjean 2010: xiii).

Along these lines, Mitchell \& Myles (1998: 2) claim that "it is sensible to include 'foreign' languages under our more general term of 'second' languages, because we believe that the underlying learning processes are essentially the same for more local and more remote target languages, despite differing in learning purposes and circumstances" (emphasis added). Leaving aside other perspectives such as linguistic, sociolinguistic, or educational -, from an acquisitional perspective, the views and definitions just discussed might be oversimplifications of the situation, failing to acknowledge the distinctive characteristics of multilingualism. Thus, Cenoz (2013: 14) draws attention to the fact that multilingualism is not "a simple addition of languages but a phenomenon with its own characteristics".

Inspired by the work of researchers such as Hufeisen (1998; 2003) and De Angelis (2007), third (or additional) language acquisition (L3) emerged as an independent field of research within multilingualism. As such, L3 acquisition is defined as the learning situation for learners "with prior experience of acquiring one or more non-native languages" (Hammarberg 2018: 128). To disseminate research that specifically addresses L3 acquisition, theoretical and empirical papers have started to be regularly presented at seminal conferences and yearly L3 workshops. The dissemination of results from some of these conferences, in the form 
of (online) publications primarily in English (see Cenoz et al. 2001) and German ${ }^{1}$ sought to build a case for multilingualism and, especially, for L3 acquisition, by arguing that the underlying learning processes in bi- and tri- and multilingual contexts are not the same. Some of the arguments offered in the literature on multilingualism research are revisited in the following paragraphs.

Problematizing how to define bilingualism and multilingualism seems necessary in order to move forward to a more rigorous and perhaps more accurate view of language acquisition in multilingual learners. At the core of the arguments used to defend the idea that the L2 and L3 learning processes are essentially not "the same" (contrary to Mitchell \& Myles 1998) is the belief that there are meaningful differences between the acquisition of an L2 and the acquisition of an L3. Before addressing these differences in more depth, a definition of what is understood as "L2" and "L3" in this chapter is offered. For a start, the working definition of L2 here resonates with Falk \& Bardel's (2010: 61) claim that a true L2 corresponds to "the first encounter with a non-native language" (but see also the definition of "L2" in §1.2). In turn, the L3 is defined as any language "beyond the L2 without giving preference to any particular language" (De Angelis 2007: 11), because the critical difference is between the acquisition of an L2 and an L3, but not between an L3 and an L4, L5, L6, etc. (Hammarberg 2001; Hufeisen 2003; De Angelis 2007). This definition of the L3 is consistent with its status as the tertiary language in compliance with proposals in early papers (Lindemann \& Hufeisen 1998; Dentler et al. 2000) as well as more recent ones (Hammarberg 2018).

\subsection{Prior language learning experiences and strategies in L3 acquisition}

The belief that there are meaningful differences between the acquisition of an L2 and that of an L3 has its roots in the so-called "difference assumption" position, which is contrary to the "no difference assumption" (De Angelis 2007) represented by the bilingual bias endorsed in the views above (Sharwood Smith 1994; Mitchell \& Myles 1998; Grosjean 2010). Within the difference assumption position, this belief is anchored in the fact that prior knowledge and, above all, prior learning experience have a big impact on the acquisition of an L3. The critical point that differentiates the acquisition of an L2 from that of an L3 is the presence, at the onset of L3 acquisition, of language-specific learning experiences, knowledge and strategies (Gibson \& Hufeisen 2003) that beginning learners of a first foreign language do not yet have. As Marx \& Hufeisen (2004: 145) put it,

\footnotetext{
${ }^{1} \mathrm{https} / /$ www.daf.tudarmstadt.de/forschungprojekte/laufende_projekte/13forschung_1/index. en.jsp.
} 


\section{Laura Sánchez}

"the addition of further languages changes the language acquisition process not only quantitatively (especially moving from L2 to L3) but - more importantly qualitatively".

Similarly, Jessner (1999: 207) points out that "prior language learning experience changes the quality of language learning", and Jessner (2006: 14) elaborates on this idea by proposing that "the process of learning and the product of having learnt a second language can potentially exert influence on the acquisition of an L3 and this involves a quality change in language learning and processing" (emphasis added). The qualitative change proposed by Hufeisen in different papers is represented in Figure 2.1 (Hufeisen 1998, also Marx \& Hufeisen 2004: 145), adapted from Hufeisen \& Marx (2007: 314).

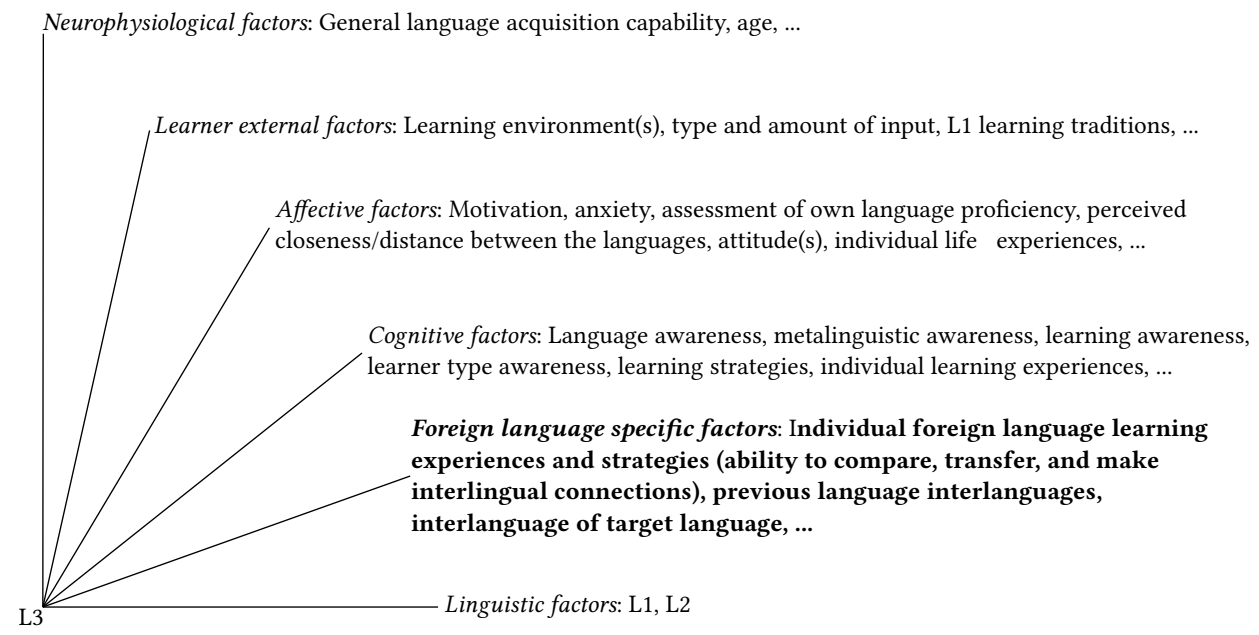

Figure 2.1: Third language acquisition (L2 vs. L3). Adapted from Hufeisen \& Marx 2007: 314, Figure 2.

The figure includes factors that are commonly investigated in bilingual and L2 acquisition research, especially from the individual differences framework that underlies much work in the field at present (e.g. Kidd et al. 2018). These individual differences (especially neurophysiological and affective ones identified in Figure 2.1) embrace, but are not limited to, age, proficiency, aptitude or motivation, which are factors frequently cited in the literature when explaining, for example, linguistic development and ultimate attainment. More importantly, the figure also incorporates foreign language specific factors such as previous interlanguages that configure the acquisition of an L3 in a multilingual learning situation. The extent to which the meaningful and qualitative differences portrayed here might indeed lead to a fundamental distinction between L2 and L3 
acquisition, as outlined earlier in this section, might possibly be confirmed in future investigations, and nowadays it constitutes a well-established, thoughtprovoking, and productive line of investigation.

In research on multilingualism, the prominent role of L2 prior language knowledge, experiences and strategies has also been highlighted in other studies that try to relate language learning experience with a number of benefits in the acquisition process. In discussing experiments conducted with multilingual learners, Sanz (2000: 35) claims that language learning experience "contributes to the automatization of basic subskills involved in input processing and frees up resources that can be devoted to focus on form". Moreover, prior language learning experience sensitizes multilingual learners to triggering data in the input they receive (Zobl 1992; Klein 1995).

One reason why language learning experience turns into an asset for multilingual learners is, according to McLaughlin \& Nayak (1989: 6) that the process of language learning "carries over to the learning of a new language". After all, as the opening quotation suggests, success in language learning very much depends on the mastery of the learning process. Above all, this carrying over takes place by building up certain basic skills that positively transfer to new language learning situations. This process would, in turn, relate to the learning of routines (Jessner 2008: 360; Rutgers \& Evans 2017: 804), especially of complex skills. In the process of language learning, routines are important because they are part of the explicit knowledge that is sustained by declarative memory (Paradis 2009; Sharwood Smith 2010; Tagarelli et al. 2011). Learners access this knowledge during sentence construction in non-native languages, and rely on linguistic routines that are stored in memory and that carry out working memory functions (Baars \& Franklin 2003; Sharwood Smith 2010). In the understanding that repeated practice leads to proceduralization, as suggested in skill acquisition theory (DeKeyser 2007; 2010), what becomes proceduralized or automatized are the implicit computational procedures. Along similar lines, Rutgers \& Evans (2017) claim that what becomes automatized are precisely the linguistic routines that involve controlled processing.

From this viewpoint, once these routines and procedures are consolidated and become automatized, learners are believed to benefit from "metaprocedural" gains from the learning of languages that trigger a more effective restructuring of internal representations (McLaughlin \& Nayak 1989; Nayak et al. 1990). These metaprocedural gains also help multilingual learners have a greater cognitive flexibility in switching strategies and a greater variety in strategy use (Missler 2000; Kemp 2007). Such strategy use is assumed to heighten language awareness (Thomas 1992), which serves as a resource to build new knowledge. By so doing, 


\section{Laura Sánchez}

strategy use and language awareness prompt multilinguals to think in a more abstract manner, and enable them to allocate processing resources in a more efficient way under different implicit and explicit learning conditions (Nation \& McLaughlin 1986), especially as far as inductive learning is concerned involving rule discovery (Nayak et al. 1990).

Another way in which prior language knowledge becomes an asset for multilingual learners could be that "experience with a number of languages may make the individual more aware of structural similarities and differences" (McLaughlin \& Nayak 1989: 11). Though the facilitative effects of similarities are generally acknowledged (Ringbom 2007; Rutgers \& Evans 2017; but see Swain et al. 1990 and Gibson et al. 2001), especially in the case of cognates (Muñoz 2020 [this volume]), it might also be the case that multilingual learners may be suspicious of strong (objective or perceived) similarities between two or more languages in their linguistic repertoire (Fouser 2001; Otwinowska \& Szewczyk 2017) or even that certain similarities would have a temporary compromising effect on underdeveloped interlanguage(s) in L3 learners (Bardel \& Falk 2007; Rast 2010; Sánchez 2012; 2020 [this volume]).

When discussing the role of prior language experience, Jessner (1999) pinpoints the advantages gained from contact with several languages and argues that such contact has "catalytic effects" (p. 203) on the learning of an L3. It must be noted, however, that it is not entirely clear to what extent the benefits observed in multilinguals are caused by a more effective strategy use, or merely by language learning experience per se, which involves skills that are developed "on account of the demands of processing multiple languages" (Kemp 2007: 243). In relation to L3 writing, for example, it has been found that learners rely on procedural language skills that reflect experience-based monitoring of which they are not necessarily aware (Rutgers \& Evans 2017).

\subsection{Multilingual language acquisition in bilingual contexts}

The role of prior linguistic experience in multilingualism has also been examined in situations where early bilingual learners acquire another language, i.e., a subtype of multilingualism that is different from the type depicted in the preceding section. So far the description of multilingualism has revolved around L3 acquisition by learners with prior experience of acquiring one or more non-native languages. This is the type of multilingualism examined in several of the chapters included in the current edited volume (Gudmundson; Salaberry; Sánchez; Sciutti and Stadt et al.). 
At this point we shift gears to another multilingual scenario where bilingual children acquire a new language, which would be the language number three (L3) in their linguistic repertoire and their first foreign language. In other words, the criterion according to which this language is an L3 is a chronological one, and as such, it needs to be distinguished and differentiated from the definition above as any language beyond the L2, that is, beyond the first non-native language (see also Muñoz 2020 [this volume] and Pfenninger 2020 [this volume]).

Research on this subtype of multilingualism has been conducted with learners from disparate language backgrounds and with disparate linguistic histories. In the case of Europe, two common scenarios emerge. In one of them simultaneous bilinguals are investigated, as in Catalonia with Spanish and Catalan (Muñoz 2000). This is similar to the case of Spanish-Basque bilinguals in the Basque Country (García Mayo \& García Lecumberri 2003). In both of these contexts, where bilingualism of two official (majority and minority) languages has additive linguistic consequences (Cenoz \& Valencia 1994; Sanz 2000), the next language to be learnt is English, which is the first foreign language, and an obligatory school subject from the age of eight. The other scenario investigates the acquisition of English as a first foreign language on the part of early (from birth) bilinguals and late (newly arrived) bilinguals who speak the community language and a heritage language at home.

Irrespective of the type of bilingualism investigated in these scenarios, the primary aim of these studies has been to demonstrate whether prior linguistic experience enhances subsequent language acquisition. On this subject, it has been suggested that bilinguals have an advantage over monolinguals when it comes to the acquisition of an L3 (Sanz 2000; Cenoz 2003; 2013; Kopečková 2016; Hiroshi \& Degani 2018), though mixed results have been reported. Among others, a possible explanation for mixed results is the large variation in the methodologies employed in these studies, from the participants' linguistic profile and socioeconomic status to the instruments employed in the data collection. Another plausible explanation is that bilingualism may not have advantages across the board for subsequent language learning, and its benefits may be constrained by the language area (e.g. lexis or syntax) or linguistic skill (e.g. reading or writing).

Counter to what was believed in the $60 \mathrm{~s}$ and the $70 \mathrm{~s}$, where bilingualism was thought to have a detrimental effect on language development, some studies have claimed that both active and passive bilingualism seem to contribute positively to the acquisition of a subsequent language (Cenoz \& Valencia 1994; Muñoz 2000; Sanz 2000; Brohy 2001), but also note studies reporting no effect (Jaspaert \& Lemmens 1990; Sanders \& Meijers 1995). The positive contribution has been found even when the learners are not literate in one of their L1s (Wagner et al. 1989), 
in contrast with the small contribution reported in contexts of higher socioeconomic status (Benmamoun et al. 2013; Polinsky 2015). The main argument put forward in trying to explain the positive contribution of bilingualism to subsequent language acquisition is the transfer of prior knowledge, skills and processing routines. This interpretation is consistent with Cummins' (1981) linguistic interdependence hypothesis for the transferability of literacy skills from the L1, and it reinforces the role played by prior language experience in multilingualism.

In more or less direct ways, the outcomes of language learning in multilingual settings are always interpreted in the light of two factors, namely age and proficiency. These two factors are reviewed in $\S \S 2$ and 3, respectively. Of course an extensive review of findings related to these factors is beyond the scope of the present chapter. Hence, the following sections try to offer a succinct outline of general findings in relation to age and proficiency, and then move on to discuss some issues more directly related to effects on multilingual language acquisition.

\section{The age factor in multilingual language acquisition}

Age is one of the most widely investigated factors in the literature on L2 acquisition (see recent reviews in Pfenninger \& Singleton 2017; Singleton \& Pfenninger 2018; Muñoz 2019; Muñoz \& Singleton 2019). While much work has been done to determine the effects of both biological (age-at-time-of-testing) and starting age (age at the onset) when it comes to the acquisition of an L2, much less work has been carried out to specifically examine the complex ways in which age and additional language acquisition relate to each other. As Muñoz (2019: 433) notices, a very early exposure to an additional language in pre-primary school is "expected to open children's minds to multilingualism". Moreover, although the starting ages for a first and a second foreign language are important, above all insofar as they have a bearing on the particular sequence in which they should be taught at school (Muñoz \& Singleton 2019: 222), very little evidence is available on how starting and biological age impacts the concurrent acquisition of two foreign languages. Thus, further evidence is needed of the effects of starting age on L3 acquisition in its definition as any language beyond the L2 or first foreign language. Rather, the evidence available in multilingualism research is informed by bilingual learners, often immigrants, learning their first foreign language in a variety of contexts, as indicated in the scenarios described at the beginning of \$1.2. Consequently, more research is needed in order to identify and single out the particularities of L3 acquisition for learners with prior experience in acquiring one or more non-native languages. Such research may focus on obtaining a 
deeper understanding of the differences between early and late multilinguals in the level of linguistic entrenchment before they are exposed to subsequent languages, and also on the consequences of this entrenchment for multilingualism, especially in cases involving the acquisition of two or more non-native languages at the same time.

One important fact that needs to be considered when discussing age effects on multilingualism is that such effects differ according to the learning environment. A distinction needs to be made between formal or instructed acquisition at school, and acquisition in naturalistic settings (Bardel 2019). While age effects have been investigated in terms of acquisition rate and ultimate attainment (nativelikeness) in both contexts, ultimate attainment could be said to have been more thoroughly investigated in naturalistic settings. The discussion here then is confined to relevant findings in relation to rate and success (efficiency) of foreign language learning.

For the purposes of this chapter, the effects of age on the rate and success of bilingual learners in multilingual language acquisition are largely grounded in the results obtained by the $\mathrm{BAF}^{2}$ project in Catalonia. This project investigated the instructed acquisition of English as a first foreign language in over 1000 primary and secondary school learners who were bilingual in Spanish and Catalan to different extents (for a detailed description, see Muñoz 2000). This large- scale study was longitudinal and relied on a large battery of tests that measured the learners' general proficiency and their proficiency in specific areas (i.e. dictation, cloze test, listening comprehension, grammar multiple choice test, written composition, oral narrative, oral interview, phonetic imitation, phonetic discrimination, and role-play).

The main goal of the project was to investigate the effects in the short and medium-terms of biological and starting age on the formal acquisition of English as a foreign language at primary and secondary schools. To this aim, data were compared from learners who had begun learning English at different ages (i.e. 8 and 11) but had received the same amount of instruction (200, 416 and 726 hours of instruction). At the time of data collection, the mean ages of the three groups of early starters were 10.9, 12.9 and 16.9, whereas the mean ages of the late starters were 12.9, 14.9 and 17.9, respectively. The main results of the project are gathered in Muñoz's (2006) edited volume, which summarizes the most important findings. The most general conclusion was that late starters (that is, those who started at age 11 instead of at age 8) and older learners (in terms of biological age) had at least an initial advantage over early starters and younger learners.

\footnotetext{
${ }^{2}$ Barcelona age factor project.
} 


\section{Laura Sánchez}

These results were consistent with those obtained in a comparable learning situation, namely, the Basque Country, with bilingual learners (Spanish and Basque) of English as a first foreign language at school (García Mayo \& García Lecumberri 2003). The data analysed by researchers in the Basque Country came from learners who were roughly the same ages as in Catalonia, but the amount and length of instruction received by those learners were slightly different (e.g. 310, 396, 594, 600, 693, or 792 hours of instruction).

Crucially, the results in Catalonia and the Basque Country have been echoed in different multilingual contexts such as Switzerland. Pfenninger (2014) and Pfenninger \& Singleton (2017; 2019), in another large scale study, investigated bilingual learners in Switzerland who spoke the community language, Swiss German, and another language at home. The starting age for the learners in these studies was similar to those in the studies discussed above (8-9), but the late starters had started at a somewhat later age (i.e. when they were 13-14 years old). Data were collected longitudinally at different points in time. At the first data collection period, early starters had received 440 hours of instruction over 5.5 years and late starters 50 hours of instruction over the course of only six months. The second data collection took place five years later when the learners were 18-19 years old and had received an additional 650 hours of instruction. In this case, the findings also conceded an advantage to older learners, and this was so in spite of the greater length and amount of instruction in the case of early starters.

In none of the multilingual learning contexts discussed here was there clearcut evidence that early starters would catch up with late starters in the long run. Summing up, the various studies in these different multilingual instructional settings come to the same results. First of all, it seems that older learners, who have undergone greater cognitive development and have higher metalinguistic awareness, outperform their younger peers when learning their first foreign language (L3 English). Moreover, this superiority is manifestly conspicuous in the area of morphosyntax (lending support to the findings reported for bilinguals in Krashen et al. 1979). In contrast, younger learners and early starters, who are at a different stage of maturity, are less efficient learners and their rate of acquisition of the L3 is slower.

Another important conclusion reached in these studies is that age alone cannot tell the whole story. More precisely, these studies have found that input is as important as, or even more so, than age (Muñoz 2006; 2014; 2019; Pfenninger \& Singleton 2017) not only in terms of amount but also of type. Interestingly, input through exposure at school is neither the only nor the most important source of input for these learners. Instead, it seems that they engage in many 
extramural English activities, which corroborates the idea of such activities benefitting foreign language learning advanced in other studies (Sundqvist \& Sylvén 2014). These activities range from simply surfing on the internet and watching TV (with or without subtitles), to reading and engaging in digital gameplay, and they seem to make a significant contribution to the acquisition of English as a foreign language, especially to the growth of vocabulary and the development of oral abilities. Besides amount and type of input, it is apparent that age is interrelated with other factors as well (Muñoz 2014), and a few studies have revealed the robust effects of parental education and literacy skills (Pfenninger \& Singleton 2017; Muñoz 2019; Muñoz \& Singleton 2019). Similar results on parental education and literacy skills were obtained in a study with 14-year-old learners of L3 English with L1 Italian and L2 German (De Angelis 2015).

Another relevant interrelation is that between age and L3 proficiency. Hence, due to the interrelation of these two factors, age-related variation in learning rate allows older and younger learners to benefit from instruction to different extents (Muñoz 2006), because proficiency does not necessarily reflect amount of instruction. In a study on the acquisition of L3 German by Swedish learners with prior knowledge of L2 English, Sayehli (2001) found that some of her 12-13 year-olds were of overall higher proficiency than 13-14 year-olds. The fact that the proficiency level of some of the less instructed learners was higher than that of their more instructed peers was explained as a result of this lack of correspondence between proficiency and amount of instruction. An important implication of this mismatch, as argued by Muñoz \& Singleton (2019: 214), is that "the degrees of proficiency attained by multilingual school learners are influenced by the age at which they begin to learn the additional language".

\section{The proficiency factor in multilingual language acquisition}

The preceding section has addressed the role of proficiency as regards its interaction with age in explaining success in foreign language acquisition. In turn, this section addresses the role of the proficiency factor in multilingual language acquisition. Another important yet difficult question to ask then is at what stage of development in the target language, the L3, learners benefit the most from their prior linguistic knowledge. Indeed, the question is essential if one considers that language learning beyond the L2 brings about the activation of the entire array of competences of multilingual speakers (Coste 1997), thereby enhancing their 


\section{Laura Sánchez}

degree of metalinguistic awareness (Jessner 2008). In the case of bilingual learners acquiring a subsequent language, $\mathrm{Cenoz}$ (2013) discusses evidence suggesting that at intermediate proficiency levels in the L3, prior language knowledge is facilitative.

In the case of L3 language acquisition, De Angelis (2007: 34) has stressed the need to "address the question of threshold levels, in other words how proficient learners need to be before their prior knowledge begins to affect the production and development of a target language to a significant extent". The need to investigate proficiency in all the languages of a multilingual learner is central to a prolific research branch within multilingualism, namely, crosslinguistic influence (see §4). Thus, research on crosslinguistic influence in multilingual language acquisition points out the importance of teasing apart the differential effects of proficiency in the target language (the L3) and proficiency in background languages that can become potential source languages of influence (e.g. Bardel \& Lindqvist 2007; De Angelis 2007; Falk \& Bardel 2010; Jaensch 2011; Lindqvist \& Bardel 2013; Sánchez \& Bardel 2016). For recent overviews of the role of proficiency in the target language (L3) and source language of influence (L2) on the occurrence of crosslinguistic influence in multilingual learners see Sánchez (2014) and Sánchez \& Bardel (2017), respectively.

A distinguishing feature of proficiency in L3 acquisition is that "from a methodological perspective, information on proficiency level in previously acquired nonnative languages is central to be able to establish a distinction between the L2 and the multilingual learner, and consequently between second language acquisition and third language acquisition" (De Angelis 2007: 34). Hence, it seems wise to define what proficiency in the L2 and the L3 refers to in each case and how the construct is operationalized. To be able to have an adequate understanding of the dynamics of proficiency in multilingualism, the definition must embrace the unique characteristics of multilingual language acquisition and capture the essence of its distinctiveness. In this endeavor, two terms that have been proposed are "multicompetence" (Cook 1995) and "multilingual proficiency".

Within the multicompetence framework, proficiency is seen as a whole and reflects the interaction between proficiencies (L1, L2, L3) in the mind of the learner, highlighting that the competence of multilinguals is different from that of monolinguals in the same way as the competence of bilinguals is different from that of monolinguals (Grosjean 2001). In turn, multilingual proficiency views proficiency as a "cumulative measure" of the various subcomponents (lexical, syntactic and phonetic) of each "language system" (i.e. background language) of the multilingual (Herdina \& Jessner 2002: 109), with some deviations from the expected language norm to be attributed to the "interaction" between the different 
language systems (p. 127). More importantly, within the dynamic model of multilingualism (Herdina \& Jessner 2002; Jessner 2008), proficiency is presumed to operate under the auspices of the so-called "M-factor" (multilingualism factor), an emergent property that "can be specified as a function of the interaction between more than one language system" (Herdina \& Jessner 2002: 130). Moreover, the authors claim, "[i]t is not necessarily relevant how these language systems develop, but may be dependent upon the number of language systems involved". Because of this interaction of proficiencies, multilinguals are expected to perform differently from bilinguals and L2 learners (Stratilaki 2006). In this respect, both multicompetence and multilingual proficiency are consistent with the idea of plurilingual competence and encompass a "composite competence" (Council of Europe 2001: 260), while highlighting the varying and uneven degrees of proficiency in each language of the multilingual (Coste 1997).

The interaction of proficiencies in multilinguals is not a new idea. In fact, it has been proposed that proficiency thresholds between non-native languages (L2 and L3) affect linguistic development in all the languages of a multilingual (De Angelis \& Selinker 2001). Cenoz (2000) warns that different areas of proficiency in the L1 and the L2 may have a specific effect on different areas of proficiency in the L3. In addition to this, she poses the question whether proficiency in other languages may be influential at all stages of the acquisition of a given L3. An important contribution to research on proficiency thresholds in L3 acquisition are the studies by Jaensch (e.g. 2011), who found a correlation between L2 morphological proficiency (measured in terms of inflection suppliance on adjectives) and the use of inflected adjectives in the L3. Along similar lines, Trévisiol (2006) found a differential effect for proficiency in the L1 and the L2 and their effect on L3 development. Whereas both the L1 (English, typologically closer to the L3s French and Italian) and the L2 (German) were equally likely to affect the L3 at low levels in this language, a proficiency-related developmental shift happened with increasing proficiency in the L3. In particular, the L1 but not the L2 had an effect on the acquisition of the L3 at higher levels of proficiency in the L3.

Another insight into the role of proficiency in multilingualism has to do with how proficiency level may affect lexico-semantic organization in L3 learners. Extending research on bilinguals to research on multilinguals, it has been suggested that proficiency mediates how lexical structure is connected between the mother tongue and non-native languages. In particular, a hypothesis that has received substantial empirical support is that lexical structure between the L1 and a weak foreign language (often the L3) is one of word association, whereas the lexical structure between the L1 and a strong foreign language (often the L2) is one of concept mediation (Abunuwara 1992; Schönpflug 2000; Herwig 2001; Cenoz et 
al. 2003). Based on evidence coming from various language combinations and analyzed using different instruments (e.g. Stroop interference test, story-telling task, translation, think-aloud protocol), the tentative conclusions drawn in these studies is that multilinguals' lexical organization shows a proficiency-related effect, that this organization changes over time as a function of adjustments in L2 and L3 proficiency, and that access in multilinguals is non-selective (Dijkstra \& van Hell 2003).

\section{Crosslinguistic influence in L3 acquisition}

One area of investigation within multilingualism research that has attracted much attention is crosslinguistic influence. From an L3 acquisition perspective, transfer or crosslinguistic influence is defined as a "largely unconscious interaction phenomenon between evolving sets of imperfectly acquired structures" (Bouvy 2000: 143). The term "crosslinguistic interaction" (Herdina \& Jessner 2002; Jessner 2003) subsumes crosslinguistic influence together with other, more conscious phenomena that take place in multilingual environments such as codeswitching and borrowing.

In addition to the body of articles and book chapters devoted to the investigation of crosslinguistic influence in multilingual language acquisition, several compilations on the topic have been published in recent years, often with a focus on L3 acquisition. Some of them address psycholinguistic and processing issues with a focus on transfer at the level of lexis, phonology and morphology (De Angelis et al. 2015; Peukert 2015). Equally, several studies focus on crosslinguistic influence in the area of syntax (Leung 2009; Cabrelli et al. 2012; Angelovska \& Hahn 2017), mainly from a generative research perspective.

In the field of L3 acquisition, the investigation of crosslinguistic influence is more complex than in L2 acquisition because this influence involves necessarily more than two languages, often non-native. Empirical studies on crosslinguistic influence involving more than two languages were already conducted in the sixties and the seventies. Despite this early interest in crosslinguistic influence, it was not until the turn of the century (e.g. Williams \& Hammarberg 1998; Cenoz et al. 2001) that crosslinguistic influence in such contexts was studied in a more systematic way, meaning that all languages in the learners' linguistic backgrounds were identified and mentioned and prior non-native languages were given their appropriate status.

A major concern in research on crosslinguistic influence in L3 acquisition has been to try and determine whether it is the L1 or the L2 that acts as the main 
source language of influence, or whether other characteristics of the background languages (such as close typological relatedness, for instance), determine the degree to which one language will influence another. Another concern is the distinction between different kinds of crosslinguistic influence in L3 acquisition depending on the direction of the influence. The most widely investigated kind is the one that occurs between two non-native languages, usually referred to as "interlanguage transfer" (De Angelis \& Selinker 2001). Another kind of crosslinguistic influence is the one that takes place from the L2 or the L3 back onto the L1 (Kecskes \& Papp 2000), also referred to as "reverse" or "backward" transfer.

Different hypotheses have been put forward about which background language of the multilingual learner is more likely than another to act as the source for crosslinguistic influence. The status of the background language (L1 or L2) has been emphasized in two models that hypothesize the primacy of either a prior non-native language or the mother tongue. The former model is referred to as the L2 status factor hypothesis (Bardel \& Falk 2007; 2012; Falk \& Bardel 2010; Bardel \& Sánchez 2017). Furthermore, following the premise that a prior L2 is a more likely candidate as a source language of influence, Bardel \& Sánchez (2017) discuss empirical evidence suggesting that L3 learners with lower cognitive abilities are less efficient in inhibiting non-intended activation and transfer from the L2 (Sánchez \& Bardel 2016; Sánchez 2019b). They use this evidence to suggest that cognitive factors play a role in the occurrence of crosslinguistic influence in L3 acquisition. Therefore, the authors argue, it is necessary to take into consideration to what extent the amount (but not the quality) of this influence might be explained by differences in cognitive abilities such as working memory capacity and attention control. All in all, the L2 status hypothesis has received much more empirical support than the second hypothesis, the L1 transfer hypothesis (Na Ranong \& Leung 2009; Hermas 2010), and it has been tested with a wider variety of language combinations. According to the L1 hypothesis, the L1 has a "privileged" role in, at least, the acquisition of L3 subtle syntactic properties, as for example in argument selection (as in these two studies). Hence, when coping with such structures, L3 learners would resort to their L1 underlying grammatical knowledge, rather than to their L2 explicit conscious knowledge (Na Ranong \& Leung 2009: 185; Hermas 2010: 358).

Rather than status, other proposals consider structural similarity and accumulated language experience to be more important factors. In the typological primacy model (Rothman 2015) and the linguistic proximity model (Westergaard et al. 2017), it is claimed that the most likely source language of influence will be the background language that more closely resembles the L3. The cumulative enhancement model for language acquisition, in turn, claims that "experi- 


\section{Laura Sánchez}

ence in any prior language can be drawn upon in subsequent acquisition" (Flynn et al. 2004: 13) and that crosslinguistic influence has a facilitative effect. Less whole-sale predictions can be made based on the scalpel model (Slabakova 2017), because it envisions crosslinguistic influence to work property by property. As such, crosslinguistic influence would be language-dependent, and it would be shaped by factors "such as construction frequency, availability of clear unambiguous input, prevalent use and structural linguistic complexity, among others" (Slabakova 2017: 653). Due to limitations of space, a more comprehensive reexamination of these and other studies is not possible in the concise set up of the scene here. Hopefully, however, these lines will serve a useful point of departure for the interested reader. For recent overviews of findings in research on crosslinguistic influence in L3 acquisition, the reader is directed to the reviews in Bardel (2019); De Angelis (2019) and Puig-Mayenco et al. (2018).

\section{Conclusions}

The present theoretical chapter has attempted to offer an overall picture of multilingual acquisition, while emphasizing the need to distinguish it from other language learning situations where only two languages are in contact. With this as the starting point, the discussion has proposed a fine-grained distinction between the two most common types of multilingual acquisition described in the literature, especially with regard to third language acquisition. Firstly, the case of third language acquisition in learners who have prior experience in acquiring one or more non-native languages. Secondly, the case of subsequent acquisition in learners who are bilingual from an early age. In order to have a better understanding of the dynamics of language acquisition in such multilingual contexts, it is necessary to take into account the effects that an earlier or later onset in the L1 and the L2 may have on development and learning in the L3. At the same time, it is also necessary to consider the asymmetries in the proficiency level of all the languages of the multilingual learner, and how they constrain and shape subsequent language acquisition. Finally, this chapter has given a grasp of current research on crosslinguistic influence in third language acquisition, with a focus on how native and non-native languages interact in the mind of the multilingual learner, and what the consequences of this interaction are for interlanguage development in the acquisition of a third or additional language. 


\section{References}

Abunuwara, Ehab. 1992. The structure of the trilingual lexicon. European fournal of Cognitive Psychology 4(4). 311-322. DOI: 10.1080/09541449208406190.

Angelovska, Tanja \& Angela Hahn (eds.). 2017. L3 syntactic transfer: Models, new developments and implications. Amsterdam: John Benjamins.

Aronin, Larissa \& David Singleton. 2008. Multilingualism as a new linguistic dispensation. International fournal of Multilingualism 5(1). 1-16. DOI: 10.2167 / ijm072.0.

Baars, Bernard \& Stan Franklin. 2003. How conscious experience and working memory interact. Trends in Cognitive Sciences 7(4). 166-172. DOI: 10.1016/S13646613(03)00056-1.

Bardel, Camilla. 2019. Syntactic transfer in L3 learning: What do models and results tell us about learning and teaching a third language? In Junkal Gutierrez-Mangado, María Martínez-Adrián \& Francisco Gallardo-del-Puerto (eds.), Cross-linguistic influence: From empirical evidence to classroom practice, 101-120. Basel: Springer.

Bardel, Camilla \& Ylva Falk. 2007. The role of the second language in third language acquisition: The case of Germanic syntax. Second Language Research 23(4). 459-484. DOI: 10.1177/0267658307080557.

Bardel, Camilla \& Ylva Falk. 2012. The L2 status factor and the declarative/procedural distinction. In Jennifer Cabrelli Amaro, Suzanne Flynn \& Jason Rothman (eds.), Third language acquisition in adulthood, 61-78. Amsterdam: John Benjamins.

Bardel, Camilla \& Christina Lindqvist. 2007. The role of proficiency and psychotypology in lexical cross-linguistic influence: A study of a multilingual learner of Italian L3. In Marina Chini, Paola Desideri, Maria Elena Favilla \& Gabriele Pallotti (eds.), Atti del VI congresso internazionale dell'Associazione Italiana di Linguistica Applicata, 123-145. Perugia: Guerra Edizioni.

Bardel, Camilla \& Laura Sánchez. 2017. The L2 status factor hypothesis revisited: The role of metalinguistic knowledge, working memory, attention and noticing in third language learning. In Tanja Angelovska \& Angela Hahn (eds.), L3 syntactic transfer: Models, new developments and implications, 85-101. Amsterdam: John Benjamins.

Benmamoun, Elabbas, Silvina Montrul \& Maria Polinsky. 2013. Heritage languages and their speakers: Opportunities and challenges for linguistics. Theoretical Linguistics 39(129-181). 3-4. DOI: 10.1515/t1-2013-0009. 
Bouvy, Christine. 2000. Towards the construction of a theory of crosslinguistic transfer. In Jasone Cenoz \& Ulrike Jessner (eds.), English in Europe: The acquisition of a third language, 143-156. Clevedon: Multilingual matters.

Brohy, Claudine. 2001. Generic and/or specific advantages of bilingualism in a dynamic plurilingual situation: The case of French as official L3 in the school of Samedan (Switzerland). International fournal of Bilingual Education and Bilingualism 4(1). 38-49. DOI: 10.1080/13670050108667717.

Cabrelli, Jennifer, Suzanne Flynn \& Jason Rothman (eds.). 2012. Third language acquisition in adulthood. Amsterdam: John Benjamins.

Cenoz, Jasone. 2000. Research on multilingual acquisition. In Jasone Cenoz \& Ulrike Jessner (eds.), English in Europe: The acquisition of a third language, 3953. Clevedon: Multilingual Matters.

Cenoz, Jasone. 2003. The additive effect of bilingualism on third language acquisition: A review. International fournal of Bilingualism 7(1). 71-87. DOI: 10.1177/ 13670069030070010501.

Cenoz, Jasone. 2013. Defining multilingualism. Annual Review of Applied Linguistics 33. 3-18. DOI: 10.1017/S026719051300007X.

Cenoz, Jasone, Britta Hufeisen \& Ulrike Jessner (eds.). 2001. Crosslinguistic influence in third language acquisition. Clevedon: Multilingual matters.

Cenoz, Jasone, Britta Hufeisen \& Ulrike Jessner (eds.). 2003. The multilingual lexicon. Dordrecht: Kluwer Academic Publishers.

Cenoz, Jasone \& José F. Valencia. 1994. Additive trilingualism: Evidence from the Basque Country. Applied Psycholinguistics 15(2). 195-207. DOI: $10.1017 /$ S0142716400005324.

Cook, Vivian. 1995. Evidence for multicompetence. Language Learning 42. 557591.

Coste, Daniel. 1997. Multilingual and multicultural competence and the role of school. Language Teaching 30(2). 90-93. DOI: 10.1017/S0261444800012817.

Council of Europe. 2001. Common European framework of reference for language: Learning, teaching, assessment.

Cummins, Jim. 1981. The role of primary language development in promoting educational success for language minority students. In California State Department of Education (ed.), Schooling and language minority students: A theoretical framework, 3-49. Los Angeles, CA: California State University.

De Angelis, Gessica. 2007. Third or additional language acquisition. Clevedon: Multilingual Matters.

De Angelis, Gessica. 2015. English L3 learning in a multilingual context: The role of parental education and 12 exposure within the living community. Interna- 
tional fournal of Multilingualism 12(4). 435-452. DOI: 10.1080/14790718.2015. 1071017.

De Angelis, Gessica. 2019. Crosslinguistic influence and multiple languages acquisition and use. In David Singleton \& Larissa Aronin (eds.), Twelve lectures in multilingualism, 163-177. Clevedon: Multilingual Matters.

De Angelis, Gessica, Ulrike Jessner \& Marijana Kresić (eds.). 2015. Crosslinguistic influence and crosslinguistic interaction in multilingual language learning. London: Bloomsbury Academic.

De Angelis, Gessica \& Larry Selinker. 2001. Interlanguage transfer and competing linguistic systems in the multilingual mind. In Jasone Cenoz, Britta Hufeisen \& Ulrike Jessner (eds.), Crosslinguistic influence in third language acquisition, 42-58. Clevedon: Multilingual Matters.

DeKeyser, Robert M. 2007. Introduction: Situating the concept of practice. In Robert M. DeKeyser (ed.), Practice in a second language: Perspectives from applied linguistics and cognitive psychology, 208-226. Cambridge: Cambridge University Press.

DeKeyser, Robert M. 2010. Practice for second language learning: Don't throw out the baby with the bathwater. International fournal of English Studies 10(1). 155-165. DOI: 10.6018/ijes/2010/1/114021.

Dentler, Sigrid, Britta Hufeisen \& Beate Lindemann (eds.). 2000. Tertiär-und Drittsprachen: Projekte und empirische Untersuchungen. Tübingen: Stauffenburg Verlag.

Dijkstra, Ton \& Janet G. van Hell. 2003. Testing the language mode hypothesis using trilinguals. International fournal of Bilingual Education and Bilingualism 6(1). 2-16. DOI: 10.1080/13670050308667769.

Falk, Ylva \& Camilla Bardel. 2010. The study of the role of the background languages in third language acquisition: The state of the art. International Review of Applied Linguistics in Language Teaching 48(2-3). 185-219. DOI: 10.1515/iral. 2010.009.

Flynn, Suzanne, Claire Foley \& Inna Vinnitskaya. 2004. The cumulativeenhancement model for language acquisition: Comparing adults' and children's patterns of development in first, second and third language acquisition of relative clauses. International fournal of Multilingualism 1(1). 3-15. DOI: $10.1080 / 14790710408668175$.

Fouser, Robert. 2001. Too close for comfort? Sociolinguistic transfer from Japanese into Korean as an $\mathrm{L} \geq 3$. In Jasone Cenoz, Britta Hufeisen \& Ulrike Jessner (eds.), Cross-linguistic influence in third language acquisition: Psycholinguistic perspectives, 149-169. Clevedon: Multilingual Matters. 
García Mayo, María del Pilar \& María Luisa García Lecumberri (eds.). 2003. Age and the acquisition of English as a foreign language. Clevedon: Multilingual Matters.

Gibson, Martha \& Britta Hufeisen. 2003. Investigating the role of prior foreign language knowledge: Translating from an unknown into a known foreign language. In Jasone Cenoz, Britta Hufeisen \& Ulrike Jessner (eds.), The multilingual lexicon, 87-102. Dordrecht: Kluwer Academic Publishers.

Gibson, Martha, Britta Hufeisen \& Gary Libben. 2001. Learners of German as an 13 and their production of German prepositional verbs. In Jasone Cenoz, Britta Hufeisen \& Ulrike Jessner (eds.), Cross-linguistic influence in third language acquisition: Psycholinguistic perspectives, 138-148. Clevedon: Multilingual Matters.

Grosjean, François. 2001. The bilingual's language modes. In Janet Nicol (ed.), One mind, two languages: Bilingual language processing, 1-22. Oxford: Blackwell.

Grosjean, François. 2010. Bilingual: Life and reality. Cambridge, MA: Harvard University Press.

Gudmundson, Anna. 2020. The mental lexicon of multilingual adult learners of Italian L3: A study of word association behavior and cross-lingual semantic priming. In Camilla Bardel \& Laura Sánchez (eds.), Third language acquisition: Age, proficiency and multilingualism, 67-109. Berlin: Language Science Press. DOI: 10.5281/zenodo.4138739.

Hammarberg, Björn. 2001. Roles of L1 and L2 in L3 production and acquisition. In Jasone Cenoz, Britta Hufeisen \& Ulrike Jessner (eds.), Cross-linguistic influence in third language acquisition: Psycholinguistic perspectives, 21-41. Clevedon: Multilingual Matters.

Hammarberg, Björn. 2018. L3, the tertiary language. In Andreas Bonnet \& Peter Siemund (eds.), Foreign language education in multilingual classroom, 127-150. Amsterdam: John Benjamins.

Herdina, Philip \& Ulrike Jessner. 2002. A dynamic model of multilingualism: Perspectives of change in psycholinguistics. Clevedon: Multilingual Matters.

Hermas, Abdelkader. 2010. Language acquisition as computational resetting: Verb movement in L3 initial state. International fournal of Multilingualism 7(4). 343-362. DOI: 10.1080/14790718.2010.487941.

Herwig, Anna. 2001. Plurilingual lexical organisation: Evidence from lexical processing in L1-L2-L3-L4 translation. In Jasone Cenoz, Britta Hufeisen \& Ulrike Jessner (eds.), Cross-linguistic influence in third language acquisition: Psycholinguistic perspective, 115-137. Clevedon: Multilingual Matters. 
Hiroshi, Zoya \& Tamar Degani. 2018. Direct and indirect effects of multilingualism on novel language learning: An integrative review. Psychonomic Bulletin and Review 25(3). 892-916. DOI: 10.3758/s13423-017-1315-7.

Hufeisen, Britta. 1998. L3 - Stand der Forschung: Was bleibt zu tun? In Britta Hufeisen \& Beate Lindemann (eds.), Tertiärsprachen: Modelle, Methoden, 169184. Tübingen: Stauffenburg Verlag.

Hufeisen, Britta. 2003. L1, L2, L3, Lx - alle gleich? Linguistische, lernerinterne und lernerexterne Faktoren in Modellen zum multiplen Spracherwerb. In Nicole Baumbartern, Claudia Böttger, Markus Motz \& Julia Probst (eds.), Übersetzen, interkulturelle Kommunikation, Spracherwerb und Sprachvermittlung: Das Leben mit mehreren Sprachen. Festschrift für fulianne House zum 60. Geburtstag, 97-109. Bochum: AKS-Verlag.

Hufeisen, Britta \& Nicole Marx. 2007. How can DaFnE and EuroComGerm contribute to the concept of receptive multilingualism? Theoretical and practical considerations. In Jan Ten Thije \& Ludger Zeevaert (eds.), Receptive multiligualism: Linguistic analyses, language policies and didactic concepts (Hamburg Studies on Multilingualism 6), 307-321. Amsterdam: John Benjamins. DOI: 10. 1075/hsm.6.20huf.

Jaensch, Carol. 2011. L3 acquisition of German adjectival inflection: A generative account. Second Language Research 27(1). 83-105. DOI: 10 . 1177 / 0267658310386646.

Jaspaert, Koen \& Gertrude Lemmens. 1990. Linguistic evaluation of Dutch as a third language. In Michael Byram \& Johan Leman (eds.), Bicultural and trilingual education: The Foyer model in Brussels, 30-56. Clevedon: Multilingual Matters.

Jessner, Ulrike. 1999. Metalinguistic awareness in multilinguals: Cognitive aspects of third language learning. Language Awareness 8(3-4). 201-209. DOI: 10.1080/09658419908667129.

Jessner, Ulrike. 2003. On the nature of crosslinguistic interaction in multilinguals. In Jasone Cenoz, Britta Hufeisen \& Ulrike Jessner (eds.), The multilingual lexicon, 45-55. Dordrecht: Kluwer Academic Publishers.

Jessner, Ulrike. 2006. Linguistic awareness in multilingualism: English as a third language. Edinburgh: Edinburgh University Press.

Jessner, Ulrike. 2008. Language awareness in multilinguals: Theoretical trends. In Jasone Cenoz \& Nancy Hornberger (eds.), Encyclopedia of language and education. Vol 6: Knowledge about language, 357-369. New York, NY: Springer.

Kecskes, Istvan \& Tünde Papp. 2000. Foreign language and mother tongue. Hillsdale, MI: Lawrencee Erlbaum. 
Kemp, Charlotte. 2007. Strategic processing in grammar learning: Do multilinguals use more strategies? International fournal of Multilingualism 4(4). 241261. DOI: 10.2167/ijm099.0.

Kidd, Evan, Seamus Donnelly \& Morten Christiansen. 2018. Individual differences in language acquisition and processing. Trends in Cognitive Sciences 22(2). 154-169. DOI: 10.1016/j.tics.2017.11.006.

Klein, Elaine. 1995. Second versus third language acquisition: Is there a difference? Language Learning 45(3). 419-465. DOI: 10/dnkc9j.

Kopečková, Romana. 2016. The bilingual advantage in 13 learning: A developmental study of rhotic sounds. International fournal of Multilingualism 13(4). 410425. DOI: 10.1080/14790718.2016.1217605.

Krashen, Stephen, Michael Long \& Robin Scarcella. 1979. Age, rate and eventual attainment in second language acquisition. TESOL Quarterly 13(3). 573-582. https://www.jstor.org/stable/3586451.

Leung, Yan-Kit Ingrid (ed.). 2009. Third language acquisition and universal grammar. Clevedon: Multilingual Matters.

Lindemann, Beate \& Britta Hufeisen (eds.). 1998. Tertiärsprachen: Theorien, Modelle, Methoden. Tübingen: Stauffenburg Verlag.

Lindqvist, Christina \& Camilla Bardel. 2013. Exploring the impact of the proficiency and typology factors: Two cases of multilingual learners' L3 learning. In Miroslaw Pawlak \& Larissa Aronin (eds.), Essential topics in applied linguistics and multilingualism: Studies in honor of David Singleton, 253-266. Dordrecht: Springer.

Marx, Nicole \& Britta Hufeisen. 2004. A critical overview of research on third language acquisition and multilingualism. International fournal of Multilingualism 1(2). 141-154. DOI: 10.1080/14790710408668184.

McLaughlin, Barry \& Nandini Nayak. 1989. Processing a new language: Does knowing other languages make a difference? In Hans Dechert \& Manfred Raupach (eds.), Interlingual processes, 419-465. Tübingen: Günter Narr.

Missler, Bettina. 2000. Previous experience of foreign language learning and its contribution to the development of learner strategies. In Sigrid Dentler, Britta Hufeisen \& Beate Lindemann (eds.), Tertiär- und Drittsprachen: Projekte und empirische Untersuchungen, 7-21. Tübingen: Stauffenburg Verlag.

Mitchell, Rosamond \& Florence Myles. 1998. Second language learning theories. London: Arnold.

Muñoz, Carmen. 2000. Bilingualism and trilingualism in school students in Catalonia. In Jasone Cenoz \& Ulrike Jessner (eds.), English in Europe: The acquisition of a third language, 157-178. Clevedon: Multilingual Matters. 
Muñoz, Carmen (ed.). 2006. Age and the rate of foreign language learning. Clevedon: Multilingual Matters.

Muñoz, Carmen. 2014. Complexities and interactions of age and second language learning: Broadening the research agenda. Applied Linguistics 35(4). 369-373. DOI: 10.1093/applin/amu033.

Muñoz, Carmen. 2019. A new look at "age": Young and old L2 learners. In John Schwieter \& Alessandro Benati (eds.), The Cambridge handbook of language learning, 430-450. Cambridge: Cambridge University Press.

Muñoz, Carmen \& David Singleton. 2019. Age and multilingualism. In David Singleton \& Larisa Aronin (eds.), Twelve lectures on multilingualism, 213-229. Clevedon: Multilingual Matters.

Muñoz, Carmen. 2020. Cognate recognition by young multilingual language learners: The role of age and exposure. In Camilla Bardel \& Laura Sánchez (eds.), Third language acquisition: Age, proficiency and multilingualism, 145165. Berlin: Language Science Press. DOI: 10.5281/zenodo.4138743.

Na Ranong, Sirita \& Yan-Kit Ingrid Leung. 2009. Null objects in L1 Thai-L2 English-L3 Chinese: An empiricist take on a theoretical problem. In Yan-Kit Ingrid Leung (ed.), Third language acquisition and universal grammar, 162-191. Clevedon: Multilingual Matters.

Nation, Robert \& Barry McLaughlin. 1986. Novices and experts: An information processing approach to the "good language learner" problem. Applied Psycholinguistics 7(1). 51-56. DOI: 10.1017/S0142716400007177.

Nayak, Nandini, Nina Hansen, Nancy Krueger \& Barry McLaughlin. 1990. Language-learning strategies in monolingual and multilingual adults. Language Learning 40(2). 221-244. DOI: 10.1111/j.1467-1770.1990.tb01334.x.

Otwinowska, Agnieszka \& Jakub Szewczyk. 2017. The more similar the better? Factors in learning cognates, false cognates and non-cognate words. International fournal of Bilingual Education and Bilingualism 22(8). 974-991. DOI: 10. 1080/13670050.2017.1325834.

Paradis, Michel. 2009. Declarative and procedural determinants of second languages. Amsterdam: John Benjamins.

Peukert, Hagen (ed.). 2015. Transfer effects in multilingual language development. Amsterdam: John Benjamins.

Pfenninger, Simone E. 2014. The literacy factor in the optimal age discussion: A five-year longitudinal study. International fournal of Bilingual Education and Bilingualism 19(3). 217-234. DOI: 10.1080/13670050.2014.972334.

Pfenninger, Simone E. 2020. Age meets multilingualism: Influence of starting age on L3 acquisition across different learner populations. In Camilla Bardel \& Laura Sánchez (eds.), Third language acquisition: Age, proficiency and mul- 
tilingualism, 167-207. Berlin: Language Science Press. DOI: 10.5281/zenodo. 4138745.

Pfenninger, Simone E. \& David Singleton. 2017. Beyond age effects in instructional L2 learning: Revisiting the age factor. Bristol: Multilingual Matters.

Pfenninger, Simone E. \& David Singleton. 2019. Starting age overshadowed: The primacy of differential environmental and family support effects on 12 attainment in an instructional context. Language Learning 69(S1). 207-234. DOI: 10. 1111/lang.12318.

Polinsky, Maria. 2015. When L1 becomes an L3: Do heritage speakers make better L3 learners? Bilingualism: Language and Cognition 18(2). 163-178. DOI: 10.1017/ S1366728913000667.

Puig-Mayenco, Eloi, Jorge González Alonso \& Jason Rothman. 2018. A systematic review of transfer studies in third language acquisition. Second Language Research 36(1). 1-34. DOI: 10.1177/0267658318809147.

Rast, Rebekah. 2010. The use of prior linguistic knowledge in the early stages of 13 acquisition. International fournal of Applied Linguistics 48(2-3). 159-183. DOI: 10.1515/iral.2010.008.

Ringbom, Håkan. 2007. Cross-linguistic similarity in foreign language learning. Clevedon: Multilingual Matters.

Rothman, Jason. 2015. Linguistic and cognitive motivations for the typological primacy model of third language (L3) transfer: Timing of acquisition and proficiency considered. Bilingualism: Language and Cognition 18(2). 179-190. DOI: 10.1017/S136672891300059X.

Rutgers, Dieuwerke \& Michael Evans. 2017. Bilingual education and L3 learning: Metalinguistic advantage or not? International fournal of Bilingual Education and Bilingualism 20(7). 788-806. DOI: 10.1080/13670050.2015.1103698.

Salaberry, Rafael. 2020. The conceptualisation of knowledge about aspect: From monolingual to multilingual representations. In Camilla Bardel \& Laura Sánchez (eds.), Third language acquisition: Age, proficiency and multilingualism, 43-65. Berlin: Language Science Press. DOI: 10.5281/zenodo.4138737.

Sánchez, Laura. 2012. 'Luisa and Pedrito's dog will the breakfast eat': Interlanguage transfer and the role of the second language factor. In Gessica De Angelis \& Jean-Marc Dewaele (eds.), New trends in crosslinguistic influence and multilingualism research, 86-104. Clevedon: Multilingual Matters. DOI: 10/d9md.

Sánchez, Laura. 2014. An inquiry into the role of L3 proficiency on crosslinguistic influence in third language acquisition. Odisea: Revista de Estudios Ingleses 15. 169-188. DOI: 10.25115/odisea.v0i15.282. 
Sánchez, Laura. 2019a. Weighing up the effects of working memory and cognitive abilities in CLIL learning. English Language Teaching 12(2). 113-126. DOI: 10. 5539/elt.v12n2p113.

Sánchez, Laura. 2019b. What else constrains the occurrence of lexical transfer in L3 acquisition? Exploring task complexity. Paper presented at the 29th Conference of the European Second Language Association. Lund.

Sánchez, Laura \& Camilla Bardel. 2016. Cognitive factors, perceptions and transfer in third language acquisition. Revue Française de Linguistique Appliqué 21(2016-2). 123-138. DOI: 10.3917/rfla.212.0123.

Sánchez, Laura \& Camilla Bardel. 2017. Transfer from an L2 in third language learning: A study on L2 proficiency. In Tanja Angelovska \& Angela Hahn (eds.), L3 syntactic transfer: Models, new developments and implications, 223250. Amsterdam: John Benjamins.

Sánchez, Laura. 2020. From L2 to L3, verbs getting into place: A study on interlanguage transfer and L2 syntactic proficiency. In Camilla Bardel \& Laura Sánchez (eds.), Third language acquisition: Age, proficiency and multilingualism, 209-235. Berlin: Language Science Press. DOI: 10.5281/zenodo.4138747.

Sanders, Marianne \& Guust Meijers. 1995. English as L3 in the elementary school. ILT: Review of Applied Linguistics 107(1). 59-78. DOI: 10.1075/itl.107-108.04san.

Sanz, Cristina. 2000. Bilingual education enhances third language acquisition: Evidence from Catalonia. Applied Psycholinguistics 21(1). 23-44. DOI: $10.1017 /$ S0142716400001028.

Sayehli, Susan. 2001. Transfer and syntax: A study on the acquisition of German word order by Swedish native speakers. Lund: Lund University, Department of Linguistics. (MA thesis).

Schönpflug, Ute. 2000. Word-fragment completions in the second (German) and third (English) language: A contribution to the organization of the trilingual speaker's lexicon. In Jasone Cenoz \& Ulrike Jessner (eds.), English in Europe: The acquisition of a third language, 143-156. Clevedon: Multilingual Matters.

Sciutti, Sandro. 2020. The acquisition of clitic pronouns in complex infinitival clauses by German-speaking learners of Italian as an L3: The role of proficiency in target and background language(s). In Camilla Bardel \& Laura Sánchez (eds.), Third language acquisition: Age, proficiency and multilingualism, 111-144. Berlin: Language Science Press. DOI: 10.5281/zenodo.4138741.

Sharwood Smith, Michael. 1994. Second language learning: Theoretical foundations. New York, NY: Longman.

Sharwood Smith, Michael. 2010. Metalinguistic processing and acquisition within the MOGUL famework. In Martin Everaert, Tom Lentz, Hannah Mulder, Øys- 
tein Nilsen \& Arjen Zondervan (eds.), The linguistic enterprise: From knowledge of language to knowledge in linguistics, 327-344. Amsterdam: John Benjamins.

Singleton, David \& Simone E. Pfenninger. 2018. L2 acquisition in childhood, adulthood and old age: Misreported and under-researched dimensions of the age factor. Journal of Second Language Studies 1(2). 254-276. DOI: 10 .1075/ jsls . 00003.sin.

Slabakova, Roumyana. 2017. The scalped model of third language acquisition. International fournal of Bilingualism 21(6). 651-665. DOI: 10 . $1177 /$ 1367006916655413.

Stadt, Rosalinde, Aafke Hulk \& Petra Sleeman. 2020. L1 Dutch vs L2 English and the initial stages of L3 French acquisition. In Camilla Bardel \& Laura Sánchez (eds.), Third language acquisition: Age, proficiency and multilingualism, 237261. Berlin: Language Science Press. DOI: 10.5281/zenodo.4138749.

Stratilaki, Sofia. 2006. Representations of plurilingual competence and language use in dynamic trilingual education. Zeitschrift für interkulturellen Fremdsprachenunterricht 11(1). https://tujournals.ulb.tu-darmstadt.de/index.php/zif/ article/view/356.

Sundqvist, Pia \& Liss Kerstin Sylvén. 2014. Language-related computer use: Focus on young L2 English learners in Sweden. ReCALL 26(1). 3-20. DOI: 10.1017 / S0958344013000232.

Swain, Merrill, Sharon Lapkin, Norman Rowen \& Doug Hart. 1990. The role of mother tongue literacy in third language learning. Language, Culture and Curriculum 3(1). 65-81. DOI: 10.1080/07908319009525073.

Tagarelli, Kaitlyn, Mailce Borges-Mota \& Patrick Rebuschat. 2011. The role of working memory in implicit and explicit language learning. In Laura Carlson, Cristoph Hoelscher \& Thomas Shipley (eds.), Proceedings on the 33th annual conference of the Cognitive Science Society, 2061-2066. Austin, TX: Cognitive Science Society.

Thomas, Jacqueline. 1992. Metalinguistic awareness in second- and thirdlanguage learning. In Richard Harris (ed.), Cognitive processing in bilinguals, 531-545. Amsterdam: North-Holland.

Tonkin, Humphrey. 2009. Where art and nature meet. In Elka Todeva \& Jasone Cenoz (eds.), The multiple realities of multilingualism, 191-208. Berlin: Mouton de Gruyter.

Trévisiol, Pascale. 2006. Influence translinguistique et alternance codique en français L3: Rôle des L1 et L2 dans la production orale d'apprenants japonais. Acquisition et Interaction en Langue Etrangère 24. 13-43. 
Wagner, Daniel, Jennifer Spratt \& Abdelkader Ezzaki. 1989. Does learning to read in a second language always put the child at a disadvantage? Some counterevidence from Morocco. Applied Psycholinguistics 10. 31-48.

Westergaard, Marit, Natalia Mitrofanova, Roksolana Mykhaylyk \& Yulia Rodina. 2017. Crosslinguistic influence in the acquisition of a third language: The linguistic proximity model. International fournal of Bilingualism 21(6). 666-682. DOI: $10.1177 / 1367006916648859$.

Williams, Sarah \& Björn Hammarberg. 1998. Language switches in L3 production: Implications for a polyglot speaking model. Applied Linguistics 19(3). 259-333. DOI: 10.1093/applin/19.3.295.

Zobl, Helmut. 1992. Prior linguistic knowledge and the conservatism of the learning procedure: Grammaticality judgments of unilingual and multilingual learners. In Susan Gass \& Larry Selinker (eds.), Language transfer in language learning, 177-196. Amsterdam: John Benjamins. 



\title{
Chapter 3
}

\section{The conceptualisation of knowledge about aspect: From monolingual to multilingual representations}

\author{
Rafael Salaberry
}

Rice University

The theoretical dissociation between prototypical and non-prototypical conceptualisations of aspect is predicated on the effect of broad levels of contextualisation of aspectual meanings (e.g. adverbial phrases, discursive grounding). Such dissociation creates a difficult challenge for the acquisition of aspect among adult L2 learners, thus providing an ideal testing ground for the analysis of the effect of distinct sources of linguistic knowledge (i.e. the L1 and the L2) on the acquisition of aspect in the L3. In the present chapter, I review the few empirical studies on the acquisition of L2/L3 aspectual knowledge to support the claim that processing constraints associated with L2/L3 acquisition are distinct from the processes linked to the $\mathrm{L} 1$ acquisition of conceptualisations of aspect. I conclude that the proper identification of the theoretical construct of aspect (narrow versus broad) may have important consequences for the evaluation of models of crosslinguistic influence in general.

Most definitions of aspect focus on the speaker's perspective about the temporal description of an eventuality, thus making such conceptualisation of situations an important component in a description of aspectual knowledge. Michaelis (1998: 5, italics added), for one, describes "aspectual categorisation as a product of the manner in which people, as producers and processors of texts, construe scenes, rather than as a reflection of the properties which situations have in the world'." Such a perspective-driven conceptualisation of aspect is even more complex once we consider the wide range of linguistic representations, not just among first language (L1) users, but among second language (L2) and third language (L3) 
users (i.e. bilinguals and multilinguals). Not surprisingly, current research has not yet fully addressed theoretical questions about the representation of aspect. For instance, the variability in contextualised interpretations among not just nonnative speakers, but among native speakers as well raises important questions that have not been coherently addressed by most theoretical descriptions (Salaberry 2008; Ziegeler 2008; Sasse 2012). Compounding the challenge of modeling adequate representations of aspect, there have been very few empirical studies that have addressed the nature of the representation of aspect among multilinguals (e.g. Salaberry 2005; Foote 2009; Diaubalick \& Guijarro-Fuentes 2016), even though such analysis may be crucial to assess the relevance of the construct of aspect in descriptions of (mostly) monolingual speakers.

Accordingly, the main claim to be made in this chapter is that the problem space created by a semantico-syntactic-discursive construct of such complexity as aspect provides an ideal opportunity to evaluate the multifaceted effect of previous languages (i.e. L1 and L2) on the development of the L3. This is mostly relevant in terms of assessing the two dimensions that have been identified in the theoretical models that have gathered the largest amount of empirical data in the field: the typological effect of previous languages, and the processing mechanisms used to acquire the L1 and/or the L2. To that effect, in the first section of this chapter I outline the challenges brought about by the acquisition of aspect to identify the complex and dynamic configuration of factors that affect the conceptualisation of this semantico-syntactic-discursive construct in the L1 and the L2/L3. In the second section, I briefly review some of the most representative theoretical claims proposed to account for crosslinguistic influence (CLI) in L3 acquisition in general. The main theoretical tenets of those proposals are assessed in $\S 3$ in the context of the acquisition of aspectual configurations in the L3. The analysis of the findings from the few empirical studies available on the topic is useful to evaluate the relative effect of (psycho)typological processes associated with the processing of L2 versus L1 data.

\section{Aspect}

\subsection{Lexical and grammatical aspect}

Aspect refers to the visualisation and conceptualisation of the temporal structure of situations or eventualities (Comrie 1976; Dahl 1985; Smith 1997). Aspectual meanings can be categorised into two distinct layers of representation: situation type (or lexical aspect) and viewpoint (or grammatical aspect). Situation type is most commonly associated with the inherent lexical aspectual value of verbal 
predicates. Vendler (1967) classified verbal predicates according to their inherent semantic meanings into four types: states (durative, non-dynamic, atelic), activities (durative, dynamic, atelic), accomplishments (durative, dynamic, telic) and achievements (non-durative, dynamic, telic). This classification of lexical aspect has been instrumental in the development of hypotheses about the acquisition of aspectual knowledge. The lexical aspect hypothesis (LAH, Andersen 1991), as an example, is based on the claim that the acquisition of L2 learners' abilities to recognise and mark aspectual configurations will happen sequentially along a developmental path that is defined by basic aspectual meanings (which are assumed to be in direct correlation with lexical aspectual values). The emphasis of the LAH is on the initial stages of the process, leaving unexplained more idiosyncratic markings based on expanded contexts of reference expected to occur in more advanced stages. This is not surprising given that lexical aspect is just one of the components in a comprehensive definition of aspect. In contrast with the plethora of studies brought about by the LAH and other similar proposals focused primarily on the effects of lexical aspect, few empirical L2 studies have addressed the more complex conceptualisation of the higher level of grammatical aspect given the need to incorporate a broader level of contextualisation into the task (see following section).

Whereas lexical aspect focuses on ontological distinctions expressed by verbal predicates, grammatical aspect makes reference to speakers' (and hearers') perspectives on the aspectual nature of situations and it is explicitly marked on verbal morphology. For instance, in the Romance languages the most commonly discussed contrast brought about by grammatical aspect is the use of perfective and imperfective past tense morphology. Whereas the perfective focuses on changes of state, the imperfective focuses on the permanence of the state in the world (Klein 1994; Caudal \& Roussarie 2005). Given its reliance on changes of state, the basic meaning of the perfective is associated with boundedness and may refer to the beginning and/or end of a situation, thus it may be inceptive, punctual or completive (e.g. Depraetre 1995). The previous summary offers a simplified description of the construct of grammatical aspect, given that when contextualised against a larger piece of discourse, aspectual meanings convey more complex representations than the ones summarised above. As an example, Binnick (1991: 156) points out that "[t]he imperfect[ive] has continual, habitual, and generic uses in many languages, while the perfect[ive] has punctual, iterative, and resultative uses." 


\subsection{Levels of conceptualisation of aspect}

Aspect is a construct that is inherently defined by varying levels of contextualisation. The more decontextualised (i.e. context-poor) the situation is, the more likely it is that selections of perfective and imperfective markings will be guided by prototypical selections associated with frequency effects (for both lexical and grammatical aspect). In the absence of contextual support, interpretations about aspect rely on the basic meanings provided by lexical aspect and some minimal expansion beyond the verbal predicate. But, once we add more layers of contextual support (i.e. from a semantics-based definition we expand to a discursive one) the intersection of various pieces of information creates a complex contextual setting against which non-prototypical interpretations of aspectual meanings are more likely to occur (cf. Binnick 1991; Doiz 2002). Figure 3.1 provides a graphical representation of the way these various layers of aspectual representations are interrelated.

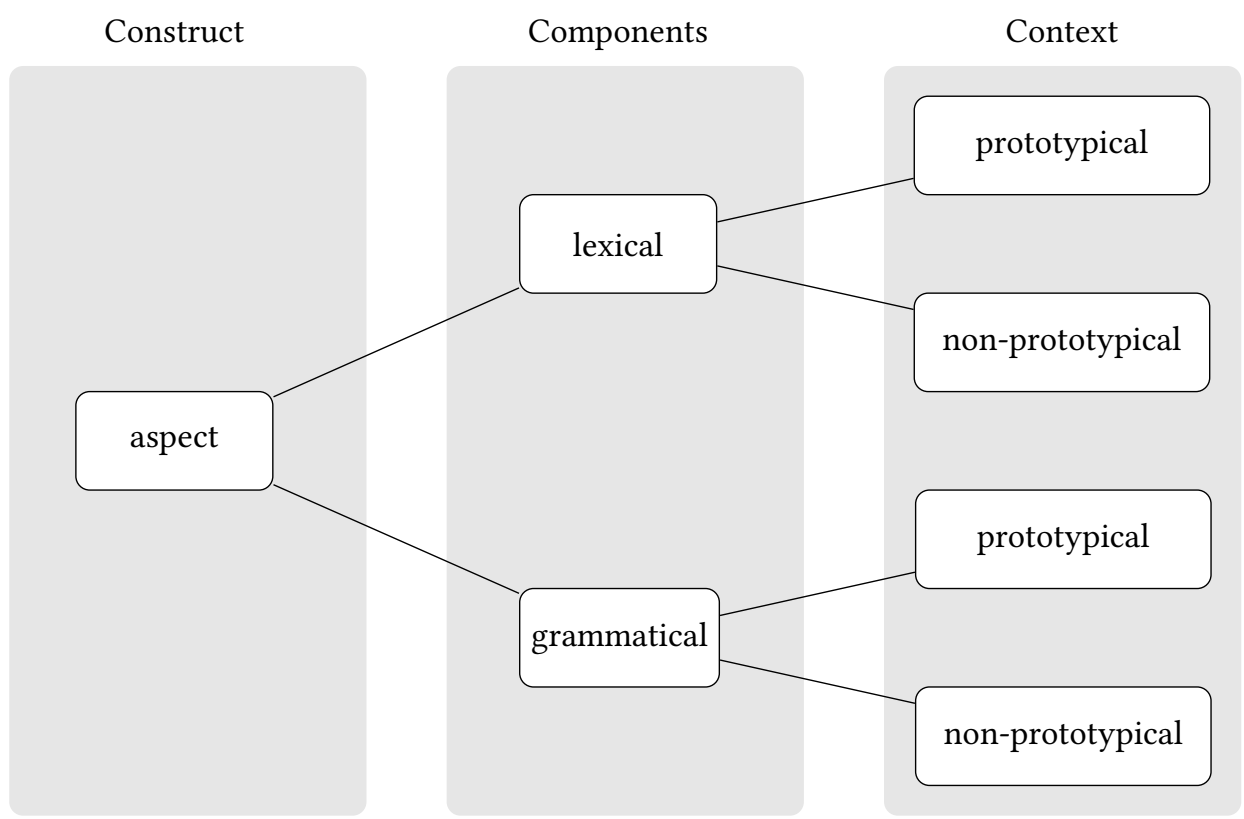

Figure 3.1: Graphical representation of layers of aspectual conceptualisation

The following examples from Spanish depict the complex nature of non-prototypical aspectualinterpretations of state verbal predicates brought about by the informational context provided by specific adverbial phrases. ${ }^{1}$

\footnotetext{
${ }^{1}$ Examples are from Güell (1998: 102).
} 
(1) a. Lo supo / *sabía durante mucho tiempo.

it know.PRET know.IPFV during much time

'(S/he) knew it for a long time.'

b. Lo *supo / sabía desde hacía mucho tiempo.

it know.PRET know.IPFV since ago much time

'(S/he) knew it from a long time ago.'

First, the non-prototypical use of the preterite (PRET) with a state verb in (1a) presented in conjunction with the adverbial durante mucho tiempo prevents an inchoative interpretation (i.e. the beginning of the state), bringing about an aspectual meaning typically reserved for the imperfective form (i.e. non-punctual, durative; IPFV). But, notice that the imperfective form is dispreferred (marked with an asterisk) in (1a). Along the same lines, the preference for the imperfective form in (1b) stands out in this context given the use of an adverbial phrase that, in principle, would trigger an inchoative interpretation. The imperfective choice maintains the focus on the actual state irrespective of the explicit highlighting of the inception point (the perfective form is dispreferred). ${ }^{2}$

An example of the complex nature of grammatical aspect is provided by the distinct meanings conveyed by the aspectual (contrastive) concepts of iterativity and habituality (e.g., de Swart 1998; Langacker 1999). In general, iterativity conveys the basic idea of the repetition of specific eventualities (focus on the episodic nature of eventualities), whereas habituality is akin to generic statements that focus on the overarching concept that an eventuality has been iterated (emphasis on the generalisation of the iteration). In the Romance languages, perfective and imperfective forms are used to describe the iteration of eventualities: iterativity and habituality are conveyed with the use of Spanish preterite and imperfect, respectively. In principle, whereas the imperfect prototypically conveys the aspectual notion of habituality (as shown in 2a), the preterite conveys a rather distinct aspectual concept, the notion of iterativity (2b).

a. Habitual

Cuando era niño, Lucas jugaba al fútbol.

When was child Lucas played at.the football

'When [he] was a child, Lucas played/used to/would (IMP) play soccer.'

${ }^{2}$ See Doiz (2002) for an expanded discussion of this complex description of aspectual contrasts in Spanish. 
b. Iterative

Lo *supo / sabía desde hacía mucho tiempo.

it know.PRET know.IPFV since ago much time

'For years, Lucas played (PRET) soccer.'

As was the case in the example described above, the specific effect of the adverbial phrase triggers distinct aspectual meanings (i.e. habituality or iterativity) that transcend the simple prototypical meanings of boundedness assigned to the imperfective-perfective contrast (e.g. Slabakova \& Montrul 2007; Scholes 2008; Salaberry 2013).

\subsection{Linear and non-linear patterns of development}

The theoretical dissociation between prototypical and non-prototypical representations of aspect brought about by the complex nature of aspectual meanings at both the level of lexical and grammatical aspect presents a challenge for the analysis of the acquisition of aspect. That is, empirical studies may focus on invariant (prototypical) or, alternatively complex (non-prototypical) meanings, thus generating possibly contradictory results across studies.

To showcase the distinct outcomes prompted by different procedures of data collection, I summarise the results of two studies focused on the acquisition of iterativity in L2 Spanish among L1 English speakers, both offering converging evidence on the separation of two types of knowledge about aspect. In the first study, Slabakova \& Montrul (2007) analysed the grammaticality judgments of English native speakers who were L2 Spanish classroom learners (27 advanced learners and 33 intermediate learners) and 27 native Spanish speakers on the use of the perfective marker with single or multiple events (punctuality versus iterativity). Overall, the results showed that, on the one hand, the judgments of all learners were indistinguishable from the responses of native speakers on the punctual interpretation of the perfective (prototypical meaning). On the other hand, there was a significant difference between learners and native speakers on the judgments of iterative interpretations (non-prototypical). In the second study, Scholes (2008) replicated the findings from Slabakova and Montrul with learners of similar levels of experience and he also included an additional group of near-native speakers (graduate students teaching Spanish). Both studies also included a traditional fill-in-the-blanks test that assessed the basic use of past tense morphology focusing on the aspectual concept of perfectivity (original test used in Salaberry 1999). 


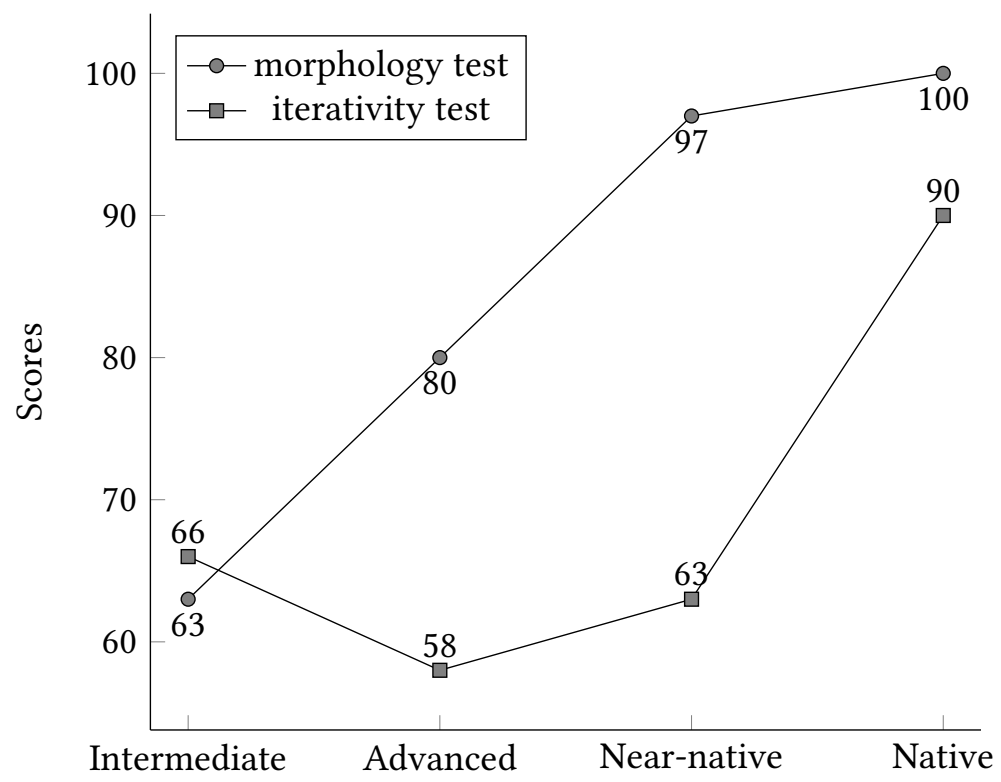

Figure 3.2: Development of perfective (prototypical) versus iterative (non-prototypical) meanings

The graphical representation of the converging findings from both studies is shown in Figure 3.2 (based on data from Scholes 2008).

The developmental trajectory for the prototypical linguistic representations of aspect in Spanish past tense morphology (63\%, 80\% and 97\%) - as measured by the responses to the fill-in-the-blanks task - shows a gradual and constant increase in the form of a linear pattern in parallel with increased experience with the L2 (intermediate, advanced and near-native). In contrast, the results from the test of iterativity show no such linear development according to proficiency level. In the iterativity test, all non-native speakers remain within the range of 50-60\% of correct responses, which is very close to chance level. We can tentatively conclude that the access to instructional activities with a metalinguistic focus on sentence-level aspectual markers leads to constant progress towards the overall use of preterite and imperfect in the context of prototypical realisations of aspect. Arguably, the lack of access to similar metalinguistic focusing activities for non-prototypical contexts of the concept of aspect may, in principle, be responsible for the lack of progress. It is also possible that no amount of instructional effort placed on the identification of (and practice with) non-prototypical representations of aspect in the L2 may be sufficient for learners to incorporate such nuanced descriptions of aspect. 
In sum, the theoretical dissociation between prototypical and non-prototypical conceptualisations of aspect is predicated on the effect of broad levels of contextualisation of aspectual meanings (e.g. effect of adverbial phrases, discursive grounding). Such dissociation happens at the levels of both lexical and grammatical aspect (e.g. non-inchoative meanings of states with perfective morphology or the concept of iterativity in contrast with habituality), creating a difficult challenge for the acquisition of aspect. The L2 studies reviewed above provide some initial empirical evidence that substantiates the above-mentioned claim.

\section{Disambiguating the concept of cross-linguistic influence}

The previous discussion of the complexity of the concept of aspect brought about by multi-layered representations of various meanings associated with aspectual knowledge is useful to assess the main postulates of hypotheses that have modeled the effect of language transfer or CLI. The latter is defined as "the influence resulting from the similarities and differences between the target language and any other language that has been previously (and perhaps imperfectly) acquired" (Odlin 1989: 27).

Given that the L3 is preceded by more than one language, the search for the identification of CLI on L3 learning is multi-faceted De Angelis (2007) and should be assessed, at a minimum, along three separate dimensions. First, there are several linguistic factors, such as typological similarities (e.g. Rothman 2011; 2015; Westergaard et al. 2017), psychotypology (e.g. Kellerman 1983; Bardel \& Lindqvist 2007) and conceptual semantic primitives (Berman \& Slobin 1994; Slobin 1996; Berkes \& Flynn 2012) that can influence CLI. Second, there are methodological factors that are likely to influence transfer, such as proficiency level (e.g. Dewaele 2001; De Angelis 2007; Lindqvist 2010), recency of use of the given languages (e.g. Williams \& Hammarberg 1998) and order of acquisition effects (e.g. Dewaele 1998; Williams \& Hammarberg 1998). Finally, language transfer may differ in the L2 and/or the L3 depending on which type of distinct learning process (e.g. declarative versus procedural knowledge) may be used as the conduit for any type of linguistic influence to materialise.

The majority of previous CLI models have focused primarily on the factors identified by the first two dimensions of analysis reviewed above (i.e. linguistic and methodological factors). The dimension of learning process has become the main component of one particular model: the L2 status factor (Bardel \& Falk 2007; 2012; Falk \& Bardel 2010; 2011). It should be noted, however, that the relevance of processing factors to guide the acquisition of the L3 still represents an important component of other models, albeit indirectly. For instance, Berkes \& Flynn 
(2012: 9) assume, a priori, a specific type of cognitive processing of language data (i.e. UG-guided). That is, in their model, the structural typological makeup of any (source or target) language "reflects the way that language-specific CP [complementiser phrase] develops within the constraints of UG." Other proposed models such as the typological primacy model (TPM, Rothman 2011; 2015) are similarly based on a UG-guided model of acquisition. To properly assess the combined effect of linguistic and methodological factors on the one hand, and learning processes on the other hand, I will review the proposals made by three theoretical models that have been claimed to account for CLI on the L3: The cumulative enhancement model (CEM), the TPM, and the L2 status factor model. ${ }^{3}$ The selection of only three models is partly based on the fact that the identified models have been supported with a fairly significant empirical database, and in part due to the inclusion of the independent variables to be discussed in this chapter (i.e. typology and learning process) among the main theoretical tenets of such models.

\subsection{Linguistic and methodological factors behind CLI}

The CEM posits that knowledge from previous languages creates a multiplying positive effect to guide the development of a third language (on a property-byproperty basis) (e.g. Berkes \& Flynn 2012; Flynn et al. 2004). More specifically, Berkes \& Flynn (2012:7) propose that "[a]ll previously known languages are available to the learner to constructively enhance subsequent language learning." Not only does this model eschew any categorical distinction between the L1 and the L2 for the development of a third one, but it also contends that the combined information from all previous languages contributes to the learning process in a positive way. The latter position contrasts with previous deficit models of CLI based on constructs such as interference and negative transfer that impeded and slowed down the acquisition process (see Odlin 1989). The CEM regards such constructs as irrelevant for the development of a language that is guided by universal grammar precepts, explicitly conceptualising any perceived negative transfer as part of temporary performance phenomena. On the other hand, it

\footnotetext{
${ }^{3}$ Apart from lack of enough empirical data, some recent proposals represent expansions of basic tenets of previous models selected for review above. For instance, Slabakova (2017) builds upon the CEM and the TPM proposals to add specific acquisition constraints (e.g. acquisition of properties one by one and the effect of non-facilitative transfer). Similarly, Westergaard et al. (2017) expand on the effect of linguistic typology (on a property-by-property basis, unlike the TPM) and add the factor of abstract structural similarities (while also allowing for both facilitative and non-facilitative effects, unlike the CEM).
} 
should be noted that Berkes \& Flynn (2012: 1-2) claim that the construction of a new grammar on the part of the learner can be made more effective (i.e. efficient cognitive processing) if learners are provided with information about "what does not have to be taught," and more importantly, about the syntactic primitives that are needed for the learner to process the L3 "in a new and economical way."

The TPM can be framed within the general claim of the full transfer/full access hypothesis proposed by Schwartz \& Sprouse (1996). It is based on a cognitive economy principle predicated on reducing the cost of processing language transfer from the already existent language systems into the L3 (e.g. Rothman 2011; 2015). Within this model, actual and perceived typological and structural similarities between the L3 and both the L1 and the L2 will be used to guide and facilitate the acquisition of the L3. Three additional tenets of the TPM provide an expansion of this basic principle of cognitive efficiency. First, Rothman (2015: 180) argues that transfer happens "holistically, that is, not on a structure-by-structure basis." Second, this overriding economy principle entails that neither the L1 nor the L2 would have any preferred status to become the source of language transfer. Third, the holistic restructuring of the L3 happens early in the acquisition process. The TPM's foundational notion - that learning any additional language carries cognitive processing costs and that learners, in principle, will use a selective process to transfer language information from previous languages based on cognitive economy - is rather uncontroversial. On the other hand, the additional tenets described above have been challenged both at the theoretical and the empirical level. From a theoretical perspective, Slabakova (2017), for instance, contends that the TPM's overarching focus on the initial state of acquisition of the L3 limits its explanatory value. She argues that wholesale transfer need not be more economical in terms of cognitive processing: "Why would the LAD/parser expend resources on blocking off some cross-linguistic influence that may turn out to be profitable later on?" (2017: 658).

As already stated, the two models of CLI highlighted above can be described as models that address, primarily, two main dimensions of analysis: the characteristics of languages previously learned (i.e. typology) and specific methodological factors (e.g. stages of acquisition of languages other than the L1).

\subsection{Types of knowledge in L3 processing}

The third model to be summarised here, the L2 status factor model, most clearly identifies the role of distinct types of knowledge as a central factor for the development of the L3. Given that this paper is focused on the effect of types of knowledge, this third model will be described in more detail than the previous 
two. The L2 status factor model is predicated on the notion that the type of cognitive processing required to learn the L3 is more similar to the processing conditions required to learn the L2 rather than the L1 (e.g. Williams \& Hammarberg 1998; Bardel \& Falk 2007; Falk \& Bardel 2011; Bardel \& Sánchez 2017). The initial claim about a qualitative difference in processing associated with previous languages stems from the analysis of empirical data carried out by Williams \& Hammarberg (1998: 323): "provided the factors of proficiency, typology and recency are at a sufficient level, L2s appear more likely to be activated than the L1 as supplier language during the early stages of L3 acquisition." Following up along that line of thought, Falk \& Bardel (2011) remarked on some similarities shared by the L2 and L3 acquisition processes: age of onset, learning outcome, learning conditions, and more importantly, the level of awareness of the learning process (including degree of metalinguistic knowledge and the use of learning strategies). A corollary of this position is that learners rely on two systems to process language information: "two separate knowledge bases working side by side without interaction" (Falk et al. 2015: 228). Eventually, Bardel \& Falk (2012) explicitly tied previous empirical findings and related theoretical claims to the development of a neurolinguistic framework of analysis that was tied to the declarative/procedural model from Paradis (2009) and others. ${ }^{4}$

Given the focus of the L2 status factor model on the assessment of relative levels of cognitive similarity of language processing between the L3 and prior non-native languages, it is important to describe two parallel theoretical contrasts predicated on the notion of awareness that separate distinct types of processing of linguistic information: the declarative-procedural and explicit-implicit dichotomies. Anderson (2013, inter alia) contrasts the knowledge of factual information (declarative) from the knowledge of how to perform skills (procedural). For his part, Williams (2005: 269) defines implicit knowledge as achieved without the intention to learn, and, more importantly, without awareness of what has been learned, whereas explicit knowledge is prompted by situations in which learners intend to learn and are aware of what they have learned. ${ }^{5}$ The non-

\footnotetext{
${ }^{4}$ The emphasis on the nature of the processing of linguistic information in the L3 does not entail that the L1 may not influence the process. For instance, Falk et al. (2015) point out that whenever learners increase their metalinguistic awareness and knowledge of their L1, such information may become part of the information fed into the L3 system under development.

${ }^{5}$ There are, however, important differences between these two contrasts. Ullman (2016), for instance, points out that the declarative-procedural memory system is based on empirical evidence from brain functions, whereas the explicit-implicit contrast is based on studies of psychological awareness that are very difficult to test empirically. Furthermore, Ullman notes that these contrasts are not isomorphic, given that the declarative memory system can underlie both explicit and implicit knowledge, whereas the procedural memory system is associated with implicit knowledge only (p. 959).
} 
interface position between these two types of knowledge was forcefully put forward by Krashen (1985) in the form of two strong postulates: acquisition and learning are distinct theoretical constructs, and second and more importantly, conscious, explicit learning of the L2 cannot lead to its (unconscious, implicit) acquisition (see also Schwartz 1993; Athanasopoulos et al. 2015, for early support of Krashen's position). More recently, Paradis (2009: 63), using neurolinguistic evidence, also rejected the claim of any type of interface via conscious access to the mental state that underlies proceduralised knowledge: "During the appropriation of an L2, the use of competence may replace the use of metalinguistic knowledge over time, [...]. This is not an interface but the substitution of the use of one mechanism for the use of another." Along the same lines, Ullman (2016: 956-957) proposes that the declarative and procedural memory systems can "acquire the same or analogous knowledge or skills." For that reason, they compete with each other (the constrained use of one will lead to compensation from the other one).

In contrast with the non-interface position, DeKeyser $(2003 ; 2009)$ argued for a strong interface between declarative and procedural knowledge. DeKeyser's assertion of causality is, however, qualified: "explicit learning certainly does not necessarily lead to eventual automatized, let alone implicit, knowledge [...]" (DeKeyser 2009: 126, italics added). As a compromise, an intermediate position, sometimes referred to as a weak interface, has been adopted by Rod Ellis $(1993 ; 2008)$ and Nick Ellis (2005). In general, this weak interface assumes that metalinguistic awareness and negative evidence serve as a conscious priming mechanism to lead learners to notice the gap between the input and their existing linguistic competence. In other words, metalinguistic information in the form of explicit teaching (creating declarative knowledge) may be relevant to realign the orientation of the L2 learner towards the implicit learning of the new linguistic system. As acknowledged by Nick Ellis (2005: 330), however, the (obvious) focusing of attention through guided metalinguistic awareness is "by no means necessary" for a causal effect on implicit knowledge. In sum, the strong and weak interface hypotheses seem to focus on correlation effects, and not causality. In other words, the apparent relationship between declarative and procedural memory systems need not entail an interface.

\subsection{Learning processes applied to aspect}

The interaction between the two knowledge systems described above (or, more precisely, their lack of interaction) is similar to the description of the acquisition of aspect along the lines of two distinct dimensions as summarised in $§ 1$. 
Most notably, the separation of the implicit competence and explicit knowledge (associated with the L1 and the subsequent Lns) parallels the demarcation between non-prototypical and prototypical conceptualisations of aspect. This is most obvious in the disconnect between the results of the iterativity test describing the iterativity-habituality contrast and the results on the traditional past tense morphology test assessing prototypical perfective-imperfective contrasts. We can surmise that if there is no interface between implicit and explicit knowledge, the L1 is most relevant for the acquisition of deep conceptual components of language (non-prototypical). That is, the non-linear type of learning associated with complex aspectual concepts is representative of the type of implicit language knowledge not readily available through focused metalinguistic awareness activities (either in the L2 or the L3). In contrast, the linear process of learning documented in the studies reviewed above for the prototypical meanings of aspect shows the effects of metalinguistic information available in the L2 and the L3.

Overall, the linguistic representation of temporality is constrained by the options afforded by each language. Picking apart the effects of several contextual layers of information is complex, and for such a complicated task, the conceptualisation of aspect from the L1 seems to guide the L2 user to identify what information is relevant for the linguistic realisation of aspectual meanings. In essence, part of the challenge is due to the subtle and difficult task of noticing configurations of aspectual representations spanning over several layers of contextual information. On this point, the analysis of data on the L2 acquisition of aspect shows that the L1 acts as a filter to acquire and develop the L2 representation of temporality. For instance, Athanasopoulos \& Bylund's study (2013: 287) focused on the aspectual contrast created by diverse languages such as English or Spanish, which have "a tendency not to mention the goal or endpoint of an event when describing goal-oriented dynamic scenes," with, on the other hand, languages like German or Swedish with "the reverse tendency, that is, a bias toward mentioning the goal of actions." Similarly, Schmiedtová et al. (2011) contend that the choice of temporal perspective is not random, but dependent on the aspectual configurations of the L1. Finally, Bylund (2011: 116) concludes that L1 conceptualisation patterns remain strong among highly competent L2 speakers.

Arguably, it appears that conceptualisation patterns from the L1 remain central for the processing of aspectual representation even in advanced stages of acquisition of an L2. It remains open to question, however, whether targeted metalinguistic awareness tasks and correlated practice may provide L2/L3 learners with the option to integrate the meanings of non-prototypical and prototypical meanings into their L2/L3 aspectual systems. Bylund (2011), for instance, notes 
that the specific representation of grammatical aspect will direct a person's attention to certain event features. Under these conditions, increased metalinguistic awareness and metacognitive skills, prompted mostly by the acquisition of the L2 (the first second language) may help learners maximise their chances of learning an L3 (at a minimum in terms of efficiency, as shown in Nayak et al. 1990).

\section{The third language acquisition of aspect}

As mentioned above, there is a dearth of studies on the L3 acquisition of aspect. In this section, I summarise the findings from three relevant studies (restricted to adult L2/L3 learners) to assess the value of some of the theoretical claims made in previous sections regarding linear and non-linear development in association with prototypical and non-prototypical meanings: Salaberry (2005); Foote (2009); Diaubalick \& Guijarro-Fuentes (2016). ${ }^{6}$

The study by Salaberry provides information about the possible limitations on the conceptualisation of aspectual configurations based on CLI from the L2. The data from Foote is useful to understand the positive effects of transfer from the L1 and the L2 on the prototypical meanings of lexical aspect. Finally, the analysis by Diaubalick \& Guijarro-Fuentes provides confirmatory evidence about the apparent failure of learners to incorporate non-prototypical aspectual configurations into their grammars in both the L2 and the L3.

Salaberry (2005) focused on the development of aspectual contrasts in L3 Portuguese among L1 English speakers who also knew Spanish as an L2. Both Spanish and Portuguese (as Romance languages) share the same conceptualisation of aspect, so it was expected that learners would benefit from their knowledge of the L2 to learn similar contrasts in the L3. The study was based on grammaticality judgment data collected with the use of a narrative text that was used to contextualise the use of a total of 30 verbal predicates divided into three lexical aspectual classes (13 telic events, 7 atelic events and 10 statives). Participants had to select the appropriate morphological marker (perfective or imperfective) for each verbal predicate used in the text. Not surprisingly, the overall findings revealed that

\footnotetext{
${ }^{6}$ Although there is an increasing number of studies on the L3 acquisition of aspect, some are not directly relevant for the present analysis because they primarily focus on constructs of aspect that do not comprise the full range of meanings of aspectual representations (i.e. including the analysis of both prototypical and non-prototypical meanings). For instance, Fessi (2013) assesses the explanatory value of the lexical aspect hypothesis, whereas Karpava et al. (2012) focus on the validity of the Full Transfer/Full Access hypothesis (see $§ 1$ above). For reference, however, one such study focused on a limited representation of the construct of aspect (Foote 2009) is described in detail given that it uses the same L3 as the studies reviewed in the present section.
} 
the L1 English-L2 Spanish learners had achieved a high level of proficiency in the selection of past tense aspectual markers in the L3. To wit, the selection of the imperfective marker was broadly distributed across lexical aspectual classes showing a clear dissociation between lexical and grammatical aspect, attesting to the advanced knowledge of aspectual marking in the L3. Furthermore, there was an overall consistent positive trend in the selections of past tense endings to mark the dynamic classes of verbal predicates (telic and atelic events) across both native and non-native groups. There was, however, one major discrepancy between the responses of native and non-native speakers of Portuguese. When the analysis of data focused on the judgments about the category of statives only, the selection of inflectional markers of past tense among L3 Portuguese participants was less consistent and less categorical than among native speakers of Portuguese. Hence, it appears that the influence of the L1 English conceptualisation of aspectual knowledge (most noticeable on the aspectual marking of states) had an effect on the conceptualisation of non-prototypical markers of states.

Foote (2009), in turn, investigated the effect of typological similarity of a Romance language used as the L1 or as the L2 on the transfer of knowledge about aspect to another Romance language functioning as the L3. The two L1-L2 combinations used in her study were: L1 English-L2 Romance language and L1 Romance language-L2 English. Both groups were also learning an L3 which was an additional Romance language (different from the one known as an L1 or L2). Foote hypothesised that knowledge of the semantic contrast of aspectual meanings irrespective of the status of this language as an L1 or an L2 - would transfer to the L3. The main assessment instrument used by Foote was a sentence conjunction judgment task which was intended to evaluate semantic implications based on the concept of perfectivity (i.e. focus on endpoint markers). Each sentence depicted an eventuality marked with perfective or imperfective morphology that was contradicted or not by another event marked with perfective morphology in the second part of the sentence. The use of the perfective form in the second part of the sentence prompted a consistent ungrammatical option (illogical), whereas the use of the imperfective led to a grammatical reading (logical).

Overall, the findings show that, irrespective of whether the Romance language was the participants' L1 or L2, all L3 speakers were able to distinguish the semantic distinctions of perfectivity depicted in the test sentences. Foote (2009: 111) concluded that both L3 groups "seem to have been able to transfer their knowledge from the previously known Romance language," further stating that her data "suggest that language typology does play a role in source(s) of transfer in L3 acquisition." By design, however, the assessment instrument used by Foote tested prototypical representations of aspectual meanings of Romance languages' past 
tense morphology. Despite the fact that Foote incorporated a triad of languages to discriminate any order effect of any particular L1/L2 combination on the L3, the data collection was predicated on a limited conceptualisation of aspect. As a consequence, the complexity of a semantico-syntactic-discursive grammatical construct like aspect cannot be evaluated with an assessment instrument focused on the decontextualised meanings of aspectual contrasts.

Finally, Diaubalick \& Guijarro-Fuentes (2016) set out to assess the knowledge of complex notions of aspectual meanings in L2 Spanish (i.e. coercion effects) among L1 German speakers. Their study is relevant for the present analysis for two important reasons. First, the majority (if not all) of the participants in the study were actually L3 Spanish learners because the German L1 speakers also knew English as an L2; their level of proficiency in L2 English was judged to be generally in the order of B1 or higher in the Common European Framework of Reference for Languages (Diaubalick, personal communication). Second, coercion effects were predicated on examples depicting the iterativity-habituality contrast reviewed above. The authors considered two hypotheses for their analysis: The interpretability hypothesis and the feature reassembly hypothesis. After the analysis of the findings, however, Diaubalick \& Guijarro-Fuentes conclude that neither one of these proposals could account for the findings of their study. In both cases, the aspectual meanings brought about by coercion of the prototypical meanings are not acquired by any of the learner groups (low intermediate, high intermediate or advanced). Diaubalick \& Guijarro-Fuentes surmise that the "uninterpretable features connected to perfectivity that are responsible for a verb rising to AspP are not acquired since even advanced speakers do not reach native level" (p. 192). With regards to the claim of the feature reassembly hypothesis they conclude that the latter "fails to explain why the differences between the German and English learners are as reported ... the problems with the coercion effects, in particular, persist until late stages" (p. 194).

The results from this study replicate the findings from the studies on the concept of iterativity reviewed above: the more complex notions of iterativity and habituality were not acquired by the L1 German-L2 English speakers in their study (for the relevance of English in this case see Athanasopoulos \& Bylund 2013 and Athanasopoulos et al. 2015). In the end, Diaubalick \& Guijarro-Fuentes conclude that their study may have focused on the incorrect hypotheses and surmise that "[p]erhaps the acquisition of the Spanish past tenses presents a phenomenon that is rather connected to the lexicon than to the interpretability of features" (2016: 194). This is a more plausible interpretation than the one initially considered by the authors, given that the shift from a purely syntactic definition of aspect toward a more contextualised (cf. lexical) one is more likely to focus on a more 
complex description of what knowledge about aspect entails in the grammar of the L1, the L2 or the L3.

The limited empirical evidence on the L3 acquisition of aspect gathered so far seems to point in the direction of a limited conceptualisation of aspect in the L2 that prevails in the process of incorporating such a theoretical construct into the L3 system. The study from Salaberry (2005) was useful to address the role of nonprototypical interpretations of the lexical aspectual category of statives leading to the conclusion that the L1 representation of lexical aspect (restricted to the limited conceptualisation of L1 English) prevailed over any possible beneficial effect of the L2 (a language that had the same representation of aspectual configurations as the L3). On the other hand, the study from Diaubalick \& GuijarroFuentes (2016) provided additional converging empirical evidence to support the same claim, but with data from the acquisition of non-prototypical instantiations of grammatical aspect (i.e. iterativity, or coercion in their description).

\section{Discussion}

In the present chapter I have brought into focus one particular construct (aspect) that can offer a viable testing ground for some of the claims made about CLI models proposed to account for the competence of both bilinguals and multilinguals. In essence, the use of aspect as the dependent variable in L3 acquisition studies provides a yet untapped context of learning that could be beneficial to (a) evaluating the nature of the development of a multilayered grammatical concept (aspect) across the L1, the L2 and any subsequent language, and (b) help elucidate the process of learning other complex grammatical concepts.

For multilingual learners who have access to two (or more) distinct sources of linguistic knowledge (i.e. the L1 and the L2), I focused on the specific analysis of two separate main effects (among many) on the processing of this complex theoretical construct: on the one hand, the specific typological structures and language information from the previous languages, and, on the other hand, the distinct way of processing linguistic information represented in the L1 and the L2. Previous models of CLI have addressed the relevance and weight of these constructs (i.e. typology or processing) in different ways, depending on various internal theoretical aspects of the frameworks that inform such CLI models. Overall, the analysis of empirical data on the acquisition of knowledge about aspect in the L3 confirms and expands on previous findings about other grammatical constructs that have been the subject of analysis of previous studies of CLI (i.e. effect of typological differences). Notwithstanding this confirmatory finding about 
the effect of typological contrasts, the analysis of the acquisition of the contextualised definition of aspect contributes important data to assess the effect of learning mechanisms across the L1, the L2 and the L3 in ways that other constructs have not tapped into.

The empirical data on the acquisition of aspect reviewed above show the following important findings. First, the available data on the type of learning process behind the acquisition of aspect in the L3 seems to indicate that the L3 system will rely on the same processing mechanisms that were used to develop the L2, inheriting in the process both the advantages and the limitations of that knowledge system. This is most clearly represented in the linear progression of aspect marking in prototypical settings demonstrating a positive correlation between improvement in aspect marking and experience with the target language (i.e. a main feature of explicit learning mechanisms). Second, despite the previous assertion, the influence of the (psycho)typological stock of the L1 for the acquisition of aspectual configurations (e.g. Bylund 2011; Schmiedtová et al. 2011; Athanasopoulos et al. 2015) seems to account for apparent discrepancies between native and non-native speakers. As demonstrated in the analysis of data of several studies, whenever aspectual meanings are the product of multiple layers of contextualisation (i.e. non-prototypical representations), there is an L1 effect across all subsequent languages. That is, for the acquisition of non-prototypical meanings of aspect at least, neither the L2 nor the L3 (processed in qualitatively different ways than the L1) can overcome the limitations of learning processes to re-conceptualise a construct (i.e. aspect in its full complex representations) that seems to be dependent on L1 processing mechanisms.

The most interesting outcome of the present analysis of the L3 acquisition of aspect is given by the apparent far-reaching effect of the L1-based conceptualisation of aspect on the development of the L3 representation of this complex construct. While, in principle, one could argue that this is evidence against the L2 status factor model, the opposite is actually the case. More precisely, the failure of L3 users to access the processing system that was part of the L1 acquisition process confirms the proposed reliance of the L3 acquisition mechanism on the L2 developmental infrastructure. This provides confirmatory evidence for the main claim of the L2 status factor model: the L1 and L2 represent distinct processing mechanisms with the L3 matching the characteristics of the L2 system. When the L2 system is not able to tap into L1 processing mechanisms, the L3 will also fail to access the L1 processing mechanisms. In sum, the basic claim of the L2 status factor of a distinction in terms of language processing may be most relevant for the evaluation of a comprehensive definition of aspect that includes a representation of distinct levels of conceptualisation of aspectual knowledge. 
Additional studies teasing apart the effects described above in different language combinations would provide empirical evidence that could attest to the empirical viability of the analysis of the currently available proposal that was summarised in this paper.

\section{References}

Andersen, Roger. 1991. Developmental sequences: The emergence of aspect marking in second language acquisition. In Thom Huebner \& Charles A. Ferguson (eds.), Crosscurrents in second language acquisition and linguistic theories, 305324. Amsterdam: John Benjamins.

Anderson, John. 2013. The architecture of cognition. New York: Psychology Press. Athanasopoulos, Panos \& Emanuel Bylund. 2013. Does grammatical aspect affect motion event cognition? A cross-linguistic comparison of English and Swedish speakers. Cognitive Science 37. 286-309.

Athanasopoulos, Panos, Ljubica Damjanovic, Julie Burnand \& Emanuel Bylund. 2015. Learning to think in a second language: Effects of proficiency and length of exposure in English learners of German. The Modern Language fournal 99. 138-153.

Bardel, Camilla \& Ylva Falk. 2007. The role of the second language in third language acquisition: The case of Germanic syntax. Second Language Research 23(4). 459-484. DOI: 10.1177/0267658307080557.

Bardel, Camilla \& Ylva Falk. 2012. The L2 status factor and the declarative/procedural distinction. In Jennifer Cabrelli Amaro, Suzanne Flynn \& Jason Rothman (eds.), Third language acquisition in adulthood, 61-78. Amsterdam: John Benjamins.

Bardel, Camilla \& Christina Lindqvist. 2007. The role of proficiency and psychotypology in lexical cross-linguistic influence: A study of a multilingual learner of Italian L3. In Marina Chini, Paola Desideri, Maria Elena Favilla \& Gabriele Pallotti (eds.), Atti del VI congresso internazionale dell'Associazione Italiana di Linguistica Applicata, 123-145. Perugia: Guerra Edizioni.

Bardel, Camilla \& Laura Sánchez. 2017. The L2 status factor hypothesis revisited: The role of metalinguistic knowledge, working memory, attention and noticing in third language learning. In Tanja Angelovska \& Angela Hahn (eds.), L3 syntactic transfer: Models, new developments and implications, 85-101. Amsterdam: John Benjamins.

Berkes, Éva \& Suzanne Flynn. 2012. Enhanced L3...Ln acquisition and its implications for language teaching. In Danuta Gabryś-Barker (ed.), Cross-linguistic influences in multilingual language acquisition, 1-22. Berlin: Springer. 
Berman, Ruth \& Dan Slobin. 1994. Relating events in narrative: A crosslinguistic developmental study. Mahwah: Lawrence Erlbaum.

Binnick, Roger. 1991. Time and the verb. Oxford: Blackwell.

Bylund, Emanuel. 2011. Language-specific patterns in event conceptualization: Insights from bilingualism. In Aneta Pavlenko (ed.), Thinking and speaking in two languages, 108-142. Clevedon: Multilingual Matters.

Caudal, Patrick \& Laurent Roussarie. 2005. Aspectual viewpoints, speech act functions and discourse structure. In Paula Kempchinsky \& Roumyana Slabakova (eds.), Aspectual inquiries, 265-290. Dordrecht: Springer.

Comrie, Bernard. 1976. Aspect. Cambridge: Cambridge University Press.

Dahl, Östen. 1985. Tense and aspect systems. Oxford: Basil Blackwell.

De Angelis, Gessica. 2007. Third or additional language acquisition. Clevedon: Multilingual Matters.

DeKeyser, Robert M. 2003. Implicit and explicit learning. In Michael Long \& Catherine Doughty (eds.), The handbook of second language acquisition, 313349. Oxford: Wiley-Blackwell.

DeKeyser, Robert M. 2009. Cognitive-psychological processes in second language learning. In Michael Long \& Catherine Doughty (eds.), The handbook of second language teaching, 119-138. Oxford: Wiley-Blackwell.

Depraetre, Ilsa. 1995. On the necessity of distinguishing between (un)boundedness and (a)telicity. Linguistics and Philosophy 18. 1-19.

de Swart, Henriette. 1998. Aspect shift and coercion. Natural Language and Linguistic Theory 16(2). 347-385.

Dewaele, Jean-Marc. 1998. Lexical inventions: French interlanguage as L2 versus L3. Applied Linguistics 19(4). 471-490. DOI: 10.1093/applin/19.4.471.

Dewaele, Jean-Marc. 2001. Activation or inhibition? The interaction of L1, L2 and L3 on the language mode continuum. In Jasone Cenoz, Britta Hufeisen \& Ulrika Jessner (eds.), Cross-linguistic influence in third language acquisition: Psycholinguistic perspectives, 69-89. Clevedon: Multilingual Matters.

Diaubalick, Tim \& Pedro Guijarro-Fuentes. 2016. How do German speakers acquire the tense-aspect-system in Spanish as a second language? An empirical study. In Pedro Guijarro-Fuentes, Maria Juan-Garau \& Pilar Larrañaga (eds.), Acquisition of Romance languages: Old acquisition challenges and new explanations from a generative perspective, 119-138. Berlin: De Gruyter.

Doiz, Aintzane. 2002. The preterit and the imperfect as grounding predications. In Frank Brisard (ed.), Grounding: The epistemic footing of deixis and reference, 299-347. Berlin: De Gruyter.

Ellis, Nick C. 2005. At the interface: Dynamic interactions of explicit and implicit language knowledge. Studies in Second Language Acquisition 27(2). 305-352. 
Ellis, Rod. 1993. Second language acquisition and the structural syllabus. TESOL Quarterly 27. 91-113.

Ellis, Rod. 2008. Investigating grammatical difficulty in second language learning: Implications for second language acquisition research and language testing. International fournal of Applied Linguistics 18(1). 4-22.

Falk, Ylva \& Camilla Bardel. 2010. The study of the role of the background languages in third language acquisition: The state of the art. International Review of Applied Linguistics in Language Teaching 48(2-3). 185-219. DOI: 10.1515/iral. 2010.009.

Falk, Ylva \& Camilla Bardel. 2011. Object pronouns in German L3 syntax: Evidence for the L2 status factor. Second Language Research 27(1). 59-82. DOI: 10.1177/0267658310386647.

Falk, Ylva, Christina Lindqvist \& Camilla Bardel. 2015. The role of L1 explicit metalinguistic knowledge in L3 oral production at the initial state. Bilingualism: Language and Cognition 18(2). 227-235. DOI: 10.1017/S1366728913000552.

Fessi, Inés. 2013. Cross-linguistic influence in tense-aspect Spanish L3 acquisition: A study of Arabic tunisian learners of 13 Spanish. Revista Nebrija de Lingüística aplicada a la enseñanza de Lenguas 20. 82-99.

Flynn, Suzanne, Claire Foley \& Inna Vinnitskaya. 2004. The cumulativeenhancement model for language acquisition: Comparing adults' and children's patterns of development in first, second and third language acquisition of relative clauses. International fournal of Multilingualism 1(1). 3-15. DOI: $10.1080 / 14790710408668175$.

Foote, Rebecca. 2009. Transfer in L3 acquisition: The role of typology. In Yan-Kit Ingrid Leung (ed.), Third language acquisition and universal grammar, 89-114. Clevedon: Multilingual Matters.

Güell, Lourdes. 1998. La adquisición del tiempo verbal en el aprendizaje del español como lengua extranjera. Unpublished doctoral dissertation. Barcelona: Universitat Autònoma de Barcelona.

Karpava, Sviatlana, Kleanthes Grohmann \& Konstantinos Fokianos. 2012. Aspect in the L2 and L3 acquisition of Greek. In Rosa Alonso Alonso (ed.), Cross-linguistic influences in multilingual language acquisition, 41-62. Berlin: Springer.

Kellerman, Eric. 1983. Now you see it, now you don't. In Susan M. Gass \& Larry Selinker (eds.), Language transfer in language learning, 112-134. Rowley, MA: Newbury House.

Klein, Wolfgang. 1994. Time in language. New York: Routledge.

Krashen, Stephen. 1985. The input hypothesis. London: Longman. 
Langacker, Ronald. 1999. Grammar and conceptualization. Stanford, CA: Stanford University Press.

Lindqvist, Christina. 2010. Inter- and intralingual lexical influences in advanced learners' French L3 oral production. IRAL-International Review of Applied Linguistics in Language Teaching 48(2-3). 131-157.

Michaelis, Laura. 1998. Aspectual grammar and past time reference. London/New York: Routledge.

Nayak, Nandini, Nina Hansen, Nancy Krueger \& Barry McLaughlin. 1990. Language-learning strategies in monolingual and multilingual adults. Language Learning 40(2). 221-244. DOI: 10.1111/j.1467-1770.1990.tb01334.x.

Odlin, Terence. 1989. Language transfer: Cross-linguistic influence in language learning. Cambridge: Cambridge University Press.

Paradis, Michel. 2009. Declarative and procedural determinants of second languages. Amsterdam: John Benjamins.

Rothman, Jason. 2011. L3 syntactic transfer selectivity and typological determinacy: The typological primacy model. Second Language Research 27(1). 107-127. DOI: $10.1177 / 0267658310386439$.

Rothman, Jason. 2015. Linguistic and cognitive motivations for the typological primacy model of third language (L3) transfer: Timing of acquisition and proficiency considered. Bilingualism: Language and Cognition 18(2). 179-190. DOI: 10.1017/S136672891300059X.

Salaberry, Rafael. 1999. The development of past tense verbal morphology in classroom L2 Spanish. Applied Linguistics 20(2). 151-178.

Salaberry, Rafael. 2005. Evidence for transfer of knowledge of aspect from L2 Spanish to L3 Portuguese. In D. Ayoun \& Rafael Salaberry (eds.), Tense and aspect in the Romance languages: Theoretical and applied perspectives, 179-210. Amsterdam: John Benjamins.

Salaberry, Rafael. 2008. Marking past tense in second language acquisition: A theoretical model. London: Continuum Press.

Salaberry, Rafael. 2013. Contrasting preterite and imperfect use among advanced L2 learners: Judgments of iterated eventualities in Spanish. International Review of Applied Linguistics 54(1). 243-270.

Sasse, Hank. 2012. Recent activity in the theory of aspect: Accomplishments, achievements, or just non-progressive state? Linguistic Typology 6. 199-271.

Schmiedtová, Barbara, Christiane Von Stutterheim \& Mary Carroll. 2011. Language-specific patterns in event construal of advanced second language speakers. In Aneta Pavlenko (ed.), Thinking and speaking in two languages, 66-107. Clevedon: Multilingual Matters. 
Scholes, Joseph. 2008. Acquisition of tense and aspectual contrasts in L1 English speakers learning Spanish. Unpublished MA thesis. Austin, TX: University of Texas.

Schwartz, Bonnie D. 1993. On explicit and negative data effecting and affecting competence and linguistic behavior. Studies in Second Language Acquisition 15(2). 147-163.

Schwartz, Bonnie D. \& Rex A. Sprouse. 1996. L2 cognitive states and the Full Transfer/Full Access model. Second Language Research 12(1). 40-72. DOI: 10. 1177/026765839601200103.

Slabakova, Roumyana. 2017. The scalped model of third language acquisition. International fournal of Bilingualism 21(6). 651-665. DOI: $10.1177 /$ 1367006916655413.

Slabakova, Roumyana \& Silvina Montrul. 2007. L2 acquisition at the grammardiscourse interface: Aspectual shifts in L2 Spanish. In Juana Liceras, Helmut Zobl \& Helen Goodluck (eds.), Formal features in second language acquisition, 452-483. Mahwah: Lawrence Erlbaum.

Slobin, Dan. 1996. From 'thought and language' to 'thinking for speaking'. In John J. Gumperz \& Stephen C. Levinson (eds.), Rethinking linguistic relativity, 70-96. Cambridge: Cambridge University Press.

Smith, Carlota. 1997. The parameter of aspect. Dordrecht: Kluwer Academic Press. Ullman, Michael. 2016. The declarative/procedural model: A neurobiological model of language learning, knowledge and use. In Gregory Hickok \& Steven Small (eds.), The neurobiology of language, 953-968. Waltham, MA: Elsevier.

Vendler, Zeno. 1967. Linguistics in philosophy. Ithaca, NY: Cornell University Press.

Westergaard, Marit, Natalia Mitrofanova, Roksolana Mykhaylyk \& Yulia Rodina. 2017. Crosslinguistic influence in the acquisition of a third language: The linguistic proximity model. International fournal of Bilingualism 21(6). 666-682. DOI: $10.1177 / 1367006916648859$.

Williams, John. 2005. Learning without awareness. Studies in Second Language Acquisition 27(2). 269-304.

Williams, Sarah \& Björn Hammarberg. 1998. Language switches in L3 production: Implications for a polyglot speaking model. Applied Linguistics 19(3). 259-333. DOI: 10.1093/applin/19.3.295.

Ziegeler, Debra. 2008. A word of caution on coercion. Fournal of Pragmatics 39. 990-1028. 



\title{
Chapter 4
}

\section{The mental lexicon of multilingual adult learners of Italian L3: A study of word association behavior and cross-lingual semantic priming}

\author{
Anna Gudmundson
}

Stockholm University

This study, a partial replication of the study conducted by Fitzpatrick \& Izura (2011) on bilingual speakers, investigates the structure and processing of the mental lexicon of multilingual speakers of first language (L1) Swedish, second language (L2) English and third language (L3) Italian in order of acquisition. By way of word association tasks in all three languages, the effect of language status (L1, L2, L3) and association category (i.e., the different kinds of word association responses) on reaction time (RT) and association distribution (i.e., proportion of associations in different association categories) is measured. Results show a significant effect of language status on association distribution and on RT. The present study also investigates the effect of long-term cross-lingual semantic priming and lexical mediation between L3 and L2 in a lexical decision task (LDT), i.e. if the activation of L3 conceptual information is mediated by the corresponding word form in the L2. The primes in this study are English words whose Italian translation equivalents were present in the prior L3 Italian word association task. The translation equivalents obtained shorter RTs compared to control words, which indicates that L2 English words were activated during the L3 Italian word association task. The kind of cross-lingual priming found in the multilinguals investigated in this study would imply that, besides the L1, also an L2 could mediate in lexical processing, and that the L1 does not have a privileged status in that respect. 


\section{Introduction}

Even though multilingualism has become a systematic research area over the last two decades (see Cenoz et al. 2001; De Angelis 2007; García Mayo 2012; SzubkoSitarek 2015), especially within acquisition, sociolinguistics and teaching, according to De Angelis (2007: 1), research on the cognitive and psycholinguistic aspects of multilingualism has been slow to appear. In addition to the so-called monolingual bias, De Angelis discusses a bilingual bias which "overshadows the identification of a range of phenomena that only multilingual speakers can display" (2007: 13), and which would be particularly pronounced in psycholinguistic research. According to Szubko-Sitarek (2015: 10), multilingual language users could be considered a new testing ground in psycholinguistics. The general objective of the present study is to contribute to filling the research gap discussed above. The study aims at shedding light on how the multilingual lexicon grows, and how lexical items from the different languages are interconnected. Particular attention is given to the role of the third language (L3), and to how L3 primes second language (L2) word activation. In this study, the terms first language (L1), L2 and L3 should be understood as referring to a chronological order of acquisition (Hammarberg 2014).

The present study is a partial replication study of Fitzpatrick \& Izura (2011), where word associations in bilingual participants of L1 Spanish and L2 English were explored. In their study, the types and the proportions of associative relations expressed in two word association tasks, first in the L1 and later in the L2, were analyzed to shed light on the structure, organization and development of the bilingual lexicon. An interesting part of the Fitzpatrick \& Izura study was the adding of a lexical decision task in the L1 that followed the L2 association task. In the lexical decision task, some of the items were translation equivalents to stimuli words from the previous L2 association task. Results revealed a longterm cross-language semantic priming effect for those items, and that finding was interpreted in favor of the revised hierarchical model (RHM) (Kroll \& Stewart 1994). The effect was explained by a lexical mediation effect between L2 and L1 that had taken place during the L2 word association task. The activation of the meaning of the L2 stimulus word had been mediated, according to Fitzpatrick \& Izura, by first activating the corresponding L1 word form. That activation left a trace and served as a prime in the following L1 lexical decision task. The present study follows the same design as the one implemented by Fitzpatrick \& Izura (2011), but contrary to their study, it focuses on multilingual speakers of a new language combination, L1 Swedish, L2 English and L3 Italian. Word associations in all three languages are analyzed, and a lexical decision task is performed, but 
instead of investigating priming between L2 and L1, as in the study by Fitzpatrick \& Izura, it investigates whether such a long-term priming effect can occur between the L3 Italian and the L2 English, i.e. if also an L2 can mediate access to conceptual information and what implications would follow as concerns the basic functioning of the RHM.

The structure of the introductory part of this paper is as follows: In $\S 1.1$ and 1.2, a presentation of the mental lexicon, both in L2 and in L3 is given. In §1.3, longterm cross-language semantic priming is discussed, while $\$ 1.4$ gives an outline of the functioning of word association studies. Finally, in $\S 1.5$, the different types of word relations identified by Fitzpatrick \& Izura (2011) are presented.

\subsection{The mental lexicon}

By mental lexicon, we mean a language user's knowledge about words, i.e. a mental representation of all the words known by a user, their meaning, their form and their internal relations (Aitchison 2012). The mental lexicon is often described as a network of connections between words, or features of words (Aitchison 2012). These connections could be based on formal or semantic similarities. The semantic similarities create semantic fields composed of words with related meanings. Learning the meaning of new words involves creating connections to other words within the network, which is then reconstructed. The mental lexicon, from that point of view, is not static, but is continually changing in a dynamic way when new words are added or when our knowledge of a word is deepened. Aitchison (2012: 209-210) uses the metaphor of a bookshelf that needs constant rearrangement when new books are added, based on their content and form. The depth-of-word-knowledge, i.e. a word's different sense relations, is linked to lexical network building in the sense that knowledge of single words increases when new words are added and when we adapt and differentiate existing lexical links. Knowledge about words and their meanings is in such defined as a word's relation to other words and it increases with breath-of-knowledge, i.e. vocabulary size (Haastrup \& Henriksen 2000: 222; Nation 2001; Read 2004).

Another relevant concept when discussing the mental lexicon of an L2 learner is the speed with which a lexical item is accessed or processed. Pellicer-Sánchez states that "[i]t is uncontroversial that the ability to process language quickly is a component of more advanced language proficiency" (2015: 127). Being able to access and retrieve lexical information in a fast and efficient way is important for a learner's capacity to speak fluently. Speed of lexical access is also referred to as automaticity (Schmitt 2010) in the sense that it measures procedural, implicit and unconscious knowledge. Segalowitz \& Hulstijn (2005: 371) argue that, 


\section{Anna Gudmundson}

generally, automaticity implies the absence of intentional control when a cognitive activity is executed. Learners go through an automatization process that is related to proficiency - with increasing proficiency, processing time diminishes and the number of errors decreases (DeKeyser 2007). Thus, lexical access should be faster in more proficient language users compared to less proficient language users. Measuring reaction times in different kinds of language processing is a common way to establish automaticity (see Segalowitz \& Hulstijn 2005 for an overview). Segalowitz \& Segalowitz (1993) and Segalowitz \& Hulstijn (2005) state that, even though speed of lexical access is an important factor in determining automaticity, equating it to automaticity is problematic. They explain that increased speed could be the consequence of two different mechanisms, the first being general quantitative speed-up, and the second being a qualitative change in the processing mechanism itself. Only the second one could be identified as a change in automaticity. Segalowitz \& Segalowitz (1993) suggest that automaticity be calculated as the standard deviation divided by mean reaction time. However, although this definition might be more linked to our understanding of the concept of automaticity, the method has been questioned (Hulstijn et al. 2009). To avoid problems related to the concept of automaticity, in this study, increased reaction times will simply be interpreted as increased fluency, no matter what the determining mechanisms are.

The internal structure of the lexical item itself is often described as composed of two different levels of representation (Levelt 1989). One level encodes semantic information or meaning and the other encodes its phonological form. In the present study the terms semantic representation, conceptual representation and meaning representation will be used synonymously. Most research on the monolingual mental lexicon is concerned with how the level of semantics and the level of meaning interact (Dell \& O’Seaghdha 1991; 1992; Levelt, Vorberg, Pechmann, Meyer, et al. 1991; Levelt, Vorberg, Pechmann, Schriefers, et al. 1991; Levelt 1992), while research on the bilingual lexicon focuses on two other fundamental questions. The first question is whether lexical representations from different languages are stored together (the integrated view) or separately (the separate view), and the second question is whether lexical access is language selective or non-selective. On seeing the English word pencil, is information of words from all languages known by the user activated, or only from those belonging to English (Weinreich 1953; Sánchez Casas et al. 1992; Poulisse 1997; Dijkstra \& Van Heuven 1998; 2002; Van Heuven et al. 1998; 2011; Dijkstra 2003; 2005; Lemhöfer \& Dijkstra 2004; Lemhöfer et al. 2004; Costa 2005; Kroll \& De Groot 2005; La Heij 2005; Dijkstra et al. 2010; Kroll et al. 2010; De Angelis et al. 2015)? 
Many models of bilingual mental representations are inspired by the early work of Weinreich (1953), who proposed three different approaches to bilingual representations. The compound approach predicts different lexical stores but a shared conceptual store, while the coordinate approach predicts separate conceptual and lexical stores. Finally, the subordinate approach predicts a store for L1 conceptual representations only, while L2 lexical items are connected to these representations indirectly via the L1 translation equivalent. Evidence was found for the compound approach (Potter et al. 1984), but Kroll \& Curley (1988) found a difference between learners at different proficiency levels; less proficient learners performed according to the subordinate approach (also known as the word association hypothesis), and the more advanced learners according to the compound approach (also known as the concept mediation hypothesis). Kroll \& Curley therefore suggested a switch from lexical to conceptual mediation as learners became more proficient. That idea was later developed into the revised hierarchical model (RHM) (Kroll \& Stewart 1994; Kroll et al. 2010), see Figure 4.1 below, which combines the subordinate and the compound approaches into a single one.

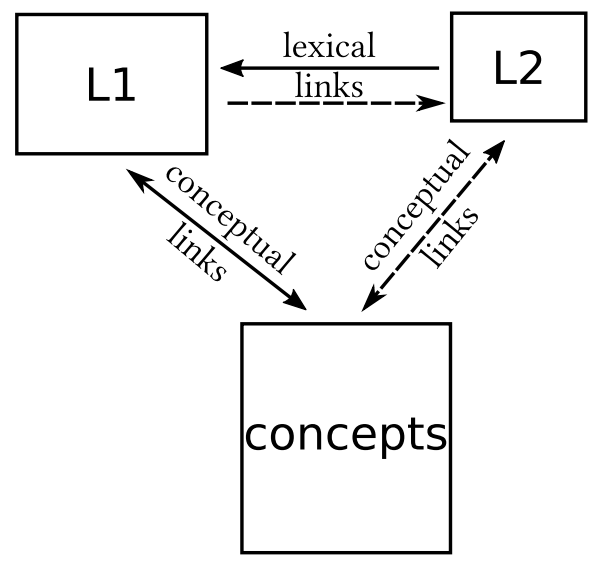

Figure 4.1: Illustration of the RHM (adapted from Kroll \& Stewart 1994).

The black solid arrows represent strong and well-developed links between word form representations and concepts, while the dashed arrows represent less well-developed links. The strength of the links varies as a function of proficiency. The model states that for less proficient L2 learners, access to meaning is mediated by L1 word forms as represented by the solid arrows, and it is only when higher proficiency levels are reached that direct links between L2 word forms and meanings are developed. The RHM also accounts for the longer translation latencies in backward translation (from L1 to L2) compared to forward transla- 


\section{Anna Gudmundson}

tion (from L2 to L1), observed in many studies, by proposing asymmetrical links between the two languages. In backward translation, the process is mediated by semantic access, i.e. the L1 word form activates the conceptual information by way of the black solid slanted line, and in a second step the corresponding L2 word form. In forward translation, on the other hand, no semantic access is necessary due to direct lexical links between L2 word forms and L1 word forms. This is represented in the figure by the black solid horizontal line. Backward translation thus requires an additional processing step. Even though, according to the RHM, faster translation time in the forward condition is explained by the fact that it does not involve semantic access, semantic priming effects have been observed in other studies (Duyck \& Brysbaert 2002; Schoonbaert et al. 2009). The absence of such an effect in earlier studies has been explained by a combination of two opposing effects that counterbalance each other: a facilitation effect and an interference effect (Wu \& Juffs 2019). The RHM has been used to analyze and describe the representation and processing of the bilingual mental lexicon. However, as pointed out by Goral et al. (2006: 236), "[ $t$ ]he model does not specify a priori whether words from additional non-native languages, learned after L2, are connected in the lexicon via the L1 words or L2 words", and as noted by Singleton (2003) and De Angelis (2007), there is nothing in Weinreich's work that indicates what would be the result when adding a third language to the already existing ones, something that will be investigated in the present study.

Models of bilingual word processing include, among others, the Inhibitory control model (Green 1986; 1998), the language mode framework (Grosjean 1997; 2001) and the bilingual interactive activation model (BIA+). The BIA+ was elaborated by Dijkstra \& Van Heuven (2002) and presupposes an integrated lexicon, integrated semantic representations, and non-selective access. According to this model, the presentation of a word in one language activates, in parallel, lexical representations in both languages and, in a second phase, the corresponding semantic representations. The activation resonates within the network and the candidate reaching the highest level of activation is identified. The model does not predict any processing differences between the languages known by a user. There is a difference between the concept of co-activation as described above and that of linguistic mediation proposed by Kroll \& Stewart (1994) and Fitzpatrick \& Izura (2011). Mediation by an L1 is said to occur as a necessary step in L2 semantic processing at beginner level, but it ceases to occur in more advanced learners. Co-activation on the other hand, is something that happens regardless of proficiency levels, and it is not a phenomenon that, in the first place, helps learners to access lexical meanings in later learned languages. 
The BIA+ is built on results from studies of the so-called cognate effect and the interlingual orthographic neighborhood effect, identified in lexical decision tasks (Sánchez Casas et al. 1992; Lemhöfer \& Dijkstra 2004; Dijkstra 2005). The cognate effect derives from the discovery that cognate words (i.e., words that have similar forms between languages and share the same meaning) are identified faster compared to non-cognates (Lemhöfer \& Dijkstra 2004). The interlingual orthographic neighborhood effect, on the other hand, derives from results showing that lexical items that are orthographically similar to many words in another language are identified more slowly compared to words that do not have the same number of orthographic neighbors, due to increased co-activation and competition (Grainger \& Dijkstra 1992; Van Heuven et al. 1998).

\subsection{Studies of the L3 mental lexicon}

Even though the structure and processing of the bilingual mental lexicon has been extensively studied in terms of interconnections, transfer, and selective or non-selective access, little research on the lexical connections among multilinguals' languages exists to date (for an overview see Cenoz et al. 2003 and Szubko-Sitarek 2015). Szubko-Sitarek (2011) and Lemhöfer et al. (2004) studied the cognate effect in trilinguals by way of a lexical decision task carried out in their third and weakest language. Participants were tested on double cognates, i.e. L1-L3 cognates, and triple cognates, i.e. L1-L2-L3 cognates, the hypothesis being that reaction times for triple cognates would be faster compared to those for double cognates, which was also found to be true in both studies. Results implied that the non-selective access approach to bilingual language processing could be extended also to a multilingual context. These effects could be ascribed to overlapping orthographic representations, overlapping semantic representations, or both. Dijkstra (2003) elaborated the multilingual interactive activation model to account for multilingual lexical processing. He stated that adding languages to existing ones means increasing the cognate effect, competition and the neighborhood effects. Lexical decision, the principal method used in studies of cognate and neighborhood effects, does not necessarily require semantic access, and Dijkstra's model does not include a semantic level of processing. That makes it less adaptable when analyzing semantic priming effects, which is the aim of the present study.

Abunuwara (1992) was among the first to test inhibitory control in trilingual speakers using the classic Stroop color-naming task. He tested the compound contra the coordinate approach in trilingual speakers of L1 Arabic, L2 Hebrew and L3 English, looking for interlingual and intraligual interference effects. He 


\section{Anna Gudmundson}

found support for a developmental approach that was similar to the one later implemented in the RHM, where L2 Hebrew was independent of L1 Arabic, while L3 English, the less proficient language, was dependent on L1 Arabic. He found no evidence of interference between the L2 and the L3, and this was interpreted in favor of a model where all non-native languages relate and depend on L1 only. The initial dependency on the L1 would diminish with increasing proficiency. A number of studies have later investigated inhibitory control in multilingual speakers using the Stroop color-naming task (Schwieter \& Sunderman 2011; Linck et al. 2012; Marian et al. 2013), and results have confirmed that language proficiency influences both the speed and the accuracy in multilingual Stroop task performance in the sense that participants are more accurate and faster in their most proficient language (L1), followed by their L2 and L3. Results also indicate greater Stroop effects when responses are made in a less proficient language than the language of the stimulus words. In addition, switching into a more proficient language is linked to greater switching costs.

Goral et al. (2006) used a different method to investigate patterns of inter-language lexical interference by studying a highly proficient multilingual speaker of Hebrew, French and English who had suffered aphasia. Even though English and French had been learned formally, starting by the age of 10 and 16 respectively, the learner is described as fluent in all languages. Goral et al. first studied naturalistic conversations and found that most inter-language interference occurred when speaking the language that had recovered least, i.e. French, and that interference came mainly from English. When English was used, there was more interference from French than from Hebrew. The authors explained this by the typological similarity between English and French compared to Hebrew, but also by the fact that both French and English had been learned formally and later in childhood. Goral et al. suggested that "a third language (L3) may be learned in connection with a previously learned non-native language (L2), and thus develop strong lexical connections with that language" (Goral et al. 2006: 244). The authors were unable though, to specify whether this was due to their status as non-native languages, their being used regularly at the time of the stroke, or their shared vocabulary, but they believed that the effect was a consequence of all factors.

Herwig (2001) studied the multilingual lexicon of four unbalanced multilingual university students by investigating the routes taken in lexical retrieval when translating from their respective L1s into German, Dutch and Swedish. Three of the students were of Irish nationality, and one was a Norwegian who had lived in Ireland for several years. Two of the students were on their second year of study, while the other two were on their fourth year. The fourth-year students 
are described as fluent, or almost fluent, in all languages, while the second-year students are described as having a good command of German, advanced skills in Dutch, and a basic knowledge of Swedish. By means of think-aloud protocols, Herwig was able to trace the chain of thought in cases of non-accessibility of a lexical item. Contrary to Goral et al. (2006), results showed that consultation from other languages occurs independently of the degree of proficiency, but that borrowings from languages that are perceived as linguistically close are important. She suggested that the search process activates semantically similar words in different languages, but that semantic information is most easily accessed in the learners' strongest L2. That would favor a subordinate approach between the strongest L2 and the other non-native languages, which seem to interact in a compound or coordinate way.

To sum up, lexical activation in multilingual speakers seems to imply some kind of co-activation, but little is known about how that co-activation behaves in relation to language status.

\subsection{Long-term cross-language semantic priming}

Priming is an unconscious process by which the recognition or production of a target word is influenced by the presentation of a previous word, the prime. For example, if the presentation of the word chair speeds up the recognition process of the word table, this could be interpreted as a semantic priming effect due to conceptual overlap. Research on bilingual speakers has shown that such priming effects occur also between languages, i.e. as interlanguage or cross-language priming (Chen \& Ho 1986; De Groot \& Nas 1991; Duyck et al. 2008; Schoonbaert et al. 2009). This has been interpreted in favor of a shared conceptual system between the two languages. Semantic priming has been shown to be particularly strong for concrete words (Jin 1990).

In a short-term priming paradigm, the target is presented immediately after the prime, while in long-term priming there are several intervening items between the prime and the target or sometimes even several hours (Wagenmakers et al. 2003). Long-term cross-language semantic priming has been difficult to obtain in lexical decision tasks, since the task does not always involve semantic activation, but relies on orthographic information (see Gollan \& Kroll 2003 for an overview). In tasks that elicit the activation of conceptual information, as in animacy decision, categorization or word association, results of long-term crosslanguage semantic priming have been obtained (Zeelenberg \& Pecher 2003; Li et al. 2009; Fitzpatrick \& Izura 2011). Results from these studies have been interpreted both in favor of the RHM, but also in favor of a model where both 


\section{Anna Gudmundson}

languages have direct access to conceptual information. To the best of my knowledge there are no previous studies of long-term cross-language semantic priming in multilinguals. The present study is an attempt to explore a possible long-term priming effect between two non-native languages.

\subsection{Word associations}

In a word association task, participants are asked to write, or say aloud, one or several words they come to think of upon seeing or hearing a stimulus word. The response patterns that emerge from that associative behavior are believed to reflect the organization and structure of the mental lexicon, and specifically how words are interconnected. Word associations can be free, i.e. participants are free to respond with any kind of word, or restricted, where a certain kind of association is requested, for example a verb. Responses are often compared to norming lists based on the most frequent answers (e.g. Postman \& Keppel 1970).

Word associations have long been used to assess how words are stored, organized and connected in the mind, (see for example Fitzpatrick 2012 for an overview) and the method fits well with the lexical network metaphor where words, or bits of words, are connected to each other by links of various strength. The activation patterns that emerge from word association tasks have shed light on both the L1 and the L2 lexicon but, to the best of my knowledge, there are no studies that investigate the association patterns of multilingual speakers.

Early studies on L1 (Ervin 1961; Entwisle et al. 1964) found that there was an increase with age as regards the proportion of paradigmatic associations, and a decrease of the proportion of syntagmatic and form associations. The substitution of syntagmatic associations for paradigmatic ones with advancing age has been known under the term the syntagmatic-paradigmatic shift. That shift could be ascribed to a general maturation of the child's cognitive information and processing abilities or, more simply, to an increasing vocabulary (Stolz \& Tiffany 1971; Cremer et al. 2010). The first explanation would imply that young children's cognition works differently from that of adults, while the second explanation would instead suggest that the size of the lexicon and the frequency of exposure would be important in determining the well-known shift.

The word association paradigm has also been used in L2 research, where association patterns in monolingual and bilingual speakers are compared (Krzeminska-Adamek 2014). Fitzpatrick \& Izura (2011) point out that learning an L2 in adulthood is not the same as learning an L1; cognitive development has already taken place and L2 learners can make use of lexical links created during L1 acquisition. For that reason it should not be taken for granted that adult L2 learners 
behave as young L1 learners. Cremer et al. (2010) tried to distinguish the effect of bilingualism from that of age and found that age was the dominant factor in word association patterns. Children tended to produce more context-dependent associations, while adults preferred more abstract context-independent associations. They concluded that conceptual development is the most important factor, regardless of L1 or L2, in determining word association responses.

Research on L2 speakers has, as for L1 children, also shown a preference for syntagmatic associations in the L2 (Meara 1978; Politzer 1978), and a replacement of syntagmatic responses for paradigmatic responses with increasing proficiency (Khazaeenezhad \& Alibabaee 2013, but see Wolter 2001 for a different point of view). Another observed characteristic of L2 association behavior is a greater variability in responses compared to L1 associations (Riegel \& Zivian 1972; Zareva 2007), and a final general trend is a greater proportion of sound associations, which seem to diminish with increasing proficiency (Riegel \& Zivian 1972). Sometimes word associations have been used specifically as an indicator of language proficiency (Riegel \& Zivian 1972; Zareva 2007), but the use of association behavior with that purpose has been criticized (Kruse et al. 1987; Cremer et al. 2010), because of divergent results found in the research.

Research on the conceptual representation of the bilingual memory is another field where word associations have been adopted (van Hell \& De Groot 1998; Fitzpatrick \& Izura 2011). Van Hell \& De Groot (1998) studied the processing of concrete versus non-concrete words, and cognate versus non-cognate words, using translation equivalents in a word association task. The experiment consisted of four conditions: L1 to L1 associations, L2 to L2 associations, L1 to L2 associations and L2 to L1 associations. Responses were compared to investigate the proportion of translation equivalents that resulted from cognate and non-cognate stimulus words and concrete versus abstract words. The proportion of translation equivalents in the cognate and concrete conditions were significantly higher, which was taken as evidence for a shared conceptual store for these kinds of words. Verspoor (2008) studied word associations in L1 and L2 translation equivalents and found that learner responses to L2 words were very much influenced by associations made with the L1 translation equivalent, but also that responses moved closer to those made by native speakers as proficiency increased. Associations in an L2 are thus influenced by L1 conceptualization.

In a word association study, Fitzpatrick (2006) found that native speakers produced significantly more consecutive collocations compared to non-native speakers, and a similar trend was found by Clenton (2015). Clenton investigated the amount of collocational word links in a word association task in English L2 and considered the proportion of collocational word associations as an indicator of 


\section{Anna Gudmundson}

the number of direct links between L2 word forms and their corresponding concepts. His starting point is that collocational associations are not mediated by the L1, since they are very much language specific. Results showed that the number of collocational associations increased with proficiency, which gave support to the RHM, which predicts less L1 mediation as learners become more proficient. Even though there are several studies on word association patterns in the L2, Cremer et al. observe that it "remains uncertain to what extent L1 or L2 speakers behave as homogeneous groups, or, how differently dispersed their responses are across different response categories" (2010: 188), and even less is known about the response patterns of multilingual speakers.

\subsection{Word relations}

Relations between words in the mental lexicon can be of different kinds, but following the categorization of Fitzpatrick \& Izura (2011), six different categories are recognized: (a) equivalent meaning relation, which includes synonymy (rug-carpet), co-ordination (bus-car), superordination (bird-robin), subordination (bird-animal) and partonymy (bird-feather); (b) non-equivalent meaning relation, which includes other conceptual representations that are semantically related, but not part of the equivalent meaning relation mentioned above, e.g. screamafraid, steak-Argentina or bubble-child. Non-equivalent meaning relations do not share formal semantic properties as is the case with equivalent meaning relation, but are dependent on context and subjective experience. Non-equivalent meaning relations are part of what Cremer et al. (2010: 194) call indirect meaning relations as opposed to direct meaning relations. Direct meaning relations are thus similar to the equivalent meaning relation stipulated by Fitzpatrick \& Izura (2011); (c) form-based relation, which means that the two words have overlapping phonology or sound, e.g. scream-ice cream; and (d) collocational relation, which is defined as a tendency of the words to co-occur forward or backward, e.g. robin-hood or bag-plastic. The final two categories proposed by Fitzpatrick \& Izura (2011) are defined by dual relational links between the words. The first is based on both form and meaning (bed-bedroom, newspaper-news), and the second is based on meaning and collocation (nail-finger, grape-fruit). These dual-link categories were proposed by Fitzpatrick \& Izura (2011) on the basis that some associations in their word association study were connected to the cue word in more than one way. Those dual-link associations obtained faster reaction times.

Equivalent meaning relations represent a close semantic relation and could be said to operate on a paradigmatic level: both words belong to the same word class, appear in the same semantic and grammatical contexts and have similar referents, 
while the non-equivalent meaning relations and the collocational meaning relations represent a looser semantic connection and a more syntagmatic-based relation. Words with a non-equivalent meaning relation often appear sequentially, but not necessarily contiguously to one another.

The categories, or relations, presented in Table 4.1 will be used in the analysis of the word association responses in the present study. They will be called association categories.

Table 4.1: Association categories: word relations as proposed by Fitzpatrick \& Izura (2011).

1. Equivalent meaning relation
synonymy (rug-carpet);
co-ordination (bus-car);
superordination (bird-robin);
subordination (bird-animal);
partonymy (bird-feather)
scream-afraid; steak-argentina;
bubble-child
scream-ice cream
robin-hood; bag-plastic
bed-bedroom; newspaper-news
nail-finger; grape-fruit

2. Non-equivalent meaning relation

3. Form-based relation

4. Collocational relations

5. Form and meaning relation

6. Meaning and collocational relation

\section{The study}

\subsection{Research questions}

The aim of the present study is to investigate the structure and processing of the multilingual mental lexicon. This is done by studying what kind of word associations (see the association categories above in Table 4.1) are produced, and how they distribute (association distribution) in the three different languages: Swedish L1, English L2, and Italian L3. In addition, the speed at which the different association categories are produced is investigated.

Finally, the present study aims at investigating whether semantic activation of an L3 word could be mediated by the corresponding L2 word, or whether this mediating function is unique to the L1.

The following research questions are asked: 


\section{Anna Gudmundson}

1. Is the association distribution homogeneously distributed over the different association categories and is the association distribution dependent on language status (Swedish L1, English L2, Italian L3)?

2. Is there a difference in reaction times over the different association categories and, if so, might this difference be related to language status (Swedish L1, English L2, Italian L3)?

3. Is it possible to obtain a long-term cross-language semantic priming effect between the L3 and the L2, i.e. can semantic activation of an L3 word be mediated by the corresponding L2 word?

Results related to the first research question will be presented in $\S 3.1$ and results related to the second research question will be presented in $\$ 3.2$. The first two research questions are tested by three word association tasks, one for each language (see §2.2.1). Results pertaining to research question 3 will be reported in $\$ 3.3$ and are built on data from the L3 Italian word association task and the lexical decision task in L2 English.

\subsection{Methodology}

Fitzpatrick (2006) and Fitzpatrick et al. (2013) noticed some weaknesses with word association studies within second language acquisition research in general and asked for more rigor as concerns the choice of stimulus words, e.g. their frequency or word class. Cremer et al. (2010: 200) suggested that participants ideally should be tested both in their L1 and in their L2 (i.e., by using a within-subjects design). Cremer et al. also claimed that oral responses are to be preferred to written ones, since oral responses would capture a more direct and spontaneous reaction to the stimulus word. Besides that, many L2 learners might find it difficult to write in a foreign language. Finally, Cremer et al. also proposed measuring response latencies to capture automaticity of processing. Fitzpatrick \& Izura stated that "[s]peeding up responses and measuring the resulting reaction times offer the possibility of inferring properties of the lexicosemantic pathways that are less dependent on strategic processes" (2011: 376). The present study aims at meeting the calls for methodological rigor as stated by Fitzpatrick et al. and Cremer et al. It follows a within-subjects design and all stimulus words have been matched as to frequency, word class, word length, age of acquisition and imageability. To capture fluency, reaction times have been measured. Finally, all responses are oral to increase the possibility of receiving more direct and spontaneous answers. 


\subsubsection{Procedure}

Each participant performed three free word association tasks in three different languages (L1 Swedish, L2 English and L3 Italian) and a lexical decision task (LDT) in English one time over two testing appointments. All participants were tested individually. On the first occasion, they completed the L3 Italian word association task that was immediately followed by the LDT in L2 English. On the second occasion, they completed the English and the Swedish word association tasks with a 15-minute pause in between. At the first appointment, after the LDT, the participants also completed two C-tests, one for Italian (Kras 2007) and one for English (Keijzer 2007). The C-tests had both been implemented within the language attrition network directed by Monika Schmid. ${ }^{1}$ The C-tests were comparable, but not identical since the same texts could not be used in both languages. C-tests, in both languages, were composed of five text extracts from different texts and text types, such as articles from magazines and newspapers and historical reports. Each extract included 20 gaps where the second half of every second word had been deleted.

The association tasks were conducted with the E-prime software and a voice key linked to a microphone positioned in front of the participants. Participants were asked to produce single oral associations to 90 cue words presented in random order on a screen positioned in front of them. The cue words showed up on the screen after the appearance of a fixation cross that remained on the screen for 1000 milliseconds. The cue word disappeared after seven seconds and a new cue word appeared on the screen. Every session started with a practice trial. Before the test, the participants were given both oral and written information and instruction about the procedure. They were informed that a word would appear in the middle of the screen one second after seeing a cross, and they were instructed to say aloud the first word they came to think of. They were told that there were no right or wrong answers and that their answers would be recorded. They were asked to respond as fast as possible and informed that the time it took to come up with an association would be measured. If they were not able to produce a response, they were asked to remain silent and wait for the next word, and to try to avoid fillers such as um or eh. Finally, they were informed that the test was composed of 90 words and that it took about 15 minutes to complete it. The time interval between the appearance on the screen of the cue word and the onset of the oral response was measured by E-prime. That time interval is equivalent to what is referred to as reaction time in this study. All responses were later transcribed.

\footnotetext{
${ }^{1}$ https://languageattrition.org/resources-for-researchers/experiment-materials/c-test/
} 


\section{Anna Gudmundson}

The first day, immediately after the L3 Italian word association task, the participants performed an LDT in L2 English. The LDT consisted of 72 cue words, 36 real words and 36 non-words. Half of the real words $(N=18)$ were translation equivalents of cue words present in the prior Italian word association task. The LDT was conducted with the E-prime software and a response box. Cue words were presented on a screen and participants were instructed to press, as fast as possible, the green right button of the response box if the word was a real English word, and the left red button if the word was not a real English word. When a decision had been made, a new cue word appeared on the screen. Each session began with a practice trial and, altogether, the LDT lasted for about four minutes. Reaction times were measured and faster reaction times were predicted for the translation equivalents if a priming/mediation effect had taken place.

\subsubsection{Participants}

Participants were recruited through printed advertisement at a Swedish university, but also through electronic advertisement on the official university web site, on Facebook and on twitter. After finishing the tests, participants were compensated with cinema tickets. All participants were unbalanced trilinguals as regards proficiency, with L1 Swedish, L2 English and L3 Italian. In the C-tests, participants obtained significantly lower results in Italian L3 $(M=563.58, \mathrm{SD}=228.06$, $N=19)$ compared to English L2 $(M=749.58, \mathrm{SD}=74.14, N=19), t(18)=3.88$, $p<0.001$, two-tailed. Besides being the last acquired language, Italian was also generally the weakest language. However, six of the participants had a proficiency level of Italian that was similar to that of English. All participants had learned English at school from early age, but as regards Italian, the background was more heterogeneous: some of the participants had learned it at school or university, while others had learned it abroad. Many of the participants also knew other languages and among them, some were Romance. Participants' ages ranged from 22 to $76(M=46)$. Altogether, 21 participants volunteered to participate, but only 19 performed the Italian word association task and the English LDT, and only 18 performed all three word association tasks.

\subsubsection{Materials}

\subsubsection{Word association task}

90 words were used in each word association task (Italian, English and Swedish). The words were extracted from psycholinguistic databases and they were all nouns, matched as to number of letters, imageability (i.e., "the ease with which 
a word gives rise to a sensory image" Bird et al. 2001: 73), age of acquisition and frequency. No cognates were included. The aim was to find short words learned at an early age. They should also be of high imageability and high frequency. All word lists are found in Appendix A together with descriptive statistics. The words used in the English association task were extracted from the MRC database (Coltheart 1981; Wilson 1988), and the words used in the Italian association task were extracted from the Varless database (Burani et al. 2001). For the Swedish word association task, no database containing psycholinguistic information such as imageability and age of acquisition exists and, therefore, such information for the chosen Swedish words were extracted from Norwegian translation equivalents present in the database Ordforradet (Lind et al. 2013) for which such information is available. That choice seems plausible because of the structural similarities between Norwegian and Swedish, often considered mutually intelligible (Gooskens 2010), but also because of the cultural similarities between Sweden and Norway. The frequency of the Swedish translation equivalents were taken from the Swedish SUC corpus (Gustafson-Capková \& Hartmann 2006). Imageability scores were in all databases based on the 7-point scale proposed by Paivio et al. (1968), where 1 equals least imageable and 7 equals most imageable. Age of acquisition scores in all three databases were based on the 7-point scale proposed by the Gilhooly \& Logie norms (1980), where 1 equals $0-2$ years and 7 equals 13 years or older.

\subsubsection{Lexical decision task}

The lexical decision task consisted of 72 words. Out of these words, 36 were nonwords and 36 were real words. Out of the real words, 18 were translation equivalents of words that had appeared in the previous Italian word association task, and 18 were controls that did not appear in the Italian word association task. No cognates were used. The English translation equivalents and controls in the LDT came from the MRC database (Coltheart 1981; Wilson 1988), and were matched as to number of letters, imageability, age of acquisition and frequency. The nonwords for the English LDT came from the ARC non-word database (Rastle et al. 2002), and were all orthographically legal in English.

\subsubsection{Design and analysis}

\subsubsection{Word association task}

For each participant, three datasets were created, one for each word association task. The datasets included responses for the 90 cue words and their correspond- 


\section{Anna Gudmundson}

ing reaction times. In the Swedish association task, 65 out of 1620 (4.01\%) cases were excluded from analysis due to missing responses, use of fillers or computer failures. The same value for the English association task was 223 out of 1620 $(13.76 \%)$, and for Italian 359 out of $1620(22.16 \%)$. When looking at the distribution of the missing data, no obvious systematic pattern could be observed. The large amount of missing responses in the Italian word association task is a consequence of participants remaining silent, either because the stimulus word was unknown to them, or because they were not able to come up with an answer within the seven-second time span. Statistics were based on the remaining 4213 observations. One coder analyzed and categorized all responses in the different association categories presented in Table 4.1. A second coder analyzed and categorized a randomized subsample of $10 \%$ of the data. Both coders had high proficiency levels in all three languages. An interrater reliability score of $91 \%$ was obtained. Since not all participants gave an answer to all stimulus words, number of responses per association category and per participant was transformed into a proportion (i.e., a percentage). That is what is called association distribution.

Two analyses were conducted in order to respond to research question 1 (see §3.1). To verify whether the association distribution was homogeneously distributed over the different association categories, a chi-square test of homogeneity was conducted, with the null hypothesis being that each association category is equally common. To verify whether the association distribution was dependent on language status, a chi-square test of independence was conducted with the null hypothesis being that it is not dependent. Log-transformed standardized residuals were used to investigate differences in association distribution related to language status and the different association categories.

As regards research question 2 (see §3.2), a general linear model approach with planned pairwise comparisons of the estimated marginal means, using Tukey's HSD method, was applied.

\subsubsection{Priming task}

With reference to research question 3 (Long-term cross-language semantic priming, §3.3), one data set was created, including reaction times for the English translation equivalents (primed condition) and the control word (non-primed condition). A $t$-test was performed with reaction time as the dependent variable and primed versus non-primed condition as independent variable.

Statistics were carried out with R, version 3.6.1. 


\section{Results}

$\S 3.1$ treats research question 1, i.e. whether the association distribution is homogeneously distributed over the different association categories and if the association distribution is dependent on language status (L1 Swedish, L2 English, L3 Italian). $\$ 3.2$ treats research question 2, i.e. whether there is a difference in reaction times over the different association categories, and if such a difference could be related to language status. Results related to research questions 1 and 2 are based on the three word association tasks. In $\S 3.3$, the results related to research question 3 are presented, i.e. whether it is possible to obtain a long-term cross-language semantic priming effect between L3 and L2. The response to this question is based on the L3 Italian word association task, and the L2 English lexical decision task.

\subsection{Association distribution: association categories and language status}

Table 4.2 summarizes the proportion of responses (mean association distribution), number of observations and standardized residuals in the three languages and the six association categories. The association distribution is also pictured in Figure 4.2.

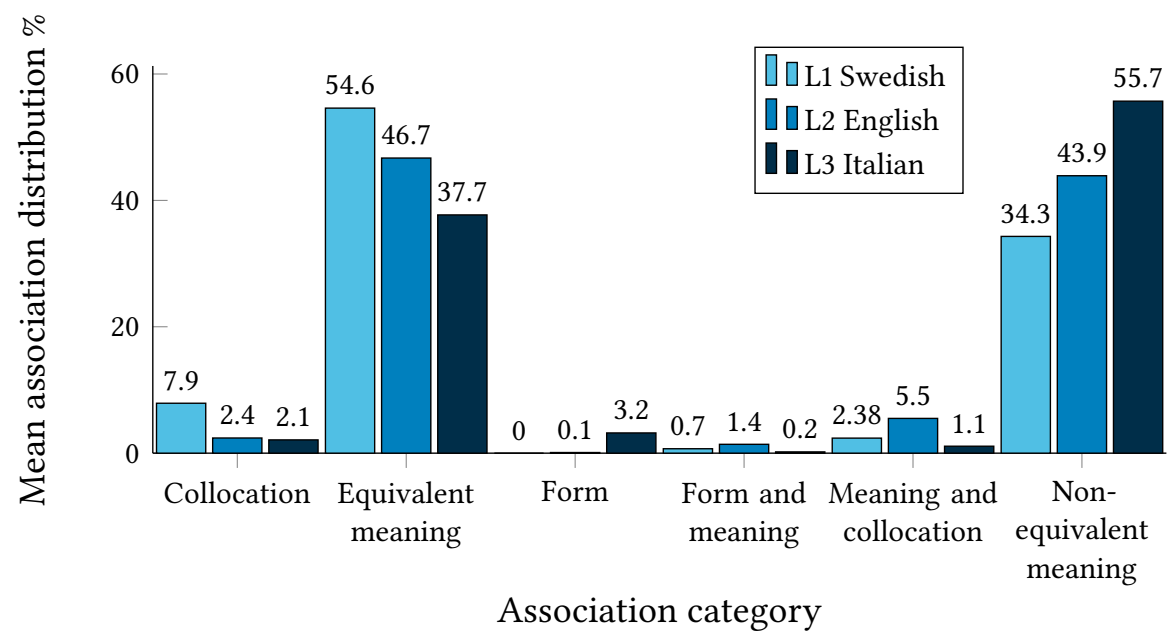

Figure 4.2: Association distribution in L1 Swedish, L2 English and L3 Italian and in the six association categories. 


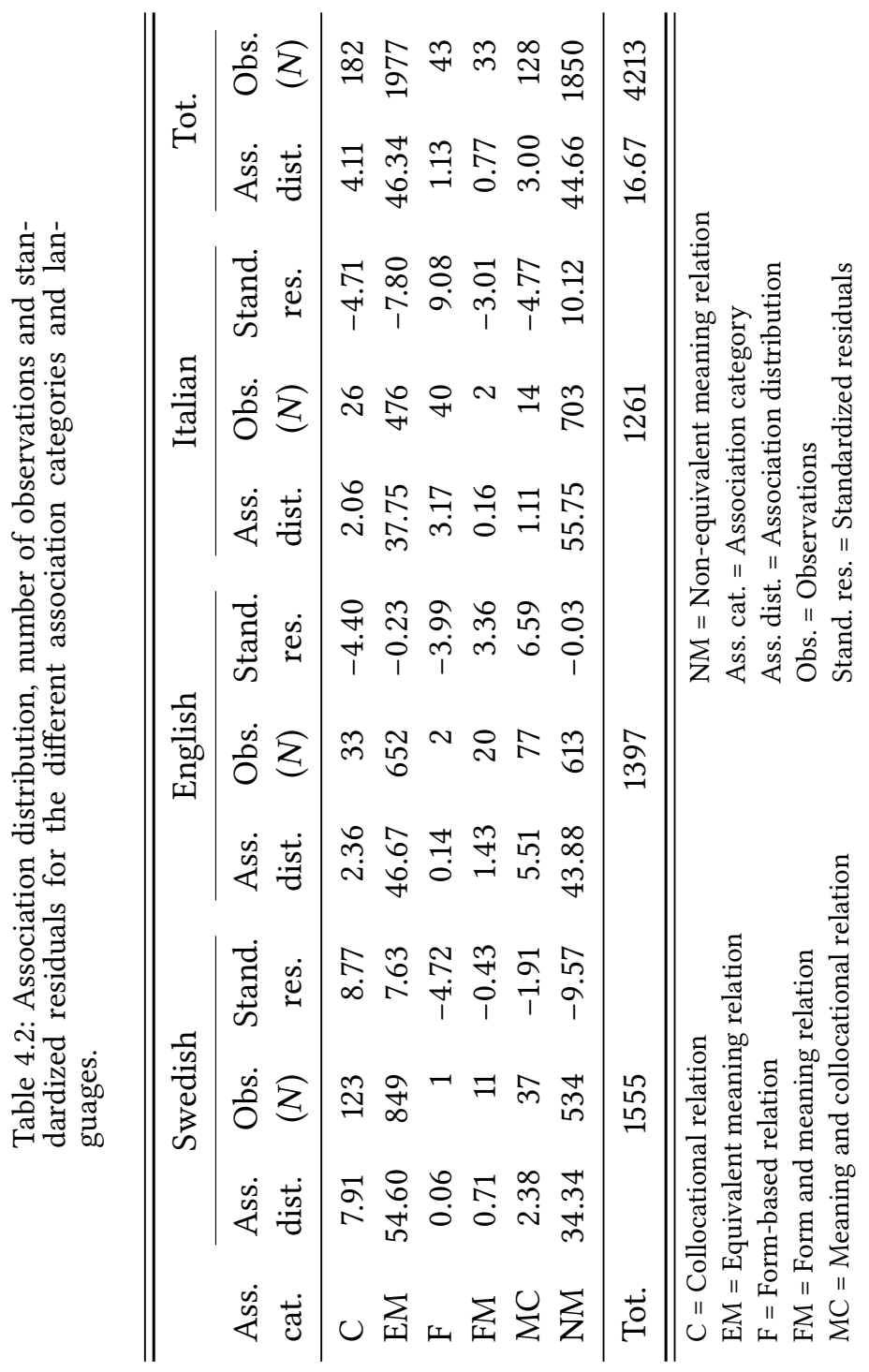


It can be noted that the greatest proportion of responses was of equivalent meaning or non-equivalent meaning type. These association categories stand out from the other categories in terms of number of associations. The third most common category was collocational, followed by the dual association category meaning and collocation. Form-based and form- and meaning-based associations were not that common. Form-based associations occurred almost only in the Italian data.

A first chi-square test of homogeneity showed that the association distribution was not homogeneously distributed over the different association categories, $\chi^{2}(5, N=4213)=6302.3, p<0.000$. The second chi-square test of independence showed that the association distribution was not equally distributed over the different languages $\chi^{2}(10, N=4213)=329.9, p<0.000$. As can be seen in Table 4.3, the association distribution in the Swedish data was significantly different from the one in the English data and from the Italian data, and the association distribution in the English data was significantly different from the one observed in the Italian data.

To follow up the chi-square test of independence, standardized residuals were analyzed. According to Agresti (2013: 81), "[a] standardized residual that exceeds about 2 or 3 in absolute value indicates lack of fit of $H_{0}$ in that cell". The standardized residuals in the six categories and the three languages are visualized in Figure 4.3.

The proportion of equivalent meaning associations in the Swedish data shows very large positive residuals, and we can infer that more L1 Swedish associations were of this type than if independence was true. The proportion of equivalent meaning associations in the L3 Italian data shows the opposite, i.e. very large negative values. The proportion of equivalent meaning associations in the L2 English data is exactly what is expected by the model. A large positive value is also found for collocational associations in L1 Swedish, while both L2 English and L3 Italian show large negative values. From Figure 4.3 we can also infer that formbased associations are very common in L3 Italian, showing large positive values, while both L2 English and L1 Swedish show large negative values. The category non-equivalent meaning is associated with very large positive values in L3 Italian and with very large negative values in L1 Swedish. The same value for L2 English is not different from what had been expected if independence was true. The dual categories form and meaning relation and meaning and collocational relation indicate positive values for L2 English, while both L1 Swedish and L3 Italian show negative values. To sum up, three different aspects stand out. The first is that the L1 Swedish and L3 Italian data show the opposite behavior for values related to equivalent meaning associations and non-equivalent meaning association, but 


\section{Anna Gudmundson}

Table 4.3: Pairwise comparisons between the three languages

\begin{tabular}{rrrrrl}
\hline \hline$\chi^{2}$ & df & $n$ & $p$-value & Adj. alpha & Languages \\
\hline 92.010 & 5 & 2952 & 0.000 & 0.010 & Swedish: English \\
216.610 & 5 & 2816 & 0.000 & 0.010 & Swedish: Italian \\
120.530 & 5 & 2658 & 0.000 & 0.010 & English: Italian \\
\hline \hline
\end{tabular}

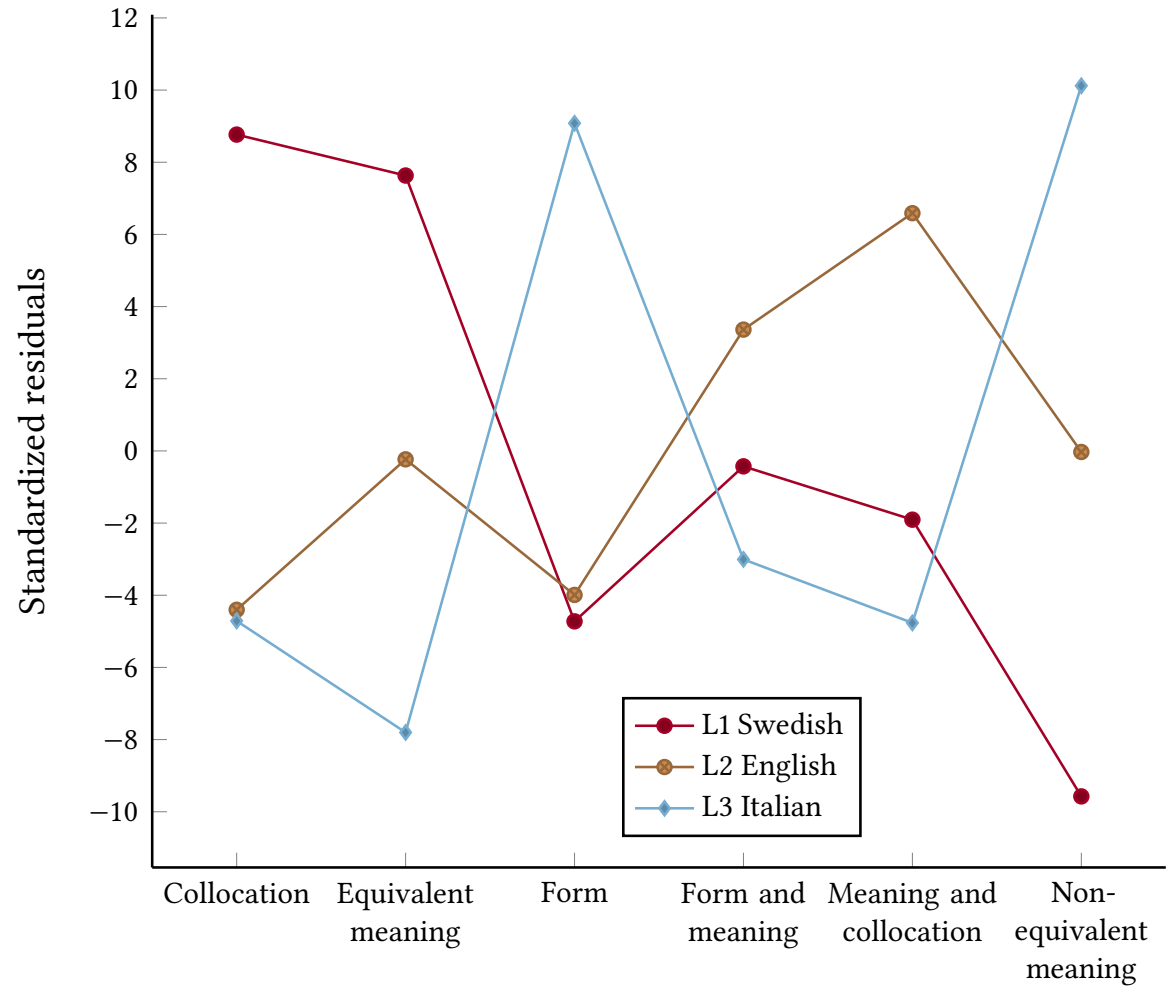

Association category

Figure 4.3: Standardized residuals in the six association categories and the three languages: L1 Swedish, L2 English and L3 Italian. 
when it comes to the L2 English data, values for these two categories are the same and located just in between the data from L1 Swedish and L3 Italian. The second aspect is that collocational associations almost only occur in the L1 Swedish data, and the third aspect is that form-based associations almost only occur in the L3 Italian data.

\subsection{Reaction time: association categories and language status}

This section addresses research question 2, i.e. whether there is a difference in reaction times over the different association categories and, if so, if this difference could be related to language status. Table 4.4 summarizes mean reaction times for the three languages and the six association categories, together with the number of observations and standard deviations. Figure 4.4 illustrates mean reaction times in the three languages and the different categories.

Table 4.4: Mean reaction times and number of observations for the different association categories and languages.

\begin{tabular}{|c|c|c|c|c|c|c|c|c|c|c|c|c|}
\hline \multirow[b]{2}{*}{$\begin{array}{l}\text { Ass. } \\
\text { cat. }\end{array}$} & \multicolumn{3}{|c|}{ Swedish } & \multicolumn{3}{|c|}{ English } & \multicolumn{3}{|c|}{ Italian } & \multicolumn{3}{|c|}{ Tot. } \\
\hline & $\begin{array}{r}\text { Obs. } \\
(N)\end{array}$ & $\begin{array}{r}M \\
\mathrm{RT}\end{array}$ & SD & $\begin{array}{r}\text { Obs. } \\
(N)\end{array}$ & $\begin{array}{r}M \\
\mathrm{RT}\end{array}$ & SD & $\begin{array}{r}\text { Obs. } \\
(N)\end{array}$ & $\begin{array}{r}M \\
\mathrm{RT}\end{array}$ & SD & $\begin{array}{r}\text { Obs. } \\
(N)\end{array}$ & $\begin{array}{r}M \\
\mathrm{RT}\end{array}$ & SD \\
\hline C & 123 & 1966 & 808 & 33 & 1994 & 794 & 26 & 2761 & 1317 & 182 & 2084 & 932 \\
\hline EM & 849 & 2169 & 1010 & 652 & 2310 & 1012 & 476 & 2757 & 1246 & 1977 & 2357 & 1097 \\
\hline $\mathrm{F}$ & 1 & 1537 & & 2 & 1746 & 185 & 40 & 3315 & 1392 & 43 & 3201 & 1407 \\
\hline FM & 11 & 2641 & 969 & 20 & 2037 & 841 & 2 & 2967 & 1909 & 33 & 2295 & 969 \\
\hline $\mathrm{MC}$ & 37 & 1914 & 799 & 77 & 1613 & 701 & 14 & 1627 & 510 & 128 & 1701 & 721 \\
\hline NM & 534 & 2261 & 1114 & 613 & 2550 & 1133 & 703 & 3184 & 1312 & 1850 & 2707 & 1260 \\
\hline Tot. & 1555 & 2181 & 1032 & 1397 & 2365 & 1070 & 1261 & 3000 & 1308 & 4213 & 2487 & 1184 \\
\hline $\begin{array}{l}\mathrm{F}=\mathrm{F} \\
\mathrm{FM}=\end{array}$ & iivaler & relation & 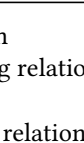 & & & & NM & 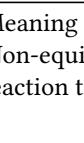 & $\begin{array}{l}\text { ralen } \\
\text { me }\end{array}$ & ation & $\begin{array}{l}\text { elation } \\
\text { lation }\end{array}$ & \\
\hline
\end{tabular}

When looking at the total values for the different languages, reaction times were fastest in Swedish, followed by English, followed by Italian. As regards the different categories, reaction times were fastest for meaning and collocational associations, i.e. a dual link between the cue word and the association implied fast responses. As far as that category is concerned, there were very small differences in response times across languages. The second fastest response times were obtained in collocational associations followed by equivalent meaning associations, i.e. associations with a significant semantic overlap. Form-based associ- 


\section{Anna Gudmundson}

ations produced the slowest responses, even though response times for Swedish and English were rather fast. It is important, though, to recognize that the English and Swedish data are built on three observations only, and that the data, in general, are rather unbalanced.

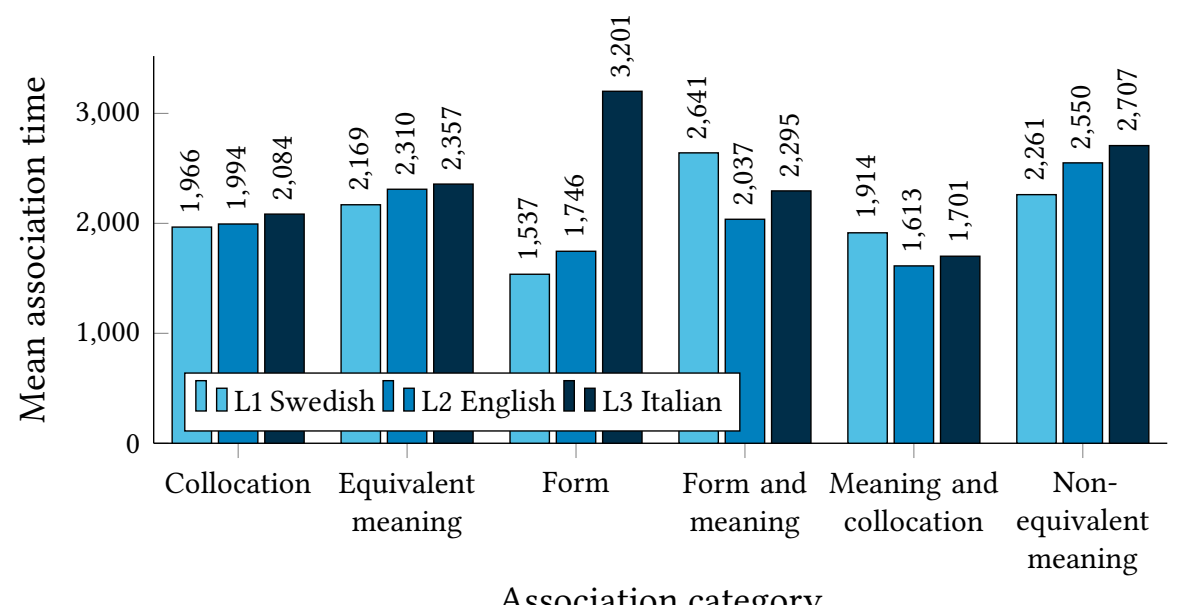

Figure 4.4: Word association task, mean reaction times over the different association categories and languages.

To verify whether language status and association category are associated with reaction time, a standard general linear model approach, assuming independent samples, was used. Since the distribution of the response time was skewed, a log transformation on the response time was applied, which resulted in an approximately normal distribution.

A significant effect $(F(2,4210)=201.8, p<0.000)$ of language status on reaction time was observed, and a significant effect of association category on reaction times $F(5,4205)=26.16, p<0.000$. There was also a significant interaction effect between language status and association category $F(10,4195)=$ $3.50, p<0.000$. Following statistical reporting guidelines (Field et al. 2012), pairwise comparisons were conducted on the significant interaction effect only. The comparisons are reported in Table 4.5. Only significant contrasts $(p \leq 0.05)$ are reported. The last column reports effect size in terms of Cohen's $d$. Cohen (1988) defined a small, a medium and a large effect size as corresponding to $0.2,0.5$ and 0.8 , respectively.

If we start by looking at the two largest association categories - equivalent meaning and non-equivalent meaning - there are significant differences between 
Table 4.5: Interaction effects: pairwise comparisons of RT

\begin{tabular}{|c|c|c|c|c|c|c|}
\hline Contrast & Estimate & $S E$ & $\mathrm{df}$ & $t$-ratio & $p$-value ${ }^{a}$ & $d$ \\
\hline \multicolumn{7}{|l|}{ Equivalent meaning } \\
\hline Swedish - English & -0.0712 & 0.0220 & 4195 & -3.229 & 0.0036 & -0.17 \\
\hline Swedish - Italian & -0.0254 & 0.0914 & 4195 & -9.780 & $<0.0001$ & -0.56 \\
\hline English - Italian & -0.1659 & 0.0255 & 4195 & -6.500 & $<0.0001$ & -0.39 \\
\hline \multicolumn{7}{|l|}{ Collocation } \\
\hline Swedish - Italian & -0.3041 & 0.0914 & 4195 & -3.328 & 0.0025 & -0.72 \\
\hline English - Italian & -0.2787 & 0.1110 & 4195 & -2.511 & 0.0324 & -0.66 \\
\hline \multicolumn{7}{|l|}{ Non-equivalent meaning } \\
\hline Swedish - English & -0.1361 & 0.0251 & 4195 & -5.432 & $<0.0001$ & -0.32 \\
\hline Swedish - Italian & -0.3618 & 0.0243 & 4195 & -14.888 & $<0.0001$ & -0.85 \\
\hline English - Italian & -0.2257 & 0.0234 & 4195 & -9.647 & $<0.0001$ & -0.53 \\
\hline \multicolumn{7}{|l|}{ English } \\
\hline $\begin{array}{l}\text { Equivalent meaning - } \\
\text { Meaning and collocation }\end{array}$ & 0.34828 & 0.0510 & 4195 & 6.828 & $<0.0001$ & 0.42 \\
\hline $\begin{array}{l}\text { Equivalent meaning - } \\
\text { Non-equivalent meaning }\end{array}$ & -0.09543 & 0.0238 & 4195 & -4.007 & 0.0009 & -0.23 \\
\hline $\begin{array}{l}\text { Collocation - } \\
\text { Non-equivalent meaning }\end{array}$ & -0.22219 & 0.0756 & 4195 & -2.937 & 0.0390 & -0.52 \\
\hline $\begin{array}{l}\text { Meaning and collocation - } \\
\text { Non-equivalent meaning }\end{array}$ & -0.44372 & 0.0512 & 4195 & -8.670 & $<0.0001$ & -1.05 \\
\hline \multicolumn{7}{|l|}{ Italian } \\
\hline $\begin{array}{l}\text { Equivalent meaning - } \\
\text { Form }\end{array}$ & -0.18901 & 0.0697 & 4195 & -2.712 & 0.0730 & -0.45 \\
\hline $\begin{array}{l}\text { Equivalent meaning - } \\
\text { Meaning and collocation }\end{array}$ & 0.47666 & 0.1148 & 4195 & 4.153 & 0.0005 & 1.13 \\
\hline $\begin{array}{l}\text { Equivalent meaning - } \\
\text { Non-equivalent meaning }\end{array}$ & -0.15520 & 0.0251 & 4195 & -6.177 & $<0.0001$ & -0.37 \\
\hline $\begin{array}{l}\text { Collocation - Meaning } \\
\text { and collocation }\end{array}$ & 0.46274 & 0.1403 & 4195 & 3.298 & 0.0126 & 1.09 \\
\hline $\begin{array}{l}\text { Form - Meaning and } \\
\text { collocation }\end{array}$ & 0.66567 & 0.1315 & 4195 & 5.064 & $<0.0001$ & 1.57 \\
\hline $\begin{array}{l}\text { Meaning and collocation - } \\
\text { Non-equivalent meaning }\end{array}$ & -0.63187 & 0.1143 & 4195 & -5.530 & $<0.0001$ & -1.49 \\
\hline
\end{tabular}

${ }^{a}$ Comparisons were made with the Tukey's HSD method 


\section{Anna Gudmundson}

all languages. These associations are produced faster in Swedish compared to English and faster in English compared to Italian. In terms of effect size, for the equivalent meaning associations, the difference between Swedish and English, and English and Italian, could be considered small, while the difference between Swedish and Italian is of medium size. When looking at the non-equivalent meaning associations, there is a small effect between Swedish and English, a medium effect between English and Italian and a large effect between Swedish and Italian. Collocational associations are significantly faster in Swedish than in Italian, and also significantly faster in English than in Italian, and those effects are rather large. No other significant differences between the three languages could be observed. It must be recognized, though, that the number of responses in the other categories is not large enough to produce reliable data. If we look at differences in reaction times between the categories within the three languages, results show there are no significant differences in Swedish. For English, on the other hand, there are significant differences between equivalent meaning and meaning and collocational associations, between equivalent meaning and non-equivalent meaning associations, between collocational and non-equivalent meaning associations and, finally, between meaning and collocational associations and nonequivalent meaning associations. Among these, the last comparison is associated with a large effect size, while the other three are associated with medium or small effect sizes. The Italian data reveal large differences in reaction times between many different categories. Significant differences in reaction times are observed between the categories equivalent meaning and form, equivalent meaning and meaning and collocation, equivalent meaning and non-equivalent meaning, collocation and meaning and collocation and, finally, meaning and collocation and non-equivalent meaning. A difference between equivalent meaning associations and form-based associations that approached a $p$-value of 0.05 (0.07) was also detected. The effect sizes in Italian are generally very large. To sum up, reaction times for the two largest categories, equivalent meaning and non-equivalent meaning, are fastest in L1 Swedish, followed by L2 English, followed by L3 Italian. As concerns the third largest category, collocations, no difference was observed between Swedish and English. The number of significant differences observed between the different categories within each language was six in L3 Italian, four in L2 English and none in L1 Swedish. The effect sizes in the Italian data were also much larger compared to the English data. 


\subsection{Long-term cross-language semantic priming}

This section refers to research question 3, i.e. whether it is possible to obtain a long-term cross-language semantic priming effect between L3 and L2, and if semantic activation of an L3 word co-activates, or requires mediation of, the corresponding L2 word. Results from the LDT are listed in Table 4.6. Table 4.6 reports mean reaction times and standard deviations for the two conditions of translation equivalent (primed condition) and control word (non-primed condition). Participants responded faster (629.77) to the primed items than to the control words (656.22). A mean difference of 26.45 milliseconds was observed between the primed and the non-primed condition.

Table 4.6: Mean reaction times for non-words, primed words and nonprimed words

\begin{tabular}{lrrr}
\hline \hline & $\begin{array}{r}\text { Translation equivalent } \\
\text { (primed) }\end{array}$ & $\begin{array}{r}\text { Control word } \\
\text { (non primed) }\end{array}$ & $\begin{array}{r}\text { Difference between primed and } \\
\text { non-primed condition }\end{array}$ \\
\hline$M$ & 629.77 & 656.22 & 26.45 \\
SD & 101.43 & 110.50 & \\
\hline \hline
\end{tabular}

A $t$-test indicated a significant effect of priming on reaction times, $t(18)=$ $4.23, p<0.000$, two-tailed. Reaction times for control words were significantly slower than reaction times for translation equivalents.

\section{Discussion}

The discussion section includes two subsections. In the first, a discussion related to the word association tasks is presented. This subsection considers both the association distribution data and the reaction time data, i.e. research questions 1 and 2. That is because a combined analysis of these two research questions is believed to be more fruitful and meaningful when it comes to understanding how the multilingual lexicon grows and evolves. $§ 4.2$ discusses research question 3 , i.e. results from the LDT and the long-term cross-language semantic priming effect observed between L3 Italian and L2 English.

\subsection{Association distribution and response times in word association}

Generally, the word association data showed that participants in the study preferred equivalent meaning and non-equivalent meaning associations in all languages, and that other kinds of responses occurred rarely. However, differences 


\section{Anna Gudmundson}

between the languages were found and it could be concluded that the association distribution differed according to language status and association category. Form-based associations occurred almost only in the L3 (Italian), whereas the proportion of collocational associations in the L1 (Swedish) was very high compared to both the L2 (English) and L3 (Italian). The last two showed similar values. In L1 Swedish, the most common association category was of equivalent meaning, while in L3 Italian, the most common association category was of nonequivalent meaning. As regards L2 English, associations expressed equivalent and non-equivalent meaning to the same extent. In other words, the proportion of equivalent meaning associations increased from the L3 to the L2 and from the L2 to the L1. On the other hand, the proportion of non-equivalent meaning associations showed the opposite behavior, i.e. they increased from the L1 to the L2 and from the L2 to the L3. Thus, the proportion of equivalent meaning versus non-equivalent meaning associations varies according to language status, a trend that resembles the traditional syntagmatic-paradigmatic shift observed in other word association studies within L1 and L2 research (Ervin 1961; Entwisle et al. 1964; Meara 1978; Politzer 1978; Fitzpatrick \& Izura 2011; Khazaeenezhad \& Alibabaee 2013).

As regards reaction times, results showed that these changed with language status, hence, fastest reaction times were obtained in L1 Swedish, followed by L2 English, and finally L3 Italian. This is what would be predicted by the RHM, i.e. longer response latencies when associating in a weaker second language since the only way to access semantic information is through the L1. Additionally, with increasing proficiency, learners should be less dependent on L1 conceptual mediation. Another possible, and simpler, explanation of the reaction time differences between the languages is fluency or automaticity, i.e. lexical access is more fluent in the L1 than in the L2, and more fluent in the L2 than in the L3.

Results showed an interaction effect between language status and association category on reaction time. As regards the largest categories, equivalent meaning and non-equivalent meaning, differences in reaction times between all languages were observed; association times were faster in L1 Swedish followed by L2 English and, finally, L3 Italian. When it comes to collocations on the other hand, even if differences in reaction times were found between Swedish and Italian, and Italian and English, no difference could be observed between Swedish and English, even if collocational associations were much more common in Swedish compared to English. An interesting fact is that there were no statistical differences in reaction times between the association categories in the Swedish data, while differences were observed both in English and in Italian. It should also be observed that more differences were found in the Italian data compared to the English data. These results indicate a trend according to which reaction times in 
the different categories are evened out with language status or with increasing proficiency and fluency. When a language user has reached a high level of proficiency, lexical retrieval is fast in all categories. A difference in reaction times between different association categories is most easily detected in less proficient language users.

As already mentioned, form-based associations occurred almost only in the L3 (Italian): while participants produced, in total, one form-based association in the L1 Swedish and two form-based associations in the L2 English, they produced as many as 40 form-based associations in the L3. Among these, we find aquila acqua ('eagle' - 'water'), cuscino - cucina ('pillow' - 'kitchen'), and doccia - dolce ('shower' - 'cake'), i.e. words that have no obvious conceptual overlap, but are related only by phonological or orthographic characteristics and word class. It is known that words that share orthographic and phonological features co-activate (Van Heuven et al. 1998; Aitchison 2012), and earlier studies have shown that these associations are particularly common in the L2 (Meara 1978; Fitzpatrick \& Izura 2011) and that they diminish with increasing proficiency (Riegel \& Zivian 1972). The large proportion of form-based associations in Italian might be due to the fact that only form-based links existed between the cue word and other words in the mental lexicon, simply because the meaning of the word was unknown and therefore failed in activating words with related meaning. Another possibility would be that the word was not unknown and that conceptual links to other words did exist, but that they were less strong compared to the orthographic links due to a limited vocabulary. Ellis states, "[a]t the point in acquisition when a particular representation is salient, that representation has a higher likelihood of driving word association responses" (1996: 93). As proposed by Nation (2001), and Haastrup \& Henriksen (2000), depth (i.e., a word's different sense relations) increases with breadth, which means that it is not until a learner has a large enough vocabulary that she or he can start to make use of conceptual links between words. This also gives support to the RHM that claims that the connections between forms and concepts are weak in languages where proficiency is low (Kroll \& Stewart 1994). As regards reaction times, form-based associations in Italian were slower compared to the other association categories. This could be explained, either by the fact that phonological or orthographic links were less strong compared to semantically related links, or by the fact that participants started out by looking for a semantically related word, failed and instead chose an orthographically or phonologically similar word. The latter explanation implies that semantic, as well as and orthographic and phonological links could be equally strong, but that participants performed additional steps when making a form-based association. 


\section{Anna Gudmundson}

Collocations were mainly produced in L1 Swedish,and rarely in L2 English or in L3 Italian. It thus seems that the use of collocational links is something that characterizes L1 behavior and makes it different from other languages learned. Fitzpatrick (2006) found that collocational responses were more common in native speakers compared to non-native speakers and that no correlation as concerns the proportion of collocations between learners at different proficiency levels was revealed. This result was replicated in the present study in the sense that participants produced significantly more collocational responses in L1 Swedish compared to both L2 English and L3 Italian. No difference was found between L2 English and L3 Italian, despite the fact that proficiency was generally higher in L2 English. These results are consistent with chunking theories (e.g. Ellis 1996; Wray 2002) that consider language, due to processing advantages, to be stored in chunks. These chunks are processed faster as a result of frequency of practice. According to Sinclair (1991: 110), "[a] language user has available to him or her a large number of semi-preconstructed phrases", but Wray (2002) claims that this is true for native speakers only; native speakers store language in bigger chunks, while non-native speakers retrieve them word by word. This has also been confirmed by research on advanced L2 speakers that show that collocations are learned late during the acquisition phase (for an overview see Erman et al. 2016). As far as reaction times are concerned, according to Erman et al. (2016: 141), formulaic sequences are processed more quickly than non-formulaic sequences and, even though processing times are generally slower for non-native speakers, this observation holds true for both native and non-native speakers. The present study confirmed this; collocational associations obtained the second fastest response times. It is interesting to notice that no differences in reaction times for collocational associations were observed between English and Swedish, i.e. even if collocational associations were much more common in the Swedish data, when they appeared in English, reaction times were not different from the ones obtained in Swedish. Fastest reaction times in total were obtained when the association category was of the dual-link response type meaning and collocation. Among the associations belonging to the dual-link category meaning and collocation we find uovo - gallina ('egg' - 'hen'), uomo - donna ('man' - 'woman'), dawn - dusk, nail - finger, body-soul, korv-bröd ('hot dog' - 'bread'), nyckel dörr ('key' - 'door') tröja-polo ('sweater' - 'polo'). These words are connected to each other both by the fact that they often co-occur syntagmatically in language, but also by the fact that they share some kind of equivalent meaning such as hyperonymy, iperonymy or partonymy. They are, so to say, well-rehearsed and connected by strong semantic links. The fact that reaction times were similar in all languages implies that fluency for some lexical connections in additional languages can be at the same level as those of native speakers. 
Cremer et al. (2010) pointed out that it was still uncertain to what extent L1 or L2 speakers act as homogeneous groups and how their word association responses distribute over different response categories. Cremer et al. also observed that even less is known about word association patterns in multilinguals. Overall, in the present study, results in the three languages were similar in nature, and the observed differences could be attributed to quantitative or developmental differences rather than to qualitative differences related to processing mechanisms or representation. Reaction times increase in the following order, if form-based relations and form and meaning relations are excluded: meaning and collocation, collocation, equivalent meaning and non-equivalent meaning. The fact that associations generally were produced faster in L1 Swedish, followed by L2 English and L3 Italian, respectively should be attributed to differences in fluency, or proficiency, and not to differences in processing itself. Other differences in association behavior that could be attributed to developmental changes or proficiency were the shift from non-equivalent meaning associations to equivalent meaning associations with language status, the high proportion of form-based associations in L3 Italian compared to the other two languages, and the high proportion of collocational associations in L1 Swedish compared to the two non-native languages. The results suggest a developmental trend that is similar, but not identical, to the one discussed by Ellis (1996: 94) who states that in the mental lexicon: "both [in] the L1 and L2, lexical items are first represented as ordered phonological strings then there is a focus on their collocations and their sequential probabilities in word strings, and only later are these patterns of occurrence analyzed to allow syntactic and semantic classification."

Results from the present study actually suggest a slightly different progression, where semantic classification precedes the focus on sequential probabilities, i.e. learners seem to be able to create strong semantic networks without being able to handle collocations and collocational probabilities, even if they are produced fast when they do occur. Daller et al. (2007) propose a three-dimensional model to illustrate word knowledge. The three dimensions - breadth, fluency and depth constitute a so-called lexical space in which the lexical knowledge of a learner can be located. They argue that some learners might, for example, show a high degree of fluency, but poor lexical breadth, or large vocabularies, but poor fluency. In what follows, a model of the developing mental lexicon composed of four different dimensions - vocabulary breadth and depth, fluency, proficiency and association category - is proposed, but it must be understood as hypothetical (Figure 4.5).

The model proposed in Figure 4.5 suggests that the connections in the mental lexicon grow in four steps in relation to increasing vocabulary breadth and 
1

Few semantic links Mainly form-based links available

2

Building of semantic links to words with remantic links to words with related, but not necessarily equivalent, meanings
Building of semantic links to words with equivalent meanings
Building of semantic links to words that often co-occur backward or forward

Fluency

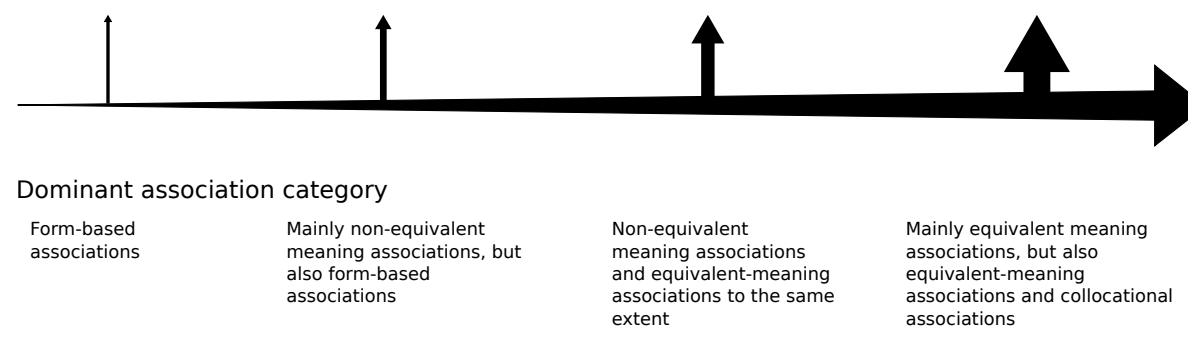

Figure 4.5: Model of the developing mental lexicon.

depth. As discussed in §1.1, these two categories are interdependent and develop in parallel - growing breadth also leads to growing depth. These steps are not to be viewed as discrete phases but rather as a continuum. The learner starts from building form-based links in the first phase since no or few semantic links are available when a word is unknown. In this step, mostly form-based associations can be performed (book-hook). In the second step, due to increasing vocabulary breadth and depth, the learner starts to create semantic relations between words with related meanings or to words that appear in the same semantic context (book-glasses). Due to a limited vocabulary, few links to words with equivalent meanings, such as synonyms, are available, and therefore associations are mostly of non-equivalent meaning. In the third phase, the number of words known by a learner has increased enough to include connections between words with equivalent meanings and the learner can start to produce associations based on synonymy or partonymy (book-volume or book-pages). In the last phase, learners start to build collocational links to words that normally co-occur backward or forward and the amount of collocational word associations increases (book-title). Fluency works in two different dimensions. The first dimension is related to language proficiency and is represented by the horizontal arrow. It presupposes that learners get more fluent and automatic in their word retrieval as they get more proficient. The second dimension of fluency is related to the different kinds of 
association categories or lexical links in the mental lexicon, and is represented by vertical arrows. Some associations, such as the one of equivalent meaning type, are produced faster due to large semantic overlap or frequent co-occurrence, and therefore represented with thicker arrows. The distinction between two different fluency dimensions might explain why some associations are faster than others within a language, but also differences between languages and as such differences related to proficiency. A collocational association such as book-title, if produced by a low proficiency language learner with poor fluency, might be faster than a non-equivalent meaning association such as book-glasses, if produced by a more proficient language learner of the same language or even by a native speaker. Speed of association, and therefore fluency, is not only a question of proficiency but also a question of association category. According to the model in Figure 4.5, the lexical development of the various languages known by a learner might have reached different phases. In the present study, for example, the L1 could be said to have reached phase, 4 while the L2 could be said to have reached phase 3 . The $\mathrm{L} 3$, on the other hand, seems to have reached only phase 2 .

\subsection{Long-term semantic priming and lexical mediation between the L3 and the L2}

The LDT reported in this study proved that during L3 production that required semantic activation (the word association task in L3), the corresponding L2 translation equivalent was unconsciously activated. Most likely, the L1 translation equivalent was also activated, but this effect is not controlled for in this study. This research is in line with results in the bilingual domain and can now be extended to a multilingual context and to a new language combination. Both Fitzpatrick \& Izura (2011) and Li et al. (2009) found an effect of long-term crosslanguage semantic priming between L2 and L1 that indicated that during L2 conceptual processing, the corresponding L1 translation equivalent had also been activated. Both interpreted the results in favor of the RHM, i.e. that L1 has a special status in acting as conceptual mediator in low proficient L2 users. The mediating effect of the L1 during the word association task postulated by Fitzpatrick \& Izura (2011) was depicted in the way presented in Figure 4.6.

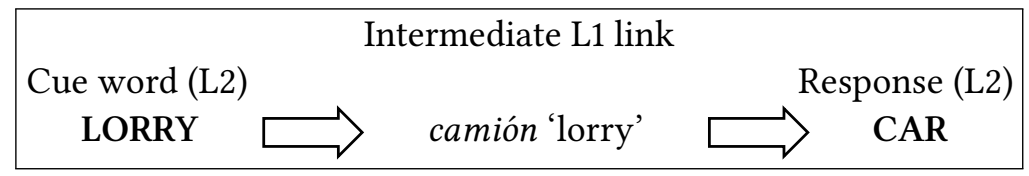

Figure 4.6: Mediation effect of the L1 Spanish during the L2 English word association task. Adapted from Fitzpatrick \& Izura (2011). 


\section{Anna Gudmundson}

In the present study, a priming effect of 26.45 milliseconds was observed between L3 and L2 in the LDT, which was similar to the one obtained by Fitzpatrick \& Izura of 20 milliseconds between L2 and L1. If we assume that conceptual access proceeds in the way postulated by the RHM (i.e., that L1 mediates conceptual access in a later learned language), it needs to be added to the model that also another non-native language could fill the same function. Such a model would look like the one presented below in Figure 4.7.

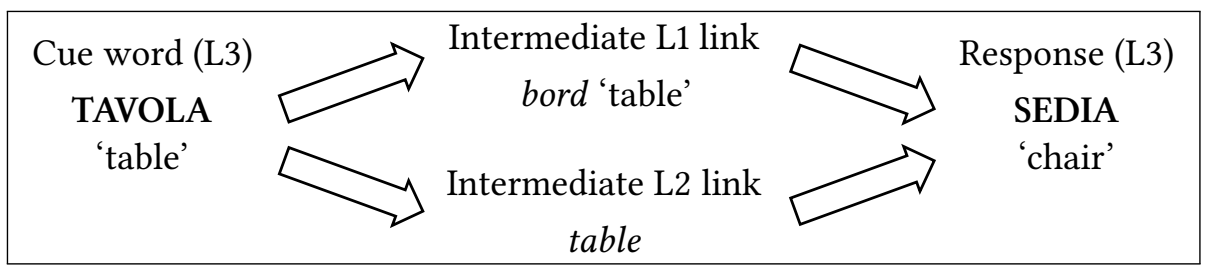

Figure 4.7: Mediation effect of the L2 and the L1 during the L3 word association task.

Abunuwara (1992) favored a model where all non-native languages relate and depend on L1 only, but the present results could be said to imply that L1 is not unique or qualitatively different from an L2 when it comes to mediating semantic access. As stated by Szubko-Sitarek, "it seems legitimate to say that the native language does not always have a privileged status" (2011: 170).

Generally, in studies of multilingual lexical processing, the L3 is the weakest language, which makes it difficult to distinguish between language status and proficiency, and this is the case in the present study. We cannot know whether the results are due to the fact that English was learned before Italian or due to the fact that proficiency was higher in English. Goral et al. suggest that "a third language (L3) may be learned in connection with a previously learned non-native language (L2), and thus develop strong lexical connections with that language" (2006: 244), and that might be independent of proficiency. It can also be added that we do not know anything about the size of the different arrows in Figure 4.7. It might be, for example, that the effect is stronger in the L1 compared to the L2, but it must be noted that that the priming effect, expressed in milliseconds, was slightly higher in this study compared to the study by Fitzpatrick \& Izura (2011).

It is difficult to understand how the RHM would account for multilingualism and how to adapt it to a situation with more than one non-native language. How would the relation between the non-native languages be represented, and when translating between two non-native languages, what would be considered backward and forward translation respectively? Few studies treat the relation 
between L2 and L3, and more research is needed to understand how and what kind of connections develop between an L3 and a speaker's L1 and L2 respectively from a coordinate or subordinate approach. Results in the present study are more easily explained by a model such as the BIA+ that presupposes activation spreading and co-activation of all known languages. The non-selective access approach is also supported by studies on the cognate effect in trilinguals (Lemhöfer et al. 2004; Szubko-Sitarek 2011). A general problem with the BIA+ model is that it does not take into account proficiency, language status and typology, factors that all seem to play a crucial role in multilingual lexical access. A future model of multilingual language processing would benefit from incorporating these factors.

\section{Conclusion}

Results in the present study of the mental lexicon of multilingual speakers point in the direction that lexical representations, access and development proceed similarly in all languages known by a trilingual language user, and that the L1 is not qualitatively different from non-native languages. Differences in association behavior (i.e., the proportion of associations in the different categories) and the speed with which associations are produced are best explained by proficiency and fluency, i.e. by the fact that languages have reached different phases in their overall and lexical development. Results also favor non-selective access and coactivation of all languages during processing. A long-term semantic priming effect was found between L3 and L2 that proved that, during L3 lexical access, the L2 was activated. This does not exclude the possibility that the corresponding L1 semantic and lexical representations were also active.

Future studies would benefit from collecting data that can discriminate language status from proficiency, i.e. studying participants whose weakest language is the L2 and not the L3, but also data that can shed light on the role of both L1 and L2 when processing L3, or the role of L3 when processing L2 or L1. The present study has only investigated high frequency nouns and in the future, besides controlling for proficiency in L2 and L3, it would be useful to investigate other word types with various frequencies.

\section{References}

Abunuwara, Ehab. 1992. The structure of the trilingual lexicon. European fournal of Cognitive Psychology 4(4). 311-322. DOI: 10.1080/09541449208406190. 


\section{Anna Gudmundson}

Agresti, Alan. 2013. Categorical data analysis (3rd edition). Hoboken: Wiley.

Aitchison, Jean. 2012. Words in the mind: An introduction to the mental lexicon. Hoboken: Wiley-Blackwell.

Bird, Helen, Sue Franklin \& David Howard. 2001. Age of acquisition and imageability ratings for a large set of words, including verbs and function words. Behavior Research Methods, Instruments and Computers 33(1). 73-79.

Burani, Cristina, Laura Barca \& Lisa S. Arduino. 2001. Una base di dati sui valori di età di acquisizione, frequenza, familiarità, immaginabilità, concretezza, e altre variabili lessicali e sublessicali per 626 nomi dell'italiano. Giornale Italiano di Psicologia 4. 839-854.

Cenoz, Jasone, Britta Hufeisen \& Ulrike Jessner (eds.). 2001. Crosslinguistic influence in third language acquisition. Clevedon: Multilingual matters.

Cenoz, Jasone, Britta Hufeisen \& Ulrike Jessner (eds.). 2003. The multilingual lexicon. Dordrecht: Kluwer Academic Publishers.

Chen, Hsuan-Chin \& Connie Ho. 1986. Development of stroop interference in Chinese-English bilinguals. fournal of Experimental Psychology: Learning, Memory, and Cognition 12(3). 397-401.

Clenton, Jon. 2015. Testing the revised hierarchical model: Evidence from word associations. Bilingualism: Language and Cognition 18(1). 118-125.

Cohen, Jacob. 1988. Statistical power analysis for the behavioral sciences (2nd edition). Hillsdale, NJ: Erlbaum.

Coltheart, Max. 1981. The MRC Psycholinguistic Database. Quartly fournal of Experimental Psychology 33A(4). 497-505.

Costa, Albert. 2005. Lexical access in bilingual production. In Judith F. Kroll \& Annette M. B. De Groot (eds.), Handbook of bilingualism: Psycholinguistic approaches, 308-325. Oxford: Oxford University Press.

Cremer, Marjolein, Daphne Dingshoff, Meike De Beer \& Rob Schoonen. 2010. Do word associations assess word knowledge? A comparison of L1 and L2, child and adult word associations. International fournal of Bilingualism 15(2). 187204.

Daller, Helmut, James Milton \& Jeanine Treffers-Daller. 2007. Editors' introduction. In Helmut Daller, James Milton \& Jeanine Treffers-Daller (eds.), Modelling and assessing vocabulary knowledge, 1-32. Cambridge: Cambridge University Press.

De Angelis, Gessica. 2007. Third or additional language acquisition. Clevedon: Multilingual Matters.

De Angelis, Gessica, Ulrike Jessner \& Marijana Kresić (eds.). 2015. Crosslinguistic influence and crosslinguistic interaction in multilingual language learning. London: Bloomsbury Academic. 
De Groot, Annette M. B. \& Gerard L. J. Nas. 1991. Lexical representation of cognates and noncognates in compound bilinguals. Journal of Memory and Language 30(1). 90-123.

DeKeyser, Robert M. 2007. Introduction: Situating the concept of practice. In Robert M. DeKeyser (ed.), Practice in a second language: Perspectives from applied linguistics and cognitive psychology, 208-226. Cambridge: Cambridge University Press.

Dell, Gary S. \& Padraig G. O’Seaghdha. 1991. Mediated and convergent lexical priming in language production: A comment on levelt et al. (1991). Psychological Review 98(4). 604-614.

Dell, Gary S. \& Padraig G. O’Seaghdha. 1992. Stages of lexical access in language production. Cognition 42. 287-314.

Dijkstra, Ton. 2003. Lexical processing in bilinguals and multilinguals. In Jasone Cenoz, Britta Hufeisen \& Ulrike. Jessner (eds.), The multilingual lexicon, 11-26. Dordrecht: Kluwer Academic Publisher.

Dijkstra, Ton. 2005. Bilingual visual word recognition and lexical access. In Judith F. Kroll \& Annette M. B. De Groot (eds.), Handbook of bilingualism: Psycholinguistic approaches, 179-201. Oxford: Oxford University Press.

Dijkstra, Ton, Koji Miwa, Bianca Brummelhuis, Maya Sappelli \& Harald Baayen. 2010. How cross-language similarity and task demands affect cognate recognition. Fournal of Memory and Language 62. 284-301.

Dijkstra, Ton \& Walter J. B. Van Heuven. 1998. The BIA model and bilingual word recognition. In Jonathan Grainger \& Arthur M. Jacobs (eds.), Localist connectionist approaches to human cognition, 189-225. Mahwah: Erlbaum.

Dijkstra, Ton \& Walter J. B. Van Heuven. 2002. The architecture of the bilingual word recognition system: From identification to decision. Bilingualism: Language and Cognition 5. 175-197.

Duyck, Wouter \& Marc Brysbaert. 2002. What number translation studies can teach us about the lexico-semantic organisation in bilinguals. Psychologica Belgica 42(3). 151-176.

Duyck, Wouter, Isabel Depestel \& Bert Reynvoet. 2008. Cross-lingual numerical distance priming with second-language number words in native-to thirdlanguage number word translation. The Quarterly fournal of Experimental Psychology 61(9). 1281-1290.

Ellis, Nick C. 1996. Sequencing in SLA: Phonological memory, chunking, and points of order. Studies in Second Language Acquisition 18. 91-126.

Entwisle, Doris M., Daniel F. Forsyth \& Rolf Muus. 1964. The syntagmaticparadigmatic shift in children's word associations. fournal of Verbal Learning and Verbal Behavior 3. 19-29. 


\section{Anna Gudmundson}

Erman, Britt, Fanny Forsberg Lundell \& Margareta Lewis. 2016. Formulaic language in advanced second language acquisition and use. In Kenneth Hyltenstam (ed.), Advanced proficiency and exceptional ability in second languages, 111-147. Berlin: De Gruyter Mouton.

Ervin, Susan M. 1961. Changes with age in the verbal determinants of word association. American fournal of Psychology 74(3). 361-372.

Field, Andy, Jeremy Miles \& Zoë Field. 2012. Discovering statistics using R. Los Angeles, CA: Sage.

Fitzpatrick, Tess. 2006. Habits and rabbits: Word associations and the L2 lexicon. EUROSLA Yearbook 6. 121-145.

Fitzpatrick, Tess. 2012. Word associations. In Carol A. Chapelle (ed.), The encyclopedia of applied linguistics (online version). Oxford: Wiley-Blackwell. DOI: 10.1002/9781405198431.wbeal1283.

Fitzpatrick, Tess \& Cristina Izura. 2011. Word association in L1 and L2: An exploratory study of response types, response times, and interlingual mediation. Studies in Second Language Acquisition 33(3). 373-398. DOI: 10.1017 / S0272263111000027.

Fitzpatrick, Tess, David Playfoot, Alison Wray \& Margaret J. Wright. 2013. Establishing the reliability of word association data for investigating individual and group differences. Applied Linguistics 36(1). 1-29.

García Mayo, María del Pilar. 2012. Cognitive approaches to L3 acquisition. International fournal of English Studies 12(1). 129-146.

Gilhooly, Ken J. \& Robert H. Logie. 1980. Age-of-acquisition, imagery, concreteness, familiarity, and ambiguity measures for 1,944 words. Behavior Research Methods, Instruments and Computers 12(4). 395-427.

Gollan, Tamar \& Judith F. Kroll. 2003. Bilingual lexical access. In Brenda Rapp (ed.), The handbook of cognitive neuropsychology: What deficits reveal about the human mind, 321-345. Hove: Taylor \& Francis.

Gooskens, Charlotte. 2010. The contribution of linguistic factors to the intelligibility of closely related languages. Journal of Multilingual and Multicultural Development 28(6). 445-467.

Goral, Mira, Erika S. Levy, Loraine K. Obler \& Eyal Cohen. 2006. Cross-language lexical connections in the mental lexicon: Evidence from a case of trilingual aphasia. Brain and Language 98. 235-247.

Grainger, Jonathan \& Ton Dijkstra. 1992. On the representation and use of language information in bilinguals. In Richard J. Harris (ed.), Cognitive processing in bilinguals, 207-220. Amsterdam: Elsevier Science Publishers.

Green, David W. 1986. Control, activation, and resource: A framework and a model for the control of speech in bilinguals. Brain and Language 27. 210-223. 
Green, David W. 1998. Mental control of the bilingual lexico-semantic system. Bilingualism: Language and Cognition 1. 67-81.

Grosjean, François. 1997. Processing mixed language: Issues, findings and models. In Annette M. B. De Groot \& Judith F. Kroll (eds.), Tutorials in bilingualis: Psycholinguistic perspectives, 225-254. Mahwah: Erlbaum.

Grosjean, François. 2001. The bilingual's language modes. In Janet Nicol (ed.), One mind, two languages: Bilingual language processing, 1-22. Oxford: Blackwell.

Gustafson-Capková, Sofia \& Britt Hartmann. 2006. Manual of the Stockholm Umeå Corpus version 2.0: Description of the content of the SUC 2.0 distribution, including the unfinished documentation by Gunnel Källgren. Stockholm.

Haastrup, Kirsten \& Birgit Henriksen. 2000. Vocabulary acquisition: Acquiring depth of knowledge through network building. International fournal of Applied Linguistics 10(2). 221-240.

Hammarberg, Björn. 2014. Problems in defining the concepts of L1, L2 and L3. In Agnieszka Otwinowska \& Gessica De Angelis (eds.), Teaching and learning in multilingual contexts: Sociolinguistic and educational perspectives, 3-18. Clevedon: Multilingual Matters.

Herwig, Anna. 2001. Plurilingual lexical organisation: Evidence from lexical processing in L1-L2-L3-L4 translation. In Jasone Cenoz, Britta Hufeisen \& Ulrike Jessner (eds.), Cross-linguistic influence in third language acquisition: Psycholinguistic perspective, 115-137. Clevedon: Multilingual Matters.

Hulstijn, Jan, Amos Van Gelderen \& Rob Schoonen. 2009. Automatization in second language acquisition: What does the coefficient of variation tell us? Applied Psycholinguistics 30(4). 555-582.

Jin, Young S. 1990. Effects of concreteness on cross-language priming in lexical decision. Perceptual and Motor Skills 70(3). 1139-1154.

Keijzer, Merel. 2007. Last in first out? An investigation of the regression hypothesis in Dutch emigrants in Anglophone Canada. Vrije Universiteit. (dissertation).

Khazaeenezhad, Bahareh \& Ahmad Alibabaee. 2013. Investigating the role of L2 language proficiency in word association behaviour of L2 learner: A case of Iranian EFL learners. Theory and Practice in Language Studies 3(1). 108-115.

Kras, Tihana. 2007. L2 acquisition of the lexicon-syntax interface and narrow syntax by child and adult Croatian learners of Italian. University of Cambridge. (dissertation).

Kroll, Judith F. \& Janet Curley. 1988. Lexical memory in novice bilinguals: The role of concepts in retrieving second language words. In Michael Grunneberg, Peter Morris \& Robert. Sykes (eds.), Practical aspects of memory: Current research and issues, vol. 2, 389-395. Chichester: John Wiley \& Sons. 


\section{Anna Gudmundson}

Kroll, Judith F. \& Annette M. B. De Groot (eds.). 2005. Handbook of bilingualism: Psycholinguistic approaches. Oxford: Oxford University Press.

Kroll, Judith F. \& Erika Stewart. 1994. Category interference in translation and picture naming: Evidence for asymmetric connections between bilingual memory representations. fournal of Memory and Language 33(2). 149-174. DOI: 10. 1006/jmla.1994.1008.

Kroll, Judith F., Janet G. van Hell, Natasha Tokowicz \& David W. Green. 2010. The revised hierarchical model: A critical review and assessment. Bilingualism 13(3). 373-381. DOI: 10.1006/jmla.1994.1008.

Kruse, Heleen, James Pankhurst \& Michael Sharwood Smith. 1987. A multiple word association probe in second language acquisition research. Studies in Second Language Acquisition 9. 141-154.

Krzeminska-Adamek, Malgorzata. 2014. Word association patterns in a second/foreign language: What do they tell us about the L2 mental lexicon. Lublin Studies in Modern Language and Literature 38(1). 141-153.

La Heij, Wido. 2005. Selection processes in monolingual and bilingual lexical access. In Judith F. Kroll \& Annette M. B. De Groot (eds.), Handbook of bilingualism: Psycholinguistic approaches, 289-307. Oxford: Oxford University Press.

Lemhöfer, Kristin \& Ton Dijkstra. 2004. Recognizing cognates and interlingual homographs: Effects of code similarity in language-specific and generalized lexical decision. Memory \& Cognition 32(4). 533-550.

Lemhöfer, Kristin, Ton Dijkstra \& Marije C. Michel. 2004. Three languages, one ECHO: Cognate effects in trilingual word recognition. Language and Cognitive Processes 19(5). 585-611.

Levelt, Willem J. M. 1989. Speaking: From intention to articulation. Cambridge, MA: MIT Press.

Levelt, Willem J. M. 1992. Accessing words in speech production: Stages, processes and representations. Cognition 42. 1-22.

Levelt, Willem J. M., Dirk Vorberg, Thomas Pechmann, Antje S. Meyer \& Jaap Havinga. 1991. The time course of lexical access in speech production: A study of picture naming. Psychological Review 98(1). 122-142. DOI: 10.1037/0033295X.98.1.122.

Levelt, Willem J. M., Dirk Vorberg, Thomas Pechmann, Herbert Schriefers, Antje S. Meyer \& Jaap Havinga. 1991. Normal and deviant lexical processing: Reply to Dell and O'Seaghdha (1991). Psychological Review 98(4). 615-618.

Li, Li, Lei Mo, Ruiming Wang, Xueying Luo \& Zhe Chen. 2009. Evidence for long-term cross-language repetition priming in low fluency Chinese-English bilinguals. Bilingualism: Language and Cognition 12(1). 13-21. 
Linck, Jared A., John W. Schwieter \& Gretchen Sunderman. 2012. Inhibitory control predicts language switching performance in trilingual speech production. Bilingualism: Language and Cognition 15(3). 651-662.

Lind, Marianne, Hanne G. Simonsen, Pernille Hansen, Elisabeth Holm \& BjørnHelge Mevik. 2013. "ordforrådet": En leksikalsk database over et utvalg norske ord. Norsk tidsskrift for logopedi 59(1). 18-26.

Marian, Viorica, Henrike K. Blumenfeld, Elena Mizrah, Ursula Kania \& AnneKristin Cordes. 2013. Multilingual stroop performance: Effects of trilingualism and proficiency on inhibitory control. International fournal of Multilingualism 10(1). 84-104.

Meara, Paul. 1978. Learners' word associations in French. Interlanguage Studies Bulletin 3(2). 192-211.

Nation, Paul. 2001. Learning vocabulary in another language. Cambridge: Cambridge University Press.

Paivio, Allan, John C. Yuille \& Stephen A. Madigan. 1968. Concreteness, imagery, and meaningfulness values for 925 nouns. fournal of Experimental Psychology 76(1). 1-25.

Pellicer-Sánchez, Ana. 2015. Developing automaticity and speed of lexical access: The effects of incidental and explicit teaching approaches. Fournal of Spanish Language Teaching 2(2). 126-139.

Politzer, Robert L. 1978. Paradigmatic and syntagmatic associations of first-year French students. In Vlademir Honsa \& Martha J. Harman-De-Bautista (eds.), Papers on linguistics and child language: Ruth Hirsch Weir memorial volume, 202-210. The Hague: Mouton.

Postman, Léo \& Geoffrey Keppel (eds.). 1970. Norms of word associations. New York: Academic Press.

Potter, Mary C., Kwok-Fai So, Barbara Von Eckardt \& Laurie B. Feldman. 1984. Lexical and conceptual representation in beginning and proficient bilinguals. fournal of Verbal Learning and Verbal Behavior 23. 23-38.

Poulisse, Nanda. 1997. Language production in bilinguals. In Annette M. B. De Groot \& Judith F. Kroll (eds.), Tutorials in bilingualism: Psycholinguistic perspectives, 201-224. Mahwah: Erlbaum.

Rastle, Kathleen, Jonathan Harrington \& Max Coltheart. 2002. 358,534 nonwords: The ARC nonword database. Quartly fournal of Experimental Psychology A 55(4). 1339-1362.

Read, John. 2004. Plumbing the depths: How should the construct of vocabulary knowledge be defined? In Paul Bogaards \& Batia Laufer (eds.), Vocabulary in a second language: Selection, acquisition and testing, 209-227. Amsterdam: John Benjamins. 


\section{Anna Gudmundson}

Riegel, Klaus F. \& Irina W. M. Zivian. 1972. A study of inter- and intralingual associations in English and German. Language Learning 21(1). 51-63.

Sánchez Casas, Rosa M., Christopher W. Davis \& José E. García Albea. 1992. Bilingual lexical processing: Exploring the cognate/noncognate distinction. European fournal of Cognitive Psychology 4. 293-310.

Schmitt, Norbert. 2010. Researching vocabulary: A vocabulary research manual. Basingstoke: Palgrave Macmillan.

Schoonbaert, Sofie, Wouter Duyck, Marc Brysbaert \& Robert J. Hartsuiker. 2009. Semantic and translation priming from a first language to a second and back: Making sense of the findings. Memory \& Cognition 37. 569-586.

Schwieter, John W. \& Gretchen Sunderman. 2011. Inhibitory control processes and lexical access in trilingual speech production. Linguistic Approaches to Bilingualism 1(4). 391-412.

Segalowitz, Norman \& Jan Hulstijn. 2005. Automaticity in bilingualism and second language learning. In Judith. F. Kroll \& Annette. M. B. De Groot (eds.), Handbook of bilingualism: Psycholinguistic approaches, 371-388. Oxford: Oxford University Press.

Segalowitz, Norman \& Sidney Segalowitz. 1993. Skilled performance, practice, and the differentiation of speek-up from automatization effects: Evidence from second language word recognition. Applied Psycholinguistics 14(3). 369-385.

Sinclair, John. 1991. Corpus, concordance, collocation. Oxford: Oxford University Press.

Singleton, David. 2003. Perspectives on the multilingual lexicon: A critical synthesis. In Jasone Cenoz (ed.), The multilingual lexicon, 167-176. Dordrech: Kluwer Academic Publisher.

Stolz, Walter S. \& Janice Tiffany. 1971. The production of "child-like" word associations by adults to unfamiliar adjectives: A research and training program in selected aspects of lexical and syntactic development in the mentally retarded. Interim report ED059572.

Szubko-Sitarek, Weronika. 2011. Cognate facilitation effects in trilingual word recognition. Studies in Second Language Learning and Teaching 1(2). 189-208.

Szubko-Sitarek, Weronika. 2015. Multilingual lexical recognition in the mental lexicon of third language users. Berlin: Springer.

Van Heuven, Walter J. B., Kathy Conklin, Emily L. Coderre, Taomei Guo \& Ton Dijkstra. 2011. The influence of cross-language similarity on within- and betweenlanguage Stroop effects in trilinguals. Frontiers in Psychology 2. 1-15.

Van Heuven, Walter J. B., Ton Dijkstra \& Jonathan Grainger. 1998. Orthographic neighbourhood effects in bilingual word recognition. fournal of Memory and Language 39(3). 458-483. 
van Hell, Janet G. \& Annette M. B. De Groot. 1998. Conceptual representation in bilingual memory: Effects of concreteness and cognate status in word association. Bilingualism: Language and Cognition 1(3). 193-211.

Verspoor, Marjolijn. 2008. What bilingual word associations can tell us. In Frank Boers \& Seth Lindstromberg (eds.), Cognitive linguistic approaches to teaching vocabulary and phraseology, 261-290. Berlin: Mouton de Gruyter.

Wagenmakers, Eric-Jan, René Zeelenberg, David Huber, Jeroen Raaijmakers, Richard M. Shiffrin \& Lael J. Schooler. 2003. Quantitative models for longterm and short-term priming in perceptual identification. In Jeffrey Bowers \& Chad Marsolek (eds.), Rethinking implicit memory, 105-123. Oxford: Oxford University Press.

Weinreich, Uriel. 1953. Language in contact: Findings and problems. New York, NY: Linguistic Circle of New York.

Wilson, Michael D. 1988. Psycholinguistic database: Machine readable dictionary, version 2. Behavior Research Methods, Instruments and Computers 20(1). 6-11.

Wolter, Brent. 2001. Comparing the 11 and 12 mental lexicon: A depth of individual word knowledge model. Studies in Second Language Acquisition 23. 41-69.

Wray, Alison. 2002. Formulaic language and the lexicon. Cambridge: Cambridge University Press.

Wu, Zhaohong \& Alan Juffs. 2019. Revisiting the revised hierarchical model: Evidence for concept mediation in backward translation. Bilingualism: Language and Cognition 22(2). 285-299.

Zareva, Alla. 2007. Structure of the second language mental lexicon: How does it compare to native speakers' lexical organization? Second Language Research 23(2). 123-153.

Zeelenberg, René \& Diane Pecher. 2003. Evidence for long-term cross-language repetition priming in conceptual implicit memory tasks. Journal of Memory and Language 49(1). 80-94. 



\title{
Chapter 5
}

\section{The acquisition of clitic pronouns in complex infinitival clauses by}

\section{German-speaking learners of Italian as an L3: The role of proficiency in target and background language(s)}

\author{
Sandro Sciutti \\ University of Genoa
}

This paper reports the findings of a study on the acquisition of clitic pronouns in complex infinitival clauses by 20 German-speaking learners of Italian as a third language, German being a language devoid of clitics. The subjects have been grouped on the basis of their proficiency in the target language (intermediate or advanced) and their knowledge of a Romance background language (French or Spanish). Those learners who had knowledge of French were further subdivided into low and high proficiency with respect to second language (L2) French. The same was not possible for learners with a background in Spanish, because of the absence of subjects with low proficiency in L2 Spanish. Performances in three experimental tests - an elicited production, a grammaticality judgment/correction task and a written translation from German into Italian - have been comparatively analysed to determine whether the acquisition of Italian clitics in complex clauses containing an infinitive is in any way affected by 1) proficiency in L3 Italian; 2) the specific Romance L2 (French vs. Spanish) and 3) proficiency in L2 French. In particular, the analysis has focused on three main aspects: 1) overall clitic production and adoption of avoidance strategies; 2) production of specific clitic categories (primarily partitive and locative clitics); 3) clitic placement. 


\section{Introduction}

Complement clitic pronouns have been repeatedly shown as one of the trickiest grammatical features to acquire among all learner populations (e.g., Belletti \& Guasti 2015). This fact is supported by a wide array of empirical research carried out on all kinds of subjects: normally developing children, children with Specific Language Impairment, bilingual children, early and adult second language (L2) learners. When it comes to Italian, this general difficulty is compounded by the fact that clitic placement is fairly complex in infinitival clauses, since clitics can occur either in an enclitic position in relation to the infinitive or in a proclitic position with regard to the finite verb governing the infinitive, as a result of a climbing movement. For this reason, L2 acquisition of Italian clitics - as is the focus of this article - can prove rather demanding.

This study was carried out within the framework of the wide-ranging research field of multilingualism and, more specifically, of additional or third language acquisition (TLA or L3A), an L3 being a non-native language acquired after one or more L2s, in line with the definition given by Hammarberg (2010: 97). Some parallel terms used in the literature are those of Ln, subsequent language, additional language, multilingual acquisition and multiple language acquisition. From this viewpoint, Italian as a non-native language, particularly abroad, is mostly learnt as an L3, after learners have already been confronted with other non-native language learning experiences: it is more often than not the case of English, but also of another Romance language like Spanish or French.

As far as clitic acquisition in non-native Italian is concerned, the potential role of another non-native language that has clitics remains to be further explored, as does the effect of proficiency level in that other non-native language (Giannini 2008: 238-239). French and Spanish as "bridge" languages between a first language (L1) and L3 Italian may provide interesting matter for comparison in this sense, although both are equipped with clitics, they differ in terms of both repertoire and placement in complex infinitival clauses. In terms of level of proficiency in the background Romance language, the consequences of its variation on the acquisition of Italian as an L3 must be thoroughly investigated, in order to ascertain whether a sound mastery in an L2 results in a higher degree of crosslinguistic influence between L2 and L3.

\section{Crosslinguistic information}

As the current study looks at German-speaking learners of L3 Italian with prior knowledge of another Romance language (Spanish or French), it is useful to pro- 
vide some information about pronouns in the languages involved in the research, in terms of both repertoire and syntax within infinitival clauses.

\subsection{Repertoire of clitic pronouns in Italian, French and Spanish}

Like all Romance languages, Italian, French and Spanish possess accusative, dative and reflexive clitic pronouns. In addition, both Italian and French have partitive and locative clitics, unlike Spanish. Partitive clitics - like the pronoun ne in Italian - are typically used to replace a noun embedded in a determiner phrase (DP) containing an expression of quantity, as in the following example:

(1) a. Ho incontrato dieci ragazz-i. have.1sg met ten boy-M.PL 'I have met ten boys.'

b. Ne ho incontrat-i dieci. Thereof have.1sg met-M.PL dieci 'I met ten of them.'

Locative clitics, for their part, represent a prepositional phrase with the function of a locative complement, like the Italian $c i$ in the example below:

(2) a. Ho abitato due anni a Firenze.

have.1sg lived two years at Florence

'I lived two years in Florence.'

b. $\mathrm{Ci}$ ho abitato due anni.

There have.1sg lived two years

'I lived there two years.'

\subsection{Pronominal syntax in infinitival clauses}

\subsubsection{Italian}

The infinitival clauses dealt with in the study are of different kinds and are characterised by varied rules as far as clitic placement is concerned. They include:

- Clauses in which the infinitive is governed by either a preposition or a predicate adjective. In these clauses clitics do not climb, as restructuring does not obtain: 
(3) Ho dimenticato di restituir=lo a Giacomo. have.1sG forgotten of give_back=it.M.SG.ACC to Giacomo 'I have forgotten to give it back to Giacomo.'

(4) Non è facile trovar=ne uno economico. not is easy find=thereof one cheap 'It is not easy to find a cheap one.'

- Clauses in which the infinitive is governed by a modal, motion or aspectual verb. In these clauses clitics may climb as a result of restructuring. Unlike modal verbs, motion and aspectual verbs are followed by a preposition:

(5)

a. Vorrei prender=ne un' altra. would_like.1sG take=thereof an.F.SG other.F.SG 'I would like to have another one.'

b. $\mathrm{Ne}$ vorrei prendere un' altra. thereof would_like.1sG take an.F.SG other.F.SG 'I would like to have another one.'

(6) a. I miei genitori sono andati ad abitar=ci. the my parents are gone to live=there 'My parents moved there.'

b. I miei genitori ci sono andati ad abitare. the my parents there are gone to live 'My parents moved there.'

(7) a. Ho iniziato a legger=lo una settimana fa. have.1sG started to read=it.M.SG.ACC one week ago 'I started reading it a week ago.'

b. L' ho iniziato a leggere una settimana fa. M.SG.ACc have.1sG started to read one week ago 'I started reading it a week ago.'

- Causative and perceptive clauses, in which the infinitive is governed by a causative (fare, lasciare) or a perceptive verb (vedere, sentire) and is not preceded by a preposition. In these clauses clitics obligatorily climb, as restructuring occurs: 
(8) Lo faccio lavare in lavanderia. it.M.SG make.1sG wash in laundry 'I'll have it washed in the laundry.'

(9) Non la vedo arrivare. not it.F.SG.ACC see.1sg arrive 'I cannot see it approaching.'

\subsubsection{German}

In German infinitival clauses, pronouns tend to occur to the left, while the infinitive is found at the end of the clause, preceded or not by the preposition $z u$, as shown in the examples (10-13) below. If the infinitive is not preceded by $z u$ (e.g. when the infinitive is governed by a modal, a causative or a perceptive verb) and the tense of the finite verb governing the infinitive is compound, the past participle of that verb is replaced by an infinitive, which occupies the last clausal position, i.e. following the infinitive governed by the finite verb (as in 14 and 15):

(10) Ich habe vergessen, ihn anzurufen.

I have forgotten, him.M.SG.ACc phone

'I have forgotten to phone him.'

(11) Ich will ihm dieses Buch schenken.

I want him.M.SG.DAT this book give

'I would like to give him this book.'

(12) Ich gehe mich waschen.

I go myself.Acc wash

'I'll go and wash myself.'

(13) Ich habe angefangen, es zu lesen.

I have started it.N.SG.ACC to read

'I have started reading it.'

(14) Sie haben mich nicht hinein-gehen lassen.

they have me.Acc not therein-go let

'They did not let me in.'

(15) Ich habe ihn hinaus-gehen sehen.

I have him.M.SG.ACC out-go see

'I saw him go out.' 


\subsubsection{French}

In French infinitival clauses, clitics occur between the finite verb and the infinitive. This holds true both for clauses which could restructure in Italian (17 to 19) and for those which would not (16):

(16) J'ai oublié de l' appeler.

I have forgotten of him.M.SG.Acc call

'I have forgotten to call him.'

(17) Je veux lui offrir ce livre.

I want him.M.SG.DAT give this.M.sG book

'I would like to give him this book.'

(18) Je vais me laver.

I go myself.ACc wash

'I'll go and wash myself.'

(19) J' ai commencé à le lire.

I have started to it.M.SG.ACC read

'I started reading it.'

Causative and perceptive clauses, however, are characterised by clitic climbing, just as in Italian:

(20) Ils ne m' ont pas laissé entrer.

they not me.ACc have not let enter

'They did not let me in.'

(21) Je l' ai vu sortir.

I him.M.SG.ACC have seen go_out

'I saw him go out.'

\subsubsection{Spanish}

In Spanish infinitival clauses, clitic placement always mirrors the one found in Italian:

(22) $\mathrm{He}$ olvidado de llamar=lo.

have.1sG forgotten of call=him.M.SG.ACC

'I saw him go out.' 
(23) a. Quiero regalar=le este libro. want.1sG give $=$ SG.DAT this book 'I would like to give him/her this book.'

b. Le quiero regalar este libro. SG.DAT want.1sG give this book 'I would like to give him/her this book.'

(24) a. Voy a lavar=me. go.1sg to wash=myself.ACc 'I'll go and wash myself.'

b. Me voy a lavar. myself.ACc go.1sG to wash 'I'll go and wash myself.'

(25) a. He empezado a leer=lo.

have.1sG started to read=it.ACC.M.SG

'I have started reading it.'

b. Lo he empezado a leer.

it.ACC.M.SG have.1sg started to read

'I have started reading it.'

(26) No me dejaron entrar. not me.ACC let.3PL.PRET enter 'They did not let me in.'

(27) Lo he visto salir. him.M.SG.ACc have.1SG seen go_out 'I saw him go out.'

\section{Previous research on L2 Italian clitic acquisition}

Several studies have been devoted to the acquisition of pronouns, most notably clitics, in L2 Italian. Berretta (1986) carried out what can be considered in many respects a pioneering work, followed after several years by research by Leonini \& Belletti (2004); Giannini \& Cancila (2006); Santoro (2007); Giannini (2008) and Maffei (2009). These studies share some common findings.

To start with, it can be said that the L2 acquisition of Italian clitic pronouns and more in general that of the clitics of the Romance languages - involves a rather slow and difficult process Bruhn de Garavito \& Montrul (1996); White 


\section{Sandro Sciutti}

(1996); Duffield \& White (1999); Duffield et al. (2002); Santoro (2007). Indeed, in her study, Giannini (2008) found out that the omission rate is high even in advanced learning stages, above all in elicited productions. This finding may reflect an avoidance strategy, which may also encompass the replacement of clitics with lexical DPs or, to a much lesser degree, with strong pronouns Leonini \& Belletti (2004). Similarly, Chini et al. (2003: 191), in comparing the use of clitics as textual anaphoric devices by L1 and L2 Italian speakers, noticed that they are much more resorted to by native speakers than by L2 Italian learners with different L1s. Sheer omission seems to be the most widespread alternative to clitic production in the acquisition of Italian as an L2, its rate ranging from $9 \%$ to $20 \%$ at most Belletti \& Guasti (2015). The use of a lexical DP in a context in which a native speaker would use a clitic is a feature distinguishing L2 from L1 acquisition: whereas it is a strategy quite often employed by L2 learners, it is very rarely found in native language acquisition (Belletti \& Guasti 2015). For instance, Leonini \& Belletti (2004) report that their L2 subjects produced a lexical DP in $40 \%$ of cases, against $7.7 \%$ in the control groups. Likewise, the German-speaking subjects investigated by Leonini (2006) used a lexical DP in $52 \%$ of cases on average. More in detail, the recourse to this strategy decreased as proficiency in Italian increased: lexical DPs were produced in $69 \%$ of cases by subjects with intermediate proficiency in Italian, in $49 \%$ of cases by advanced learners and in $32 \%$ by near-natives. As for the use of strong pronouns in place of clitics, it is something which occurs very rarely in the L2 acquisition of Italian (Belletti \& Guasti 2015).

The relatively slow acquisition of clitics in comparison with other grammar structures is possibly due to the structural complexity of the cliticisation phenomenon and may, therefore, point to a difficulty with processing on the part of the learners. This is maintained by Belletti \& Guasti (2015), who pinpoint the special and complex morphosyntax of clitics as one of the reasons why they tend to be avoided in the early L2 productions. Bottari et al. (2000) identify a series of possible reasons accounting for the difficulty in acquiring clitics (i.e. phonological saliency, argument structure, control, morphological paradigms and syntactic representation), in particular in the field of chain formation. Another reason might be the markedness of clitics from a typological point of view, as highlighted by Berretta (1986: 329).

As to the mistakes made by L2 learners, in most cases, they seem to concern more the morphological features of clitics - number, gender and case - than the syntactic ones (i.e. those related to their placement with respect to the verb). In other words, the former appear to be acquired more slowly and less accurately than the latter. However, some scholars counsel caution in this regard as placement errors amongst L2 learners do not seem to be utterly negligible, as reported 
with French clitics (White 1996; Hulk \& Müller 2000; Belletti \& Hamann 2004; Granfeldt \& Schlyter 2004; Hamann \& Belletti 2006).

Hamann \& Belletti (2006) suggest that misplacement errors found in the L2 acquisition of French clitics may be due to an initial interpretation of complement clitics as weak pronouns, instantiated as nominative phonological clitics in French. The smaller presence of weak pronouns in Italian might account for the reported lack of misplacement errors in Italian (Belletti \& Guasti 2015). However, as rare as they may be, misplacement errors in the L2 acquisition of Italian clitics are not totally lacking. For instance, in her research on the acquisition of personal pronouns in L2 Italian, based on a sample of ADIL2 corpus made up of 823 informants with 27 different L1s, Maffei (2009: 116) mentions cliticisation with imperatives, infinitives, compound tenses and modal verbs amongst the placement errors:

Spero che tu non avrai più paura di ti

hope.1sG that you not have.FUT.2sG more fear of yourself.ACC risvegliare.

wake

'I hope that like this one you will be no more afraid of waking up'

It must be pointed out that some studies on the acquisition of clitics in L2 Italian focused on less complex clauses than, say, the infinitival ones, such as those with a single finite verb conjugated in a simple or compound tense, exhibiting only proclisis (Leonini \& Belletti 2004; Leonini 2006). Turning the attention more closely to instances of pronominal enclisis or to those subject to clitic climbing phenomena, misplacement errors are not entirely negligible. For instance, in the research carried out by Giannini \& Cancila (2006) on nine English-speaking subjects, such phrasal contexts are characterised by the highest rate of mistakes and omissions by the learners. The authors put this result down to the high computational load required by clauses stemming from a twofold syntactic movement. In the same vein, in the corpus collected by Berretta (1986), the otherwise very rare syntactic mistakes to be found are linked with complex infinitival clauses subject to restructuring:

*Vuoi=mi dare il libro, per piacere? want.2SG=meDAT give the book, for pleasure

'Would you please give me the book?'

*Voglio far dir=gli=la. want.1sG make say=sG.DAT=itF.SG.ACC

'I want to get him/her to say it.' 


\section{Sandro Sciutti}

Similar results are found in the research carried out by Bennati \& Matteini (2006) on eighteen L2 Italian learners with different L1s (English, German and Spanish): compared with the almost total lack of placement errors in clauses with a finite verb conjugated in a compound tense, the syntactic mistake rate is far higher in complex infinitival clauses subject to restructuring, such as causative clauses and clauses made up of an infinitive governed by a modal or a motion verb. Similar data can be found in the longitudinal study carried out by Ferrari (2006) on two Italian/German bilingual children (see also Bernardini \& Timofte 2017 and Bernardini \& van de Weijer 2017 for comparable results). Here no syntactic mistakes are reported in clauses made up of a single finite verb (exhibiting pronominal proclisis), in complex infinitival clauses not subject to restructuring and in imperative clauses (both showing pronominal enclisis); however, clitics are often placed - in $63 \%$ and $27 \%$ of the instances found in the two children's productions - between the finite verb and the infinitive in complex infinitival clauses containing a modal verb (where restructuring obtains):

$$
\begin{aligned}
& \text { *Anche tu vuoi lo mangiare? } \\
& \text { also you want.2sG it.M.SG.ACc eat? } \\
& \text { 'Do you want to eat it, too?' } \\
& \text { * Voglio mi mettere. } \\
& \text { want.1sG myself.ACc put } \\
& \text { 'I want to put myself.' }
\end{aligned}
$$

Finally, Corino (2012: 58) too points out that, in the corpus she analysed, the clitic placement errors are mostly found in connection with compound tenses, infinitives and imperatives:

$$
\begin{aligned}
& \text { * } \mathrm{Mi} \text { sembra-va che lui fosse in grado di si liberare. } \\
& \text { me.DAT seemed-IPFv that he was in degree of himself.Acc free } \\
& \text { 'It seemed to me that he was able to free himself.' }
\end{aligned}
$$

As for the role of the learners' prior linguistic knowledge in the acquisition of Italian clitics, whereas that of the L1 has already been investigated in some studies (Berretta 1986; Leonini \& Belletti 2004; Bennati \& Matteini 2006; Giannini \& Cancila 2006; Giannini 2008; Maffei 2009), that of a Romance L2 is still partially unexplored, thus providing the opportunity for further research. However, at least two findings are worth reporting.

The first stems from the research carried out by Leonini \& Belletti (2004) on twenty-six L2 Italian learners with different L1s (German, French, Polish, Dutch, 
Russian, Greek, Albanian and Bosnian). A German-speaking subject in this study (referred to as subject no. 15), reveals, in acquiring Italian clitics, a very different behaviour from the rest of the German-speaking subjects, even though he was exposed to Italian - at first in his home country and then in Italy - not as long as the other subjects with the same L1: his clitic production rate amounts to $87 \%$, compared with the average of German-speaking subjects (22\%). Since this datum cannot be put down to a longer exposure to Italian, the authors suggest that it may be due to the learner's advanced knowledge of L2 Spanish, acquired in fifteen years of school education.

The second finding is found in the research carried out by Corino (2012) on German-speaking learners' L2 Italian. For some productions, the author acknowledges a possible influence of L2 French, as in the use of lui instead of gli (2012: 48):

* Quest' altro lui faceva paura.

this.M.SG other.M.SG him.M.SG.DAT made.3sG.IMPFV fear

'This other scared him.'

* La ragazza lui ha detto: che hai fatto!
the girl him.M.SG.DAT has said what have.2sg done
'The girl told him: what have you done!'

The role of an L2 is, therefore, a research field still in need of further empirical data in order to confirm or downplay the importance that a Romance L2 plays in acquiring Italian clitics.

\section{The current study}

\subsection{Methodology}

\subsubsection{Research design and goals}

The study aims primarily at investigating the role of two Romance L2s - French and Spanish - in the acquisition of clitic pronouns in infinitival clauses by German-speaking learners of Italian. Since clitic pronouns do not exist in German, it may well be that an L2 equipped with clitics, as is the case of French and Spanish, exerts an influence on the acquisition of a similar syntactic category in L3 Italian, be it for the better or the worse. As illustrated in §2 above, despite both being equipped with clitics, French and Spanish also display substantial crosslinguistic differences as regards both repertoire and syntax. In terms of a 


\section{Sandro Sciutti}

comparison with Italian, there are syntactic similarities between Spanish and Italian, while between French and Italian the similarities have to do with the repertoire of the clitics instantiated.

A further goal of the study is probing the role of proficiency in both L3 Italian and L2 French, in an attempt to ascertain whether a varying degree of mastery of L3 Italian or L2 French affects the occurrence of crosslinguistic influence arising from the similarities and differences between L2 and L3.

The study looks into both the production and placement of clitics. As far as the former is concerned, two main questions arise, as follows:

1. As proficiency in either a Romance L2 (French) ${ }^{1}$ or in L3 Italian increases, is the high rate of avoidance strategies - mostly omissions or replacements with lexical DPs - found in previous studies (Chini et al. 2003: 191; Leonini \& Belletti 2004; Leonini 2006; Giannini 2008; Maffei 2009) reduced (with a parallel increase in overall clitic production)?

2. Does prior knowledge of L2 French - as well as a varying degree of proficiency in it - affect the learners' production rates and grammaticality judgments of both partitive and locative clitics (instantiated in French but not in Spanish)?

The question linked to clitic placement is whether prior knowledge of L2 Spanish reduce the occurrence of mistakes in infinitival clauses. This is because, as shown earlier on, clitics are differently placed in French and Italian, whereas in Spanish their placement mirrors the one obtaining in Italian.

\subsubsection{Informants}

The informants were twenty German-speaking learners of Italian enrolled the University of Hamburg, aged between 20 and 47 years old (on average 25.8). Fifteen of them were attending an intermediate course, whereas five of them were attending an advanced course. In order to collect their personal and language background data, the students were asked to fill out a questionnaire, which included, among other things, a self-evaluation of their level of proficiency in L2 French or Spanish. The informants with intermediate proficiency in L3 Italian have therefore been divided into the following three groups on based on their self-rated proficiency in L2 French or Spanish:

\footnotetext{
${ }^{1}$ The effect of varying proficiency in L2 Spanish could not be tested owing to a lack of informants with a suitable profile.
} 
Group 1: five informants with high proficiency in L2 French

Group 2: five informants with high proficiency in L2 Spanish

Group 3: five informants with low proficiency in L2 French

No group of informants with low proficiency in L2 Spanish was formed due to a lack of learners with such a profile. As far as the informants with advanced proficiency in L3 Italian are concerned, these groups were not divided into subgroups according to their prior knowledge of a Romance L2, as the actual focus of the research lay on learners having an intermediate proficiency in L3 Italian. This additional group mainly served the purpose of providing information about the development over time of clitic acquisition in non-native Italian, as proficiency in this language increases. Finally, the control group was made up of 21 Italian-speaking subjects, five of whom with knowledge of L2 German.

\subsubsection{Tasks}

The informants attending an intermediate Italian course carried out the following four tasks:

- An oral elicitation task based on a series of pictures each accompanied by a question

- A written translation task from German into Italian

- An oral grammaticality judgment task (GJT1) made up of 70 Italian sentences

- An oral grammaticality judgment task (GJT2) made up of 48 Italian sentences

The two GJTs were administered in two separate sessions and had a different focus on Italian clitics. The first one tested mainly clitic placement in infinitival clauses, whereas the second one also aimed at gathering information on the learners' competence related to partitive and locative clitics. The informants attending an advanced Italian course carried out all the tasks with the sole exception of the GJT2.

The use of both written and oral tests was meant to vary and balance the nature of the data collected. As pointed out by Bialystok \& Ryan (1985), Montrul (2009) and Ellis (2005) amongst others, in L2 acquisition research written 
tasks performed in absence of time constraints are liable to lead to data linked to learners' explicit or declarative knowledge, whereas oral tasks subject to time constraints are bound to give rise to data shedding light on learners' implicit or procedural knowledge. Also, it was deemed necessary to include oral tasks besides the translation from L1 German into L3 Italian because the latter is liable to give rise to a slightly higher degree of crosslinguistic influence from the subjects' L1 as compared to the elicitation and the GJTs, as noted by Bennati \& Di Domenico (2008) and Tytus (2019), amongst others. ${ }^{2}$

\subsubsection{Elicitation task}

The elicitation task consisted of a PowerPoint presentation containing twentyfour pictures (twelve experimental items and twelve fillers ${ }^{3}$ ), each accompanied by a question, which the subjects could read and hear simultaneously. Every picture was visible on the screen, along with its question, until the subject gave his/her answer. Immediately after that, the next picture appeared on the screen. Before the actual test began, each subject was asked to read the instructions for the task in his/her L1 and went through a training session made up of six items. For each item, the subjects were instructed to repeat a part of the question coloured in red - and not to repeat another part of the question, which was consistently crossed out. The part not to be repeated in the answer was the subject of the sentence in the mock test and in the test fillers (which did not require the production of any complement clitics), while it corresponded to a complement of the infinitival clause for ten experimental items of the actual test. Two experimental items aimed at eliciting reflexive clitics and so the subjects did not have to repeat once more the subject of the sentence - there was no complement which could be replaced by a clitic in this case. Thus the test was designed in such a way as to prompt the production of twelve clitics on the whole. All test items were randomised, so that their order was different for each subject. The following is an example of an experimental item of the test:

(36) Questa è una coppia di fidanzati. Che cosa vuole regalare il this is a couple what thing wants give as present the

ragazzo alla ragazza?

boy to.the girl

'This is a couple. What does the boy want to give the girl?'

\footnotetext{
${ }^{2}$ One suggestion to keep this potentially disturbing factor at bay in future research could be that of having the subjects translate from their L2 into the L3.

${ }^{3}$ For example, the image shown in the experiment for (36-37) is available at https://www.flickr. com/photos/sunumer/3337961554/.
} 
(37) Expected answers:

a. Le vuole regalare un fiore. her want give a flower

b. Vuole regalar=le un fiore. want give=her a flower

He wants to give her a flower.

\subsubsection{Translation task}

The translation task consisted of ten short paragraphs in German to be translated into Italian. In order to maximise the production of clitics in the Italian translation, the German text was equipped with footnotes containing suggestions for the lexical items deemed less accessible to intermediate learners and essential for the translation of the experimental infinitival clauses. ${ }^{4}$ For the same reason, the subjects were allowed to resort to a bilingual dictionary, as the focus of the task was essentially grammatical. Moreover, the task was introduced by a chart showing an example of infinitival clause governed by a causative verb and its translation into Italian, so as to minimise the risk that such clauses, which the subjects may not have been familiar with, were skipped altogether in the translation. The sequence of the paragraphs within the German text was randomised.

\subsubsection{Grammaticality judgment tasks (GJTs)}

The two GJTs consisted of Powerpoint Presentations made up of Italian sentences which the subjects could read on a computer screen and hear simultaneously. Every sentence was visible for seventeen seconds, after which the next sentence appeared on the screen. Before the actual test began, each subject was asked to read the instructions for the task in his/her L1 and went through a training session made up of five items. For each item, the subjects were instructed to say whether the sentence was grammatically correct or not. Additionally, if they found that the sentence was not grammatically correct, they had to identify the mistake and correct it orally. The subjects' responses were recorded and then transcribed in writing for the sake of data analysis. All test items were randomised.

\footnotetext{
${ }^{4}$ The lexical items whose translation into Italian were provided in the footnotes were also chosen by making reference to the word list corresponding to the B1 level of proficiency contained in Spinelli \& Parizzi (2010).
} 


\section{Sandro Sciutti}

\subsubsection{Data analysis}

In order to provide answers to the aforementioned research questions, the data resulting from the subjects' performances in the experimental tasks were compared as follows:

- The group with advanced proficiency in Italian was compared with the group having intermediate proficiency in the same language, irrespective of any L2s known by the subjects. A $t$-test was carried out to ascertain the existence of any statistically significant differences between the results of the two groups.

- Among the intermediate-level learners of Italian, the subgroup with high proficiency in L2 French was compared with the group with high proficiency in L2 Spanish on the one hand and with the group with low proficiency in L2 French on the other. A one-way ANOVA test, followed by a Bonferroni comparison, was carried out to ascertain the existence of any statistically significant differences between the results of the two groups in each case. Given the limited number of subjects in each subgroup and of tokens in each test, though, statistically significant differences - if any - were typically found in omission rates rather than in production ones in both the elicitation and the translation tasks. For the same reason, no statistically significant difference usually emerged from the comparisons involving the production of lexical DPs or the use of other avoidance strategies. ${ }^{5}$

- Still within the group with intermediate proficiency in Italian, the two subgroups with high proficiency in L2 French and in L2 Spanish, taken as a whole, were compared with that having a low proficiency in L2 French. A $t$-test was carried out to ascertain the existence of any statistically significant differences.

When analysing the data of the elicitation and translation tasks, one consistent finding emerged from the corpus: in some cases the subjects produced non-target or weak pronouns (i.e. ones which did not exhibit all the features of either clitic or strong pronouns in Italian, but typically a mixture of the two). For this reason, when discussing the subjects' pronominal production, the kind of pronouns produced will also be described, whether they were clitic, strong or weak pronouns.

\footnotetext{
${ }^{5}$ Considering the small datasets - only five participants per group - it must be borne in mind that in some cases inferential statistics may be of limited relevance only.
} 


\subsection{Results}

\subsubsection{Pronominal production}

\subsubsection{Overall pronominal production}

As far as overall pronominal production is concerned, Table 5.1 recapitulates the results of the elicitation and translation tasks.

Table 5.1: Overall pronominal production in the elicitation and translation tasks

\begin{tabular}{|c|c|c|c|c|c|c|c|c|}
\hline \multirow[b]{2}{*}{ Group } & \multicolumn{4}{|c|}{ Elicitation task } & \multicolumn{4}{|c|}{ Translation task } \\
\hline & $\begin{array}{c}\text { Produc- } \\
\text { tion }\end{array}$ & Omissior & $\begin{array}{l}\text { Lexical } \\
\text { DP }\end{array}$ & $\begin{array}{l}\text { Other } \\
\text { avoid. }\end{array}$ & $\begin{array}{c}\text { Produc- } \\
\text { tion }\end{array}$ & Omissior & $\begin{array}{l}\text { Lexical } \\
\text { DP }\end{array}$ & $\begin{array}{l}\text { Other } \\
\text { avoid. }\end{array}$ \\
\hline $\begin{array}{l}\text { High L2 } \\
\text { French }\end{array}$ & $\begin{array}{l}25 / 50 \\
(50 \%)\end{array}$ & $\begin{array}{r}9 / 50 \\
(18 \%)\end{array}$ & $\begin{array}{l}13 / 50 \\
(26 \%)\end{array}$ & $\begin{array}{l}3 / 50 \\
(6 \%)\end{array}$ & $\begin{array}{r}92 / 110 \\
(84 \%)\end{array}$ & $\begin{array}{r}17 / 110 \\
(15 \%)\end{array}$ & $\begin{array}{r}1 / 110 \\
(1 \%)\end{array}$ & $\begin{array}{r}0 / 110 \\
(0 \%)\end{array}$ \\
\hline $\begin{array}{l}\text { High L2 } \\
\text { Spanish }\end{array}$ & $\begin{array}{l}19 / 50 \\
(38 \%)\end{array}$ & $\begin{array}{l}20 / 50 \\
(40 \%)\end{array}$ & $\begin{array}{r}8 / 50 \\
(16 \%)\end{array}$ & $\begin{array}{l}3 / 50 \\
(6 \%)\end{array}$ & $\begin{array}{r}75 / 110 \\
(68 \%)\end{array}$ & $\begin{array}{r}34 / 110 \\
(31 \%)\end{array}$ & $\begin{array}{r}1 / 110 \\
(1 \%)\end{array}$ & $\begin{array}{r}0 / 110 \\
(0 \%)\end{array}$ \\
\hline $\begin{array}{l}\text { Low L2 } \\
\text { French }\end{array}$ & $\begin{array}{r}7 / 50 \\
(14 \%)\end{array}$ & $\begin{array}{l}39 / 50 \\
(78 \%)\end{array}$ & $\begin{array}{l}0 / 50 \\
(0 \%)\end{array}$ & $\begin{array}{l}4 / 50 \\
(8 \%)\end{array}$ & $\begin{array}{r}62 / 110 \\
(56 \%)\end{array}$ & $\begin{array}{r}43 / 110 \\
(39 \%)\end{array}$ & $\begin{array}{r}1 / 110 \\
(1 \%)\end{array}$ & $\begin{array}{r}4 / 110 \\
(4 \%)\end{array}$ \\
\hline $\begin{array}{l}\text { Intermediate } \\
\text { L3 Italian }\end{array}$ & $\begin{array}{r}51 / 150 \\
(34 \%)\end{array}$ & $\begin{array}{r}68 / 150 \\
(45 \%)\end{array}$ & $\begin{array}{r}21 / 150 \\
(14 \%)\end{array}$ & $\begin{array}{r}10 / 150 \\
(7 \%)\end{array}$ & $\begin{array}{c}229 / 330 \\
(69 \%)\end{array}$ & $\begin{array}{r}94 / 330 \\
(29 \%)\end{array}$ & $\begin{array}{r}3 / 330 \\
(1 \%)\end{array}$ & $\begin{array}{r}4 / 330 \\
(1 \%)\end{array}$ \\
\hline $\begin{array}{l}\text { Advanced } \\
\text { L3 Italian }\end{array}$ & $\begin{array}{l}40 / 50 \\
(80 \%)\end{array}$ & $\begin{array}{l}3 / 50 \\
(6 \%)\end{array}$ & $\begin{array}{r}5 / 50 \\
(10 \%)\end{array}$ & $\begin{array}{l}2 / 50 \\
(4 \%)\end{array}$ & $\begin{array}{r}92 / 110 \\
(84 \%)\end{array}$ & $\begin{array}{r}17 / 110 \\
(15 \%)\end{array}$ & $\begin{array}{r}0 / 110 \\
(0 \%)\end{array}$ & $\begin{array}{r}1 / 110 \\
(1 \%)\end{array}$ \\
\hline $\begin{array}{l}\text { L1 Italian } \\
\text { Control }\end{array}$ & $\begin{array}{r}95 / 100 \\
(95 \%)\end{array}$ & $\begin{array}{r}0 / 100 \\
(0 \%)\end{array}$ & $\begin{array}{r}3 / 100 \\
(3 \%)\end{array}$ & $\begin{array}{r}2 / 100 \\
(2 \%)\end{array}$ & $\begin{array}{c}109 / 110 \\
(99 \%)\end{array}$ & $\begin{array}{r}1 / 110 \\
(1 \%)\end{array}$ & $\begin{array}{r}0 / 110 \\
(0 \%)\end{array}$ & $\begin{array}{r}0 / 110 \\
(0 \%)\end{array}$ \\
\hline
\end{tabular}

As can be seen, in both tasks the group with an advanced proficiency in Italian shows a higher production rate and a lower omission rate than the group with an intermediate proficiency in Italian. Within the latter, the subgroup with high proficiency in L2 French produces more pronouns and omits fewer than that with high proficiency in L2 Spanish and that with low proficiency in L2 French. As far as production rates are concerned, in both tasks there are statistically significant differences between the two groups with high proficiency in either French or Spanish as an L2, considered as a whole, and those of the group with low proficiency in L2 French $(t=2.5078 ; p=0.0267$ in the elicitation task; $t=3.3365$; $p=0.0059$ in the translation task). On the contrary, there are no statistically significant differences between the production rates of the three subgroups of subjects with an intermediate proficiency in Italian in either task. There is also a 


\section{Sandro Sciutti}

statistically significant difference between the groups with an intermediate proficiency in Italian, considered as a whole, and that with an advanced proficiency in Italian, but only in the elicitation task $(t=-3.2697$; $p=0.01)$. As for omission rates, in both tasks there are statistically significant differences between the omission rates of the two groups with high proficiency in either French or Spanish as an L2, considered as a whole, and those of the group with low proficiency in L2 French $(t=-6.0777 ; p=0.0000$ in the elicitation task; $t=-2.8441$; $p=0.0176$ in the translation task). There are also significant differences between the groups with high proficiency in either French or Spanish as an L2 $(F=70.73$; $p=0.012$ in the elicitation task; $F=36.76 ; p=0.024$ in the translation task) as well as between the group with low proficiency in L2 French and that with high proficiency in L2 French $(F=70.73 ; p=0.000$ in the elicitation task; $F=36.76$; $p=0.000$ in the translation task). Moreover, there is a statistically significant difference between the group with an intermediate proficiency in Italian and that with an advanced proficiency in Italian, but only in the elicitation task $(t=2.8912$; $p=0.0097)$.

\subsubsection{Kind of pronominal production}

As to the kind of pronominal production, one finding worth reporting is that within the group of subjects with intermediate proficiency in Italian only those proficient in French as an L2 sometimes produce strong pronouns placing them in a position which cannot be occupied by strong pronouns in Italian, as in (38) here below:

$$
\begin{aligned}
& \text { *Ho intenzione di lei dare un libro. } \\
& \text { have.1sg intention of her.F.SG.DAT give a book } \\
& \text { 'I am going to give her a book.' }
\end{aligned}
$$

This is done in 2 cases out of 25 (i.e. $8 \%$ ) by one subject with high proficiency in French in the elicitation task and in 5 cases out of 62 (i.e. 8\%) by subjects with low proficiency in French in the translation task.

\subsubsection{Production of partitive pronouns}

Table 5.2 highlights the production and omission rates of partitive pronouns in the elicitation and translation tasks. These data thus represent a sub-set of the dataset presented in Table 5.1.

As the table shows, in both tasks the group with advanced proficiency in Italian displays a higher production rate and a lower omission rate than the group 
Table 5.2: Production of partitive pronouns in the elicitation and translation tasks

\begin{tabular}{|c|c|c|c|c|c|c|c|c|}
\hline \multirow[b]{2}{*}{ Group } & \multicolumn{4}{|c|}{ Elicitation Task } & \multicolumn{4}{|c|}{ Translation Task } \\
\hline & $\begin{array}{l}\text { Produc- } \\
\text { tion }\end{array}$ & Omissio & $\begin{array}{l}\text { Lexical } \\
\text { DP }\end{array}$ & $\begin{array}{l}\text { Other } \\
\text { Avoid. }\end{array}$ & $\begin{array}{c}\text { Produc- } \\
\text { tion }\end{array}$ & Omissio & $\begin{array}{c}\text { Lexical } \\
\text { DP }\end{array}$ & $\begin{array}{l}\text { Other } \\
\text { Avoid. }\end{array}$ \\
\hline $\begin{array}{l}\text { High L2 } \\
\text { French }\end{array}$ & $\begin{array}{r}4 / 10 \\
(40 \%)\end{array}$ & $\begin{array}{l}0 / 10 \\
(0 \%)\end{array}$ & $\begin{array}{r}6 / 10 \\
(60 \%)\end{array}$ & $\begin{array}{l}0 / 10 \\
(0 \%)\end{array}$ & $\begin{array}{l}14 / 30 \\
(47 \%)\end{array}$ & $\begin{array}{l}16 / 30 \\
(53 \%)\end{array}$ & $\begin{array}{l}0 / 30 \\
(0 \%)\end{array}$ & $\begin{array}{l}0 / 30 \\
(0 \%)\end{array}$ \\
\hline $\begin{array}{l}\text { High L2 } \\
\text { Spanish }\end{array}$ & $\begin{array}{r}3 / 10 \\
(30 \%)\end{array}$ & $\begin{array}{r}4 / 10 \\
(40 \%)\end{array}$ & $\begin{array}{r}3 / 10 \\
(30 \%)\end{array}$ & $\begin{array}{l}0 / 10 \\
(0 \%)\end{array}$ & $\begin{array}{l}0 / 30 \\
(0 \%)\end{array}$ & $\begin{array}{r}30 / 30 \\
(100 \%)\end{array}$ & $\begin{array}{l}0 / 30 \\
(0 \%)\end{array}$ & $\begin{array}{l}0 / 30 \\
(0 \%)\end{array}$ \\
\hline $\begin{array}{l}\text { Low L2 } \\
\text { French }\end{array}$ & $\begin{array}{l}0 / 10 \\
(0 \%)\end{array}$ & $\begin{array}{r}10 / 10 \\
(100 \%)\end{array}$ & $\begin{array}{l}0 / 10 \\
(0 \%)\end{array}$ & $\begin{array}{l}0 / 10 \\
(0 \%)\end{array}$ & $\begin{array}{l}2 / 30 \\
(6 \%)\end{array}$ & $\begin{array}{l}28 / 30 \\
(94 \%)\end{array}$ & $\begin{array}{l}0 / 30 \\
(0 \%)\end{array}$ & $\begin{array}{l}0 / 30 \\
(0 \%)\end{array}$ \\
\hline $\begin{array}{l}\text { Intermediate } \\
\text { L3 Italian }\end{array}$ & $\begin{array}{r}7 / 30 \\
(23 \%)\end{array}$ & $\begin{array}{l}14 / 30 \\
(47 \%)\end{array}$ & $\begin{array}{r}9 / 30 \\
(30 \%)\end{array}$ & $\begin{array}{l}0 / 30 \\
(0 \%)\end{array}$ & $\begin{array}{l}16 / 90 \\
(18 \%)\end{array}$ & $\begin{array}{l}74 / 90 \\
(82 \%)\end{array}$ & $\begin{array}{l}0 / 90 \\
(0 \%)\end{array}$ & $\begin{array}{l}0 / 90 \\
(0 \%)\end{array}$ \\
\hline $\begin{array}{l}\text { Advanced } \\
\text { L3 Italian }\end{array}$ & $\begin{array}{r}8 / 10 \\
(80 \%)\end{array}$ & $\begin{array}{r}1 / 10 \\
(10 \%)\end{array}$ & $\begin{array}{r}1 / 10 \\
(10 \%)\end{array}$ & $\begin{array}{l}0 / 10 \\
(0 \%)\end{array}$ & $\begin{array}{l}14 / 30 \\
(47 \%)\end{array}$ & $\begin{array}{l}16 / 30 \\
(53 \%)\end{array}$ & $\begin{array}{l}0 / 30 \\
(0 \%)\end{array}$ & $\begin{array}{l}0 / 30 \\
(0 \%)\end{array}$ \\
\hline $\begin{array}{l}\text { L1 Italian } \\
\text { Control }\end{array}$ & $\begin{array}{l}18 / 20 \\
(90 \%)\end{array}$ & $\begin{array}{l}0 / 20 \\
(0 \%)\end{array}$ & $\begin{array}{r}2 / 20 \\
(10 \%)\end{array}$ & $\begin{array}{l}0 / 20 \\
(0 \%)\end{array}$ & $\begin{array}{r}30 / 30 \\
(100 \%)\end{array}$ & $\begin{array}{l}0 / 30 \\
(0 \%)\end{array}$ & $\begin{array}{l}0 / 30 \\
(0 \%)\end{array}$ & $\begin{array}{l}0 / 30 \\
(0 \%)\end{array}$ \\
\hline
\end{tabular}

with intermediate proficiency in Italian. Within the latter, the subgroup with high proficiency in French produces more partitive clitics and omits fewer than the subgroup with high proficiency in Spanish and the subgroup with low proficiency in French. As far as production rates are concerned, in the elicitation task there is a statistically significant difference between the group with intermediate proficiency in Italian and that with advanced proficiency in Italian $(t=-3.1153$; $p=0.0060$ ). On the contrary, in the translation task, there are no statistically significant differences. As to omission rates, in both tasks there is a statistically significant difference between the subgroup with high proficiency in L2 French and that with high proficiency in L2 Spanish within the group of subjects with intermediate proficiency in Italian $(F=41.63 ; p=0.004$ in the elicitation task; $F=28.60 ; p=0.038$ in the translation task). In the elicitation task, there is also a statistically significant difference between the subgroup with low proficiency in L2 French and that with high proficiency in L2 French $(F=41.63 ; p=0.000)$.

\subsubsection{Production of locative pronouns}

Table 5.3 highlights the production and omission rates of locative pronouns in the elicitation and translation task. These data thus represent a sub-set of the dataset presented in Table 5.1. 
Table 5.3: Production of locative pronouns in the elicitation and the translation task

\begin{tabular}{|c|c|c|c|c|c|c|c|c|}
\hline \multirow[b]{2}{*}{ Group } & \multicolumn{4}{|c|}{ Elicitation Task } & \multicolumn{4}{|c|}{ Translation Task } \\
\hline & $\begin{array}{l}\text { Produc- } \\
\text { tion }\end{array}$ & Omission & $\begin{array}{c}\text { Lexical } \\
\text { DP }\end{array}$ & $\begin{array}{l}\text { Other } \\
\text { Avoid. }\end{array}$ & $\begin{array}{l}\text { Produc- } \\
\text { tion }\end{array}$ & Omissior & $\begin{array}{c}\text { Lexical } \\
\text { DP }\end{array}$ & $\begin{array}{l}\text { Other } \\
\text { Avoid. }\end{array}$ \\
\hline $\begin{array}{l}\text { High L2 } \\
\text { French }\end{array}$ & $\begin{array}{r}5 / 10 \\
(50 \%)\end{array}$ & $\begin{array}{r}3 / 10 \\
(30 \%)\end{array}$ & $\begin{array}{r}2 / 10 \\
(20 \%)\end{array}$ & $\begin{array}{l}0 / 10 \\
(0 \%)\end{array}$ & $\begin{array}{l}17 / 20 \\
(85 \%)\end{array}$ & $\begin{array}{l}1 / 20 \\
(5 \%)\end{array}$ & $\begin{array}{l}0 / 20 \\
(0 \%)\end{array}$ & $\begin{array}{r}2 / 20 \\
(10 \%)\end{array}$ \\
\hline $\begin{array}{l}\text { High L2 } \\
\text { Spanish }\end{array}$ & $\begin{array}{l}0 / 10 \\
(0 \%)\end{array}$ & $\begin{array}{r}9 / 10 \\
(90 \%)\end{array}$ & $\begin{array}{r}1 / 10 \\
(10 \%)\end{array}$ & $\begin{array}{l}0 / 10 \\
(0 \%)\end{array}$ & $\begin{array}{l}12 / 20 \\
(60 \%)\end{array}$ & $\begin{array}{r}2 / 20 \\
(10 \%)\end{array}$ & $\begin{array}{l}1 / 20 \\
(5 \%)\end{array}$ & $\begin{array}{r}5 / 20 \\
(25 \%)\end{array}$ \\
\hline $\begin{array}{l}\text { Low L2 } \\
\text { French }\end{array}$ & $\begin{array}{l}0 / 10 \\
(0 \%)\end{array}$ & $\begin{array}{r}10 / 10 \\
(100 \%)\end{array}$ & $\begin{array}{l}0 / 10 \\
(0 \%)\end{array}$ & $\begin{array}{l}0 / 10 \\
(0 \%)\end{array}$ & $\begin{array}{l}1 / 20 \\
(5 \%)\end{array}$ & $\begin{array}{r}9 / 20 \\
(45 \%)\end{array}$ & $\begin{array}{l}1 / 20 \\
(5 \%)\end{array}$ & $\begin{array}{r}9 / 20 \\
(45 \%)\end{array}$ \\
\hline $\begin{array}{l}\text { Intermediate } \\
\text { L3 Italian }\end{array}$ & $\begin{array}{r}5 / 30 \\
(17 \%)\end{array}$ & $\begin{array}{l}22 / 30 \\
(73 \%)\end{array}$ & $\begin{array}{r}3 / 30 \\
(10 \%)\end{array}$ & $\begin{array}{l}0 / 30 \\
(0 \%)\end{array}$ & $\begin{array}{l}30 / 60 \\
(50 \%)\end{array}$ & $\begin{array}{l}12 / 60 \\
(20 \%)\end{array}$ & $\begin{array}{l}2 / 60 \\
(3 \%)\end{array}$ & $\begin{array}{l}16 / 60 \\
(27 \%)\end{array}$ \\
\hline $\begin{array}{l}\text { Advanced } \\
\text { L3 Italian }\end{array}$ & $\begin{array}{r}7 / 10 \\
(70 \%)\end{array}$ & $\begin{array}{r}3 / 10 \\
(30 \%)\end{array}$ & $\begin{array}{l}0 / 10 \\
(0 \%)\end{array}$ & $\begin{array}{l}0 / 10 \\
(0 \%)\end{array}$ & $\begin{array}{l}17 / 20 \\
(85 \%)\end{array}$ & $\begin{array}{r}2 / 20 \\
(10 \%)\end{array}$ & $\begin{array}{l}0 / 20 \\
(0 \%)\end{array}$ & $\begin{array}{l}1 / 20 \\
(5 \%)\end{array}$ \\
\hline $\begin{array}{l}\text { L1 Italian } \\
\text { Control }\end{array}$ & $\begin{array}{l}12 / 20 \\
(60 \%)\end{array}$ & $\begin{array}{r}8 / 20 \\
(40 \%)\end{array}$ & $\begin{array}{l}0 / 20 \\
(0 \%)\end{array}$ & $\begin{array}{l}0 / 20 \\
(0 \%)\end{array}$ & $\begin{array}{l}16 / 20 \\
(80 \%)\end{array}$ & $\begin{array}{r}3 / 20 \\
(15 \%)\end{array}$ & $\begin{array}{l}0 / 20 \\
(0 \%)\end{array}$ & $\begin{array}{l}1 / 20 \\
(5 \%)\end{array}$ \\
\hline
\end{tabular}

As can be noticed, in both tasks the group with an advanced proficiency in Italian shows a higher production rate and a lower omission rate than the group with an intermediate proficiency in Italian. Within the latter, the subgroup with high proficiency in L2 French produces more locative clitics and omits fewer than those with high proficiency in L2 Spanish and low proficiency in L2 French. As far as production rates are concerned, there are no statistically significant differences in either task. As to omission rates, in both tests there are statistically significant differences between the subgroup with low proficiency in L2 French and that with high proficiency in L2 French within the group of subjects with intermediate proficiency in Italian $(F=11.90 ; p=0.010$ in the elicitation task; $F=7.51$; $p=0.002$ in the translation task). Moreover, in the elicitation task there is a statistically significant difference between the subgroup with high proficiency in L2 French and that with high proficiency in L2 Spanish within the group of subjects with intermediate proficiency in Italian $(F=11.90 ; p=0.041)$. In the translation task, there is also a statistically significant difference between the subgroup with high proficiency in L2 French and those with high proficiency in L2 Spanish and low proficiency in L2 French, if considered as a whole $(t=-2.2422 ; p=0.0433)$.

\footnotetext{
${ }^{5}$ The term pro-forms refers to the use of a locative adverb such as the Italian equivalent of there where a locative clitic was expected to be produced.
} 


\subsubsection{Detection of omissions of partitive and locative pronouns}

As far as partitive and locative pronouns are concerned, the findings of the elicitation and translation tasks seem to be corroborated by those stemming from the second GJT. Table 5.4 recapitulates the judgments given to the three ungrammatical items in which partitive clitics were omitted.

Table 5.4: Judgments on items including an omission of a partitive clitic (ungrammatical)

\begin{tabular}{lrrr}
\hline \hline & Grammatical & \multicolumn{2}{c}{ Ungrammatical } \\
\cline { 3 - 4 } Group & & Right correction & Wrong correction \\
\hline High L2 French & $9 / 15(60 \%)$ & $4 / 15(27 \%)$ & $2 / 15(13 \%)$ \\
High L2 Spanish & $12 / 15(80 \%)$ & $1 / 15(7 \%)$ & $2 / 15(13 \%)$ \\
Low L2 French & $12 / 14(86 \%)$ & $0 / 14(0 \%)$ & $2 / 14(14 \%)$ \\
Intermediate L3 Italian & $33 / 44(75 \%)$ & $5 / 44(11 \%)$ & $6 / 44(14 \%)$ \\
L1 Italian Control & $1 / 27(4 \%)$ & $26 / 27(96 \%)$ & $0 / 27(0 \%)$ \\
\hline \hline
\end{tabular}

These data mirror those obtained with the elicitation and translation tasks. Among the subjects with an intermediate proficiency in Italian the acceptance rate of the subgroup with high proficiency in L2 French is lower than those of the subgroup with high proficiency in L2 Spanish and of the subgroup with low proficiency in L2 French. At the same time, the subgroup with high proficiency in L2 French judges the omissions of partitive clitics as ungrammatical - providing the right correction - to a greater extent than those with high proficiency in L2 Spanish and a low proficiency in L2 French, who never provide the right correction. In any case, there are no statistically significant differences in the GJT between the single experimental groups.

Table 5.5 recapitulates the judgments given to the three items in which locative clitics were omitted.

These data again mirror - partially, at least - those obtained with the elicitation and translation tasks. Within the group of subjects with an intermediate proficiency in Italian the acceptance rate of the subgroup with high proficiency in L2 French is lower than that of the subgroup with high proficiency in L2 Spanish and of the subgroup with low proficiency in L2 French. At the same time, the subgroup with high proficiency in L2 French judges the omissions of locative clitics as ungrammatical - providing the right correction - to a greater extent than the subgroup with high proficiency in L2 Spanish and the subgroup with 


\section{Sandro Sciutti}

Table 5.5: Judgments on items including an omission of a locative clitic (ungrammatical)

\begin{tabular}{lrrr}
\hline \hline & Grammatical & \multicolumn{2}{c}{ Ungrammatical } \\
\cline { 3 - 4 } Group & & Right correction & Wrong correction \\
\hline High L2 French & $8 / 14(57 \%)$ & $4 / 14(29 \%)$ & $2 / 14(14 \%)$ \\
High L2 Spanish & $11 / 15(73 \%)$ & $2 / 15(13.5 \%)$ & $2 / 15(13.5 \%)$ \\
Low L2 French & $13 / 15(87 \%)$ & $0 / 15(0 \%)$ & $2 / 15(13 \%)$ \\
Intermediate L3 Italian (Total) & $32 / 44(73 \%)$ & $6 / 44(13.5 \%)$ & $6 / 44(13.5 \%)$ \\
L1 Italian Control & $3 / 27(11 \%)$ & $24 / 27(89 \%)$ & $0 / 27(0 \%)$ \\
\hline \hline
\end{tabular}

low proficiency in L2 French, whose subjects never provide the right correction. In any case, there are no statistically significant differences between the single experimental groups in this grammaticality judgment task.

\subsubsection{Clitic placement}

As far as pronominal placement is concerned, a comparison between the elicitation and the translation tasks highlights that within the group of subjects with intermediate proficiency in Italian the only instances of pronouns placed before an infinitive - an ungrammatical option in Italian - are found in the subgroups with high and low proficiency in L2 French. Table 5.6 shows these findings.

Table 5.6: Pronouns placed before an infinitive in the elicitation and translation tasks

\begin{tabular}{lrr}
\hline \hline Group & Elicitation task & Translation task \\
\hline High L2 Fr & $1 / 30(3 \%)$ & $7 / 105(7 \%)$ \\
High L2 Sp & $0 / 18(0 \%)$ & $0 / 83(0 \%)$ \\
Low L2 Fr & $1 / 4(25 \%)$ & $16 / 54(30 \%)$ \\
Intermediate L3 Italian (Total) & $2 / 52(4 \%)$ & $23 / 242(9.5 \%)$ \\
Advanced L3 Italian & $0 / 47(0 \%)$ & $0 / 107(0 \%)$ \\
L1 Italian Control & $0 / 107(0 \%)$ & $0 / 121(0 \%)$ \\
\hline \hline
\end{tabular}

Indeed, the subgroup with high proficiency in L2 French places pronouns before an infinitive in $3 \%$ of cases (i.e. 1 out of 30 ) in the elicitation task and $7 \%$ of cases (i.e. 7 out of 105) in the translation task. The subgroup with low proficiency in L2 French, for its part, places pronouns before an infinitive in $25 \%$ of 
cases (i.e. 1 out of 4 ) in the elicitation task and $30 \%$ of cases (i.e. 16 out of 54 ) in the translation task. On the contrary, no instances of pronouns placed before an infinitive are found in the productions of the subgroup with high proficiency in L2 Spanish nor in the group with advanced proficiency in Italian. As far as statistics are concerned, the low production rates in the elicitation task do not make it possible to establish whether the differences between the experimental groups are significant or not. In the translation task, within the group of subjects with intermediate proficiency in Italian there is a significant difference between the subgroups with low and high proficiency in L2 French with respect to the placement of the clitic directly before the infinitive, but only in clauses not licensing restructuring $(F=6.87 ; p=0.020)$. Moreover, there is also a significant difference in all clause types between the subgroup with low proficiency in L2 French and that with high proficiency in L2 Spanish $(F=6.87 ; p=0.003$ in clauses not licensing restructuring; $F=6.94 ; p=0.011$ in optionally restructuring clauses and in obligatorily restructuring clauses governed by a causative verb).

These results seem to be substantiated by those obtained with the first GJT. Table 5.7 recapitulates the judgments given to the fourteen items in which a clitic was placed before an infinitive. ${ }^{6}$

Table 5.7: Judgments on items including a clitic placed before an infinitive

\begin{tabular}{lrrr}
\hline \hline & Grammatical & \multicolumn{2}{c}{ Ungrammatical } \\
\cline { 3 - 4 } Group & & Right correction & Wrong correction \\
\hline High L2 French & $27 / 60(45 \%)$ & $24 / 60(40 \%)$ & $9 / 60(15 \%)$ \\
High L2 Spanish & $17 / 65(26 \%)$ & $33 / 65(51 \%)$ & $15 / 65(23 \%)$ \\
Low L2 French & $43 / 55(78 \%)$ & $4 / 55(7.5 \%)$ & $8 / 55(14.5 \%)$ \\
Intermediate L3 Italian (Total) & $87 / 180(48 \%)$ & $61 / 180(34 \%)$ & $32 / 180(18 \%)$ \\
Advanced L3 Italian & $10 / 67(15 \%)$ & $41 / 67(61 \%)$ & $16 / 67(24 \%)$ \\
L1 Italian Control & $0 / 168(0 \%)$ & $165 / 168(98.5 \%)$ & $3 / 168(1.5 \%)$ \\
\hline \hline
\end{tabular}

These data mirror those obtained with the elicitation and translation tasks. As can be observed, within the group of subjects with intermediate proficiency in Italian, the subgroup with low proficiency in L2 French accepts these ungrammatical items to a greater extent than the other two subgroups. For its part, the subgroup with high proficiency in L2 French judges these items as grammatical to a greater extent than does the group with high proficiency in L2 Spanish.

\footnotetext{
${ }^{6}$ Since some subjects did not express any judgment over some of the items, the total number of items per group is variable.
} 


\section{Sandro Sciutti}

The rate of acceptance of the group with advanced proficiency in L3 Italian is only a $15 \%$ (i.e. 10 cases out of 67 ), against $48 \%$ (i.e. 87 out of 180 ) for the overall group with an intermediate proficiency in Italian. An ANOVA test followed by a Bonferroni comparison reveals that there is a significant difference in the acceptance rates between the subgroup with low proficiency in L2 French and that with high proficiency in L2 Spanish $(F=17.44 ; p=0.008)$, in line with the finding of the translation task. Turning to the ungrammatical judgments provided with the right correction, a similar picture emerges. Indeed, within the group of subjects with intermediate proficiency in Italian, the subgroup with low proficiency in L2 French both judges these items as ungrammatical and provides the right correction to a lesser extent than the other two subgroups. For its part, the subgroup with high proficiency in L2 French does so to a lesser extent than that with high proficiency in L2 Spanish. Finally, the rate of exact answers provided by the group with advanced proficiency in Italian is higher than that of the group with intermediate proficiency in Italian.

\section{Discussion}

\subsection{Pronominal production}

\subsubsection{Overall pronominal production}

As a reminder, the research question pertaining to overall pronominal production was the following: As proficiency in either French L2 or L3 Italian increases, does the high rate of avoidance strategies - mostly omissions or replacements with lexical DPs - reduce (with a parallel increase in overall clitic production)?

The findings pertaining to overall pronominal production might point to the fact that high proficiency in a Romance L2 increases pronominal production and reduces instances of omissions, substitutions or avoidances in L3 Italian to a greater extent than does low proficiency in a Romance L2. German learners seem all the more able to transfer their knowledge about the existence of a clitic pronominal series from one Romance language to another as their proficiency in a background Romance language increases. However, a wider corpus would be needed to support this claim. The data available only allow a comparison between learners with a high and a low proficiency in L2 French, but nothing can be said about proficiency in L2 Spanish, for example. Additionally, pronominal production is boosted, with a parallel decrease in omissions, substitutions and avoidances, as proficiency in Italian increases: advanced learners of Italian have 
been shown to produce more pronouns - and fewer instances of omissions, substitutions and avoidances - than intermediate ones in both the elicitation and the translation tasks. ${ }^{7}$

\subsubsection{Kind of pronominal production}

As to the kind of pronominal production, within the group of subjects with an intermediate proficiency in Italian, only those proficient in French as an L2 sometimes produced strong pronouns, placing them in a position which cannot be occupied by strong pronouns in Italian. There were no such instances in the subgroup of subjects with high proficiency in L2 Spanish, nor in the group with an advanced proficiency in Italian. Hamann \& Belletti (2006) discuss a similar error found by Granfeldt \& Schlyter (2004: 355) and made by an L2 speaker, here reported for comparison:

$$
\begin{aligned}
& \text { *Il a lui assis. } \\
& \text { he has him.M.sG.ACc sat } \\
& \text { 'He sat him down.' }
\end{aligned}
$$

This kind of error is said to be typical of the productions of German-speaking learners of French (Herschensohn 2004). Consider these examples of productions of German-speaking learners of Italian taken from the VALICO corpus (Corino 2012: 48, 55):

* Quest' altro lui faceva paura.

this other him-M.SG.DAT made.3SG.IMPFV fear

'This other scared him.'
${ }^{*}$ La ragazza lui
ha detto: che hai
fatto! the girl him.M.S.DAT has said: what have.2.SG done 'The girl told him: what have you done!'

Hamann \& Belletti (2006) claim that this error derives from a misanalysis of complement clitics as weak pronouns, instantiated in German, much as the error consisting of placing a clitic in a thematic position after a finite verb, reported by Granfeldt \& Schlyter (2004: 355) as produced by a Swedish-speaking learner of French:

\footnotetext{
${ }^{7}$ Only in the translation task are the avoidance rates the same, equalling $1 \%$.
} 


\author{
${ }^{*}$ Elle croit la. \\ She believes her.F.SG.ACC \\ 'She believes her.'
}

According to Hamann \& Belletti (2006), such a misanalysis might be reinforced by the fact that weak pronouns are also instantiated in French, although not with the function of complements. Indeed, subject pronouns in French are in fact weak pronouns. In the cases found in this experiment, the same principle might be at work. In other words, it may well be that German-speaking learners of Italian first tend to assimilate clitics to weak pronouns, instantiated in German, thus producing non-target pronouns of the same kind as the one in (38). The fact that such errors are only found among the subjects proficient in French as an L2 might indicate that such a misinterpretation is again reinforced by the existence of weak pronouns in French in the shape of subject pronouns. In any case, it seems that a high proficiency in L2 Spanish as well as advanced proficiency in Italian reduce the likelihood of occurrence of such non-target pronouns.

\title{
5.1.3 Partitive and locative clitics
}

The research question related to partitive and locative clitics was the following: Does prior knowledge of L2 French - as well as a varying degree of proficiency in it - affect the learners' production rates and grammaticality judgments of both partitive and locative clitics (instantiated in French but not in Spanish)?

On the whole, the findings related to partitive and locative clitics may be an indication of the fact that a good prior knowledge of French increases production of both partitive and locative clitics and reduces instances of their omissions in L3 Italian. German learners seem all the more able to transfer their knowledge about the existence of partitive and locative clitics from French to Italian as their proficiency in French increases. Indeed, the subjects with high proficiency in L2 French have produced the most - and omitted the least - partitive and locative clitics within the group with an intermediate proficiency in Italian. The instantiation of partitive and locative clitics in French has apparently had the effect of boosting the production of partitive and locative clitics in Italian, while limiting instances of omissions. The fact that the subjects with high proficiency in L2 Spanish have produced more - and omitted fewer - partitive and locative clitics than the subjects with low proficiency in L2 French may indicate that the former find themselves in a more advanced stage in the acquisition path of partitive and locative clitics. Production of both partitive and locative clitics increases, with a parallel decrease in omissions, also as proficiency in Italian increases. As a matter 
of fact, advanced learners of Italian have produced more partitive and locative clitics - with fewer instances of omissions - than intermediate ones in both the elicitation and the translation task.

\subsection{Pronominal placement}

The research question regarding clitic placement was the following: does prior knowledge of L2 Spanish reduce the occurrence of mistakes in infinitival clauses?

As far as pronominal placement is concerned, it seems that the tendency to place and accept clitics before an infinitive is favoured by prior knowledge of L2 French. Cases of placement errors similar to those found in the experiment (i.e. with clitics placed in an intermediate position between two verbs) have been reported by several authors as typical of L2 learners, especially those with a Germanic L1 (Gundel \& Tarone 1983; Connors \& Nuckle 1986; Zobl 1992; Towell \& Hawkins 1994; Grondin \& White 1996; Hulk \& Müller 2000; Herschensohn 2004; Ferrari 2006; Maffei 2009; Corino 2012). Such errors are part of the following sequence of acquisition of pronominal placement identified by Towell \& Hawkins (1994) and Herschensohn (2004) for English-speaking learners of French and by Schlyter (1997) for Swedish-speaking learners of French:

1. Postverbal position:

$$
\begin{aligned}
& \text { * Je vois lui } \\
& \text { I see him.sG.ACC }
\end{aligned}
$$

2. Omission of the object:
* Je ai vu $\varnothing$
I have seen $\varnothing$

3. Intermediate position:
* Je ai le $\mathrm{vu}$
I have him.sG.ACC seen

4. Pre-finite position, target-like:
(46) * Je l'
ai vu
I him.sG.ACC have seen
'I have seen him.' 
Even though in the previous examples the intermediate position of the clitic involves an auxiliary verb and a past participle of a lexical verb, clitics found between a finite verb and the infinitive in the corpus of this study might also belong to the third stage of the acquisition process. The same sequence could also hold for German-speaking learners of Italian, as suggested by Hamann \& Belletti (2006). The presence of clitics in an intermediate position, between the finite verb and the infinitive, in those subjects proficient in L2 French could be accounted for by a similarity between German and French which apparently reinforces the general tendency of German-speaking learners to place clitics in an intermediate position, as typical of a stage of their acquisition process. ${ }^{8}$ Indeed, at a superficial level, clitic placement in French complex clauses containing an infinitive which do not restructure and in those which optionally do resembles the word order found in German, since the pronouns occur in a higher position in syntax than the infinitive in both languages, as the following example shows:
a. Je vais me laver.
I go myself.Acc wash
'I'll go and wash myself.'
I go myself.Acc wash
'I'll go and wash myself.'
b. Ich gehe mich waschen.

As in the case discussed above of strong pronouns filling a position which cannot be occupied by strong pronouns in Italian, this similarity between French and German word order may induce a misanalysis of Italian word order contributing to an extension of the third stage in the sequence mentioned above for the learners with prior knowledge of French. In other words, for these learners the process of acquisition of clitic placement may be temporarily slowed down. As in the case of partitive and locative clitics discussed above, the fact that the subjects with high proficiency in L2 French have placed fewer clitics before an infinitive than those with low proficiency in L2 French may be explained by a greater degree of metalinguistic awareness that usually goes hand in hand with high proficiency in an L2 - especially in one closely related to the target language. There are several studies in support of this claim, all of which point to heightened metalinguistic awareness and enhanced metacognitive skills in learners with high proficiency in one or more L2s. For instance, Fouser (2001) carried out an introspective study on

\footnotetext{
${ }^{8}$ There is a striking similarity with what was suggested above when discussing the instances of strong pronouns placed in a position which cannot be occupied by strong pronouns.
} 
two English-speaking learners of Korean who had prior advanced knowledge of Japanese as a non-native language and found that their reflection on their learning process and their awareness of the relationship between Korean and Japanese facilitated their task. Another study worth mentioning is the one carried out by Jessner (1999), who analysed qualitative data stemming from think-aloud protocol sessions. She reports that Italian/German bilingual learners of English as a non-native language consciously reflect on and compare their prior knowledge of two languages in searching for a word in an L3. Thus the boost to metalinguistic awareness and metacognitive skills typically spotted in multilingual learners may be due to the interactive nature of knowledge within the multilingual mind (Herdina \& Jessner 2000; 2002; Jessner 2003; 2008a,b; 2009). As regards the subjects of this study, those with high proficiency in L2 French are apparently more aware than the low-proficient ones of the contrast between French and Italian in the complex infinitival clauses mentioned above, which makes the placement of clitics in an intermediate position less likely for the former than for the latter. Finally, the complete lack of instances of clitics placed before an infinitive in the learners with high proficiency in L2 Spanish and in those with high proficiency in Italian might be an indication of the fact that these learners are already past the stage in which clitics are placed in an intermediate position.

\section{Conclusion}

On the whole, the experimental data have shed light on the roles of the subjects' L1 and L2s in their process of acquisition of Italian clitics in complex infinitival clauses, as well as on the evolution over time of the acquisitional patterns of German-speaking learners of Italian as a non-native language, as their proficiency in the target language increases.

Clitics confirm themselves as a tricky syntactic feature to acquire, in that their properties are not fully mastered at intermediate level of proficiency in Italian. However, high proficiency in a Romance L2 - French or Spanish - is likely to influence the overall acquisition of Italian clitics, by enhancing their production and correspondingly reducing the occurrence of omissions. When it comes to specific categories of clitics like partitive and locative ones, high proficiency in a Romance language like French in which they are instantiated is likely to foster their production while reducing their omissions correspondingly. An in-depth investigation of some issues related to pronominal placement in the clauses which constitute the focus of this research has made it possible to further examine the role of French and Spanish as L2s, their interactions with the subjects' L1 as well 


\section{Sandro Sciutti}

as the effect of varying proficiency in L2 French. Since the patterns of clitic placement in infinitival clauses are identical in Spanish and Italian, prior knowledge of the former apparently plays a facilitative role in the subsequent acquisition in Italian in this respect. On the contrary, prior knowledge of French, a language in which the patterns of clitic placement in infinitival clauses mostly differ from Italian, seems to have the effect of reinforcing an underlying tendency which some authors ascribe to the learners' L1. In both cases, an L2 interacts with the $\mathrm{L} 1$ and, depending on the specific features instantiated in the L2, the outcome of such an interaction is either a speeding up or a slowing down of the acquisitional process.

A similar conclusion has been reached to account for another phenomenon spotted in the productions of the subjects proficient in L2 French and totally absent from those of the subjects proficient in L2 Spanish, namely instances of strong pronouns used in positions which are illicit for strong pronouns in Italian. This finding too has been compared with the existing data from previous studies pointing to similar pronominal productions in the utterances of Germanspeaking learners of French. It has been argued that clitics tend to be assimilated to Germanic weak pronouns at first, and that this temporary misinterpretation may well be reinforced by the instantiation of weak pronouns in French in the shape of phonological subject clitics.

Proficiency in L2 French plays a role in the acquisition of L3 Italian, too. Indeed, the comparison between the subjects with a high and a low proficiency in L2 French has revealed that a higher proficiency in this language generally leads to more target-like pronominal productions: fewer clitics are placed before an infinitive and fewer strong pronouns are used in positions which cannot be occupied by strong pronouns in Italian. High proficiency in L2 French may therefore have the effect of speeding up the process of clitic acquisition in L3 Italian.

Finally, the degree of proficiency in the target language is yet another factor which has repercussions on the acquisition of Italian clitics in complex clauses containing an infinitive: all in all, the subjects with an advanced proficiency in Italian outperform those with an intermediate proficiency in Italian, showing a more thorough mastery of the properties of cliticisation. This is apparent across all the experimental tasks and for all the phenomena investigated. However, a close examination of certain structures characterised by a very high degree of complexity, such as the clauses containing an infinitive governed by a causative verb, reveals that even advanced learners are still struggling with the multifaceted phenomenon of cliticisation of the Italian language. 


\section{References}

Belletti, Adriana \& Maria Teresa Guasti. 2015. The acquisition of pronominal clitics. In Adriana Belletti \& Maria Teresa Guasti (eds.), The acquisition of Italian: Morphosyntax and its interfaces in different modes of acquisition, 81-128. Amsterdam: John Benjamins.

Belletti, Adriana \& Cornelia Hamann. 2004. On the L2/bilingual acquisition of French by two young children with different source languages. In Philippe Prévost \& Johanne Paradis (eds.), The acquisition of French in different contexts: Focus on functional categories, 147-174. Amsterdam: John Benjamins.

Bennati, Elisa \& Elisa Di Domenico. 2008. Individual and task-related differences in the L2 acquisition of English 's-genitive constructions by native speakers of Italian. (Poster presented at the XVIII Colóquio de Gramática Generativa, Lisboa, April 17-19.)

Bennati, Elisa \& Simona Matteini. 2006. Object clitic climbing in L2 learners of Italian. In A. Belletti, Elisa Bennati, C. Chesi, E. di Domenico \& I. Ferrari (eds.), Language acquisition and development: Proceedings of GALA 2005, 3548. Newcastle-upon-Tyne: Cambridge Scholars Press.

Bernardini, Petra \& Monica Timofte. 2017. Cross-linguistic influence in the acquisition of object clitics: A matter of complexity? In Elisa Di Domenico (ed.), Syntactic complexity from a language acquisition perspective, 207-232. Cambrdige: Cambridge Scholars Publishing.

Bernardini, Petra \& Joost van de Weijer. 2017. On the direction of crosslinguistic influence in the acquisition of Italian and French. Language Interaction and Acquisition (LIA) 8. 204-233.

Berretta, Monica. 1986. Per uno studio dell'apprendimento dell'italiano in contesto naturale: Il caso dei pronomi personali atoni. In Anna Giacalone Ramat (ed.), L'apprendimento spontaneo di una seconda lingua, 329-352. Bologna: Il Mulino.

Bialystok, Ellen \& Ellen Bouchard Ryan. 1985. A metacognitive framework for the development of first and second language skills. In Donna-Lynn ForresterPressley, G. E. MacKinnon \& Thomas Gary Waller (eds.), Metacognition, cognition and human performance, 207-252. Orlando: FL Academic Press.

Bottari, Piero, Paola Cipriani \& Anna Maria Chilosi. 2000. Dissociations in the acquisition of clitic pronouns by dysphasic children: A case study from Italian. In Cornelia Hamman \& Susan M. Powers (eds.), The acquisition of scrambling and cliticization, 237-277. Dordrecht: Kluwer. 
Bruhn de Garavito, Joyce \& Silvina Montrul. 1996. Verb movement and clitic placement in French and Spanish as a second language. In Elizabeth Hughes, Mary Hughes \& Annabel Greenhill (eds.), Proceedings of the 21st annual Boston University Conference on Language Development, 123-134. Boston: Cascadilla Press.

Chini, Marina, Stefania Ferraris, Ada Valentini \& Barbara Businaro. 2003. Aspetti della testualità. In Anna Giacalone Ramat (ed.), Verso l'italiano, 179-200. Roma: Carocci.

Connors, Kathleen \& Lucie Nuckle. 1986. The morphosyntax of French personal pronouns and the acquisition/learning dichotomy. In Osvaldo Jaeggli \& Carmen Silva-Corvalán (eds.), Studies in Romance linguistics, 225-242. Dordrecht: Foris.

Corino, Elisa. 2012. Italiano di tedeschi: Una ricerca corpus-based. Perugia: Guerra.

Duffield, Nigel Gordon \& Lydia White. 1999. Assessing L2 knowledge of Spanish clitic placement: Converging methodologies. Second Language Research 15. 133-160.

Duffield, Nigel Gordon, Lydia White, Joyce Bruhn de Garavito, Silvina Montrul \& Philippe Prévost. 2002. Clitic placement in L2 French: Evidence from sentence matching. Journal of linguistics 38. 487-525.

Ellis, Rod. 2005. Measuring implicit and explicit knowledge of a second language: A psychometric study. Studies in Second Language Acquisition 27(2). 141-172.

Ferrari, Ida. 2006. Acquisition of object clitics by two Italian/German bilingual children. In Adriana Belletti, Elisa Bennati, Cristiano Chesi, Elisa Di Domenico \& Ida Ferrari (eds.), Language acquisition and development: proceedings of GALA 2005, 173-183. Newcastle-upon-Tyne: Cambridge Scholars Press.

Fouser, Robert. 2001. Too close for comfort? Sociolinguistic transfer from Japanese into Korean as an $\mathrm{L} \geq 3$. In Jasone Cenoz, Britta Hufeisen \& Ulrike Jessner (eds.), Cross-linguistic influence in third language acquisition: Psycholinguistic perspectives, 149-169. Clevedon: Multilingual Matters.

Giannini, Stefania. 2008. Proprietà formali e distribuzionali dei clitici in italiano L2. In Romano Lazzeroni, Emanuele Banfi, Giuliano Bernini, Marina Chini \& Giovanna Marotta (eds.), Diachronica et synchronica: Studi in onore di Anna Giacalone Ramat, 217-240. Pisa: Edizioni ETS.

Giannini, Stefania \& Jessica Cancila. 2006. Direzionalità d'accesso nell'acquisizione dei clitici pronominali in italiano L2. In Raffaella Bombi, Guido Cifoletti, Flavia Fusco, Lucia Innocente \& Vincenzo Orioles (eds.), Studi linguistici in onore di roberto gusmani, 883-905. Alessandria: Edizioni dell'Orso. 
Granfeldt, Jonas \& Suzanne Schlyter. 2004. Cliticization in the acquisition of French as L1 and L2. In Philippe Prévost \& Johanne Paradis (eds.), The acquisition of French in different contexts: Focus on functional categories, 333-370. Amsterdam: John Benjamins.

Grondin, Nathalie \& Lydia White. 1996. Functional categories in child L2 acquisition of French. Language Acquisition 5. 1-34.

Gundel, Jeanette K. \& Elaine Tarone. 1983. 'language transfer' and the acquisition of pronominal anaphora. In Susan M. Gass \& Larry Selinker (eds.), Language transfer in language learning, 281-296. Rowley (MA): Newbury House.

Hamann, Cornelia \& Adriana Belletti. 2006. Developmental patterns in the acquisition of complement clitic pronouns: Comparing different acquisition modes with an emphasis on French. Rivista di Grammatica Generativa 31. 39-78.

Hammarberg, Björn. 2010. The languages of the multilingual: Some conceptual and terminological issues. International Review of Applied Linguistics 48. 91104.

Herdina, Philip \& Ulrike Jessner. 2000. The dynamics of third language acquisition. In Jasone Cenoz \& Ulrike Jessner (eds.), English in Europe: The acquisition of a third language, 115-137. Clevedon: Multilingual Matters.

Herdina, Philip \& Ulrike Jessner. 2002. A dynamic model of multilingualism: Perspectives of change in psycholinguistics. Clevedon: Multilingual Matters.

Herschensohn, Julia. 2004. Functional categories and the acquisition of object clitics in L2 French. In Philippe Prévost \& Johanne Paradis (eds.), The acquisition of French in different contexts: Focus on functional categories, 207-242. Amsterdam: John Benjamins.

Hulk, Aafke \& Natascha Müller. 2000. Bilingual first language acquisition at the interface between syntax and pragmatics. Bilingualism: Language and Cognition 3. 227-244.

Jessner, Ulrike. 1999. Metalinguistic awareness in multilinguals: Cognitive aspects of third language learning. Language Awareness 8(3-4). 201-209. DOI: $10.1080 / 09658419908667129$.

Jessner, Ulrike. 2003. On the nature of crosslinguistic interaction in multilinguals. In Jasone Cenoz, Britta Hufeisen \& Ulrike Jessner (eds.), The multilingual lexicon, 45-55. Dordrecht: Kluwer Academic Publishers.

Jessner, Ulrike. 2008a. A DST-model of multilingualism and the role of metalinguistic awareness: Second language development as a dynamic process. Modern Language fournal (92). 270-283.

Jessner, Ulrike. 2008b. Language awareness in multilinguals: Theoretical trends. In Jasone Cenoz \& Nancy Hornberger (eds.), Encyclopedia of language and education. Vol 6: Knowledge about language, 357-369. New York, NY: Springer. 


\section{Sandro Sciutti}

Jessner, Ulrike. 2009. The role of metalinguistic knowledge in L2 and L3 development: A dynamic-systems-theory perspective. The Modern Language fournal 92. 270-283.

Leonini, Chiara. 2006. Object clitics and determiners in the acquisition of Italian as L1 and L2. In Adriana Belletti, Elisa Bennati, Cristiano Chesi, Elisa Di Domenico \& Ida Ferrari (eds.), Language acquisition and development: Pproceedings of GALA 2005, 343-348. Newcastle-upon-Tyne: Cambridge Scholars Press.

Leonini, Chiara \& Adriana Belletti. 2004. Adult L2 acquisition of Italian clitic pronouns and subject inversion/VS structures. In Jacqueline van Kampen \& Sergio Baauw (eds.), Language acquisition and development: Pproceedings of GALA 2004, 293-304. Utrecht: LOT.

Maffei, Sabrina. 2009. Osservazioni sullo sviluppo dei pronomi personali. In Massimo Palermo (ed.), Percorsi e strategie di apprendimento dell'italiano lingua seconda: Sondaggi su ADIL 2, 103-119. Perugia: Guerra.

Montrul, Silvina. 2009. Re-examining the fundamental differences hypothesis: What can early bilinguals tell us? Studies in Second Language Acquisition 2. 225-257.

Santoro, Maurizio. 2007. Second language acquisition of Italian accusative and dative clitics. Second Language Research 23. 37-50.

Schlyter, Suzanne. 1997. Formes verbales et pronoms objets chez des apprenants adultes de français en milieu naturel. In Claire Martinot (ed.), Actes du Colloque International sur l'acquisition de la syntaxe en langue maternelle et en langue étrangère, 273-295. Paris: Les Belles Lettres.

Spinelli, Barbara \& Francesca Parizzi. 2010. Profilo della lingua italiana: Livelli di riferimento del QCER A1, A2, B1, B2. Firenze: La Nuova Italia.

Towell, Richard \& Roger Hawkins. 1994. Approaches to second language acquisition. Clevedon: Multilingual Matters.

Tytus, Agniezska Ewa. 2019. Active and dormant languages in the multilingual mental lexicon. International fournal of Multilingualism 16. 357-374.

White, Lydia. 1996. Clitics in L2 French. In Harald Clahsen (ed.), Generative perspectives on language acquisition, 335-368. Amsterdam: John Benjamins.

Zobl, Helmut. 1992. Prior linguistic knowledge and the conservatism of the learning procedure: Grammaticality judgments of unilingual and multilingual learners. In Susan Gass \& Larry Selinker (eds.), Language transfer in language learning, 177-196. Amsterdam: John Benjamins. 


\section{Chapter 6}

\section{Cognate recognition by young multilingual language learners: The role of age and exposure}

\section{Carmen Muñoz}

\section{Universitat de Barcelona}

The present study set out to investigate the recognition of cognates by young multilingual learners of English as a foreign language. While there is a wealth of research on the role of cognates in vocabulary recognition by bilingual children, much less is known in relation to bilinguals learning a foreign language with limited exposure to that language. The specific research questions that guided the study were: (1) to what extent do young Spanish-Catalan bilingual learners of English recognise English cognate words over non-cognate words in the PPVT test? and (2) what are the respective roles of age (7 vs. 9 years) and amount of exposure to English in cognate word recognition and non-cognate word recognition? Do these factors have the same roles in non-cognate word recognition? To answer these questions, the study examined the extent to which young learners recognised cognates in the Peabody picture vocabulary test (PPVT) (Dunn \& Dunn 2007). Participants were 170 children distributed into a group of 7 year-olds and a group of 9 year-olds. They were all Spanish-Catalan bilinguals, so that English was their third language. The results of the analyses indicated that age was the strongest determinant of cognate word recognition, whereas hours of exposure was the stronger predictor of non-cognate word recognition.

\section{Introduction}

An important issue in studies in second language (L2) learning is whether learners can use their first language (L1) vocabulary knowledge to identify, interpret, 
and use target language vocabulary (Méndez Pérez et al. 2010). Cognates are defined as word pairs in two different languages that share both meaning (translation equivalents) and form (phonological or orthographic similarity) (Kohnert et al. 2004). This definition subsumes three types of cognates: words that are phonologically similar and orthographically identical, words that are phonologically similar but orthographically different, and false cognates in which words are phonologically and orthographically similar but not related in meaning (e.g., Spanish embarazada and English embarrassed) (e.g., Rodríguez 2001).

Cognates have been extensively studied in language processing and learning in bilinguals, but their role in foreign language learning has been somehow neglected in research in spite of the fact that it has always been commonly acknowledged that closely related languages are easier and faster to learn. In fact, one manifestation of cross-linguistic influence or transfer is that learning a new language will be facilitated by the resemblance of that language with a language or languages known to the learner, in particular in receptive tasks (Ringbom 2007). This is the case of cognate words, which will be more likely noticed by the learner in the input and thus also more likely processed and retained in longterm memory. Certainly, research on L2 vocabulary learning has shown that the lexico-semantic representations of new words are better established when they overlap with the native language at form-based linguistic levels (orthography and phonology). In other words, cognates are easier to learn and integrate into the lexicon (e.g., Ellis \& Beaton 1993; De Groot \& van Hell 2005).

One of the reasons for the relative neglect of cognates in foreign language learning research in the last decades has been the emphasis on the use of the target language in the classroom downplaying the role of the learners' native language, although this is currently changing thanks to the influence of teaching perspectives favouring translanguaging in the classroom, which entails using one language to reinforce the other (e.g., Williams 2002; García \& Lin 2016). In addition, communicative language teaching has been somehow perceived as in opposition to explicit approaches to teaching, precluding the teacher's promotion of learners' metalinguistic awareness. This has been especially the case in the young learners' classroom. However, although there are few pedagogically oriented studies on the use of cognates (see Otwinowska 2016), there is now some evidence that instruction designed to raise cross-linguistic awareness of cognates helps school learners recognise similarities between words that were previously unnoticed (White \& Horst 2012), which can boost learners' vocabulary and general L2 proficiency. The main aim of the current study is to shed more light on children's ability to recognise cognates by examining young foreign language 
learners' recognition of cognates and the role of age and exposure to (or contact with $)^{1}$ the foreign language. In addition, the study gathers evidence from bilingual (Spanish-Catalan) learners of a third language (English), which will be especially valuable for future studies addressing differences in cognate recognition in different multilingual constellations.

\section{Literature review}

\subsection{Cognate processing: the cognate facilitation effect}

The cognate facilitation effect refers to the well-documented finding in bilingual studies that cognate words are easier and faster to recognise than non-cognate words (e.g., Caramazza \& Brones 1979; Costa et al. 2000). There is a wealth of research on cognate processing (e.g., van Hell \& De Groot 1998; Dijkstra et al. 1999), with important implications for theories of the bilingual mental lexicon/models of lexical access. A well-established finding from studies on lexical access is that word recognition in a second (or foreign) language is influenced by the native language (e.g., Kroll \& Dijkstra 2002) and that the degree of reliance on the native language depends upon L2 proficiency.

Research has pointed out that the cognate facilitation effect decreases as a function of proficiency, possibly suggesting lower reliance on native language representations at higher proficiency levels (Kroll et al. 2010). Confirmation of this relationship was also found in a study with adult foreign language learners by Casaponsa et al. (2015) in which they explored the strength of the cognate effect as a predictor factor of reading comprehension in two groups of English as a foreign language (EFL) learners at different levels of proficiency. The cognate effect was measured by subtracting reaction times to cognate words from reaction times to non-cognate words in a lexical decision task. The cognate effect was found to be a significant predictor of reading comprehension scores for both groups, but the relationship was positive for the lower proficiency group (level A2 of the CEFR), whereas the degree of reliance on cross-linguistic similarity appeared inversely related to reading comprehension achievement in learners at the relatively higher level of proficiency (level B1). According to Casaponsa and colleagues, this finding suggests a decrease on the strength of L1 reliance in favour of the direct links between L2 lexical representations and semantic concepts, in line with the predictions of current theoretical models (e.g., Kroll \& Stewart 1994).

\footnotetext{
${ }^{1}$ Although the term "contact" may be more adequate than "exposure" in that it also implies productive use of the language, both terms are used indistinctly in this paper.
} 
Only a limited amount of research has addressed cognate processing in trilinguals (van Hell \& Dijkstra 2002; Lemhöfer et al. 2004; Szubko-Sitarek 2011; Poarch \& van Hell 2012). A pioneer study was conducted by van Hell \& Dijkstra (2002) with two groups of trilingual young adults, with Dutch as their native language and English and French as foreign languages. In one group, participants' proficiency in English (L2) was higher than in French (L3), and in the other group their proficiency levels in L2 and L3 were comparable. The aim of the study was to examine whether knowledge of a weaker language would influence performance on words in the dominant language (L1). Participants were presented with word stimuli in their L1; one set of words were cognates with English, one set were cognates with French, and one set consisted of non-cognates. The study found that word association and lexical decision times in the two groups of trilinguals were shorter for words that were cognates with their L2 translations than for words that were non-cognates. For words that were cognates with their L3 translations, a cognate effect was only found in the group with high proficiency in that language.

In other words, a cognate advantage was noticeable only when the speaker was relatively proficient in the non-native language. Similar results were obtained in a study with young children including L2 learners, bilinguals and trilinguals by Poarch \& van Hell (2012). Results indicated a bidirectional cognate facilitation effect but only for bilinguals and trilinguals. For L2 learners only an effect from L1 to L2 was found, which led Poarch \& van Hell to conclude that lower levels of proficiency in an additional language allows only limited cross-linguistic activation.

\subsection{Children's recognition of cognates}

Research that focuses on the spontaneous recognition of cognates by children who have not been instructed to recognise them is especially interesting for the present study. Most research about these children's ability to use cognates as a vocabulary learning strategy or their ability to recognise cognates indicates that, like adults, bilingual and trilingual children also show a cognate facilitation effect (Poarch \& van Hell 2012; Potapova et al. 2016).

Most studies with bilingual children in the US have employed the Peabody picture vocabulary test (PPVT; Dunn \& Dunn 1981; 1997), a standardised receptive vocabulary test, to investigate the potential for a cognate advantage. Umbel et al. (1992) evaluated first graders' performance on the PPVT and the Spanish version, test de vocabulario en imágenes Peabody (TVIP; Dunn et al. 1986). Children from 
Spanish monolingual and Spanish-English bilingual homes in US achieved similar overall scores on both tests and children responded correctly to cognates and non-cognates at about the same rate (68\% vs. $67 \%)$. In a second study, Umbel \& Oller (1994) tested first, third, and sixth graders using the same instruments. The rate of response was similar holding at $60 \%$ for the cognates and $65 \%$ for the noncognates. These researchers concluded that children do not employ awareness of cognates as a vocabulary learning strategy. In the study by Cunningham \& Graham (2000), participants were a group of fifth and sixth grade English-native students in a Spanish immersion programme and a parallel group of monolingual English children. The results showed that on cognate items in the PPVT-revised (PPVT-R; Dunn \& Dunn 1981) the bilingual group did better than the monolingual group, thanks to the positive transfer from Spanish to English, which provides evidence that cognate transfer operates in both directions. In another study, Kelley \& Kohnert (2012) investigated the existence of a cognate advantage in a group of typically developing 8-13 years old Spanish-speaking English-language learners in the US. The cognate advantage was operationalised as the substraction of the proportion of non-cognate items answered correctly from the proportion of cognate items answered correctly. Kelley \& Kohnert used a graded method for objectively classifying crosslinguistic overlap at the phonological level between English and Spanish translation equivalents in the PPVT: the crosslinguistic overlap scale for phonology (COSP). This scale indexes the degree of phonological overlap with respect to four different features: initial sound, number of syllables, percentage of overlapping consonants, and percentage of overlapping vowels (Kohnert et al. 2004: 548). On this basis, participants' accuracy on cognates was estimated at three levels of difficulty, which added information about individuals' performance complementing the finding of a cognate advantage. Kelly \& Kohnert found that at the group level, participants demonstrated a cognate advantage but with large within-group variation. They also found that age predicted significant amounts of variance in cognate performance on the receptive test (PPVT-3; Dunn \& Dunn 1997). Kelley \& Kohnert argued that the children's growing cognate sensitivity may be the result of growing metalinguistic skills.

Other studies have used different tests to investigate cognate recognition. For example, Malabonga et al. (2008) designed the cognate awareness test (CAT) to measure bilingual Spanish-English third, fourth and fifth graders' awareness of cognates. They report that children demonstrated sensitivity to cognate status and that the recognition of cognates increased with age. The CAT was administered in written form, which may also explain the better performance of older children with higher levels of orthography and literacy. Other authors such as Méndez Pérez et al. (2010) have also attributed differences in findings to the appli- 
cation of basal and ceiling rules in the PPVT. They used the picture vocabulary subtest of the TOLD-P:3 (test of language development primary; Newcomer \& Hammill 1997) with kindergarten and first graders, and the criteria selection of cognates was that the two words share three phonemes. In this test cognates are represented in comparable proportions in the first and second halves of the test, suggesting that they are of comparable difficulty level relative to the noncognates. Méndez Pérez and colleagues found that performance on cognate status was related to the children's amount of language exposure: high Spanish exposure bilinguals performed higher on cognates than high English exposure bilinguals and vice versa. No differences were found in cognate recognition between kindergarten and first graders: very young children "may not be overtly aware of cognates, but they are sensitive to them and use their knowledge to respond correctly to items presented verbally" (2010: 7).

Bosma et al. (2019) studied Frisian-Dutch bilingual children's performance on a Frisian receptive vocabulary test at three times (age 5 and 6 at time 1, age 6 and 7 at time 2, age 7 and 8 at time 3). Based on previous findings (Méndez Pérez et al. 2010; Dijkstra 2013) showing that intensity of exposure has an influence on the cognate effect, children were distributed into three groups of exposure to Frisian. The degree of cross-language similarity was operationalised using four different cognate categories, and these were evenly distributed over the task. The results showed that the overlap between Frisian and Dutch words helped children with a low intensity of exposure to Frisian to understand Frisian words that are cognates to Dutch, though for children with high intensity of exposure, no differences between cognate and non-cognate recognition were found. Moreover, the more similar were the words to Dutch, the easier were they to understand. An effect of time was also found in that children improved their sensitivity to words with a lower degree of cross-language similarity. Bosma and colleagues conclude from these findings that for bilingual children, the activation of semantic and phonological representations of both languages depends on the cross-language overlap of a cognate pair, thus implying a gradual cognate facilitation effect.

\subsection{Cognates in FL learning by young school learners}

From time to time, studies conducted with school children have shown the influence on learning outcomes of the language distance between the learners' L1 and the foreign language (e.g., Bild \& Swain 1989; D’Ydewalle \& van de Poel 1999). More recently, research has also highlighted the benefits that the closeness between the native language and the target language may grant very young learners. For example, Unsworth et al. (2015), when comparing grade 1 and grade 
2 Dutch learners of English with different amounts of instruction hours, found that a control group without English instruction also did significantly better on the PPVT test with time. The researchers' suggestion is that because the Dutch vocabulary of those children increased with age, so did the Dutch-English cognates, which helped them recognise more words in the English test.

However, research specifically studying the role of cognates in young learners' foreign language learning is still in relatively short supply. A recent exception is the study by Goriot et al. (2018) which aimed at investigating the extent to which phonological overlap between item-translation pairs predicts the performance on the PPVT-4 of five different groups of Dutch young learners of English. Goriot and colleagues used a continuous measure, the phonological Levenshtein distance (Schepens et al. 2013), to determine phonological similarity between pairs of items; this measure showed a high correlation with a subjective measure obtained from a group of Dutch-L1 raters. The study also focused on word frequency (in Dutch and English) and its potential predictive role in different age and exposure groups. Their findings show that phonological similarity between Dutch and English words was a positive and significant predictor of pupils' performance on the test. This result was found across all age groups: in primary school children (4-5, 8-9, and 11-12 year-olds) and in secondary school children (12-13 and 14-15 year-olds), and the effect was larger for older than for younger children.

Other recent studies with young foreign language learners have taken a comparative perspective, focusing on the role of cognates in the degree of difficulty that the same target language represents for learners with different native languages. An example is the study of a large group of fourth graders (10-11 years old) across seven European countries by Lindgren \& Muñoz (2013). These researchers found that cognate linguistic distance, a measure of the degree of relatedness of the learners' L1 to the target language (Dyen et al. 1992), together with out-of-school contact, predicted a large part of the variance in the learners' listening and reading comprehension test scores. Furthermore, cognate linguistic distance explained more variance in listening comprehension than in reading comprehension. The study by Muñoz et al. (2018) also provides comparative evidence of the very strong role played by cognates in the acquisition of the same foreign language by young learners with different native languages. In this study, the researchers compared the English receptive grammar skills of two groups of 7- and 9-year-old L1-Danish children at the beginning of English instruction and two groups of L1-Spanish-Catalan children of the same age after several years of instruction. As a measure of cognate recognition skills, these researchers used a cognate recognition index calculated from the proportion of cognates that were 


\section{Carmen Muñoz}

recognised in the PPVT-4. The results showed that Danish children's receptive knowledge of English prior to school instruction was largely similar to that of Spanish children after several years of instruction, and the strongest predictor of outcomes was the respective groups' cognate recognition skills, followed by out-of-school contact with English. Another finding of the study was that the 9-year olds attained higher mean scores than the 7-year olds, but this result may be seen as the result of instruction and exposure only in the case of the Spanish learners. The advantage of the older over the younger Danish children on the receptive vocabulary test appears to be an effect of their older age. Because of their older age, the 9-year olds had a larger vocabulary in Danish, which likely helped them recognise more cognate words in English (as suggested for Dutch children by Unsworth et al. 2015), and they seemingly had a superior crosslinguistic awareness that also helped them recognise words in a language that is close to their L1 (Otwinowska 2016).

All together, it seems that the effect of cognates may be pervasive across different learning settings, for both adults and children, and for bilingual, trilingual, and foreign language learners. However, results of studies may have been affected by the type of test, method of classification of cognate status, selection of cognates, or test scoring. Unclear results have been obtained in relation to an increase in cognate recognition with age or grade level, as seen above, and the effect of age and exposure may have not been totally dissociated in some studies.

\section{Method}

This study aims at exploring the role of phonological cognates in vocabulary recognition by young foreign language learners and, in particular, to throw more light on the role that age and amount of exposure to the language may have. While there is a wealth of research on the role of cognates in vocabulary recognition by bilingual children, much less is known in relation to bilinguals learning a foreign language with limited exposure to that language. The specific research questions of the study are the following:

1. To what extent do young Spanish-Catalan bilingual learners of English recognise English cognate words over non-cognate words in the PPVT test?

2. What are the respective roles of age (7 vs. 9 years) and amount of exposure to English in cognate word recognition? Do these factors have the same roles in non-cognate word recognition? 


\subsection{Participants}

Participants were 170 children distributed into a group of 7 year-olds in grade 2 ( $n=77 ; 42$ males and 35 females) and a group of 9 year-olds in grade $4(n=93$; 40 males and 53 females). They were all Spanish-Catalan bilinguals, so that English was their third language. Although Catalan is the language of the school in Catalonia, Spanish is the majority language and its presence in the media and in society is strong. Children may have Spanish or Catalan as the family language, or both, and their type of bilingualism may be considered balanced in most cases. Spanish and Catalan are two closely related Romance languages and their respective cognate linguistic distance to English (Dyen et al. 1992) is very similar (240 and 236, respectively). ${ }^{2}$ Participants came from four primary schools in the area of Barcelona, and the schools varied in their provision of English instruction hours and even more so of CLIL (content and language integrated learning) hours. It was a convenience sample offering large variability in the number of contact hours, which allowed us to dissociate age and amount of contact hours (see Table $6.1 \mathrm{in} \S 4$ ). Consent was obtained from the families through the schools.

\subsection{Instrument and procedure}

To assess children's recognition of cognates, the Peabody picture vocabulary test, fourth edition (PPVT-4) (Dunn \& Dunn 2007) was used. This test is a pictureselection test consisting of 228 items organised into 19 sets, containing 12 items each. Children hear a word (e.g. "ball") and have to choose the corresponding picture from a set of four (a flower, a pumpkin, a ball, and a bird). For each learner, the test administration stops when the learner does not answer more than eight questions correctly in the same set.

The administration of the PPVT followed the manual indications with the exception that the test was given from the beginning to every child, independent of their age (see Unsworth et al. 2015). The test was administered one-on-one at the children's schools and a female native speaker of Catalan (a model similar to the children's teachers) produced the oral stimuli for all children. Scoring procedures followed the test manual. Raw scores for each child were calculated. The maximum score on this test was 228 .

\footnotetext{
${ }^{2}$ These values show the distance in a three-digit format, representing the percentage of the compared cognates that the languages share: English and Spanish share 24.0 percent and English and Catalan share 23.6 percent of cognates.
} 


\subsection{Cognate selection and measures}

First of all, items in the PPVT were categorised as cognates or non-cognates based on etymology. Then, phonological cognates were selected from the larger set of etymological or linguistic cognates, because the latter may not be identified when heard, even by adults (Stadthagen-González et al. 2013). This selection eliminated linguistic cognates that have different phonological forms although they could be recognised in written form or through training or instruction. Following Méndez Pérez et al. (2010) the criterion used was that the English word shared three phonemes with the corresponding word in Spanish or Catalan (no discrepancies between the two languages were found). For very short words such as chef two equal phonemes were considered sufficient to determine cognate status. This method yielded a list of cognate words that perfectly correlated with the list obtained from a group of 10 naïve adult Spanish-Catalan L1 speakers (with very little or no knowledge of English), who were asked to provide translation equivalents of the words in the PPVT. Words were read aloud (without pictures) with the aim of verifying the degree to which cognates could be identified phonologically. Based on the responses, the category of sound-based or phonological cognate was decided where more than $50 \%$ of the responses given were accurate (see a similar procedure in Stadthagen-González et al. 2013).

The number of English-Spanish/Catalan cognates the participants were exposed to was 48 , because none of the children could go beyond set 11 (see Appendix for the list of 48 cognate words). As a consequence of the administration procedure (see above), not all children were exposed to the same number of cognates, which made it necessary to use a measure that took into account both the number of cognate words recognised by each child and the number of cognate words the child had been exposed to (see Muñoz et al. 2018). Thus, using the responses of each participant to PPVT items, the following calculations were made:

a. the total number of words heard (individual ceiling);

b. the total number of correct responses on cognates and non-cognate words;

c. a cognate recognition index (CRI) defined as the total number of cognate words correctly identified out of the total number of cognate words heard, which measures the degree of recognition for cognate items;

d. a non-cognate recognition index (NCRI) defined as the total number of noncognate words correctly identified out of the total number of non-cognate words heard and used as a measure of the degree of recognition for noncognate items. 
Age 7 or 9 corresponded to grades 2 and 4, respectively, and this is the variable used in the analyses. As for amount of exposure to English, it was decided to include the sum of both hours of English instruction and CLIL hours in the analysis. This follows from the assumption (confirmed by the participants' teachers) that cognates are not the focus of explicit attention in the English class. Therefore, the total number of hours of contact with English, both in English subject classes and in content subject classes where English was used as the medium of instruction, was deemed to be a better measure of exposure or contact with English. It needs to be reminded that amount of contact hours with the English language is largely independent of grade because schools varied in their provision of English.

\section{Results}

Table 6.1 provides the descriptive statistics for the total number of correct responses (PPVT raw scores), the cognate recognition index (CRI), the non-cognate recognition index (NCRI) and the amount of exposure to English in English lessons (EFL Hours) and in English and CLIL lessons.

Table 6.1: Descriptive statistics

\begin{tabular}{|c|c|c|c|c|c|c|c|c|c|c|}
\hline \multirow[b]{2}{*}{ Group } & \multicolumn{2}{|c|}{ PPVT } & \multicolumn{2}{|c|}{ CRI } & \multicolumn{2}{|c|}{ NCRI } & \multicolumn{2}{|c|}{ EFL Hours } & \multicolumn{2}{|c|}{ EFL+CLIL Hours } \\
\hline & $M$ & SD & $M$ & $\mathrm{SD}$ & $M$ & $\mathrm{SD}$ & $M$ & $\mathrm{SD}$ & $M$ & SD \\
\hline $\begin{array}{l}7 \text { yrs/Grade } 2 \\
(N=77)\end{array}$ & 30.08 & 17.67 & 0.64 & 0.17 & 0.49 & 0.08 & 281.92 & 123.25 & 385.94 & 175.27 \\
\hline $\begin{array}{l}9 \text { yrs/Grade } 4 \\
(N=93)\end{array}$ & 59.03 & 28.43 & 0.74 & 0.11 & 0.55 & 0.07 & 525.21 & 138.82 & 858.02 & 299.01 \\
\hline
\end{tabular}

In order to answer the first research question, which asked whether these young Spanish-Catalan learners of English would recognise cognate words better than non-cognate words, the proportion of correct cognates out of the cognates they heard (CRI) and the proportion of correct non-cognates out of the noncognates they heard (NCRI) were compared first for the two groups together. Outliers were recoded to the highest and lowest reasonable score $(\max \pm 1)$. A test of normality (Shapiro-Wilk) showed that the variable CRI was still not normally distributed. Accordingly, the difference was tested with a related-samples Wilcoxon signed rank test. The test indicated that cognates were more frequently recognised $($ median $=0.71)$ than non-cognates $($ median $=0.53)$ and the effect size is large, $Z=-9.97, p<0.001, r=0.54$. Subsequent related-samples Wilcoxon 


\section{Carmen Muñoz}

signed rank tests with grade 2 and grade 4 separately confirmed that the difference is statistically significant in both groups (see Figures 6.1-6.2). For the younger group, in grade 2, the results indicated that the participants recognised cognates (median $=0.67)$ more accurately than non-cognates (median $=0.50$ ), $Z=-5.89, p<0.001, r=0.47$. Likewise, the older children, in grade 4 , recognised cognates (median $=0.76)$ more accurately than non-cognates (median $=$ 0.56) $Z=-8.08, p<0.001, r=0.59$. The effect sizes were large in both cases.

Furthermore, to see if the difference in cognate recognition between the two age groups is statistically significant, an independent samples Mann-Whitney $U$ test was conducted. The difference in cognate recognition between 9-year-old learners (median $=0.76)$ and 7-year-old learners (median $=0.67)$ was shown to be significant, $U=4901, p<0.001, r=0.32$. Another independent samples Mann-Whitney $U$ test also showed that 9-year-olds (median $=0.56$ ) outperformed 7-year-olds (median $=0.50)$ in non-cognate recognition. $U=5176$, $p<0.001, r=0.38$. The effect sizes were moderate.

The second research question was concerned with the respective role of age (7 vs. 9 years) and amount of contact hours on cognate word recognition. A generalised linear mixed model (GLMM) analysis was calculated with CRI as the dependent variable. Participants were nested into age groups and groups into schools. Age and contact hours (the sum of English instruction and CLIL hours) were the fixed factors; there was no multicollinearity between these two variables (VIF < 3). School was introduced as a random intercept. The results, displayed in Table 6.2, show that there was a significant effect of age $(p<0.01)$, with the younger group scoring lower than the older group by about 0.12 points when all other factors were held constant. In contrast, the factor contact hours did not show a significant effect.

Table 6.2: Parameter estimates from the model for CRI

\begin{tabular}{lccrrrr}
\hline \hline & \multicolumn{6}{c}{ Fixed effects } \\
\cline { 2 - 7 } Parameters & Estimate & \multicolumn{1}{c}{ SE } & \multicolumn{1}{c}{$t$} & $p$-value & {$[95 \%$ CI $]$} \\
\hline Intercept & 0.77 & 0.08 & 10.13 & 0.000 & 0.620 & 0.921 \\
Age/Grade $^{a}$ & -0.12 & 0.04 & -2.91 & 0.004 & -0.199 & 0.038 \\
Contact hours $^{6}$ & $6.24 \times 10^{-5}$ & $8.39 \times 10^{-5}$ & -0.74 & 0.458 & 0.000 & 0.000 \\
\hline \hline
\end{tabular}

${ }^{a}$ Age $7 /$ Grade 2 is the reference group 
6 Cognate recognition by young multilingual language learners

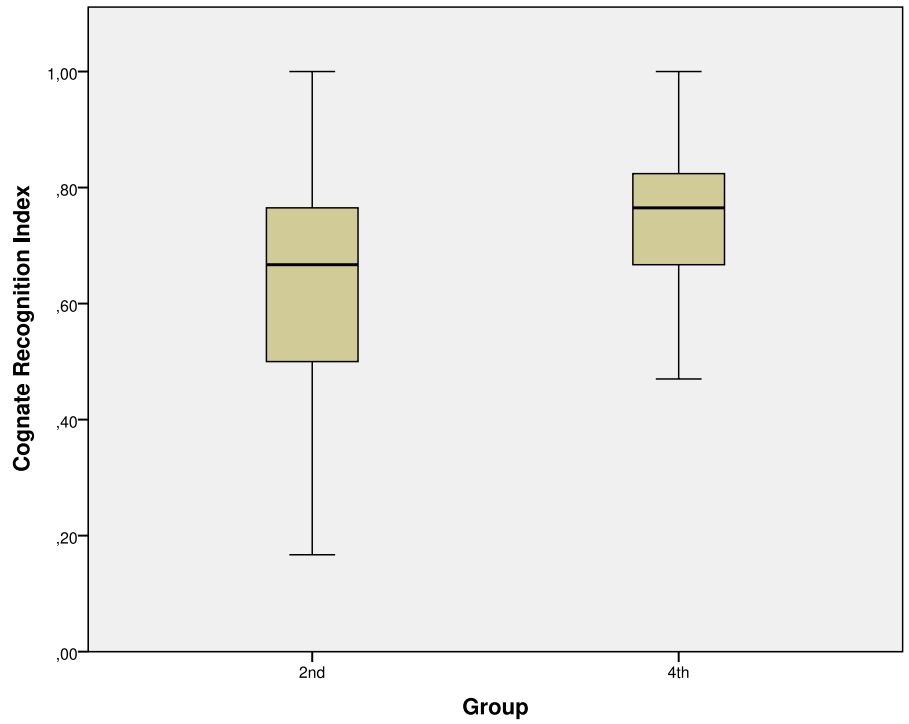

Figure 6.1: Boxplot of CRI per age/grade level

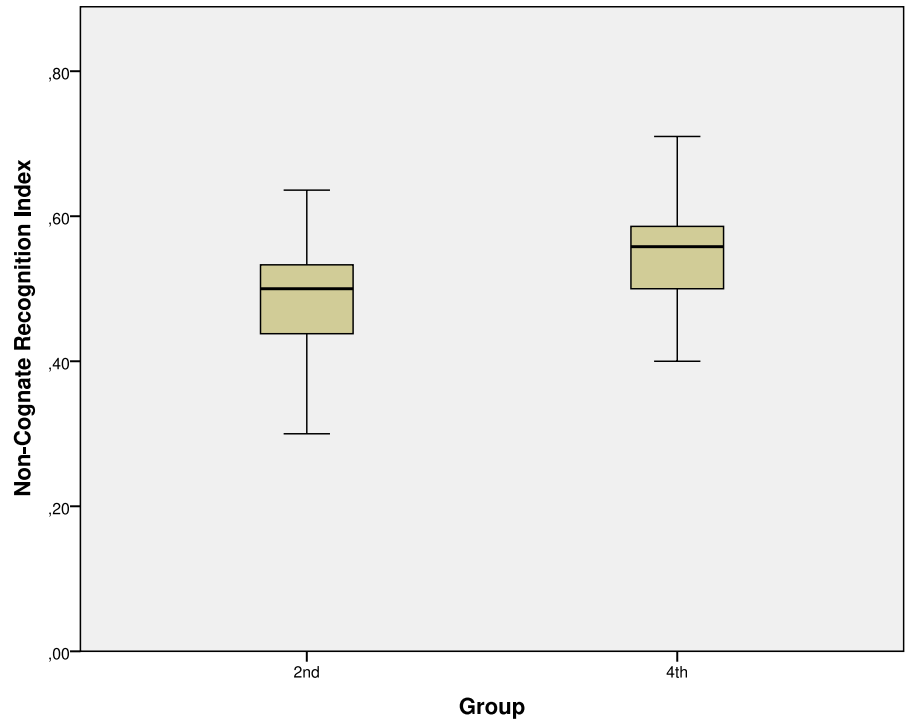

Figure 6.2: Boxplot of NCRI per age/grade level 


\section{Carmen Muñoz}

A similar analysis was conducted to assess the role of age and contact hours on these children's recognition of non-cognate words. As displayed in Table 6.3, age was not a significant predictor of non-cognate word recognition, but there was a main effect of total hours of contact $(p<0.01)$. In other words, the higher the amount of contact hours with English, the more non-cognate words were known (although the increase that an average child would experience for every 1 extra hour is extremely small).

Table 6.3: Parameter estimates from the model for NCRI

\begin{tabular}{lccrcrc}
\hline \hline & \multicolumn{5}{c}{ Fixed effects } \\
\cline { 2 - 7 } Parameters & Estimate & \multicolumn{1}{c}{ SE } & \multicolumn{1}{c}{$t$} & $p$-value & \multicolumn{2}{c}{ [95\% CI] } \\
\hline Intercept & 0.47 & 0.03 & 15.45 & 0.000 & 0.407 & 0.527 \\
Age/Grade $^{a}$ & -0.02 & 0.02 & -0.87 & 0.386 & -0.053 & 0.021 \\
Contact hours & $9.701 \times 10^{-5}$ & $3.578 \times 10^{-5}$ & 2.71 & 0.007 & $2.637 \times 10^{-5}$ & 0.000 \\
\hline \hline
\end{tabular}

${ }^{a}$ Age $7 /$ Grade 2 is the reference group

\section{Discussion}

In order to answer the first research question, which asked whether young Spanish-Catalan learners of English as a third language recognise cognate words better than non-cognate words, the proportion of correct answers to cognates and the proportion of correct answers to non-cognates were compared. The results indicated that these learners spontaneously relied on phonological similarity as a strategy to match the word they heard with the meaning provided by the picture they chose. As seen above, this cognate advantage was not found in the studies by Umbel et al. (1992) and Umbel \& Oller (1994) with Spanish-speaking children in English immersion programmes in the US. One possible explanation may be that they included all linguistic cognates in the analysis, some of which may not have been recognised by the children because of pronunciation differences. The results of the current study line up with most previous results, such as those by Cunningham \& Graham (2000) also using the PPVT with English-monolingual and English-Spanish bilingual children and showing higher recognition of cognate words by the latter. A cognate advantage was also found in the study by Kelley \& Kohnert (2012) with Spanish-speaking English-language learners using the PPVT and a scale indexing cognate overlap and degree of difficulty. With young 
foreign language learners, Goriot et al. (2018) found that phonological similarity between Dutch and English words was a positive and significant predictor of pupils' performance on the PPVT.

Another finding of the current study is that, although both 7-year olds and 9 year-olds showed a large and significant difference in the proportion of correct answers to cognate items and non-cognate items, the older children significantly outperformed the younger children in both groups of items. This result is in line with the result obtained by Malabonga et al. (2008), who found that the recognition of cognates by bilingual Spanish-English children increased with age in their first, third, and fifth graders. However, the test in that study was administered in written form, which may also explain the better performance of older children with higher levels of orthography and literacy. The current study also revealed a better performance by the older children group, but the test was administered in oral form, which avoids the confounding effect of literacy. The older advantage in cognate recognition has also been found in recent studies with bilingual children (Bosma et al. 2019) and young foreign language learners (Goriot et al. 2018; Muñoz et al. 2018). The explanation of this age advantage may be found in the concurrent development of metalinguistic skills (Muñoz 2006; 2014; Kelley \& Kohnert 2012) and of L1 vocabulary size (Unsworth et al. 2015) with age.

The issue of whether the older children's advantage is an effect of age solely, or of previous amount of exposure to English as well, was addressed by the analyses pertaining to the second research question. A GLMM allowed us to account for the variability introduced by the different schools. The analyses showed that age was a very strong predictor of cognate recognition. On the other hand, the factor contact hours (including English instruction hours as well as CLIL hours) was not. This result is in line with the results of the first research question showing the significant effect of age on cognate recognition and confirms findings from previous research with bilingual children and with young foreign language learners (see above). The fact that the age gap was relatively small (2 years) also suggests that cognate awareness undergoes significant development between the two age points examined in the current study (age 7 and 9). The fact that age and contact hours could be dissociated here to some extent, because of the variability in the provision of English in the different schools, yields evidence that the effect of age on cognate-word recognition is stronger than the effect of contact hours in the learners in the current study. In contrast to the results relative to cognate word recognition, the results concerning non-cognate word recognition showed that hours of contact with English was a stronger explanatory factor of these children's performance on non-cognate words than age. This finding was not unexpected and may be certainly attributed to the differences in proficiency 
and vocabulary size resulting from the different amounts of instruction and contact hours. However, the finding is valuable in showing a marked contrast between the results from cognate recognition and from non-cognate recognition, respectively, validating and highlighting the strong influence of age and cognate awareness on the former.

\section{Conclusion and future perspectives}

This study examined young learners' recognition of English-Spanish/Catalan cognate words through the analysis of their performance on the PPVT. It provided evidence of a cognate advantage in two different age groups (age 7 and 9) as well as evidence of an age advantage in that the older group outperformed the younger group in cognate recognition. The strong influence of age as an indicator of children's stage of cognate awareness has been highlighted by the results that have contrasted the effects of age and contact hours on cognate and non-cognate word recognition.

Based on these findings, several pedagogical implications can be inferred. The study has revealed a cognate effect in young foreign language learners who have not been instructed to rely on cross-linguistic similarities. Teachers could use this incipient cognate awareness and foster it in the classroom to help young learners build a substantial L2 vocabulary that acts as a springboard for further L2 development, which would maximise classroom English language learning. Later on, teachers could capitalise on learners' spontaneous recognition of phonological cognates to guide them through the phonological rules in the two languages (and the respective grapho-phonemic rules to enhance their recognition of written words; Lázaro Ibarrola 2010) in order to improve their vocabulary and comprehension.

This study is not without limitations. The first one is the use of the PPVT itself. Although the PPVT is probably the most popular test in this area, it may not be totally adequate for bilingual or foreign language learners because it was normed on a monolingual population. In addition, a test especially designed to measure awareness of cognate pairs between specific languages may be preferable (see Goriot et al. 2018; Leśniewska et al. 2018). Future research could look at larger age differences to better appreciate changes in cognate recognition with age. Longitudinal studies could also inform us of the developmental course. The design of future studies could also try to control for the variable amount of contact with the target language in order to shed more light on the respective predictive power of the two variables in different combinations of age and amount of 
contact hours (including out-of-school hours; see Muñoz et al. 2018). Finally, an issue that remains to be explored is the relationship between the cognate effect and proficiency levels that are higher than the beginner levels in this study, since there is some evidence of a decrease in cognate effect with adult foreign language learners with intermediate proficiency levels (i.e., at B1 in Casaponsa et al. 2015). Such a study should likely be conducted with older children than those in the current study, who will be expected to have reached higher proficiency levels.

\section{Acknowledgments}

This study was funded by the grant SGR 560 awarded to the GRAL group by AGAUR. I am very grateful to the schools and children that participated in the study, and to Ferran Gesa, Geòrgia Pujadas, and Radha Chandy for their help with the data.

\section{Appendix A List of Spanish/Catalan cognates in the PPVT (Sets 1-11)}

banana - banana/banana
bus - (auto)bús/(auto)bús
painting - pintando/pintant
dancing - danzando/dansant
lamp - lámpara/làmpada
castle - castillo/castell
penguin - pingüino/pingüí
fountain - fuente/font
tunnel - túnel/túnel
diamond - diamante/diamant
calendar - calendario/calendari
panda - panda/panda
cactus - cactus/cactus
dentist - dentista/dentista
floating - flotando/flotant
uniform - uniforme/uniforme
gigantic - gigantesco/gegantí(gegantesc)
violin - violin/violí
group - grupo/grup
globe - globo/globus

chef - chef/xef

flamingo - flamenco/flamenc

chimney - chimenea/xemeneia

vegetable - vegetal/vegetal

hyena - hiena/hiena

horrified - horrorizado/horroritzat

pigeon - pichón (paloma)/colom

flaming - flambeado/flamejat

aquarium - acuario/aquari

reptile - reptil/rèptil

canoe - canoa/canoa

directing - dirigiendo/dirigint

digital - digital/digital

dissecting - diseccionando/diseccionant

predatory - predatorio/predatori

hydrant - hidrante/hidrant

surprised - sorprendido/sorprès

palm - palma/palma

clarinet - clarinete/clarinet

kiwi - kiwi/kiwi 


\section{Carmen Muñoz}

interviewing - entrevistando/entrevistant solo - solo/sol

pastry - pastel/pastís

inflated - inflado/inflat

assisting - asistiendo/assistint

trumpet - trompeta/trompeta

fragile - frágil/fràgil

rodent - roedor/rosegador

\section{References}

Bild, Eva-Rebecca \& Merrill Swain. 1989. Minority language students in a French immersion programme: Their French proficiency. Journal of Multilingual and Multicultural Development 10(3). 255-274. DOI: 10.1080/01434.9994377.

Bosma, Evelyn, Elma Blom, Eric Hoekstra \& Versloot Arjen. 2019. A longitudinal study on the gradual cognate facilitation effect in bilingual children's Frisian receptive vocabulary. International fournal of Bilingual Education and Bilingualism 22(4). 371-385. DOI: 10.0050.2016.1254152.

Caramazza, Alfonso \& Isabel Brones. 1979. Lexical access in bilinguals. Bulletin of the Psychonomic Society 13. 212-214. DOI: 10.3758/BF03335062.

Casaponsa, Aina, Eneko Antón, Alejandro Pérez \& Jon Andoni Duñabeitia. 2015. Foreign language comprehension achievement: Insights from the cognate facilitation effect. Frontiers in Psychology 6. DOI: 10.3389/fpsyg.2015.00588.

Costa, Albert, Alfonso Caramazza \& Núria Sebastian-Gallés. 2000. The cognate facilitation effect: Implications for models of lexical access. Fournal of Experimental Psychology: Learning, Memory and Cognition 26(5). 1283-1296.

Cunningham, Thomas. H. \& C. Ray Graham. 2000. Increasing native English vocabulary recognition through Spanish: Cognate transfer from foreign to first language. Fournal of Educational Psychology 92. 37-49.

D’Ydewalle, Géry \& Marijke van de Poel. 1999. Incidental foreign-language acquisition by children watching subtitled television programs. Fournal of Psycholinguistic Research 28(3). 227-244. DOI: 10.1023/A:1023202130625.

De Groot, Annette M. B. \& Janet G. van Hell. 2005. The learning of foreign language vocabulary. In Judith F. Kroll \& Annette M. B. De Groot (eds.), Handbook of bilingualism: Psycholinguistic approaches, 9-29. Oxford: Oxford University Press.

Dijkstra, Jelske. 2013. Growing up with Frisian and Dutch. Leeuwarden: Fryske Akademy.

Dijkstra, Ton, Jonathan Grainger \& Walter J. B. van Heuven. 1999. Recognition of cognates and interlingual homographs: The neglected role of phonology. Journal of Memory and Language 41. 496-518. DOI: 10.1006/jmla.1999.2654.

Dunn, Lloyd M. \& Douglas M. Dunn. 2007. Peabody picture vocabulary test. 4th edn. Bloomington, MN: NCS Pearson. 
Dunn, Lloyd M. \& Leota M. Dunn. 1981. Peabody picture vocabulary test: Revised. Circle Pines: AGS.

Dunn, Lloyd M. \& Leota M. Dunn. 1997. Peabody picture vocabulary test: Third edition. Circle Pines, MN: AGS.

Dunn, Lloyd M., Eligio R. Padilla, Delia E. Lugo \& Leota M. Dunn. 1986. Test de vocabulario en imágenes peabody. Circle Pines, MN: AGS.

Dyen, Isidore, Joseph. B. Kruskal \& Paul Black. 1992. An Indoeuropean classification: A lexicostatistical experiment. Transactions of the American Philosophical Society 82 . iii-132.

Ellis, Nick C. \& Alan Beaton. 1993. Factors affecting the learning of foreign language vocabulary: Imagery keyword mediators and phonological short-term memory. Quarterly fournal of Experimental Psychology 46(3). 533-558. DOI: 10.1080/14640749308401062.

García, Ofelia \& Angel Lin. 2016. Translanguaging in bilingual education. In Ofelia García, Angel Lin \& Stephen May (eds.), Bilingual and multilingual education, 117-130. Berlin: Springer International Publishing.

Goriot, Claire, Roeland van Hout, Mirjam Broersma, Vanessa Lobo, James M. McQueen \& Sharon Unsworth. 2018. Using the Peabody picture vocabulary test in L2 children and adolescents: Effects of L1. International fournal of Bilingual Education and Bilingualism. Advanced online publication. DOI: 10.0050.2018. 1494131.

Kelley, Alaina \& Kathryn Kohnert. 2012. Is there a cognate advantage for typically developing Spanish-speaking English-language learners? Language, Speech, and Hearing Services in Schools 43(2). 191-204.

Kohnert, Kathryn, Jennifer Windsor \& Ruth Miller. 2004. Crossing borders: Recognition of Spanish words by English-speaking children with and without language impairment. Applied Psycholinguistics 25. 542-564. DOI: 10.1017/ S0142716404001262.

Kroll, Judith F. \& Ton Dijkstra. 2002. The bilingual lexicon. In Robert B. Kaplan (ed.), Handbook of applied linguistics, 301-321. Oxford: Oxford University Press.

Kroll, Judith F. \& Erika Stewart. 1994. Category interference in translation and picture naming: Evidence for asymmetric connections between bilingual memory representations. Fournal of Memory and Language 33(2). 149-174. DOI: 10. 1006/jmla.1994.1008.

Kroll, Judith F., Janet G. van Hell, Natasha Tokowicz \& David W. Green. 2010. The revised hierarchical model: A critical review and assessment. Bilingualism 13(3). 373-381. DOI: 10.1006/jmla.1994.1008. 


\section{Carmen Muñoz}

Lázaro Ibarrola, Amparo. 2010. English phonics for Spanish children: Adapting to new English as a Foreign Language classrooms. In Bårbel Diehr \& Jutta Rymarczyk (eds.), Researching literacy in a foreign language among primary school learners, 89-106. Bern: Peter Lang. DOI: 10.3726/978-3-653-05656-3.

Lemhöfer, Kristin, Ton Dijkstra \& Marije Michel. 2004. Three languages, one ECHO: Cognate effects in trilingual word recognition. Language and Cognitive Processes 19. 585-611.

Leśniewska, Justyna, François Pichette \& Sébastien Béland. 2018. First language test bias? Comparing French-speaking and Polish-speaking participants' performance on the Peabody picture vocabulary test. Canadian Modern Language Review 74(1). 27-52. DOI: 10.3138/cmlr.3670.

Lindgren, Eva \& Carmen Muñoz. 2013. The influence of exposure, parents, and linguistic distance on young European learners' foreign language comprehension. International fournal of Multilingualism 10. 105-129.

Malabonga, Valerie, Dorry M. Kenyon, María Carlo, Diane August \& Mohammed Louguit. 2008. Development of a cognate awareness measure for Spanishspeaking English language learners. Language Testing 25(4). 495-519.

Méndez Pérez, Anita, Elizabeth D. Peña \& Lisa M. Bedore. 2010. Cognates facilitate word recognition in young Spanish-English bilinguals' test performance. Early Childhood Services 4(1). 55-67.

Muñoz, Carmen (ed.). 2006. Age and the rate of foreign language learning. Clevedon: Multilingual Matters.

Muñoz, Carmen. 2014. Complexities and interactions of age and second language learning: Broadening the research agenda. Applied Linguistics 35(4). 369-373. DOI: 10.1093/applin/amu033.

Muñoz, Carmen, Teresa Cadierno \& Isabel Casas. 2018. Different starting points for English language learning: A comparative study of Danish and Spanish young learners. Language Learning 68(4). 1076-1109.

Newcomer, Phyllis L. \& Donald P. Hammill. 1997. Test of language developmentprimary. 3rd edn. Austin, TX: PRO-ED.

Otwinowska, Agnieszka. 2016. Cognate vocabulary in language acquisition and use: Attitudes, awareness, activation. Clevedon: Multilingual Matters.

Poarch, Gregory J. \& Janet G. van Hell. 2012. Cross-language activation in children's speech production: Evidence from second language learners, bilinguals, and trilinguals. Journal of Experimental Child Psychology 111. 419-438.

Potapova, Irina, Henrike. K. Blumenfeld \& Sonja Pruitt-Lord. 2016. Cognate identification methods: Impacts on the cognate advantage in adult and child Spanish-English bilinguals. International fournal of Bilingualism 20(6). 714-731. DOI: 10.006915586586. 
Ringbom, Håkan. 2007. Cross-linguistic similarity in foreign language learning. Clevedon: Multilingual Matters.

Rodríguez, Timothy A. 2001. From the known to the unknown: Using cognates to teach English to Spanish-speaking literates. Reading Teacher 45. 744-747.

Schepens, Job, Ton Dijkstra, Franc Grootjen \& Walter J. B. van Heuven. 2013. Cross-language distributions of high frequency and phonetically similar cognates. DOI: 10.1371/journal.pone.0063006.

Stadthagen-González, Hans, Virginia C. Mueller Gathercole, Rocío Pérez-Tattam \& Feryal Yavas. 2013. Vocabulary assessment in bilinguals: To cognate or not to cognate. In Virginia C. Mueller Gathercole (ed.), Solutions for the assessment of bilinguals, 125-145. Clevedon: Multilingual Matters.

Szubko-Sitarek, Weronika. 2011. Cognate facilitation effects in trilingual word recognition. Studies in Second Language Learning and Teaching 1(2). 189-208.

Umbel, Vivian M. \& D. Kimbrough Oller. 1994. Developmental changes in receptive vocabulary in Hispanic bilingual school children. Language Learning 44(2). 221-242.

Umbel, Vivian M., Barbara Z. Pearson, María C. Fernández \& D. Kimbrough Oller. 1992. Measuring bilingual children's receptive vocabulary. Child Development 63. 1012-1020.

Unsworth, Sharon, Liv Persson, Tineke Prins \& Kees De Bot. 2015. An investigation of factors affecting early foreign language learning in the Netherlands. Applied Linguistics 36(5). 527-548.

van Hell, Janet G. \& Annette M. B. De Groot. 1998. Conceptual representation in bilingual memory: Effects of concreteness and cognate status in word association. Bilingualism: Language and Cognition 1(3). 193-211.

van Hell, Janet G. \& Ton Dijkstra. 2002. Foreign language knowledge can influence native language performance in exclusively native contexts. Psychonomic Bulletin and Review 9. 780-789.

White, Joanna \& Marlise Horst. 2012. Cognate awareness-raising in late childhood: Teachable and useful. Language Awareness 21(1-2). 181-196.

Williams, Cen. 2002. Extending bilingualism in the education system. Education and lifelong learning committee ELL-06-02. http://www.assemblywales.org/ 3c91c7af00023d820000595000000000.pdf (3 October, 2017). 



\title{
Chapter 7
}

\section{Age meets multilingualism: Influence of starting age on $\mathrm{L} 3$ acquisition across different learner populations}

\author{
Simone E. Pfenninger \\ University of Salzburg
}

This paper combines two major strands of multilingualism research, namely that of the role of starting age in (multiple) foreign language (FL) learning, and that of the influence of bilingualism and biliteracy on third language (L3) acquisition. I report on the results of a five-year longitudinal study in Switzerland, in which we assessed the English development of 636 secondary school students, who had all learned Standard German and French at primary school, but only half of whom had had English from third grade (age 8) onwards, the remainder having started English instruction five years later at secondary school. The main goals were to analyze (1) whether early bilinguals were more successful than later bilinguals and monolinguals at learning a new language from primary school through the end of secondary school; and (2) how literacy skills in the home language(s) affected literacy development in EFL. The findings suggest that different learner populations (monolinguals, simultaneous bilinguals, sequential bilinguals) are differentially affected by age of EFL onset effects, partly due to individual differences (e.g. (bi)literacy skills), partly due to contextual effects that mediate successful L3 outcomes.

\section{Introduction}

In the past decade, there has been a dramatic increase in two major strands of multilingualism research: on the one hand, research investigating the linguistic and cognitive abilities of bilingual children, particularly in terms of how bilingualism may alter the path of development typically taken by their monolingual 
peers (see e.g. Bialystok \& Feng 2011), and on the other one, studies that explore the role of starting age in (multiple) foreign language (FL) learning. This study attempts to combine these two strands. It was prompted by a need to explore the benefits of early FL programs for different learner populations in the light of the heterogeneous nature of early FL classrooms. Specifically, I intend to shed light on three widely held - and competing - elements of folk wisdom: first, the assumption that "younger is better" in FL learning; second, the idea that solidity in the L1 - particularly L1 literacy skills - is a prerequisite for successful second language (L2) learning; and third, the belief that the early introduction of several FLs puts children (particularly from immigrant backgrounds) at risk in that it might have a detrimental effect on the development of (literacy) skills in the language of the country/region.

So far there has been a monolingual bias present in age-related classroom research in SLA (e.g. García Mayo \& García Lecumberri 2003; Muñoz 2006) as age effects on the additional language learning of different types of bilinguals have not yet been investigated with some systematicity, which is regrettable for several reasons. On the one hand, it has been well-documented that bi/multilinguals make up a significant portion of the population, and multilingualism has become an international fact of life (Grosjean 2010), which means that we are dealing with increasing numbers of multilingual children with a variety of different cultural backgrounds in our schools (Meijer et al. 2003). On the other hand, the profile of second language (L2) skill development that has been obtained for monolingual early and late starters of an L2 may be different in crucial respects from that of children who are developing two languages in childhood and establishing basic cognitive competencies through the mediation of two languages (for a recent review see Bialystok et al. 2016). Bilinguals are often regarded as particularly talented language learners, and research has corroborated the belief that the more languages you know the easier it is to learn an additional language (e.g. Cenoz \& Valencia 1994) - although the opposite has also been found, i.e. a whole body of evidence questioning the notion of a general bilingual advantage has emerged recently (see e.g. De Bot 2017). Thus, we might obtain different age-related results for different learner populations and/or different interaction effects between the age factor and bilingualism/biliteracy effects.

The purpose of this study is to contribute to this line of research with evidence from Switzerland and to move towards a deeper understanding of the potential benefits of early FL instruction. I am not concerned with the process by which two languages are acquired and developed; there is a good deal of research on this (see e.g. Aronin \& Hufeisen 2009). Instead, issues examined here include the 
questions whether different subject populations (e.g. monolinguals vs. multilinguals; simultaneous vs. sequential bilinguals) are differentially affected by age of onset (AO) effects, and whether AO and literacy skills in the L1(s) have any bearing on third language (L3) learning later in secondary school - and to what extent they interact.

\section{Literature review}

\subsection{The Beyond age effects project}

In the Beyond age effects (BAE) project conducted in Switzerland between 2008 and 2016 (Pfenninger 2017), we examined the role of AO in the context of a multilingual educational model (Switzerland), focusing on the beginning and end of secondary school, thereby offering a long-term view of the teenage experience of FL learning in a broader European context. The project had two main goals. First, we set out to identify factors that prevent early starters from profiting from their extended learning period (compared to late starters), as has been documented in numerous classroom studies (see e.g. Al-Thubaiti 2010 for Saudi Arabia; Buchholz 2007 for Austria; Genelot 1997 for France; Jaekel et al. 2017 for Germany; Larson-Hall 2008 for Japan; Muñoz 2006 for Catalonia (Spain); Graham et al. 2017 for Great Britain; Pfenninger 2017; 2018 for Switzerland; Unsworth et al. 2015 for the Netherlands). Second, we wanted to better understand the mechanisms that provide late starters with faster learning rates in the initial stages of learning, enabling them to catch up relatively quickly with early starters. More specifically, we were interested in explaining the persistence of older learners' superiority, as reported, for example, in Muñoz (2006), who tested different-aged learners (ages $8,11,14$ and $18+)$ in a FL setting as part of the Barcelona age factor (BAF) project. Close analysis of the interplay of variables showed that a number of factors such as effects of instruction-type (i.e. intensity of instruction), literacy skills, classroom effects, extracurricular exposure and socio-affective variables such as motivation, attitudes and beliefs - are much stronger predictors than starting age for a range of FL proficiency dimensions.

One of the remarkable outcomes of the BAE project involved the lag in the development of L2 German writing ability among early starter students whose first exposure to L3 English began in grade 2 (for a similar result see Genesee 2004). The late starters, on the other hand, began L3 English education with a better foundation in their L2 (Standard German), that is, the language in which they had become literate (L1 was Swiss German). With this essential basis they seemed to have been better equipped to transfer their conceptual vocabulary and 
grammatical knowledge to the L3 (English). The early starters, however, were still developing their L2 when they were faced with the task of learning EFL, and, thus, their unstable knowledge of the L2 might have been insufficient to have a positive influence on their learning of the L3 (see also Sánchez 2012; 2015). This finding supports both the idea that L1 and L2 literacy skills are manifestations of a common underlying proficiency (Cummins 1976; 1981); see also Sparks's (2012) linguistic coding differences hypothesis, and the idea that a threshold level exists in order for L2 writing to transfer to L3, meaning that language learners require sufficient levels of proficiency in their language of literacy to be able to sustain the self-regulated behavior that writing performance in a FL requires (see also Schoonen et al. 2011: 66). Along those lines Lightbown (2000: 449) observed that "[i]f the total amount of time of instruction is limited, it is likely to be more effective to begin instruction when learners have reached an age at which they can make use of a variety of learning strategies, including their L1 literacy skills, to make the most of that time."

One of the most important features of the early starters' lag in German literacy skills was that it was temporary, providing reassurance to educators and parents that students' Standard German language skills will not be sacrificed as a result of their engaging in an early EFL program. This result was not new: with respect to the impact of the FL on the L1, there are numerous European studies that have documented the idea that there is no loss of L1 due to early exposure to a new language (e.g. Goorhuis-Brouwer \& De Bot 2010). Despite these observations, there is still a widespread assumption that the early introduction of several FLs puts children - particularly from immigrant backgrounds - at risk in that it might have a detrimental effect on the development of (literacy) skills in the community language i.e. the majority language. For instance, bilingual immigrant children have been found to perform worse in their new (or additional) language than their monolingual peers in reading acquisition (August \& Hakuta 1997; Slavin \& Cheung 2003). In the German-speaking part of Switzerland the problem is further complicated by the fact that the language of instruction and literacy is not the everyday language, which is hypothesized to add to the acquisitional challenge of migrant children.

It needs to be borne in mind that the BAE study has so far focused on monolingual children learning to speak and read in German, English and French in an instructed setting (for a definition of monolingualism and bilingualism, see §3.1). Monolinguals represent a significant portion of children in Switzerland but of course not all school children are monolingual. In Switzerland, the number of children (ages 5-15) who come from non-Swiss-German-speaking homes 
was roughly 252,868 (27\%) in 2016/17, a rise from 203,874 (21.3\%) in 2000/01 (Bundesamt für Statistik Schweiz). The current study attempts to close the gap in existing research on age and bilingualism.

\subsection{Effects of bilingualism and biliteracy on additional L2 acquisition}

A growing body of research on the acquisition of an L3 in bilingual contexts shows that bilingualism results in more efficient language learning, in terms of both general language proficiency (e.g. Lasagabaster 2000; Muñoz 2000), literacy skills (e.g. Kovelman et al. 2008) and cognitive variables (e.g. Bialystok 2007; Adesope et al. 2010). For instance, developing the concepts of print (decoding, recoding) that support reading is influenced both by bilingualism and by the specific language and writing system used in the bilingual child's two languages (Bialystok, Luk, et al. 2005; Kovelman et al. 2008).

However, recent studies revealed inconsistent evidence of a bilingual advantage in executive processing (Paap \& Greenberg 2013; de Bruin et al. 2014; Yow \& Li 2015). Morton (2014: 929) even goes so far as to dismiss the bilingual benefit as a myth and describes it as "an insufferable mixture of excessive claims and weak evidence". One potential source of explanation for the contradictory evidence with respect to the bilingual advantage is the multifaceted experience of the bilinguals in these studies. Different bilingual groups never perform equally well, nor are they comparable in terms of cognitive, psychosocial, and linguistic variables related to command and use of the L1 and L2 (see De Angelis 2015 for a discussion of this subject selection bias). It is also well-known that effects of bilingualism on internal, cognitive variables are mediated by key external factors related to particular sociolinguistic situations. Sanz (2008: 225), for instance, argued that "in the end, it is the social aspect of bilingualism, and especially the availability of bilingual education, which determines the development of cognitive benefits deriving from experience with two languages, including benefits involved in the acquisition of an L3".

Furthermore, some scholars have pointed out that the key to the cognitive advantage reflected in more efficient L3 acquisition is biliteracy rather than bilingualism (where bilingualism refers exclusively to oral skills (Swain et al. 1990; Rauch et al. 2012). For instance, Swain et al. (1990) examined the effect of mother tongue literacy on third language learning by testing children who had acquired a heritage language at home (some of them were literate in this language) and were enrolled in an English/French bilingual program. Bilinguals illiterate in their heritage language did not perform significantly better in the vocabulary and structure sections of the CELT English proficiency test than their monolingual 
counterparts. Along similar lines, but from a socio-affective perspective, various studies have shown that a strong basis in the L1 promotes school achievement in the L2 and is important to ensure that children do not become alienated from their families and communities (Castro et al. 2011; Murphy \& Evangelou 2016).

The question as to whether earlier bilinguals (i.e. simultaneous bilinguals and those who have acquired the L2 before age 6) benefit from extended practice with two languages and therefore show greater ability in learning the L3 than later (or sequential) bilinguals has also been addressed. Comparing different age groups (120 Catalan-Spanish bilinguals learning English), Sanz (2008) could not identify age of L2 acquisition as having predictive value over the dependent variable of achievement: simultaneous bilinguals did not show an advantage when compared with those who had learned the L2 at age 7, after having been exposed to literacy in their L1.

By contrast, a number of studies have demonstrated negative correlations between the onset age of active bilingualism and English proficiency. Luk et al. (2011), for instance, who studied the relationship between onset age of bilingualism and cognitive control, recruited 157 university students who were either early bilinguals (those who started active bilingualism before 10-years-old), late bilinguals (an onset age of active bilingualism after 10-years-old), or English-speaking monolinguals. The early and late bilingual participants spoke a large variety of languages in addition to English, such as Cantonese, French, Korean, Hebrew, Italian, Mandarin, Farsi, Russian, Tamil, Urdu, among many others. Early bilinguals and monolinguals demonstrated similar levels of English proficiency, and both groups were more proficient in English than late bilinguals (see also Soveri et al. 2011). Interestingly, Stafford et al. (2010: 179) found a tendency for late bilinguals (Spanish-English bilingual adults learning L3 Latin) to develop higher proficiency than early bilinguals in adult L3 learning. While there was little difference in the L3 outcomes observed between early- and late-onset bilinguals, the authors detected "a slight advantage" for late bilinguals over early bilinguals with respect to ability to retain what the participants learned about the new and complex noun case morphology cue. They ascribed this finding to the highly structured and explicit instructional treatment that might have been more in tune with late bilinguals' learning strategies.

This conflicting state of the literature is suggested to have stemmed from possible confounds between bilingualism and biliteracy on the one hand, and balance and age of L2 acquisition on the other, as well as confounds between biological age and starting age. For instance, some studies (e.g. Bialystok, Martin, et al. 2005) reported an inconsistency in bilingual advantage across different age groups in that there seems to be a bilingual advantage in older adults but not younger adults. 


\section{This study}

\subsection{Research questions}

The present study focuses on (1) learners of English of different starting ages raised in Germanophone Switzerland with German (Swiss and Standard) and who had then learned English, and (2) learners of English of different starting ages who had either been born in Switzerland and brought up from birth with Swiss German plus another language (early bilinguals) or else had arrived in Switzerland from another language background at age 5 or 6 and had acquired German in addition to their L1 in mid-childhood (late bilinguals). I call the former "monolingual" learners of English (i.e. monolingual before learning English as a first FL), ignoring for present purposes the fact that Swiss German is very different from Standard German as well as the fact that the children had some school contact with French (see discussion below). The latter group we label "bilingual", categorizing them into three subsets, according to their experience, once again simplifying things terminologically, by again glossing over the Swiss/Standard German distinction and the (minimal) French connection.

The following research questions guide my study:

1. Are early bilinguals more successful than late bilinguals and monolinguals at learning a new language from primary school through the end of secondary school?

2. How do literacy skills in the L1(s) affect literacy development in EFL?

\subsection{Participants}

While most studies mentioned in the literature review have compared monolinguals with bilinguals or literates with illiterates, in this study four groups with a total of 636 learners will be compared so as to capture differences between bilinguals as well as among them. All participants were within the age-range 13-14 (mean age 13;4) at the first data collection time in 2009 and in the range 18-19 (mean age 18;6) at the second measurement in 2014. In each group, roughly half the participants were early classroom learners of English (ECLs; AO 8, Year 2 i.e. second grade of primary school), while the other half were late classroom learners (LCLs; AO 13, Year 7). They were clustered in five state schools in 33 classes, ranging in size from 9 to 23 members. At no point were early starters mixed with late starters in the same class. The first test series was administered after six months of EFL in secondary school, that is, after 440 hours of English instruction (ECLs) and 50 hours of instruction (LCLs) respectively. The second 
data collection took place five years (680 hours of English) later. The participants had not stayed outside of Switzerland for more than one month; they had limited access to English outside the school (assessed via a questionnaire on extracurricular activities, see Pfenninger \& Singleton 2017); they reported living in homes with caregivers who spoke Swiss German and/or Spanish, Portuguese, Croatian, Serbian, Albanian, Arabic, or Italian (see below); they had not attended an English-medium school at any point in their prior schooling, and they had never had to repeat a grade in their schooling. As pointed out above, the goal was to recruit learners of EFL who represented the most common learner groups in Switzerland: children who grew up as monolinguals before learning the first FL (English) in school, simultaneous bilinguals (monoliterate or biliterate) or sequential bilinguals:

- Group MONO: 200 Swiss monolinguals, born in Switzerland (literate in the community language)

- 100 early classroom learners (ECLs) (AO 8)

- 100 late classroom learners (LCLs) (AO 13)

- Group SIMBI I: 144 simultaneous bilinguals, born in Switzerland (biliterate)

- 73 ECLs (AO 8)

- 71 LCLs (AO 13)

- Group SIMBI II: 107 simultaneous bilinguals, born in Switzerland (literate in the community language, illiterate in the other L1)

- 57 ECLs (AO 8)

- 50 LCLs (AO 13)

- Group SEQBI: 185 sequential bilinguals, age of arrival in Switzerland 5-6 (illiterate in L1, literate in L2, i.e. the community language)

- 95 ECLs (AO 8)

- 90 LCLs (AO 13)

All the children had also received initial literacy instruction in German, starting in Year 1 of primary school (age 7). Thus, for the sequential bilinguals, the language of schooling was not the same as the language of the home. They acquired German language literacy in school in spite of having a weak command of spoken German. As pointed out above, technically speaking, for the Swiss monolinguals 
and the Swiss bilinguals, German is not spoken at home or in the community either. As the Swiss term for Standard High German (Schriftsprache or Schriftdeutsch) implies, Swiss Standard German is primarily a written language, and so the situation obtaining is sometimes referred to as "medial diglossia" (Kolde 1981) or "functional diglossia" (Rash 1998).

In the three bilingual groups, the number of L1s in each group was controlled for (e.g., each group contained the same number of L1 Spanish speakers). Since the age of first exposure to the second, majority, language seems to affect L1 skills (see e.g. Cobo-Lewis et al. 2002), it was decided to include only individuals in the SEQBI group who had moved to Switzerland between the ages of 5-6. During their first five years they were only exposed to their L1 and acquired some (modest) preliteracy skills which were not maintained after the children began literacy training in the majority language (German). Answers to an extensive biodata questionnaire completed by all participants confirmed that the bilingual groups did not start school behind their monolingual peers, and their families were not disproportionally low-income compared to the monolingual families.

It has to be mentioned that the study does not operationalize level of bilingualism (i.e. proficiency and dominance). However, parents completed a questionnaire in which they were asked to explain the patterns of language use in the home and the types of language, and particularly literary language, to which children were exposed in each language. While I made sure to only include children who could be considered functionally bilinguals, they undoubtedly had slightly different levels of oral proficiency in their different languages.

\subsection{Tasks and instruments}

In order to analyze the family circumstances, parental reports on literacy practices were examined (see Pfenninger 2017 for a detailed description of this questionnaire):

- Number of books/e-books in the household: ordinal

- between 0 and 50 books at home

- between 51 and 100 books at home

- more than 100 books at home

- Degrees of in/direct parental involvement in child's study and education (3 items in a 5-level ordinal measure):

1. the frequency with which the parents helped their child with L1 literacy; 
2. parents' attitudes toward L1 literacy;

3. parents' attitudes toward EFL learning.

- Frequency with which the parents read with their children: ordinal, $5=$ daily, $4=$ three times $a$ week, $3=$ once $a$ week, $2=$ once $a$ month, $1=$ never .

As for the participants' language proficiency, the following tasks and instruments were administered to measure a wide range of linguistic skills.

By using a variety of tasks, I hoped to be able to tease apart knowledge from task effects, considering that effects of $\mathrm{AO}$ have been found to be different for different tasks (see Pfenninger 2017). Two of the tasks (listening comprehension task, productive vocabulary test) could only be administered once, at Time 2, mainly because the pilot testing showed that those measures might have been appropriate for the students at Time 2, but they would have shown floor effects at Time 1.

Oral and written competence was measured in terms of fluency, lexical and syntactic complexity, and accuracy. Following Wolfe-Quintero et al. (1998), fluency in English and German was examined in terms of words per T-unit (W/TU), which is defined as one main clause and all of the dependent modifying clauses (Ellis \& Barkhuizen 2005). Oral and written syntactic complexity was examined in English and German using the clauses per T-unit (CL/TU) complexity ratio. Lexical complexity in the oral and written data was examined using Guiraud's index of lexical richness (GUI): word types divided by the square root of the word tokens. Accuracy (ERR/TU) was examined by counting (a) the number of misspellings (excluding "mechanical errors" such as punctuation errors), and (b) the number of morphosyntactic errors per T-unit. For the holistic evaluation of the English and German essays (narrative and argumentative essays), I partly followed Jacobs et al. 1981's scale, which considers the communicative effect of the speaker's linguistic production on the receptor and, therefore, comes close to the main objective of the process of language acquisition, namely interpersonal communication. My evaluation system consists of two criteria which measure different aspects of written production (Lasagabaster \& Doiz 2003: 142-143):

- Content (30 points): this category considers the development and comprehension of the topic as well as the adequacy of the content of the text.

- Organization (20 points): several factors are considered here, namely the organization of ideas, the structure and cohesion of paragraphs and the clarity of exposition of the main and secondary ideas. 
Table 7.1: Tasks and skills measured (all pilot-tested and used in Pfenninger \& Singleton 2017)

\begin{tabular}{ll}
\hline \hline Task & Skill measured \\
\hline $\begin{array}{l}\text { 2 standardized listening comprehension } \\
\text { tasks (CEFR level B2) }\end{array}$ & Listening comprehension \\
$\begin{array}{l}\text { Receptive vocabulary test: Academic } \\
\text { sections in Schmitt et al.'s (2001) Versions }\end{array}$ & Receptive vocabulary \\
A and B of nation's vocabulary levels test & \\
Productive vocabulary test: & Productive vocabulary \\
productive vocabulary size test by Laufer & \\
\& Nation (1999) & \\
English argumentative essay on the pros & Written content \\
and cons of (reality TV) talent shows & Written organization \\
& Written lexical richness \\
& Written syntactic complexity \\
$\begin{array}{l}\text { German argumentative essay on the pros } \\
\text { and cons of early instruction of multiple } \\
\text { foreign languages }\end{array}$ & Written accuracy \\
& Written content \\
& Written organization \\
& Written syntactic complexity \\
Oral tasks (re-telling task, & Written fluency \\
spot-the-difference task) & Written accuracy \\
items and .95 for ungrammatical items) & Oral lexical richness \\
Grammaticality judgment task including & Orammaticality judgments \\
\hline \hline
\end{tabular}




\subsection{Statistical analyses}

Analyses were conducted using mixed-effects models with hierarchical random effects for classes and schools, and crossed random effects for subjects and items respectively, using the lme4 package (version 1.1-7) in $\mathrm{R}$ (version 3.1.0). The final models included contrast coded fixed effects for $\mathrm{AO}(-0.5=$ early, $0.5=$ late), bilingualism $(-0.5=$ non-bilingual, $0.5=$ bilingual $)$, biliteracy $(-0.5=$ non-biliterate, $0.5=$ biliterate), type of bilingualism $(-0.5=$ simultaneous, $0.5=$ sequential $)$, as well as time (for the growth analyses), number of books/e-books, degrees of in/ direct parental involvement, and frequency of reading. Literacy in Standard German was assessed by inclusion of a continuous fixed-effect predictor of lexical richness, fluency and complexity in the written German essay (standardized as $z$-scores). Random effects were fitted using a "maximal" random effects structure (Barr et al. 2013; but, for recent challenges to this approach, see Bates et al. 2015). I included random effects (intercepts) to account for class-to-class and schoolto-school differences that induce correlation among scores for students within a school and within a class.

In those cases where the dependent variables were not continuous but categorical/binary - e.g. grammaticality judgments (correct/incorrect) - I used the mixed-effects implementation of logistic regression, or mixed logit models. In the case of count data (number of errors in the accuracy measure, and counts of words and clauses in the fluency and complexity measures respectively), which were not normally distributed either, a generalized mixed effects model (glmer ( ) ) with the Poisson distribution was used. I used visual inspection of residual plots in order to find out if there were any obvious deviations from homoscedasticity or normality. Models were fitted using a maximum likelihood technique. $P$ values were obtained by likelihood ratio tests of the full model with the effect in question against the model without the effect in question.

\section{Results}

In the following, the two research questions that were formulated in $\S 3.1$ are repeated and the findings summed up.

\subsection{RQ1: Are early bilinguals more successful than later bilinguals and monolinguals at learning a new language from primary school through the end of secondary school?}

Tables 7.2 and 7.3 present descriptive statistics of the performance of the early classroom learners (ECL) and late classroom learners (LCL) of each language 
group (MONO, SIMBI I, SIMBI II, and SEQBI) across a range of EFL skills at each data collection times ( $\mathrm{T} 1$ at the beginning of secondary school and $\mathrm{T} 2$ five years later at the end of mandatory school time):

As can be seen in Table 7.2, in each group, the ECLs outperformed the LCLs in receptive vocabulary, written lexical richness, written fluency, oral lexical richness, oral accuracy and written grammaticality judgments at Time 1. However, parity between early starters and late starters had already been reached after six months of secondary school EFL instruction in terms of written and oral complexity, written accuracy, and oral fluency. At the end of mandatory school time these $\mathrm{AO}$ effects had been effectively washed out; i.e. only written lexical richness seemed to have benefitted from an earlier starting age (Table 7.3).

The results of the mixed models specified for each of the 14 tested FL skills corroborated this impression, indicating that $\mathrm{AO}$ was a predictor of short-term FL learning outcome, i.e. there were main effects of $\mathrm{AO}$ in favor of the early starters at the first data collection time for $50 \%$ of the measures (see Tables 7.4-7.6), notably receptive vocabulary, written organization, lexical richness and fluency, oral lexical richness and accuracy, as well as grammaticality judgments. Five years later, these $\mathrm{AO}$ effects had disappeared except for written lexical richness (see Tables 7.7-7.9), which was anticipated (see results in Pfenninger \& Singleton 2017). What was not anticipated was the finding that there were significant interactions between $\mathrm{AO}$ and biliteracy for half the measures at Time 2. In other words, there were no overall starting age effects at the end of mandatory school time across all groups save for the SIMBI I group, who was still susceptible to $\mathrm{AO}$ at Time 2 with respect to receptive vocabulary, productive vocabulary, written lexical richness, written fluency, and oral complexity (see also Pfenninger \& Singleton 2019).

Both bilingualism and biliteracy had a positive influence on about half the measures at both data collection times; however, this finding only surfaced for those experiencing substantial parental support and positive parental attitudes, i.e. there were always also significant interactions between them and environmental factors (see Appendix A). In other words, bilingualism and biliteracy alone did not predict FL learning outcome. The interactions between bilingualism and contextual factors on the one hand, and biliteracy and contextual factors on the other, were to a large extent due to the fact that the SIMBI I group received substantially more parental support than the other groups, and their parents had significantly more positive attitudes towards FL learning and multilingualism (see Figures 7.1-7.2). 


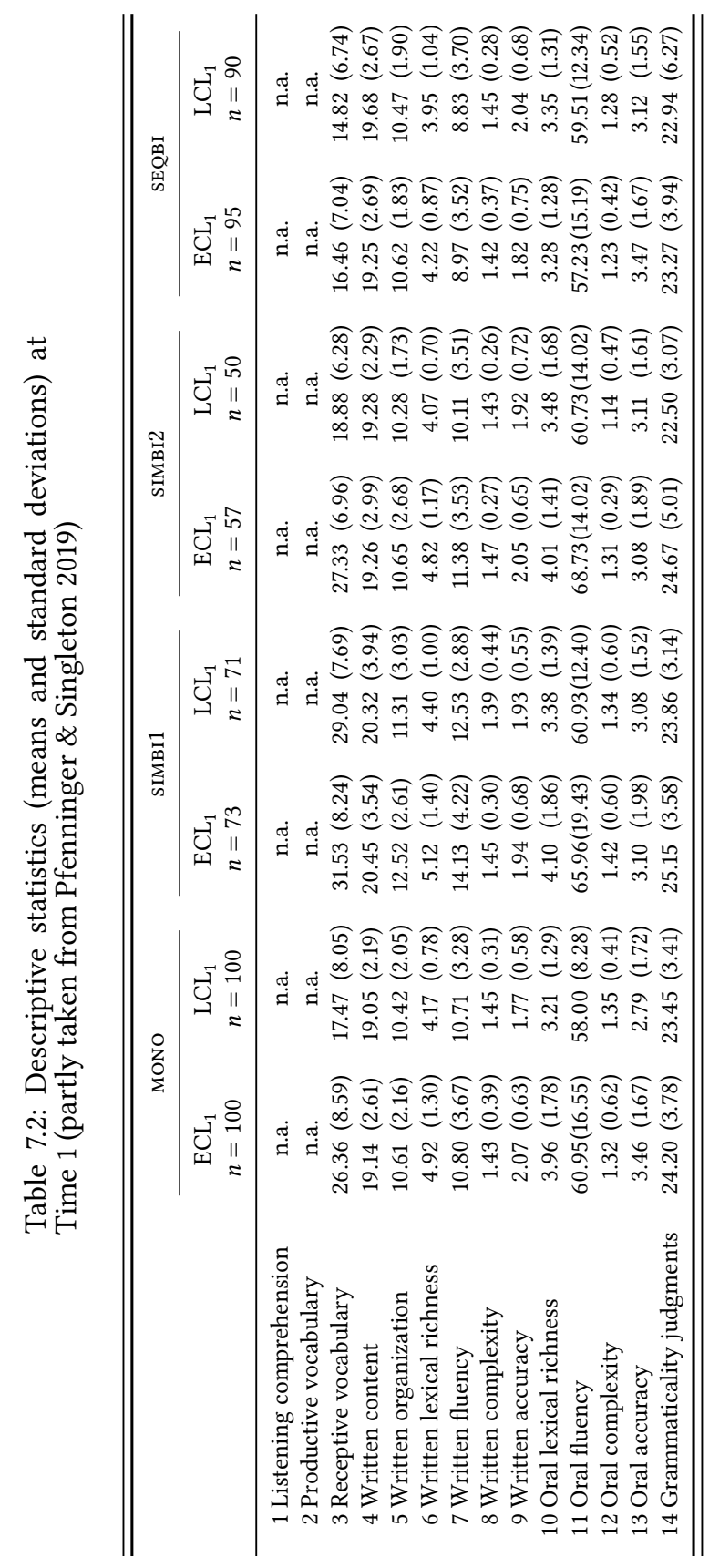




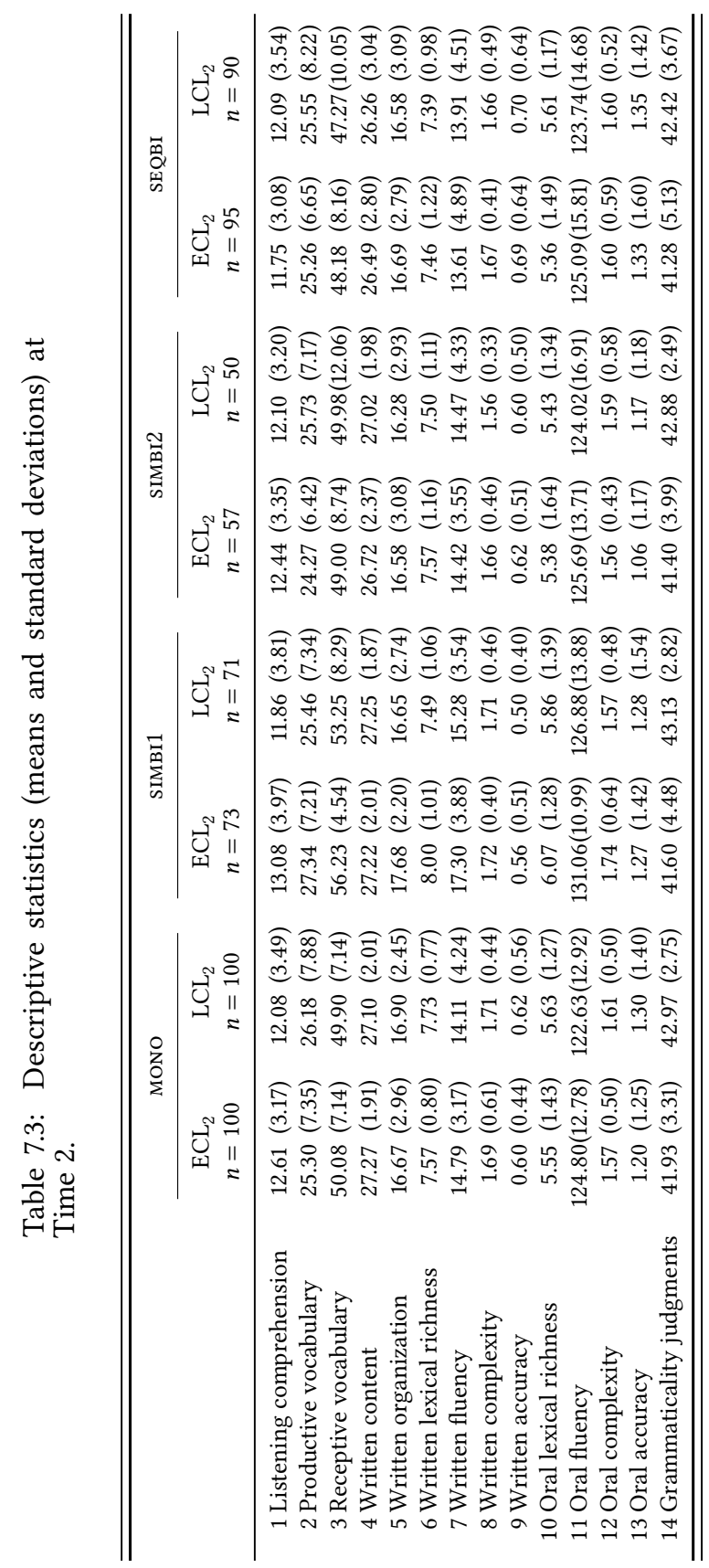


Table 7.4: Multilevel regression analyses for the investigated dependent variables at Time 1. Fixed effect estimates for A0.

\begin{tabular}{lrcc}
\hline \hline & Estimate \pm SE & $t$ & Main effect $p$ \\
\hline Receptive vocabulary & $-1.73 \pm 1.83$ & -5.95 & $<0.0001^{* *}$ \\
Written content & $-0.29 \pm 0.35$ & -0.83 & 0.209 \\
Written organization & $-0.62 \pm 0.15$ & -4.22 & $0.0001^{* *}$ \\
Written lexical richness & $-0.54 \pm 0.27$ & -2.01 & $0.041^{*}$ \\
Written fluency & $-0.00 \pm 0.03$ & -0.12 & 0.913 \\
Written complexity & $0.01 \pm 0.10$ & 0.13 & 0.914 \\
Written accuracy & $-0.54 \pm 0.33$ & -2.07 & $0.049^{*}$ \\
Oral lexical richness & $-2.82 \pm 2.95$ & -0.96 & $0.322^{*}$ \\
Oral fluency & $-0.04 \pm 0.09$ & -0.51 & $0.592^{*}$ \\
Oral complexity & $-0.35 \pm 0.15$ & -2.36 & 0.018 \\
Oral accuracy & $-1.12 \pm 0.41$ & -2.73 & 0.007 \\
GJT & $-0.62 \pm 0.15$ & -4.22 & $0.0001^{* *}$ \\
\hline \hline
\end{tabular}

Table 7.5: Multilevel regression analyses for the investigated dependent variables at Time 1. Fixed effect estimates for bilingualism. ${ }^{*} p<0.05$, ${ }^{* *} p<0.001$.

\begin{tabular}{lrrc}
\hline \hline & Estimate \pm SE & \multicolumn{1}{c}{$t$} & Main effect $p$ \\
\hline Receptive vocabulary & $1.46 \pm 0.87$ & 1.67 & 0.084 \\
Written content & $-0.55 \pm 0.31$ & -0.83 & 0.556 \\
Written organization & $-0.30 \pm 0.25$ & 1.20 & 0.691 \\
Written lexical richness & $0.29 \pm 0.12$ & 2.45 & 0.003 \\
Written fluency & $6.89 \pm 1.15$ & 6.00 & $<0.0001^{* *}$ \\
Written complexity & $0.21 \pm 0.11$ & 1.92 & 0.064 \\
Written accuracy & $0.13 \pm 0.10$ & 1.35 & 0.073 \\
Oral lexical richness & $1.07 \pm 0.44$ & 2.46 & $0.040 *$ \\
Oral fluency & $8.67 \pm 4.20$ & 2.06 & 0.106 \\
Oral complexity & $0.16 \pm 0.06$ & 2.67 & $0.009 * *$ \\
Oral accuracy & $-0.99 \pm 0.45$ & -2.22 & 0.074 \\
GJT & $2.91 \pm 1.17$ & 2.50 & $0.033 *$ \\
\hline \hline
\end{tabular}


Table 7.6: Multilevel regression analyses for the investigated dependent variables at Time 1 . Fixed effect estimates for biliteracy. ${ }^{*} p<0.05$, ** $p<0.001$.

\begin{tabular}{lrrc}
\hline \hline & Estimate \pm SE & \multicolumn{1}{c}{$t$} & Main effect $p$ \\
\hline Receptive vocabulary & $11.18 \pm 0.23$ & 1.68 & 0.081 \\
Written content & $-0.41 \pm 0.35$ & -2.16 & $0.010^{*}$ \\
Written organization & $-1.37 \pm 0.28$ & -4.83 & $<0.0001^{* *}$ \\
Written lexical richness & $0.42 \pm 0.23$ & 1.86 & $0.090^{* *}$ \\
Written fluency & $-1.48 \pm 0.44$ & -3.35 & $0.001^{* *}$ \\
Written complexity & $0.76 \pm 0.20$ & 3.73 & $0.0002^{* *}$ \\
Written accuracy & $-0.05 \pm 0.09$ & -0.62 & 0.506 \\
Oral lexical richness & $-0.24 \pm 0.20$ & -1.20 & 0.247 \\
Oral fluency & $12.29 \pm 6.72$ & 1.82 & 0.060 \\
Oral complexity & $0.82 \pm 0.28$ & 2.87 & 0.007 \\
Oral accuracy & $-3.32 \pm 0.95$ & -3.49 & 0.002 \\
GJT & $-0.81 \pm 0.49$ & -1.66 & 0.099 \\
\hline \hline
\end{tabular}

Table 7.7: Multilevel regression analyses for the investigated dependent variables at Time 2. Fixed effect estimates for AO. ${ }^{*} p<0.05,{ }^{* *} p<$ 0.001 .

\begin{tabular}{lrcc}
\hline \hline & Estimate \pm SE & \multicolumn{1}{c}{$t$} & Main effect $p$ \\
\hline Listening & $-0.33 \pm 0.37$ & -0.90 & 0.317 \\
Productive vocabulary & $-0.85 \pm 1.65$ & -0.51 & 0.372 \\
Receptive vocabulary & $-0.86 \pm 1.14$ & -0.76 & 0.415 \\
Written content & $-0.29 \pm 0.35$ & -0.83 & 0.209 \\
Written organization & $-0.15 \pm 0.25$ & -0.59 & 0.189 \\
Written lexical richness & $-0.50 \pm 1.17$ & -2.95 & 0.012 \\
Written fluency & $-1.28 \pm 0.73$ & -1.74 & 0.193 \\
Written complexity & $-0.00 \pm 0.05$ & -0.17 & 0.851 \\
Written accuracy & $-0.01 \pm 0.05$ & -0.27 & 0.840 \\
Oral lexical richness & $0.03 \pm 0.31$ & 0.08 & 0.927 \\
Oral fluency & $-2.63 \pm 3.20$ & -0.82 & 0.387 \\
Oral complexity & $-0.19 \pm 0.11$ & -1.71 & 0.132 \\
Oral accuracy & $0.05 \pm 0.16$ & 0.31 & 0.750 \\
GJT & $1.20 \pm 0.67$ & 1.80 & 0.085 \\
\hline \hline
\end{tabular}


Table 7.8: Multilevel regression analyses for the investigated dependent variables at Time 2. Fixed effect estimates for bilingualism.

\begin{tabular}{lrcc}
\hline \hline & Estimate \pm SE & \multicolumn{1}{c}{$t$} & Main effect $p$ \\
\hline Productive vocabulary & $9.18 \pm 2.91$ & 3.16 & $0.001^{* *}$ \\
Receptive vocabulary & $3.62 \pm 1.76$ & 2.06 & 0.102 \\
Written content & $-0.56 \pm 0.31$ & -1.82 & 1.41 \\
Written organization & $0.26 \pm 0.27$ & 0.96 & 0.450 \\
Written lexical richness & $0.66 \pm 0.23$ & 2.82 & $0.001^{* *}$ \\
Written fluency & $3.91 \pm 1.10$ & 3.55 & $0.0002^{* *}$ \\
Written complexity & $0.32 \pm 0.12$ & 2.76 & $0.022^{*}$ \\
Written accuracy & $-0.72 \pm 0.17$ & -4.26 & $0.0002^{* *}$ \\
Oral lexical richness & $1.27 \pm 0.28$ & 4.56 & $<0.0001^{* *}$ \\
Oral fluency & $2.53 \pm 1.64$ & 1.55 & 0.135 \\
Oral complexity & $0.08 \pm 0.06$ & 1.34 & 0.257 \\
Oral accuracy & $-1.65 \pm 0.46$ & -3.60 & $0.002^{* *}$ \\
GJT & $4.46 \pm 0.98$ & 4.56 & $<0.0001^{* *}$ \\
\hline \hline
\end{tabular}

Table 7.9: Multilevel regression analyses for the investigated dependent variables at Time 2 Fixed effect estimates for biliteracy) ${ }^{*} p<0.05$, ${ }^{* *} p<0.001$.

\begin{tabular}{lrcc}
\hline \hline & Estimate \pm SE & \multicolumn{1}{c}{$t$} & Main effect $p$ \\
\hline Listening & $0.60 \pm 0.45$ & 1.34 & 0.186 \\
Productive vocabulary & $13.89 \pm 3.97$ & 3.50 & $<0.0001^{* *}$ \\
Receptive vocabulary & $-1.68 \pm 2.52$ & -0.67 & 0.403 \\
Written content & $0.72 \pm 0.26$ & 2.80 & $0.012^{*}$ \\
Written organization & $-0.39 \pm 0.32$ & -1.23 & 0.85 \\
Written lexical richness & $-0.82 \pm 0.33$ & -2.51 & $0.018^{*}$ \\
Written fluency & $-0.82 \pm 0.64$ & -1.29 & $0.264^{*}$ \\
Written complexity & $0.51 \pm 0.15$ & 3.41 & $0.001^{* *}$ \\
Written accuracy & $0.38 \pm 0.16$ & 2.31 & 0.010 \\
Oral lexical richness & $0.20 \pm 0.27$ & 0.74 & 0.540 \\
Oral fluency & $-1.76 \pm 2.86$ & -0.62 & $0.400^{*}$ \\
Oral complexity & $-0.38 \pm 0.16$ & -2.39 & $0.050^{*}$ \\
Oral accuracy & $-3.53 \pm 0.74$ & -4.80 & $<0.0001^{* *}$ \\
GJT & $2.29 \pm 1.14$ & 1.10 & $0.026^{*}$ \\
\hline \hline
\end{tabular}




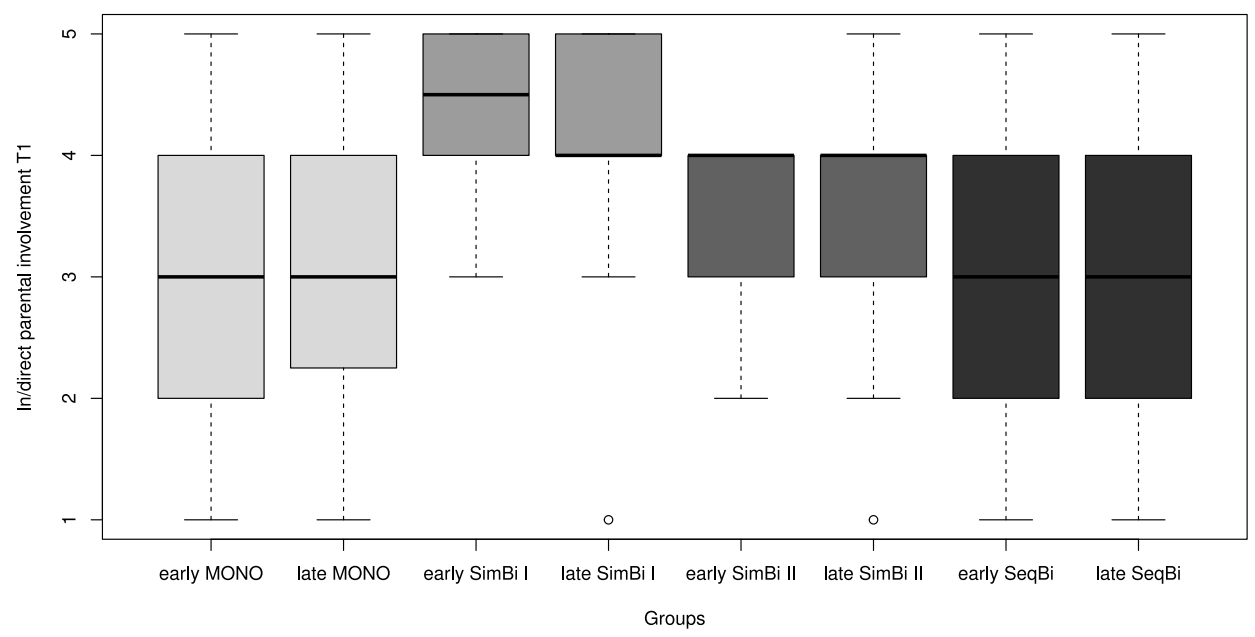

Figure 7.1: In/direct parental involvement by $\mathrm{AO}$ and language group at Time 1

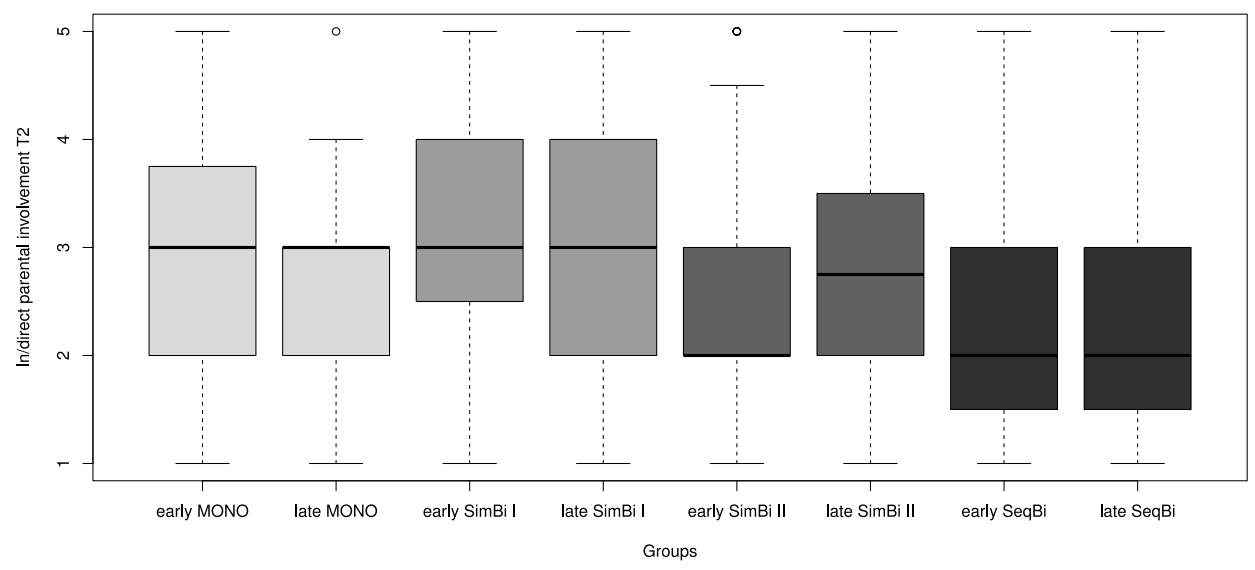

Figure 7.2: In/direct parental involvement by $\mathrm{AO}$ and language group at Time 2 
Family circumstance - as measured by number of books/e-books in the household, frequency with which the parents read with/to their children and in/direct parental involvement in child's study and education - predicted between $50 \%$ and $75 \%$ of the EFL measures, irrespective of $\mathrm{AO}$ and biological age of the participants (see Tables 7.12-7.17 in Appendix B). While each language group was similarly affected by home context, there were significant interactions between biliteracy and family circumstance across all FL measures as the SIMBI I group received substantially more parental support than the other groups (see also Pfenninger \& Singleton 2019).

Turning to simultaneous vs. sequential bilinguals, the findings revealed significant differences between them at the beginning and at the end of secondary school, with simultaneous bilinguals clearly outperforming monolinguals and sequential bilinguals (see e.g. Figures 7.3-7.4 for receptive vocabulary). However, when the samples were controlled for biliteracy, these differences had vanished by Time 2 (see Figures 7.5-7.6).

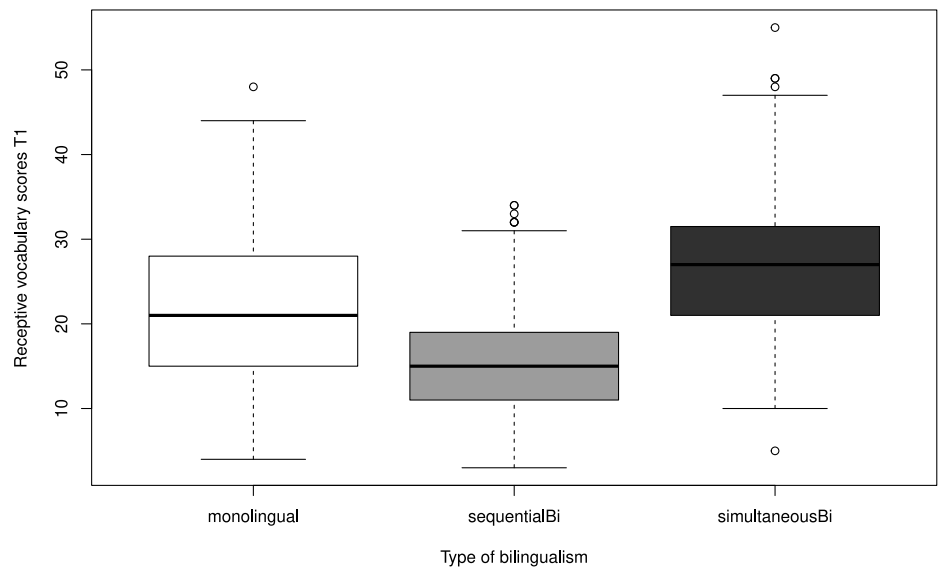

Figure 7.3: Receptive vocabulary by type of bilingualism at Time 1 


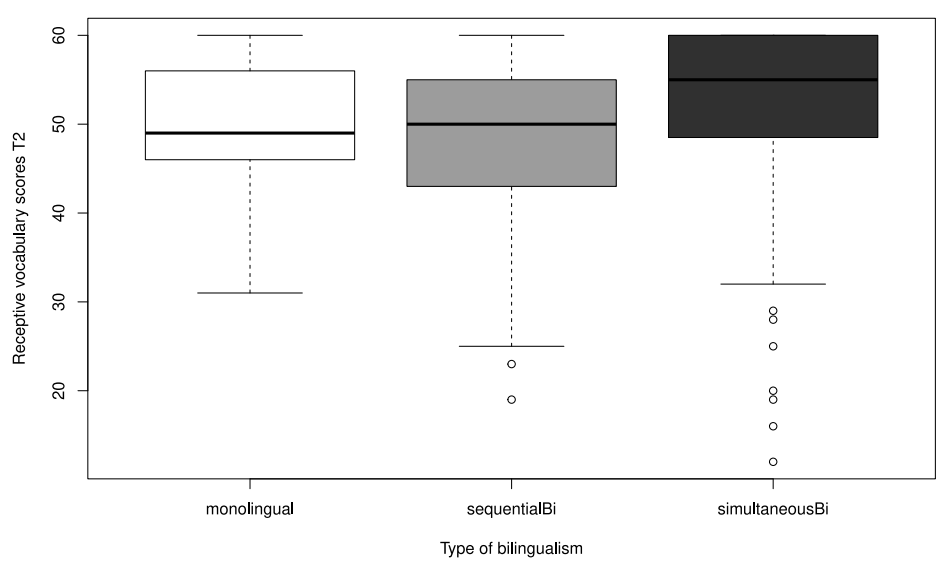

Figure 7.4: Receptive vocabulary by type of bilingualism at Time 2

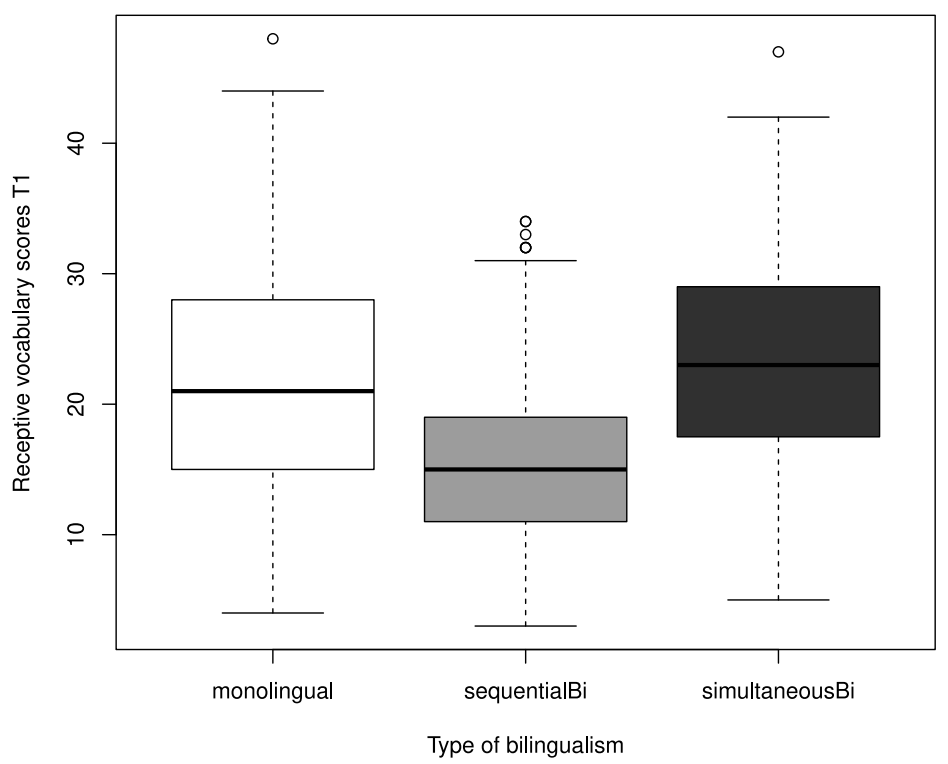

Figure 7.5: Receptive vocabulary by type of bilingualism (w/o biliterates) at Time 1 


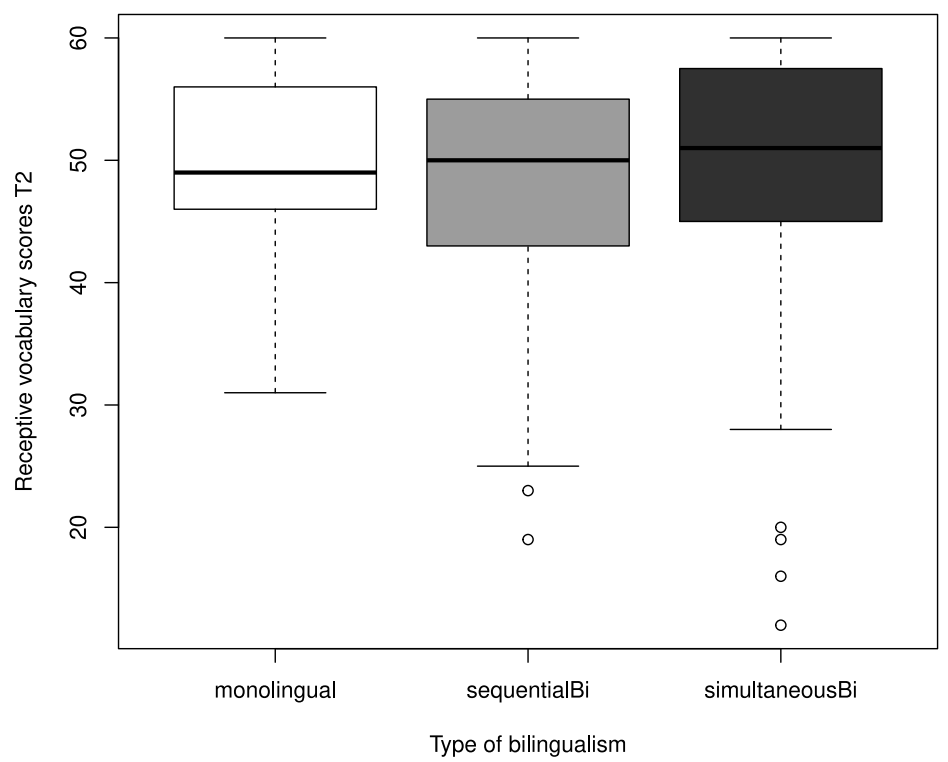

Figure 7.6: Receptive vocabulary by type of bilingualism (w/o biliterates) at Time 2

\subsection{RQ2: How do literacy skills in the L1(s) affect literacy development in EFL?}

L1 literacy skills were clearly positively related to L2 literacy skills in all groups, predicting written content, organization, lexical richness, fluency and complexity, as Figure 7.8 and Figure 7.9 illustrate for written fluency scores (see also Pfenninger 2014).

The association between German literacy and English literacy is important inasmuch as the mixed models yielded statistically significant differences across language groups as well as across $\mathrm{AO}$ groups with respect to German writing performance: on the one hand, late starters consistently outperformed early starters in each language group at the beginning of secondary school; on the other hand, there were significant interactions between language group and German literacy skills at Time 1, as the sequential bilinguals (SEQBI group) had significantly lower scores across all skills tested (see Figure 7.10-7.11 for written fluency and written content respectively). At the end of secondary school, these differences had disappeared (see e.g. Figure 7.7 for written fluency and Tables 7.13a-7.13b in Appendix B). 
Table 7.10: Impact of Standard German writing ability on English writing ability at Time 1

\begin{tabular}{lrcc}
\hline \hline & Estimate $\pm \mathrm{SE}$ & $t$ & $p$ \\
\hline Written content (English) & $0.22 \pm 0.03$ & 6.56 & $<0.001^{* *}$ \\
Written organization (English) & $0.12 \pm 0.03$ & 4.12 & $<0.001^{* *}$ \\
Written lexical richness (English) & $0.08 \pm 0.03$ & 2.51 & $0.008^{*}$ \\
Written fluency (English) & $6.01 \pm 1.01$ & 5.39 & $<0.001^{* *}$ \\
Written complexity (English) & $0.10 \pm 0.02$ & 4.89 & $<0.001^{* *}$ \\
\hline \hline
\end{tabular}

Table 7.11: Impact of Standard German writing ability on English writing ability at Time $2 .{ }^{*} p<0.05,{ }^{* *} p<0.001$.

\begin{tabular}{lrcc}
\hline \hline & Estimate \pm SE & $t$ & \multicolumn{1}{c}{$p$} \\
\hline Written content (English) & $0.21 \pm 0.05$ & 4.38 & $<0.001^{* *}$ \\
Written organization (English) & $0.38 \pm 0.07$ & 5.49 & $<0.001^{* *}$ \\
Written lexical richness (English) & $0.16 \pm 0.04$ & 3.71 & $0.0002^{* *}$ \\
Written fluency (English) & $0.16 \pm 0.07$ & 2.23 & $0.034^{*}$ \\
Written complexity (English) & $0.27 \pm 0.04$ & 7.26 & $<0.001^{* *}$ \\
\hline \hline
\end{tabular}

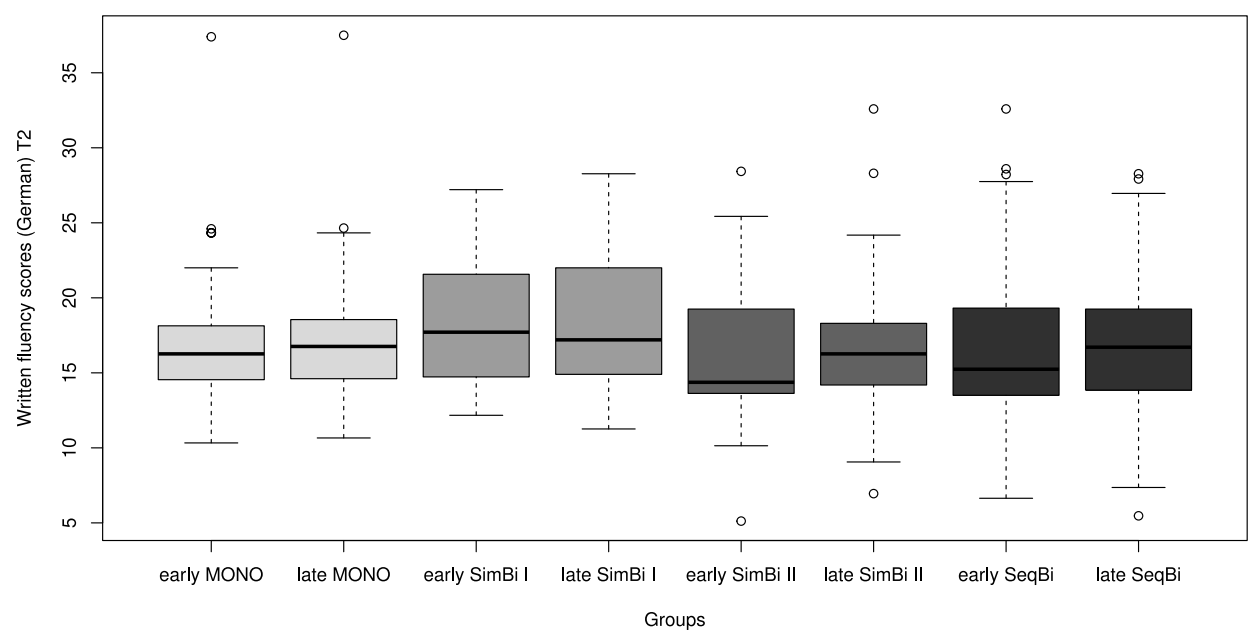

Figure 7.7: Written fluency (German) by AO and language group at Time 2 


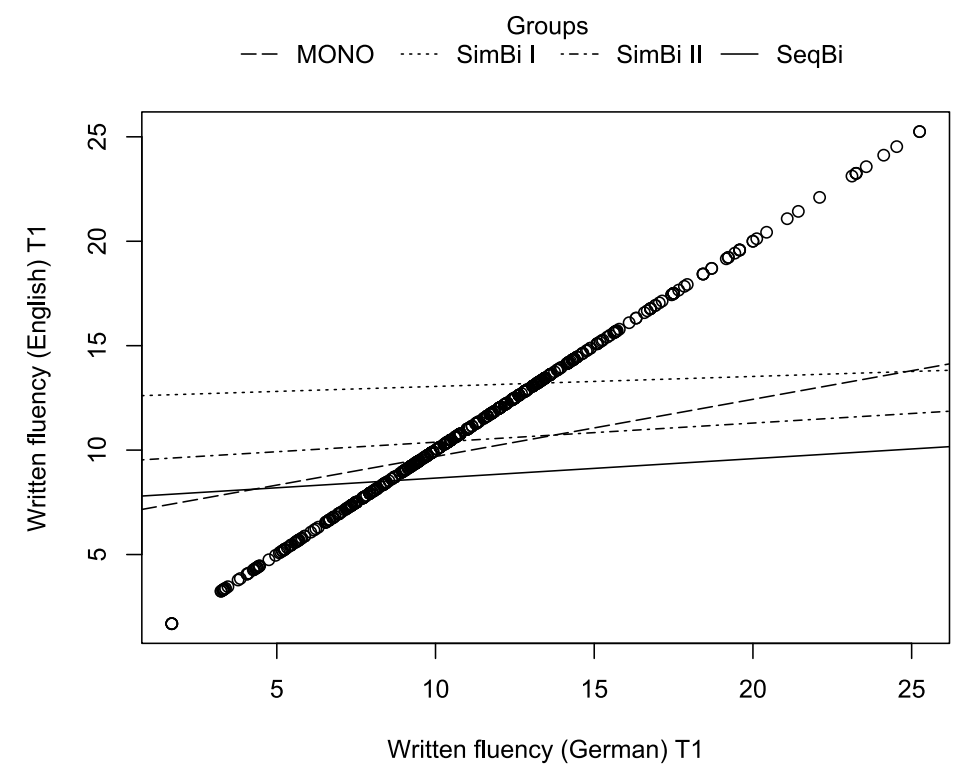

Figure 7.8: Impact of written fluency (German) on language group at Time 1
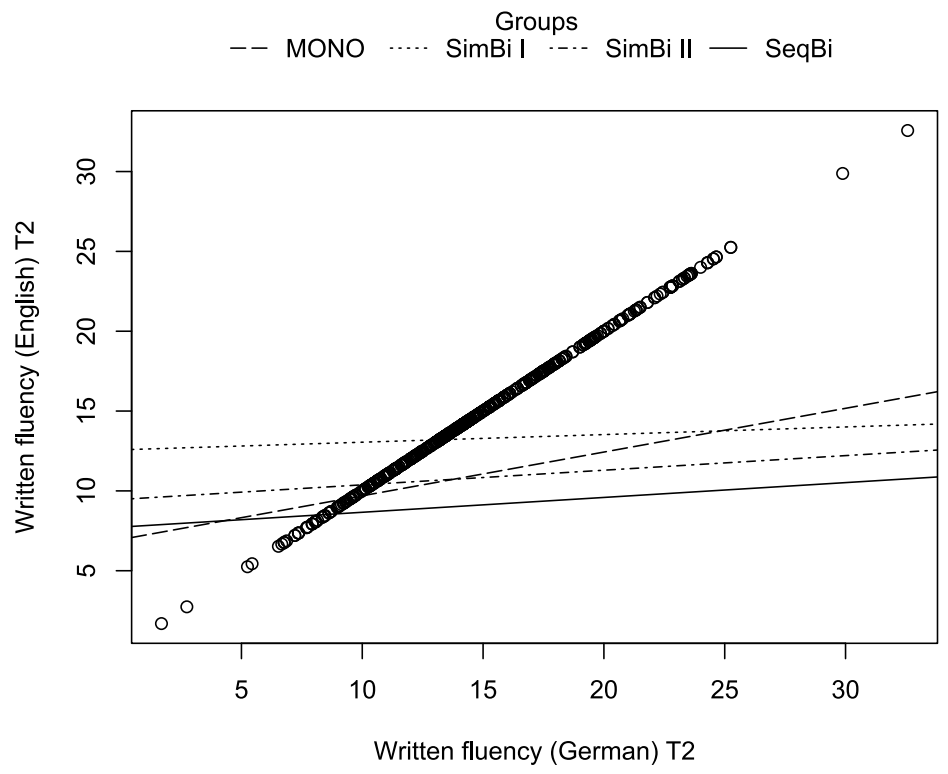

Figure 7.9: Impact of written fluency (German) on language group at Time 2 


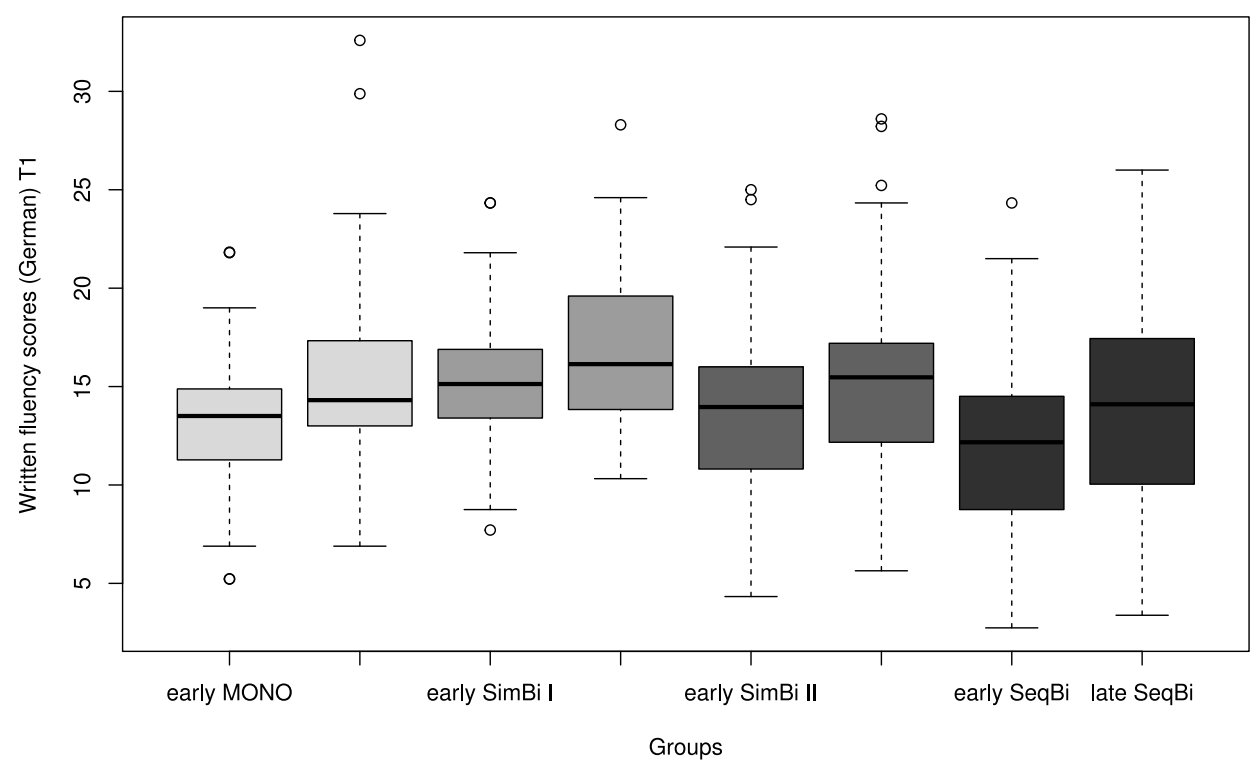

Figure 7.10: Written fluency (German) by $\mathrm{AO}$ and language group at Time 1

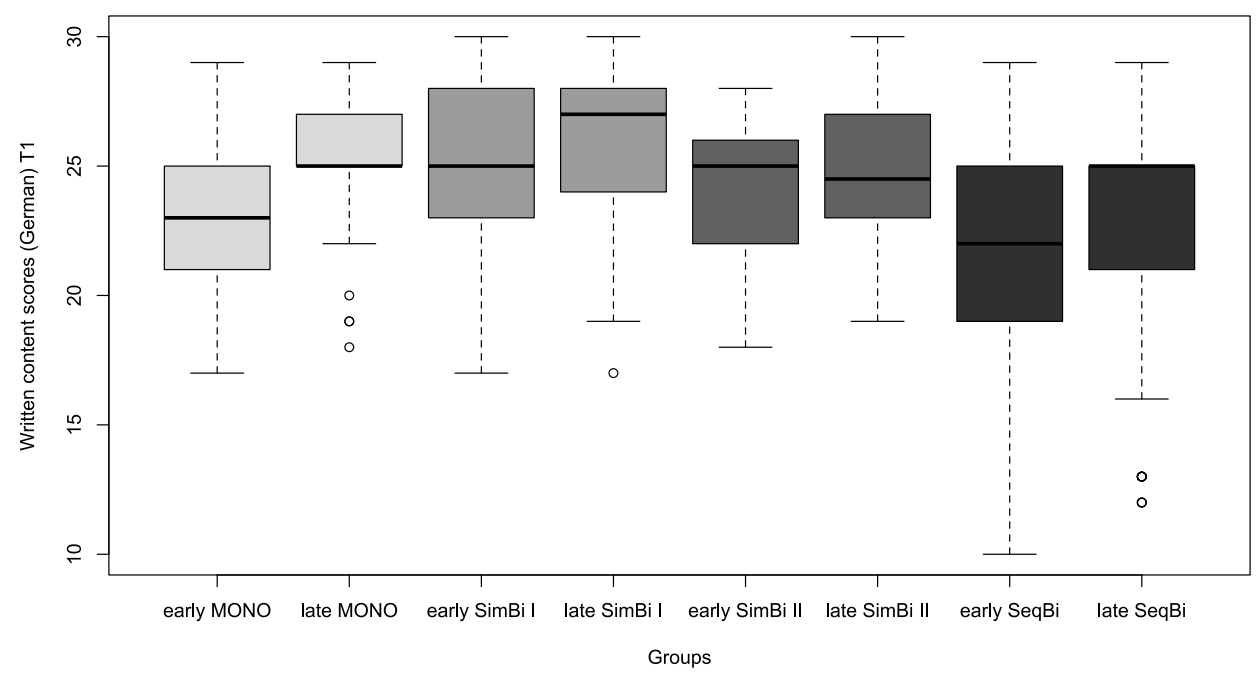

Figure 7.11: Written content (German) by $\mathrm{AO}$ and language group at Time 1 


\section{Discussion}

On the one hand, the results of this study shed light on the susceptibility of different learner groups to an earlier vs. later starting age in FL learning and the importance of literacy skills in the L1(s); on the other hand, they revealed the mitigating influence of the hybridity of experiences of bilinguals on $\mathrm{AO}$ effects. While three out of the four groups tested (the monolinguals, simultaneous bilinguals (SIMBI II), and sequential bilinguals) displayed AO effects that are typical of monolinguals in school contexts - unstable temporary benefits of an earlier start - the simultaneous bilingual-biliterates (SIMBI I group) showed a pattern that is more reminiscent of naturalistic settings: the earlier the $\mathrm{AO}$, the better the FL outcome in the long run.

A close analysis of the strength of the individual predictors as well as the interaction between them showed that this might be due to the fact that the SIMBI I participants were biliterate on top of being bilingual. Growing up bilingual endowed them with different preliteracy knowledge than monolingual children, as they had to acquire concepts of sound, word, and the function of print in their different languages before they could read (Bialystok 2007). Bialystok (2007) also suggests that the early experience of knowing two languages influences the acquisition of literacy; she hypothesizes that one avenue of that influence may be through the type of oral competence established by these children.

However, while bilingualism per se did not have an effect on the EFL outcome, unless it was coupled with a supportive learning environment, biliteracy impacted on most of the EFL measures. Before the SIMBI I group began primary school, they showed emergent literacy skills (developmental precursors to literacy) in two languages, both of which were later consolidated. In fact, these participants displayed very strong German literacy skills at Time 1, outperforming the other groups with respect to content, organization, fluency, complexity and accuracy of written output. Considering the high impact of German literacy skills on English literacy skills, it is perhaps not surprising that the SIMBI I had a temporary advantage in this realm. They might also benefit from heightened metalinguistic insights, which results from exposure to literacy in two languages (Sanz 2000; Bialystok 2007).

Finally, it is noteworthy that the SIMBI I group also received support from parents who encouraged biliteracy, owned a lot of books and had a habit of reading regularly to their children. Although emergent literacy skills could not be measured before primary school, we know that the parents of the SIMBI I students encouraged bilingual literacy skills from an early age on, i.e. they valued literacy skills in the home language highly. The SIMBI I students (both early and late starters) thus received more literacy support in their L1s than the early and 
late SEQBI participants. In the light of studies in Spain described in the literature review (e.g. Sanz 2008), where bilinguals are always biliterate and no "earlier is better" effect could be observed for biliterate bilinguals, the main distinguishing factor may be parental support rather than biliteracy in this study.

This leads us to the question as to why the early starters in the other two bilingual groups (SIMBI II and SEQBI) could not benefit more from their earlier start, i.e. why they show similar AO effects as the monolingual students. One potential reason for this is that they were not biliterate; the SEQBI participants, for instance, had virtually no literacy skills in their home language at the first data collection time. Before they had begun primary school, they showed emergent literacy skills (developmental precursors to literacy) in their L1 (not German) according to their parents, but this effort was later abandoned. While they received the same amount of literacy support in German as the SIMBI groups, there was a common belief among their parents that native language use at home interferes with the acquisition of L2 learning at school.

The SEQBI group also had poorer L2 (German) literacy skills than the other groups at the beginning of secondary school, arguably due to slowly developing literacy skills throughout primary school: when they began L3 English instruction in second grade, they were only marginally bilingual and were typically exposed to the oral and written forms of their L2 (German) simultaneously (see also the results in Sánchez \& Bardel 2017). Referring to a number of other authors (e.g. Collier 1987; Cummins 1991; August \& Hakuta 1997), Bialystok (2007) points out that children who acquire language literacy in school in spite of having a weak oral command of that language typically achieve lower levels of reading competence than their peers and require between four and seven years to reach gradelevel standards in academic and literacy achievement. Bialystok (2007: 22) adds that " $[\mathrm{m}]$ ore important, however, is that the social and educational background of these children may compromise their ability to acquire literacy, irrespective of language proficiency".

It needs to be emphasized, however, that there were no more differences between early and late monolinguals, simultaneous bilinguals, and sequential bilinguals at the end of mandatory school time. The fact that the early starters' lag in German literacy skills - as well as the differences between simultaneous and sequential bilinguals - were of temporary nature should provide reassurance to educators and parents that (1) students' L1 literacy skills will not be sacrificed by an early EFL program and (2) early bilingualism does not jeopardize either the development of literacy skills in the community language or the acquisition of an additional L2 - quite to the contrary! 


\section{Conclusions and implications}

Of prime interest in this study was how an earlier vs. later AO influences the EFL outcomes of different learner groups (monolinguals vs. bilinguals, simultaneous vs. sequential bilinguals and bilinguals vs. biliterates). The results of a longitudinal analysis with 636 secondary school students revealed that an earlier AO is only beneficial for one specific learner group across a range of productive and receptive, oral and written FL measures: simultaneous bilinguals who are biliterate and receive substantial parental support (in the short and the long-run), as opposed to monolinguals and non-biliterate bilinguals (simultaneous or sequential), who do not benefit from an earlier $\mathrm{AO}$ in the long run.

Besides these differential $\mathrm{AO}$ effects, the results also revealed that sociolinguistic context in which languages are highly valued may also have positive consequences with respect to the bilingual advantage. Quality in the home environment seems to be important regardless of differences in $\mathrm{AO}$ or biological age (see also Pfenninger \& Singleton 2019). The beneficial effects of parental sensitivity maps onto the bilingualism literature quite well. For instance, family circumstances in which bilingualism is valued provide children with the opportunities to use and switch between two languages, which in turn could enhance their executive functions (see Goriot et al. 2016). The lack of difference in additional language learning between monolingual and bilingual students is informative, confirming that we cannot ignore the fact that many factors affect the language acquisition process, and bilingualism is an important but not exclusive influence (see e.g. Cenoz 2009). Also, the fact that there are no differences between simultaneous vs. sequential bilinguals when biliteracy is controlled for highlights the heterogeneity of bilingual populations and the importance of distinguishing between different types of bilinguals.

The results from this study also have important educational implications in light of the increasing number of multilingual students (e.g. children with an immigrant background), who, in the early primary grades, have to learn and become literate in two languages other than the one first learned at home. While the observation that almost all subskills that form an integral part of the skill of L2 writing correlate with L1 writing ability is not new, one of the remarkable outcomes of this study involves the lag in the development of German writing ability among early starters in each language group. Thus, L1 and L2 educators and policy makers should understand that mastery of literacy skills in the elementary school years is important for students attempting to learn a FL several years later, as already discussed in Pfenninger (2014). 
The importance of L1 literacy skills calls for research that identifies and evaluates best practices regarding support of language and literacy development for multilingual children. Parents, teachers, and policy-makers should be made aware of the benefits of bilingualism, and the consequences of their appreciation of different L1s for children's cognition. According to Goldenberg et al. (2006), instructional enhancements are necessary to support sequential bilinguals' language and literacy development, especially when instruction is conducted only in the language of the community. This means that teachers need to be better trained to work with and enhance language and literacy among dual language learners. There is also a dearth of intervention studies focusing on promoting multilingual language and literacy development in young learners who are not yet proficient in the language of the target culture (here German) (see August \& Shanahan 2006).

Finally, I note some limitations of this study. At the beginning of primary school, the sequential bilinguals were learning literacy skills in their weak language (German) at the same time as they were learning to read in their strong language (L1), which means that the transfer of skills from the dominant language might have facilitated literacy in the weaker language, obscuring any effect that bilingualism per se might have imparted (see Bialystok 2007). In future studies it would be fruitful to add balance to the equation and analyze if more balanced use and a more balanced level of proficiency of two languages within the bilingual groups has significant effects on the L3 learning outcome. Yow \& Li (2015), for instance, found a significant effect of the latent variable balanced bilingualism (balanced usage and proficiency in two languages) on certain components of executive functioning - in addition to effects of the impact of age of L2 acquisition. In a next step it would also be interesting to analyze the same variables in a comparable socio-educational context that involves typologically different languages. In the present study, language typology is not a variable under analysis. I made sure, however, that the participants in the three bilingual groups came from the same L1 backgrounds (Spanish, Portuguese, Croatian, Serbian, Albanian, Arabic, or Italian) by controlling the number of L1s in each group. None of these languages were part of the school curriculum. What is more, we find the same number and types of language pairs (e.g. German-Albanian, German-Serbian) in each bilingual group. Nevertheless, in considering these arguments, the reader should bear in mind that the relationship among the languages involved might also account for differences in the results of research on the effects of bi/literacy on L3 learning. 


\section{Appendix A Significant interactions between bilingualism and environmental factors, and biliteracy and environmental factors respectively}

\section{A.1 Time 1}

receptive vocabulary: Biliteracy:InB_Parents $\beta=-1.41 \pm 0.45, t=-3.10$

lexical richness: Bilingualism:AttitudesParents $\beta=-0.21 \pm 0.09, t=-2.28$,

Biliteracy:InB_Parents $\beta=-0.25 \pm 0.07, t=-3.63$

written fluency: Bilingualism:Books $\beta=-0.95 \pm 0.43, t=-2.20$,

Bilingualism:DirB $\beta=-1.43 \pm 0.32, t=-4.49$

written complexity: Bilingualism:AttitudesParents $\beta=-0.07 \pm 0.03, t=-2.30$,

Biliteracy:InB_Parents $\beta=-0.06 \pm 0.02, \mathrm{t}=-2.76$,

Biliteracy:AttitudesParents $\beta=-0.11 \pm 0.05, t=-2.52$

written accuracy: Biliteracy:AttitudesParents $\beta=0.15 \pm 0.09, t=2.01$

oral lexical richness: Bilingualism:DirB $\beta=-0.25 \pm 0.13, t=-2.03$

oral fluency: Bilingualism:DirB $\beta=-2.58 \pm 1.25, t=-2.07$,

Biliteracy:Score1.DirB $\beta=-2.82 \pm 2.01, t=1.41$

oral complexity: Biliteracy:InB_Parents $\beta=-0.10 \pm 0.03, t=-3.03$,

Biliteracy:AttitudesParents $\beta=-0.16 \pm 0.06, t=-2.46$

oral accuracy: Bilingualism:Books $\beta=0.42 \pm 0.20, t=2.10$,

Biliteracy:AttitudesParents $\beta=0.73 \pm 0.22, t=3.13$

grammaticality judgments: Bilingualism:DirB $\beta=-0.77 \pm 0.36, t=-2.14$ 


\section{A. 2 Time 2}

listening comprehension: Bilingualism:Books $\beta=-0.76 \pm 0.42, t=-1.82$, Bilingualism:DirB $\beta=-0.84 \pm 0.27, t=-3.12$

productive vocabulary: Bilingualism:Books $\beta=--2.55 \pm 0.88, t=-2.91$,

Bilingualism:DirB $\beta=-1.18 \pm 0.54, t=-2.17$, Biliteracy:Score.Books

$\beta=-3.32 \pm 1.39, t=-2.38$, Biliteracy:Score.IndB_Parents

$\beta=-1.74 \pm 0.48, t=-3.65$

receptive vocabulary: Bilingualism: $\operatorname{DirB} \beta=-1.22 \pm 0.63, t=-1.95$,

Biliteracy:IndB_Parents $\beta=-1.42 \pm 0.53, t=-2.69$,

Biliteracy:Score2.DirB $\beta=1.21 \pm 0.70, t=1.71$

written lexical richness: Bilingualism:AttitudesParents $\beta=-0.18 \pm 0.08$, $t=-2.19$, Biliteracy:Score2.DirB $\beta=0.16 \pm 0.08, t=1.91$

written fluency: Bilingualism: Books $\beta=-1.89 \pm 0.47, t=-4.03$

written complexity: Bilingualism:AttitudesParents $\beta=-0.09 \pm 0.04, t=-2.49$,

Biliteracy:InB_Parents $\beta=-0.08 \pm 0.03, t=-2.42$, Biliteracy:Score2.DirB

$\beta=-0.10 \pm 0.04, t=-2.57$

written accuracy: Bilingualism:Books $\beta=0.17 \pm 0.06, t=2.68$,

Bilingualism:DirB $\beta=0.13 \pm 0.04, t=3.08$, Biliteracy:Score2.DirB

$\beta=-0.14 \pm 0.06, t=-2.94$

oral lexical richness: Bilingualism: $\operatorname{DirB} \beta=-0.31 \pm 0.10, t=-3.28$,

Biliteracy:InB_Parents $\beta=-0.24 \pm 0.08, t=-2.87$

oral accuracy: Bilingualism:InB_Parents $\beta=0.39 \pm 0.14, t=2.81$,

Bilingualism:DirB $\beta=0.26 \pm 0.11, t=2.41$, Biliteracy:Score.Books

$\beta=1.23 \pm 0.26, t=4.64$

oral fluency: Biliteracy:InB_Parents $\beta=-1.73 \pm 0.86, t=-2.01$

oral complexity: Biliteracy:Score.AttitudesParents $\beta=0.06 \pm 0.04, t=1.32$

grammaticality judgments: Bilingualism:AttitudesParents $\beta=-1.13 \pm 0.31$,

$t=-3.62$, Biliteracy:Score2.DirB $\beta=-0.85 \pm 0.32, t=-2.68$ 


\section{Appendix B Statistical analysis output}

Table 7.12: Multilevel regression analyses for environmental influences at Time 1 (fixed effect estimates for home variables). ${ }^{*} p<0.05$, ** $p<0.001$.

\begin{tabular}{lrcc}
\hline \hline & \multicolumn{3}{c}{ Fixed effect: Books } \\
\cline { 2 - 4 } & Estimate \pm SE & $t$ & Main effect $p$ \\
\hline Receptive vocabulary & $1.52 \pm 0.43$ & 3.58 & $0.0003^{* *}$ \\
Written lexical richness & $0.15 \pm 0.06$ & 2.34 & $0.018^{*}$ \\
Written fluency & $1.00 \pm 0.26$ & 3.81 & $0.001^{* *}$ \\
Written complexity & $0.03 \pm 0.02$ & 1.49 & 0.129 \\
Written accuracy & $-0.09 \pm 0.04$ & -2.35 & $0.018^{*}$ \\
Oral lexical richness & $0.16 \pm 0.09$ & 1.80 & 0.068 \\
Oral fluency & $1.61 \pm 0.83$ & 1.93 & $0.050^{*}$ \\
Oral complexity & $0.08 \pm 0.03$ & 2.81 & $0.005^{* *}$ \\
Oral accuracy & $-0.48 \pm 0.13$ & -3.75 & $0.001^{* *}$ \\
GJT & $-0.04 \pm 0.26$ & -0.15 & 0.900 \\
\hline & Fixed effect: Frequency of reading \\
\hline Receptive vocabulary & $1.16 \pm 0.32$ & 3.60 & $0.0002^{* *}$ \\
Written lexical richness & $0.08 \pm 0.05$ & 1.72 & 0.087 \\
Written fluency & $1.15 \pm 0.20$ & 5.62 & $<0.0001^{* *}$ \\
Written complexity & $-0.00 \pm 0.02$ & -0.26 & 0.790 \\
Written accuracy & $-0.07 \pm 0.03$ & -2.37 & $0.018^{*}$ \\
Oral lexical richness & $0.22 \pm 0.08$ & 2.70 & $0.024^{*}$ \\
Oral fluency & $4.48 \pm 1.85$ & 2.42 & $0.019^{*}$ \\
Oral complexity & $-0.02 \pm 0.02$ & -1.09 & 0.276 \\
Oral accuracy & $0.01 \pm 0.10$ & 0.09 & 0.908 \\
GJT & $0.56 \pm 0.26$ & 2.14 & $0.050^{*}$ \\
\hline \hline
\end{tabular}



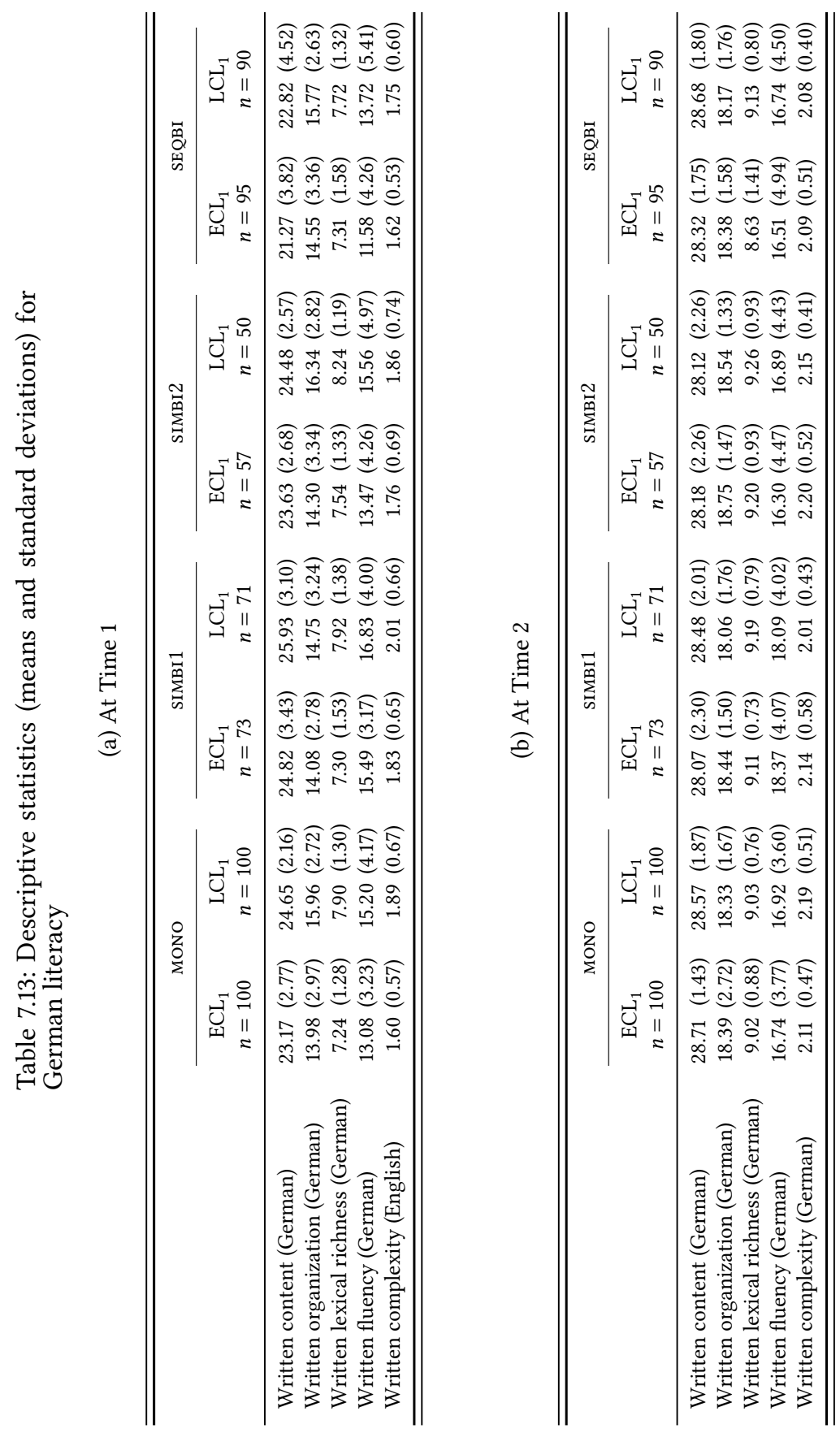
Table 7.14: Multilevel regression analyses for environmental influences at Time 1. Fixed effect estimates for home variable in/direct parental involvement. ${ }^{*} p<0.05,{ }^{* *} p<0.001$.

\begin{tabular}{lrcc}
\hline \hline & \multicolumn{3}{c}{ Fixed effect: In/direct parental involvement } \\
\cline { 2 - 4 } & Estimate \pm SE & \multicolumn{1}{c}{$t$} & Main effect $p$ \\
\hline Receptive vocabulary & $1.81 \pm 0.31$ & 5.84 & $<0.0001^{* *}$ \\
Written lexical richness & $0.13 \pm 0.06$ & 2.24 & $0.037^{*}$ \\
Written fluency & $0.39 \pm 0.15$ & 2.53 & $0.010^{*}$ \\
Written complexity & $0.13 \pm 0.04$ & 3.12 & $0.001^{* *}$ \\
Written accuracy & $0.01 \pm 0.03$ & 0.39 & 0.702 \\
Oral lexical richness & $-0.04 \pm 0.06$ & -0.62 & 0.538 \\
Oral fluency & $0.57 \pm 0.60$ & 0.94 & 0.956 \\
Oral complexity & $0.18 \pm 0.10$ & -3.01 & $0.010^{*}$ \\
Oral accuracy & $-0.69 \pm 0.21$ & -3.31 & $0.004^{* *}$ \\
GJT & $0.20 \pm 0.19$ & 1.05 & 0.289 \\
\hline \hline
\end{tabular}

Table 7.15: Multilevel regression analyses for scores as dependent variable at Time 2 (fixed effect estimates for home variables). ${ }^{*} p<0.05$, ** $p<0.001$.

\begin{tabular}{lrrc}
\hline \hline & \multicolumn{3}{c}{ Fixed effect: Books } \\
\cline { 2 - 4 } & Estimate \pm SE & \multicolumn{1}{c}{$t$} & Main effect $p$ \\
\hline Listening & $0.43 \pm 0.26$ & 1.63 & 0.135 \\
Productive vocabulary & $4.72 \pm 1.30$ & 3.62 & $<0.0001^{* *}$ \\
Receptive vocabulary & $2.82 \pm 0.46$ & 6.08 & $<0.0001^{* *}$ \\
Written lexical richness & $0.14 \pm 0.06$ & 2.31 & $0.021^{*}$ \\
Written fluency & $1.51 \pm 0.29$ & 5.20 & $<0.0001^{* *}$ \\
Written complexity & $0.05 \pm 0.03$ & 1.86 & 0.067 \\
Written accuracy & $-0.12 \pm 0.04$ & -3.10 & $0.009^{* *}$ \\
Oral lexical richness & $0.07 \pm 0.07$ & 1.01 & $0.001^{*}$ \\
Oral fluency & $1.88 \pm 0.78$ & 2.42 & $0.015^{*}$ \\
Oral complexity & $0.06 \pm 0.03$ & 1.96 & $0.043^{*}$ \\
Oral accuracy & $-1.06 \pm 0.26$ & -4.14 & $<0.0001^{* *}$ \\
GJT & $0.17 \pm 0.24$ & 0.70 & 0.491 \\
\hline \hline
\end{tabular}


Table 7.16: Multilevel regression analyses for scores as dependent variable at Time 2 (fixed effect estimates for home variables) (continued from Table 7.15)

\begin{tabular}{lrrc}
\hline \hline & \multicolumn{3}{c}{ Fixed effect: Frequency of reading } \\
\cline { 2 - 4 } & Estimate \pm SE & \multicolumn{1}{c}{$t$} & Main effect $p$ \\
\hline Listening & $0.35 \pm 0.15$ & 2.40 & $0.006^{* *}$ \\
Productive vocabulary & $0.75 \pm 0.30$ & 2.54 & $0.026^{*}$ \\
Receptive vocabulary & $0.57 \pm 0.60$ & 0.94 & 0.955 \\
Written lexical richness & $-0.04 \pm 0.08$ & -0.52 & 0.098 \\
Written fluency & $0.45 \pm 0.14$ & 3.17 & $0.002^{*}$ \\
Written complexity & $0.06 \pm 0.04$ & 1.83 & $0.024^{*}$ \\
Written accuracy & $0.01 \pm 0.04$ & 0.16 & $<0.0001^{* *}$ \\
Oral lexical richness & $0.16 \pm 0.05$ & 3.16 & $0.001^{* *}$ \\
Oral fluency & $-0.56 \pm 0.47$ & -1.21 & 0.222 \\
Oral complexity & $0.00 \pm 0.02$ & 0.20 & 0.871 \\
Oral accuracy & $-0.05 \pm 0.06$ & -0.83 & 0.103 \\
GJT & $0.90 \pm 0.28$ & 3.25 & $0.001^{* *}$ \\
\hline \hline
\end{tabular}

Table 7.17: Multilevel regression analyses for scores as dependent variable at Time 2 (fixed effect estimates for home variables). ${ }^{*} p<0.05$, ${ }^{* *}$ $p<0.001$.

\begin{tabular}{lrrc}
\hline \hline & \multicolumn{3}{c}{ Fixed effect: In/direct parental involvement } \\
\cline { 2 - 4 } & Estimate \pm SE & \multicolumn{1}{c}{$t$} & Main effect $p$ \\
\hline Listening & $0.31 \pm 0.13$ & 2.42 & $0.013^{*}$ \\
Productive vocabulary & $0.36 \pm 0.26$ & 1.42 & 0.144 \\
Receptive vocabulary & $0.76 \pm 0.28$ & 2.69 & $0.007^{* *}$ \\
Written lexical richness & $0.07 \pm 0.04$ & 1.59 & 0.080 \\
Written fluency & $0.33 \pm 0.14$ & 2.32 & $0.019^{*}$ \\
Written complexity & $0.02 \pm 0.02$ & 1.16 & $0.045^{*}$ \\
Written accuracy & $-0.00 \pm 0.02$ & -0.04 & 0.957 \\
Oral lexical richness & $0.15 \pm 0.04$ & 3.28 & $0.001^{* *}$ \\
Oral fluency & $0.28 \pm 0.47$ & 0.59 & 0.548 \\
Oral complexity & $-0.02 \pm 0.04$ & -0.53 & 0.208 \\
Oral accuracy & $-0.17 \pm 0.05$ & -3.30 & $0.001^{* *}$ \\
GJT & $0.73 \pm 0.17$ & 4.23 & $<0.0001^{* *}$ \\
\hline \hline
\end{tabular}




\section{References}

Adesope, Olusola O., Tracy Lavin, Terri Thompson \& Charles Ungerleider. 2010. A systematic review and meta-analysis of the cognitive correlates of bilingualism. Review of Educational Research 80(2). 207-245.

Al-Thubaiti, Kholoud Abdullah. 2010. Age effects in a minimal input setting on the acquisition of English morphosyntactic and semantic properties by L1 speakers of Arabic. Essex: University of Essex. (Doctoral dissertation).

Aronin, Larissa \& Britta Hufeisen. 2009. The exploration of multilingualism: Development of research on L3, multilingualism and multiple language acquisition. Amsterdam: John Benjamins.

August, Diane \& Kenji Hakuta (eds.). 1997. Improving schooling for languageminority children: A research agenda. Washington, DC: National Academies Press.

August, Diane \& Timothy Shanahan (eds.). 2006. Developing literacy in secondlanguage learners: Report of the national literacy panel on language-minority children and youth. Mahwah, NJ: Erlbaum.

Barr, Dale J., Roger Levy, Christoph Scheepers \& Harry J. Tily. 2013. Random effects structure for confirmatory hypothesis testing: Keep it maximal. fournal of Memory and Language 68. 255-278.

Bates, Douglas, Reinhold Kliegl, Shravan Vasishth \& Harald Baayen. 2015. Parsimonious mixed models. Electronic publication ahead of print version. https: //arxiv.org/abs/1506.04967 (29 May, 2017).

Bialystok, Ellen. 2007. Acquisition of literacy in bilingual children: A framework for research. Language Learning 57(1). 45-77.

Bialystok, Ellen, Jubin Abutalebi, Thomas Hieronymus Bak, Deborah M. Burke \& Judith F. Kroll. 2016. Aging in two languages: Implications for public health. Ageing Research Reviews 27. 56-60.

Bialystok, Ellen \& Xiaojia Feng. 2011. Language proficiency and its implications for monolingual and bilingual children. In Aydin Yücesan Durgunoglu \& Claude. Goldenberg (eds.), Language and literacy development in multilingual settings, 121-138. New York: Guilford Press.

Bialystok, Ellen, Gigi Luk \& Ernest Kwan. 2005. Bilingualism, biliteracy, and learning to read: Interactions among languages and writing systems. Scientific Studies of Reading 9(1). 43-61.

Bialystok, Ellen, Michelle Martin \& Mythili Viswanathan. 2005. Bilingualism across the lifespan: The rise and fall of inhibitory control. International fournal of Bilingualism 9. 103-119. 
Buchholz, Barbara. 2007. Facts and Figures im Grundschul-Englisch: Eine Untersuchung der verbindlichen Übung Lebende Fremdsprache an österreichischen Volksschulen. Wien: LIT Verlag.

Castro, Dina C., Mariela Páez, David K. Dickinson \& Ellen Frede. 2011. Promoting language and literacy in young dual language learners: Research, practice and policy. Child Development Perspectives 5(1). 15-21.

Cenoz, Jasone. 2009. Towards multilingual education: Basque educational research from an international perspective. Bristol: Multilingual Matters.

Cenoz, Jasone \& José F. Valencia. 1994. Additive trilingualism: Evidence from the Basque Country. Applied Psycholinguistics 15(2). 195-207. DOI: 10 .1017/ S0142716400005324.

Cobo-Lewis, Alan B., Barbara Zurer Pearson, Rebecca E. Eilers \& Vivian C Umbel. 2002. Effects of bilingualism and bilingual education on oral and written Spanish skills: A multifactor study of standardized test outcomes. In D. Kimbrough Oller \& Rebecca E. Eilers (eds.), Language and literacy in bilingual children, 98117. Clevedon: Multilingual Matters.

Collier, Virginia. 1987. Age and rate of acquisition of second language for academic purposes.

Cummins, Jim. 1976. The influence of bilingualism on cognitive growth: A synthesis of research findings and explanatory hypotheses. Working Papers on Bilingualism 9. 1-43. https://eric.ed.gov/?id=ED125311.

Cummins, Jim. 1981. The role of primary language development in promoting educational success for language minority students. In California State Department of Education (ed.), Schooling and language minority students: A theoretical framework, 3-49. Los Angeles, CA: California State University.

Cummins, Jim. 1991. Interdependence of first- and second language proficiency. In Ellen Bialystok (ed.), Language processing in bilingual children, 70-89. Cambridge: Cambridge University Press. DOI: 10.1017/CBO9780511620652.006.

De Angelis, Gessica. 2015. English L3 learning in a multilingual context: The role of parental education and 12 exposure within the living community. International fournal of Multilingualism 12(4). 435-452. DOI: 10.1080/14790718.2015. 1071017.

De Bot, Kees. 2017. The future of the bilingual advantage. In Simone E. Pfenninger \& Judit Navracsics (eds.), Future research directions for applied linguistics, 1532. Bristol: Multilingual Matters.

de Bruin, Angela, Barbara Treccani \& Sergio Della Sala. 2014. Cognitive advantage in bilingualism: An example of publication bias? Psychological Science 26(1). 99-107. 
Ellis, Rod \& Gary Barkhuizen. 2005. Analysing learner language. Oxford: Oxford University Press.

García Mayo, María del Pilar \& María Luisa García Lecumberri (eds.). 2003. Age and the acquisition of English as a foreign language. Clevedon: Multilingual Matters.

Genelot, Sophie. 1997. L'enseignement des langues vivantes à l'école élémentaire: Éléments d'évaluation des effets au college. Revue Française de Pédagogie 118. 27-42.

Genesee, Fred. 2004. What do we know about bilingual education for majority language students? In Tej K. Bhatia \& William Ritchie (eds.), Handbook of bilingualism and multiculturalism, 547-576. Malden, MA: Blackwell.

Goldenberg, Claude, Robert S. Rueda \& Diane August. 2006. Social and cultural influences on the literacy attainment of language-minority children and youth. In Diane August \& Timothy Shanahan (eds.), Report of the national literacy panel on language minority children and youth, 136-160. Mahwah: Lawrence Erlbaum.

Goorhuis-Brouwer, Sieneke \& Kees De Bot. 2010. Impact of early English language teaching on L1 and L2 development in children in Dutch schools. International fournal of Bilingualism 14. 289-302.

Goriot, Claire, Eddie Denessen, Joep T. A. Bakker \& Mienke Droop. 2016. Benefits of being bilingual? The relationship between pupils' perceptions of teachers' appreciation of their home language and executive functioning. International fournal of Bilingualism 20(6). 700-713.

Graham, Suzanne, Louise Courtney, Theodoros Marinis \& Alan Tonkyn. 2017. Barly language learning: The impact of teaching and teacher factors. International fournal of Bilingualism 67. 922-958.

Grosjean, François. 2010. Bilingual: Life and reality. Cambridge, MA: Harvard University Press.

Jacobs, Holly L., Stephen A. Zinkgraf, Deanna R. Wormuth, V. Faye Hartfiel \& Jane B. Hughey. 1981. Testing ESL composition. Newbury: Rowley.

Jaekel, Nils, Michael Schurig, Merle Florian \& Markus Ritter. 2017. From early starters to late finishers? A longitudinal study of early foreign language learning in school. Language Learning 67(3). 631-664. DOI: 10.1111/lang.12242.

Kolde, Gottfried. 1981. Sprachkontakte in gemischtsprachigen Städten: Vergleichende Untersuchungen über Voraussetzungen und Formen sprachlicher Interaktion verschiedensprachiger fugendlicher in den Schweizer Städten Biel/Bienne und Fribourg/Freiburg. Wiesbaden: Franz Steiner Verlag. 
Kovelman, Ioulia, Stephanie A. Baker \& Laura-Ann Petitto. 2008. Age of first bilingual language exposure as a new window into bilingual reading development. Bilingualism Language and Cognition 11(2). 203-223.

Larson-Hall, Jenifer. 2008. Weighing the benefits of studying a foreign language at a younger starting age in a minimal input situation. Second Language Research 24. 35-63.

Lasagabaster, David. 2000. Three languages and three linguistic models in the Basque educational system. In Ulrike Jessner \& Jasone Cenoz (eds.), English in Europe: The acquisition of a third language, 179-197. Clevedon: Multilingual Matters.

Lasagabaster, David \& Aintzane Doiz. 2003. Maturational constraints on foreignlanguage written production. In María del Pilar García Mayo \& María Luisa García Lecumberri (eds.), Age and the acquisition of English as a foreign language, 136-160. Clevedon: Multilingual Matters.

Laufer, Batia \& Paul Nation. 1999. A vocabulary size test of controlled productive ability. Language Testing 16(1). 33-51.

Lightbown, Patsy Martin. 2000. Classroom second language acquisition research and second language teaching. Applied Linguistics 21(4). 431-482.

Luk, Gigi, Eric de Sa \& Ellen Bialystok. 2011. Is there a relation between onset age of bilingualism and enhancement of cognitive control?

Meijer, Cor, Victoria Soriano \& Amanda Watkins (eds.). 2003. Special needs education in Europe. with the contribution of EURYDICE, The Information Network on Education in Europe. https://www.european-agency.org/sites/default/ files/special-needs-education-in-europe \%5C_sne\%5C_europe\%5C_en.pdf (13 July, 2017).

Morton, J. Bruce. 2014. A sunny review casts a foreboding shadow over status quo bilingual advantage research. Applied Psycholinguistics 35(5). 929-931.

Muñoz, Carmen. 2000. Bilingualism and trilingualism in school students in Catalonia. In Jasone Cenoz \& Ulrike Jessner (eds.), English in Europe: The acquisition of a third language, 157-178. Clevedon: Multilingual Matters.

Muñoz, Carmen (ed.). 2006. Age and the rate of foreign language learning. Clevedon: Multilingual Matters.

Murphy, Victoria A. \& Maria Evangelou (eds.). 2016. Early childhood education in English for speakers of other languages. London: British Council.

Paap, Kenneth R. \& Zachary I. Greenberg. 2013. There is no coherent evidence for a bilingual advantage in executive processing. Cognitive Psychology 66(2). 232-258. 
Pfenninger, Simone E. 2014. The literacy factor in the optimal age discussion: A five-year longitudinal study. International fournal of Bilingual Education and Bilingualism 19(3). 217-234. DOI: 10.1080/13670050.2014.972334.

Pfenninger, Simone E. 2017. Not so individual after all: An ecological approach to age as an individual difference variable in a classroom. Studies in Second Language Learning and Teaching 7(1). 19-46.

Pfenninger, Simone E. \& David Singleton. 2017. Beyond age effects in instructional L2 learning: Revisiting the age factor. Bristol: Multilingual Matters.

Pfenninger, Simone E. \& David Singleton. 2019. Starting age overshadowed: The primacy of differential environmental and family support effects on 12 attainment in an instructional context. Language Learning 69(S1). 207-234. DOI: 10. 1111/lang.12318.

Rash, Felicity. 1998. The German language in Switzerland: Multilingualism, diglossia, and variation (German Linguistic and Cultural Studies 3). Bern: Peter Lang.

Rauch, Dominique Patrizia, Johannes Naumann \& Nina Jude. 2012. Metalinguistic awareness mediates effects of full biliteracy on third-language reading proficiency in Turkish-German bilinguals. International fournal of Bilingualism 16(4). 402-418.

Sánchez, Laura. 2012. 'Luisa and Pedrito's dog will the breakfast eat': Interlanguage transfer and the role of the second language factor. In Gessica De Angelis \& Jean-Marc Dewaele (eds.), New trends in crosslinguistic influence and multilingualism research, 86-104. Clevedon: Multilingual Matters. DOI: 10/d9md.

Sánchez, Laura. 2015. L2 activation and blending in third language acquisition: Evidence of crosslinguistic influence from the L2 in a longitudinal study on the acquisition of L3 English. Bilingualism: Language and Cognition 18(2). 252269.

Sánchez, Laura \& Camilla Bardel. 2017. Transfer from an L2 in third language learning: A study on L2 proficiency. In Tanja Angelovska \& Angela Hahn (eds.), L3 syntactic transfer: Models, new developments and implications, 223250. Amsterdam: John Benjamins.

Sanz, Cristina. 2000. Bilingual education enhances third language acquisition: Evidence from Catalonia. Applied Psycholinguistics 21(1). 23-44. DOI: 10.1017/ S0142716400001028.

Sanz, Cristina. 2008. Predicting enhanced L3 learning in bilingual contexts: The role of biliteracy. In Carmen Pérez-Vidal, Aurora Bel \& Maria Juan-Garau (eds.), A portrait of the young in the new multilingual Spain, 220-240. Clevedon: Multilingual Matters. 
Schmitt, Norbert, Diane Schmitt \& Caroline Clapham. 2001. Developing and exploring the behaviour of two new versions of the vocabulary levels test. Language Testing 18(1). 55-88.

Schoonen, Rob, Amos van Gelderen, Reinoud D. Stoel, Jan Hulstijn \& Kees de Glopper. 2011. Modeling the development of L1 and EFL writing proficiency of secondary school students. Language Learning 61(1). 31-79.

Slavin, Robert Edward \& Alan Cheung. 2003. Effective reading programs for English language learners. Baltimore, MD: Center for Research on the Education of Students Placed at Risk, The Johns Hopkins University.

Soveri, Anna, Antoni Rodriguez-Fornells \& Matti Laine. 2011. Is there a relationship between language switching and executive functions in bilingualism? Introducing a within-group analysis approach. Frontiers in Psychology 2. https: //www.ncbi.nlm.nih.gov/pmc/articles/PMC3150725/ (31 August, 2017).

Sparks, Richard L. 2012. Individual differences in L2 learning and long-term L1L2 relationships. Language Learning 62 (Suppl. 2). 5-27.

Stafford, Catherine A., Cristina Sanz \& Harriet Bowden. 2010. An experimental study of early 13 development: Age, bilingualism and classroom exposure. International fournal of Multilingualism 7(1). 162-183.

Swain, Merrill, Sharon Lapkin, Norman Rowen \& Doug Hart. 1990. The role of mother tongue literacy in third language learning. Language, Culture and Curriculum 3(1). 65-81. DOI: 10.1080/07908319009525073.

Unsworth, Sharon, Liv Persson, Tineke Prins \& Kees De Bot. 2015. An investigation of factors affecting early foreign language learning in the Netherlands. Applied Linguistics 36(5). 527-548.

Wolfe-Quintero, Kate, Shunji Inagaki \& Hae-Young Kim. 1998. Second language development in writing: Measures of fluency, accuracy and complexity. Hawai' i: University of Hawai' i.

Yow, Wei Quin \& Xiaoqian Li. 2015. Balanced bilingualism and early age of second language acquisition as the underlying mechanisms of a bilingual executive control advantage: Why variations in bilingual experiences matter. Frontiers in Psychology 6. 164. 



\title{
Chapter 8
}

\section{From L2 to L3, verbs getting into place: A study on interlanguage transfer and L2 syntactic proficiency}

\section{Laura Sánchez}

\author{
Stockholm University
}

\begin{abstract}
One of the least understood (and also least investigated) factors conditioning interlanguage transfer from a prior non-native language (L2) to a subsequent non-native language (L3) is proficiency in the source language of influence. The present study examined whether L2 German syntactic proficiency, defined here as level of development in a cluster of structural properties related to verb placement, had any effect on the occurrence of interlanguage transfer in the L3 English. More specifically, the research question guiding the study asked whether mastery of these properties (discontinuous verb placement, verb final and inversion) constrained the timing, extent and type of such transfer. The corpus analyzed comprised L2 and L3 data from Spanish/Catalan bilingual learners $(n=238)$ aged $9-13$. A series of ANCOVAs were run on the data, keeping constant various measures of L2 syntactic proficiency and controlling for L3 overall proficiency and biological age as covariates. The results of these tests yielded a significant effect for verb final $(p=0.046)$ and subject-verb inversion $(p=0.002)$. Furthermore, an inverse relationship was found between L2 syntactic proficiency and interlanguage transfer, in that low L2 proficiency in the use of verb final and (especially) inversion was associated with an overgeneralization of discontinuous verb placement in embedded clauses in the L3.
\end{abstract}

\section{Introduction}

Ever since the pioneering work of Williams \& Hammarberg (1998) back in the late nineties, a growing body of empirical studies has been published on the influence 


\section{Laura Sánchez}

of a prior non-native language in the linguistic repertoire of a speaker (L2) upon another non-native language subsequently learnt (L3), commonly referred to as interlanguage transfer (De Angelis \& Selinker 2001). Less attention, however, has been paid to investigating the factors that may potentially favour or constrain the occurrence of this specific kind of transfer. Within this line of inquiry, the study reported in this chapter sets out to examine the effects of L2 syntactic proficiency (henceforth, L2SP) on the interlanguage transfer of linguistic structures from the L2 during L3 processing and production. More specifically, the study tries to ascertain whether different levels of L2SP may contribute to increasing or decreasing the chances of interlanguage transfer occurring from the L2 to the L3.

The data investigated in this study come from a larger corpus that comprises written data in L2 German and L3 English. This corpus has been investigated in a series of studies on lexical (Sánchez 2015b) and syntactic transfer (Sánchez 2012; 2015a, among others). The main conclusion reached in these studies singled out the L2 as the primary source language of influence, overriding the first languages (L1s) (Spanish and Catalan). With this as the point of departure, the present study expands the scope of previous work by the author, examining the effect that different levels of L2SP may have on the timing (i.e., chronology), extent (i.e., frequency), and type of interlanguage syntactic transfer (henceforth, ILST).

\section{Background of the study}

\subsection{Typological contrasts in syntax between German and English}

In this study, the source language of influence (L2 German) and the target language (L3 English) differ in the crucial linguistic feature selected for investigation, i.e., verb placement. As far as this is concerned, German is classified as head-final (Beck 1998) and complements are pre-verbal (object-verb, OV). As a consequence, its basic word order is $\mathrm{SOV}^{1}$ (subject-object-verb). In contrast, the L3 English is head-initial and complements are post-verbal (subject-verb-object, SVO), the same as in the two L1s of the participants, Spanish and Catalan. At a surface level, the head-final feature is associated with a number of structural properties, above all, subject-verb inversion, discontinuous verb placement, and verb final. These properties are presented in Table 8.1, alongside the clause category (main vs. embedded) where they occur.

${ }^{1}$ For theoretical arguments on the potential mixed headedness of German see Abraham (1992). 
Table 8.1: German OV structural properties and related clause categories (main vs. embedded)

\begin{tabular}{lll}
\hline \hline Structural property & Clause type & Description \\
\hline Inversion rule (INV) & Main & $\begin{array}{l}\text { Subject-verb inversion when } \\
\text { the subject does not occupy } \\
\text { the first position in the clause }\end{array}$ \\
$\begin{array}{lll}\text { Rule of discontinuous verb } \\
\text { placement (SEP) }\end{array}$ & Main & $\begin{array}{l}\text { The finite verb occupies the } \\
\text { second position in the clause } \\
\text { (V2) and the non-finite verb } \\
\text { occupies the last position in } \\
\text { the clause }\end{array}$ \\
& Embedded & $\begin{array}{l}\text { The verb always appears at } \\
\text { the end of the clause. In }\end{array}$ \\
& & $\begin{array}{l}\text { periphrastic constructions, } \\
\text { the non-finite form precedes } \\
\text { the finite form }\end{array}$ \\
\hline \hline
\end{tabular}

As a result of the head-final feature, in German, the finite verb always appears in second position in main clauses. Hence, when a constituent other than the subject occupies the first position (as in the example given in 1), there is subjectverb inversion (INV). For the sake of clarity, the verb phrases in these examples, adapted from Sánchez (2016), are italicized.

(1) Gerade schreibt Peter einen Brief. at.this.moment writes Peter a letter

'Peter is writing a letter at this moment.'

Another structural property of main clauses is the discontinuity of verb placement or verb separation (SEP). The SEP property separates the finite and nonfinite verbs in periphrastic constructions, that is, complex verb phrases with lexical and auxiliary verbs. Hence, SEP affects thematic verbs such as tense (2) and modal (3) auxiliaries. The following examples illustrate the surface word orders associated with SEP.

(2) Peter hat gerade einen Brief geschrieben.

Peter has at.this.moment a letter written

'Peter has just written a letter.' 


\section{Laura Sánchez}

(3) Peter kann ins Kino gehen.

Peter can to the cinema go

'Peter can go to the cinema.'

In turn, verb final (VFINAL) in embedded clauses moves the verb phrase to the end of the clause (as in 4). In periphrastic constructions, the non-finite form precedes the finite form (as in 5).

(4) daß Peter heute ins Kino geht. that Peter today to.the cinema goes 'that Peter is going to the cinema today'

(5) daß Peter heute ins Kino gegangen ist. that Peter today to.the cinema gone is 'that Peter has gone to the cinema today.'

\subsection{The corpus}

As indicated in the introduction, the data of the present study come from a larger corpus of written data compiled in various studies on ILST from L2 German to L3 English. The examples below (adapted from Sánchez 2011; 2015a; 2016) illustrate the occurrence of ILST of two OV structural properties in the corpus, namely, SEP and VFINAL. The occurrence of ILST of SEP separated finite and non-finite verbs in periphrastic constructions, and it affected main clauses with tense (6-7) and modal (8-9) auxiliaries. The examples here and in the remainder of the chapter are presented as learners wrote them, so mispellings and other inaccuracies have been preserved.

(6) The dog has got the eat geeat

(7) The mother is tea preparing

(8) We can in the garden walk

(9) They willen a Picknick eat!

Besides ILST, (6) and (9) exhibit lexical transfer as well, suggesting co-occurrence of transfer at the level of syntax and at the interface between lexis and morphology, leading to the creation of lexical inventions. Specifically, the forms * geeat (6) and *willen (9) are blends of an L3 English lexeme and an L2 German morpheme. The form * geeat is a blend of the English lexeme eat and the German prefix ge- (used for the formation of the past participle), and it represents 
a productive word formation pattern in clauses that exhibited ILST (along with others such as * geluncht, " geeats, * geeating, " geeate, " geeiten or * geeatet, to name just a few; see Sánchez 2015b for a full inventory). In turn, the form *willen is a blend of the English lexeme will and the German suffix -en, used here for the formation of the 3rd person plural in present simple (the same as forms such as runnen, walken or maken).

In some cases, ILST of SEP co-occurred also with INV, as in (10) and (11) below.

(10) Then have Tom the water genommen ${ }^{2}$

(11) and then hat a dog in then basket $g^{3}$

On other occasions, SEP was also transferred to embedded clauses with periphrastic constructions, as in examples (12-15). Sánchez (2016) explains this as an overgeneralization of SEP to linguistic contexts where VFINAL would have applied in the L2 German. The following examples show the ILST of SEP in embedded clauses of different types, above all nominal, causal, and relative.

(12) because the dog has he's dinner eat

(13) that the dog has the lunch eating

(14) who has the bread and the cake eat

(15) because the dog is the food eating

As regards VFINAL, (16-19) below illustrate the occurrence of ILST of VFINAL in embedded clauses with both simple verb phrases (16-17) and periphrastic constructions (18-19). The latter co-existed with embedded clauses that exhibited an overgeneralization of SEP, as in examples (12-15) above.

(16) When the brothers in the picknick are

(17) when the kids with his mother spoke

(18) because the dog the sandwich eat has

(19) that their dog in the bascket had (ponerse dentro ${ }^{4}$ )

\footnotetext{
${ }^{2}$ genommen is a borrowing from the L2 German (equivalent to L3 English 'taken').

${ }^{3}$ hat is a borrowing from the L2 German (equivalent to L3 English 'has').

${ }^{4}$ L1 Spanish ponerse dentro can be roughly translated into English as 'put (oneself) in or inside'. The learner in (19) resorts to a borrowing or code-switch as a compensatory strategy for the lack of the appropriate lexical item in the target language (L3 English). Interestingly, this borrowing is inserted in a clause whose frame corresponds to the L2 German and shows ILST of VFINAL as it would occur in clauses with periphrastic constructions in this language.
} 


\subsection{L2 proficiency and interlanguage transfer in L3 learning}

The role of the proficiency factor on the occurrence of ILST in this corpus has been examined in various studies, focusing on the role of both L3 proficiency (Sánchez 2014) and of L2 proficiency (Sánchez 2011; Sánchez \& Bardel 2017). As for L2 proficiency, which is the focus of this chapter, these two studies employed different instruments to measure it and operationalized it in different ways. On the one hand, Sánchez \& Bardel (2017) examined the role of overall proficiency, which they defined, following guidelines in the CEFR, as "competence put to use" (Council of Europe 2001: 187). Hence, it was defined as global within the system "as a whole" (p. 42), and it was measured using a standardized general proficiency test, i.e. the German placement test. Both Sánchez (2011) and Sánchez \& Bardel (2017) concluded that this factor constrained the timing and extent of ILST.

\subsubsection{Interlanguage transfer at low L2 proficiency levels}

In this respect, Montrul et al. (2011: 24) claim that L2 proficiency "matters for the timing and extent of transfer in L3 acquisition", and therefore "studies should also control for proficiency levels in the L2". The highest incidence of ILST in previous studies (Sánchez 2011; Sánchez \& Bardel 2017) was concentrated primarily at low and (to a somewhat lesser extent) intermediate L2 proficiency levels, and both identified the achievement of an intermediate proficiency in the source language of influence as a turning point that triggered a linear fall in the extent of ILST in the L3. Additionally, based on the assumption that ILST occurred primarily at lower L2 proficiency levels, Sánchez (2011) concluded that a high proficiency level in the source language of influence may not be a prerequisite for ILST to occur, thereby lending support to theoretical claims in previous studies (De Angelis \& Selinker 2001; De Angelis 2007; Ringbom 2007; Rast 2010; Sánchez 2012). This finding was later confirmed by Sánchez \& Bardel (2017), who found that a low overall proficiency in the source language of influence suffices to exert a powerful impact on the L3.

To explain the relationship between low L2 proficiency and the extent of interlanguage transfer, an argument that has been cited is that shortcomings in L2 proficiency may cause a failure to effectively inhibit unintended language activation of the L2 during L3 processing and production and, consequently, may lead to a higher incidence of transfer (Shanon 1991; Dewaele 2001; De Bot 2004). More specifically, it has been suggested that interlanguage underdevelopment may be the driving force behind transfer, "putting the target language (L3) at a higher risk of being influenced by another non-native language” (Sánchez \& 
Bardel 2017: 241; also Leung 2003; 2005; Sánchez 2011). At the same time, however, it is also possible that interlanguage transfer might be more likely when the L2 proficiency of the learner is high (Odlin 1990; Dewaele 1998; Groseva 2000; Hammarberg 2001b; Ringbom 2001; 2007). Taking Bouvy's (2000) claim that at least some knowledge of the element transferred from the L2 is necessary for transfer to occur, it makes sense to believe that some knowledge and control of linguistic structures at the level of syntax is a developmental prerequisite for the transferability of these structures. From this it would follow that advances in L2SP may have implications for the occurrence of ILST, as developmentallyrelated changes in the mental representation of properties of the L2 and their transferability may affect the extent of ILST and L3 interlanguage development (Sánchez 2011). After all, as Herdina \& Jessner (2002: 40) indicate, a significant change in proficiency in a language "will affect the development of $\mathrm{LS}_{1}$ [language system 1], $\mathrm{LS}_{2}$ [language system 2], etc."

The relationship between L2SP and ILST depicted here resembles Cummins' (1979) developmental interdependence hypothesis, which postulates that proficiency in the L1 and the L2 are interrelated. According to Cenoz, this hypothesis might be extended to multilingual learning, especially in situations of asymmetric proficiency and development in two or more languages. She further argues that this hypothesis may be used to investigate the relationship between L2 and L3 proficiency (see also Abunuwara 1992; Chumbow 1981; Thomas 1988), because "different degrees of proficiency in the first and second languages would affect the acquisition of the third (or fourth) language" (Cenoz 2000: 46).

The approach taken to the interdependence of the L2 and the L3 and to the constraints of L2 proficiency on the occurrence of ILST in the studies by Sánchez (2011) and Sánchez \& Bardel (2017) cited above is heuristic, as it looks at L2 proficiency holistically. Holistic approaches highlight the unique configuration of multicompetence (Cook 1992) or composite competence (Council of Europe 2001: 60) typical and exclusive of multilingual learners. Another way of looking at L2 proficiency in the corpus investigated here would be to adopt a different perspective by focusing not on general proficiency, but on proficiency in relation to specific aspects of language proficiency (North 1997). This other way of examining L2 proficiency corresponds to analytic approaches (Herdina \& Jessner 2002; Stratilaki 2006), which try to identify the differential roles of each background language. Both heuristic and analytic approaches offer distinct yet complementary approaches, or as Sánchez \& Bardel (2017: 242) propose, they would be different sides of the same coin. Hence, if the findings reported in Sánchez (2011) and Sánchez \& Bardel (2017) - both of which adopt a heuristic approach - are only one side of the coin, it is hoped that the other side of the story might be told in 


\section{Laura Sánchez}

the present, analytic, study. Hence, as Sánchez \& Bardel (2017) conclude, further research is necessary in order to clarify whether the decreases observed in interlanguage transfer in general (and in ILST in particular) are "caused by advances in general development in this language [the L2] or in domain-specific knowledge of the targeted structures in one or both languages" (Sánchez \& Bardel 2017: 244).

To be able to objectively measure the effects of L2 proficiency at a domainspecific level (in syntax, in this case), "learners should be tested on the structure being studied [in the L3] in the background languages" (Falk \& Bardel (2010: 197), and using "more precise measures" to obtain a better understanding of this factor (p. 211). The reasoning behind these considerations is consistent with Jarvis' (2000) claim that, for a rigorous analysis and identification of transfer, the design of the study needs to include analogous data both in the source and target languages. Furthermore, the data need to allow for a comparison that appraises the intra-group congruity of the learners' linguistic performance in the source and the target languages in relation to a given linguistic feature. In L3 acquisition, this comparison involves searching for similarities between the L2 and L3 interlanguage performances of a given group of learners. Thus, this type of comparison is important because it reveals what it is in the L2 that motivates the L3 interlanguage performance (see Jarvis 2000: 255). This is precisely what the present study attempts to do, first by examining how L2 proficiency at a domainspecific level in syntax (namely, L2SP) affects the occurrence of interlanguage transfer in the L3 also at this same level (i.e., ILST). Secondly, the study is based on the comparison of performance in L2 German OV structures with ILST of these properties in the L3 English.

Bearing in mind these considerations, the study presented in this chapter embraces a narrower definition of specific proficiency (L2SP) in the selected linguistic feature in the L2, namely, the OV structural properties of the L2 German. By adopting an analytic approach, a novelty of the study is that the methodology makes it possible to more easily tease apart and isolate differential effects for the source language of influence. This narrow, more focused account and measurement of L2 proficiency is consonant with the "assumed level of acquired knowledge" in Herdina \& Jessner's (2002: 57) definition of proficiency in each language of the multilingual learner. Likewise, this account of proficiency is consonant also with Leung's (2003: 199) definition of proficiency as knowledge in relation to "the steady state of a previously acquired (inter)language" (emphasis added; see also Leung 2005: 40). Besides, as far as ILST is concerned, she further argues that what is transferred at the outset of L3 learning is fundamentally this 
knowledge, i.e. the steady state of previously acquired interlanguages. Along similar lines, De Angelis (2007: 115) points out that what the learner transfers to the L3 and what affects performance in this language is "the linguistic development reached in one language".

\section{The present study and research question}

The study presented here is a contribution to research on the role played by L2 proficiency on the occurrence of ILST in L3 learning, and the data analyzed are part of the corpus compiled by the author and described in detail in the background of the study. Adopting an analytic approach, the study sets out to examine how L2 proficiency at a domain-specific level and in relation to particular linguistic forms (OV structural properties) may affect the likelihood of occurrence of ILST. With this in mind, the research question guiding the study asks whether L2SP, defined here as mastery of the OV structural properties (SEP, VFINAL, INV) in the L2, has any effect on the occurrence of ILST in the L3. The research question has been formulated as follows:

$R Q$ : Does mastery of the OV structural properties in the source language of influence (L2 German) constrain the timing, extent, and type of ILST in the target language (L3 English)?

\section{Participants}

In order to answer the research question guiding the study, data were used from Spanish/Catalan learners (aged 9-13) of L3 English with prior knowledge of L2 German $(n=280)$, which they were learning simultaneously. They were born in Spanish and/or Catalan speaking homes and used these languages to different degrees in their everyday lives, although both languages are official and co-exist at the community level. Moreover, their parents were native speakers of these languages and most of them had little or no knowledge of German. The learners had started learning the L2 German at school at the age of 5, in a programme that combined language learning and content in subjects such as history, geography or arts. Exposure to this language was virtually limited to the school, with the exception of occasional extracurricuar activities organized by the school. Despite this early starting age and the type of exposure to this language, their overall proficiency in this language was generally low (Sánchez \& Bardel 2016), as assessed by the standardized proficiency test employed in previous studies with 


\section{Laura Sánchez}

this corpus and discussed in the background of the study (see Sánchez \& Bardel 2017 for a more detailed account). In contrast to the homogeneous exposure to the L2 in terms of formal input and starting age, the situation for the L3 English was more heterogeneous. The learners started learning English when they were 8 years old (or later), within a communication-oriented teaching programme. It is important to point out that younger learners did not necessarily have less exposure to the L3 English than their older peers. This is because recent changes in the school curriculum had moved up the starting age and the hours of instruction per week. Hence, it was possible for different-aged learners to have received the same amount of instruction, or even that younger learners were somewhat more instructed than their older peers. In any case, participants took only one to two 50-minute English lessons per week, so they had received a maximum of 165 hours of instruction in this language by the time the data were collected. The overview of the partipants, presented in Table 8.2, aims to outline their linguistic profile. Hence in this table (but not in the data analysis) they are grouped according to age and instructional time. However, in order to prevent any undesired variability in the results caused by these differences, the learners' overall proficiency in the L3 and their biological age were controlled for (see §8).

Table 8.2: Overview of the participants

\begin{tabular}{rccc}
\hline \hline Mean age & $n$ & L3 instructional time (hrs) & Age of onset \\
\hline 9.9 & 70 & $33-66$ & $8-9$ \\
10.9 & 50 & $33-66$ & 9 \\
11.9 & 50 & $99-165$ & 9 \\
12.9 & 56 & $132-165$ & $9-11$ \\
13.9 & 54 & $132-165$ & $9-11$ \\
\hline \hline
\end{tabular}

\section{Instruments and data collection procedures}

The battery of tests employed in the data collection consisted in a background language questionnare to select the participants, a picture story-telling task to elicit written production in the L3 English and L2 German, and a cloze test to measure their overall proficiency in the L3 English. It is important to clarify that even though proficiency in this language was not the factor investigated here, it was included in the study design because L3 proficiency was used as a control 
variable in the statistical tests run on the data, as explained below. All the tests were administered in class time and in the presence of the researcher. The data from each participant were collected in two sessions. In the first session, the learners filled in the questionnaire, carried out the narrative task in either English or German, and completed the cloze test. In the second session, they performed the narrative task in the other non-native language.

A questionnaire was administered to intact classes to select the participants. The main criteria for inclusion in the study were (i) for the learners to be native speakers of Spanish and/or Catalan, (ii) that German preceded English in the chronological order of acquisition, and (iii) that they would not speak any other language. This questionnaire was originally inspired by an already existing bilingual questionnaire (i.e., Baker \& Prys Jones 1998) used in the BAF Project by the GRAL research group ${ }^{5}$, but it had been piloted and validated by the author (Sánchez 2011) to satisfy the needs specific to the multilingual acquisition setting analysed here, where the participants were trilingual (for further details on this questionnaire, see Sánchez 2015b).

The story-telling task used for the elicitation of written data in the L3 (and in the L2 for comparison purposes and to measure L2SP) was The dog story (Heaton 1966). It is based on visual stimuli in a picture series that comprises six strips, and it has proved suitable for the investigation of transfer (Sánchez \& Jarvis 2008). As discussed earlier, having analogous data not only from the L3 but also from the L2 was necessary for appraising the congruity of the learners' interlanguage performance (Jarvis 2000: 55) in the source and target languages in relation to the structural properties investigated here. By so doing, it would be possible to identify what it was in the L2 that motivated the L3 ILST behaviour. For this same reason, data could be analyzed only from participants who would produce the targeted linguistic feature both in the L3 and the L2. This could not be guaranteed beforehand because the uncontrolled nature of the story-telling task did not force learners to use the targeted feature or any other feature in particular. The administration of the writing task was counterbalanced in the two languages, to avoid any order effect on performance. The task was time-controlled (ca. 15 minutes), and participants were not allowed to ask questions related to the vocabulary of the story, nor were they permitted to use a dictionary or any other reference tool.

With the purpose of having a proficiency measure in the L3 English, the participants carried out a 30-item cloze test based on the Little red riding hood. The

\footnotetext{
${ }^{5}$ The BAF Project (Barcelona age factor) was conducted within the GRAL research group (Grup de recerca d'adquisició de llengües), of which the author is a collaborator.
} 


\section{Laura Sánchez}

decision to use this test was grounded on strong beliefs that it is an indicator of overall proficiency in a foreign language (e.g. Hanzeli 1977; Katona \& Dörnyei 1993). In addition, the cloze test had been validated before using it here (Muñoz 2006) by means of a reliability test conducted on data from the BAF Project in the GRAL research group. This reliability test had shown high and significant correlations of the results from the cloze test with other proficiency measures from the battery of tests employed in that project assessing auditory, phonological, grammatical, and lexical development, along with receptive and productive abilities. By using the cloze test to measure the overall L3 proficiency of the participants in this study, it was possible to compare learners of the same and different ages and instructional times.

\section{Data analysis}

The design of the study included a dependent variable that registered the raw frequency of occurrence of ILST in the learners' L3 production, an independent variable of L2SP consisting of three measures, and two covariates. The inclusion of the covariates in the design was justified by the need to tease apart the effects of L2SP from other confounding factors it may interact with. Here these factors were the overall L3 proficiency and the age of the participants. Thus, the statistical test chosen in order to find out whether L2SP had an effect on the occurrence of ILST was the analysis of covariance (ANCOVA).

The qualitative analysis of ILST in the present study was based on data elicited by means of the story-telling task (i.e., the L3 English version), and it targeted two OV structural properties, namely, SEP and VFINAL. The reason to select these properties (but not INV) was that these two show the largest, more salient and unambiguous contrast in surface word order between the L2 German and the L3 English (Gawlitzek-Maiwald \& Tracy 2005: 293), and also between the L2 German and the two L1s. More importantly, previous studies with this corpus revealed the virtual absence of inverted orders in the L3 English data (Sánchez $2010 ; 2011 ; 2012$ ), with a few exceptions such as those shown in (10) and (11) above. Hence, it would not have been possible to examine ILST of INV in this study.

The measurement of L3 overall proficiency was based on data from the cloze test. The cloze tests were scored by the researcher, and the raw scores ${ }^{6}$ recorded in a quantitative variable. The raw scores were saved as $z$-scores, and the variable recording these $z$-scores was later entered as a covariate in the ANCOVA.

${ }^{6}$ The mean score for correct answers was 8 , and the maximum number of correct answers was 24 (out of the 30 items the cloze test consisted of). 
In turn, the measurement of L2SP was based on data elicited by means of the story-telling task (i.e., the L2 German version). The measurement of the L2SP of the participants relied on the assessment of the accuracy of their performance in the cluster of OV structural properties observed in the L2 German. Measuring L2 proficiency precisely on the basis of performance in relation to these structures made it possible to have a more sound definition of L2 proficiency in relation to domain-specific knowledge. On the other hand, by gathering data in the source language of influence and in the target language, it was possible to test the participants on the structure being studied both in the L3 and the L2.

Since L2SP was going to be used as the fixed factor in the ANCOVA test, L2SP was operationalized as a categorical variable (which was necessary because it was included in the ANCOVA as a fixed effect). To this aim, L2SP was measured using dichotomous variables that coded the learners' accurate or inaccurate use of SEP, VFINAL, and INV in three separate variables. Because the uncontrolled nature of the story-telling task did not force learners to use the targeted linguistic feature, some learners did not use any of these structural properties, some used only some of them, and others all three. On the other hand, because the writing task was time-limited and the participants' overall proficiency in this language was low, as pointed out earlier, the length of their texts was relatively short (the mean and maximum lengths of the texts, for example, were 91 and 251 words, respectively). Likewise, their interlanguage was still under development and exhibited the unsystematic co-occurrence of grammatical and ungrammatical syntactic constructions. In any case, what was important for the purposes of the present study was to detect inaccurate uses of these structures in the L2, to be able to compare them with the transferred structures in the L3.

In each of the three dichotomous variables, if all the instances of the structural property in question were correct, the learner was given a 1 . On the contrary, if one or more of these instances were incorrect, the learner was given a 0 . Also for each variable separately, learners who did not use any of the properties were coded with a 2 and removed from subsequent analyses. These three variables were later used in order to divide the sample into two levels of L2SP in each of them, that is, low and high (for those coded 0 and 1 , respectively). The breakdown of participants into two proficiency levels for each OV structural property is presented in Table 8.3.

This table shows the number of participants per level and structural property, and also the percentage they represented in each case. As can be seen, there was a ceiling effect in SEP, because nearly all participants were assigned to the high proficiency group (98.1\%). The assignment of participants to different proficiency levels in VFINAL was also unbalanced (77\% in the high proficiency group), 


\section{Laura Sánchez}

though not as much as in SEP. A more balanced distribution of participants was found in INV (with $49.2 \%$ and $50.8 \%$ in the low and high proficiency groups, respectively). The data from the 280 participants in the study were examined. Even though the vast majority of them used SEP, VFINAL and/or INV in their L2 German story-telling task, 42 participants had to be removed from the working sample because they did not produce analogous structures in the the L3 English and L2 German, which was a necessary condition for the analysis of L2SP and ILST. Therefore, the final number of participants in the study was 238 .

Table 8.3: Participants' classification according to L2SP in each OV structural property

\begin{tabular}{lrrrrr}
\hline \hline & \multicolumn{2}{c}{ Low } & \multicolumn{2}{c}{ High } & \\
\cline { 2 - 5 } Structural property & $n$ & $\%$ & $n$ & $\%$ & Total \\
\hline SEP & 4 & 1.9 & 208 & 98.1 & 212 \\
VFINAL & 50 & 23 & 167 & 77 & 217 \\
INV & 117 & 49.2 & 121 & 50.8 & 238 \\
\hline \hline
\end{tabular}

\section{Results}

The report of the results is presented in what follows. It starts with an overview of the data to illustrate the different types of ILST encountered in the data and how they patterned across different levels of L2SP in each structural property. This is followed by an explanation of the results obtained in the series of ANCOVAs that were run on the data with the purpose of ascertaining whether L2SP had an effect on ILST.

The types of ILST encountered in the data included SEP in main clauses (as in 6-9 in §2), VFINAL in embedded clauses with simple verb phrases (16-17) and periphrastic constructions (18-19), and also overgeneralization of SEP in embedded clauses with a periphrastic construction (12-15). This last type of ILST is of interest here because it reflects that what learners were able to transfer was often an L2 rule still under development. For the present purposes, what is relevant is the comparison of analogous data by the same participant not only in the target language (the L3 English), but also in the source language of influence (the L2 German). The examples below, (20-23), illustrate this type of ILST in the L3 (i.e. overgeneralization of SEP in embedded clauses) along with the participants' use 
of the corresponding structure in the L2. As can be seen in these examples, some of the participants did not have full mastery of VFINAL in embedded clauses in the L2. Consequently, instead of applying the VFINAL rule to embedded clauses, they overgeneralized SEP in the L2, and this is also what they transferred to the L3. Each pair of examples illustrates data from one and the same participant, with the purpose of showing congruence in the production in the L2 and the L3.

(20) a. L3 English: because they will your pastel ${ }^{7}$ eat

b. L2 German:

... und sehen das seinen Hund hat alles gegesen

... and see that their dog has all eaten

'... and see that their dog has eaten all'

(21) a. L3 English: beacos the dog has the food eat

b. L2 German:

das der Hund hat das essen gegessen

that the dog has the food eaten

'that the dog has the food eaten'

(22) a. L3 English: weil ${ }^{8}$ the dog has the food eat

b. L2 German:

weil der Hund hatte alles gegessen

because the dog had all eaten

'because the dog had eaten all'

(23) a. L3 English: because the dog had the sandwiches eated

b. L2 German:

weil der Hund hat die Sandwiches gegessen

because the dog has the sandwiches eaten

'because the dog has eaten the sandwiches'

Similarly, the incomplete mastery of INV in the L2, the source language of influence, was related to a higher incidence of ILST in the L3. Specifically, learners who exhibited uninverted orders in the L2 (nearly half the sample $49.2 \%$, as can be seen in Table 8.3) also showed evidence of ILST in the L3 involving SEP in main clauses (ex. 24-25), VFINAL in embedded clauses with simple verb phrases (26-27) and overgeneralization of SEP in embedded clauses (28-29).

\footnotetext{
${ }^{7}$ pastel is the L1 Spanish term for L3 English 'cake'.

${ }^{8}$ weil is the L2 German term for English 'because'.
} 
(24) a. L3 English: Then dog has got the eat geeat

b. L2 German:

Am letztes Bild die zwei Kindern sehen das...

in.the last picture the two children see that

'In the last picture the two children see that...'

(25) a. L3 English: Theyr motheris they a map giving

b. L2 German:

Eines Tages zwei Kinder wollten ein picknick machen

one day two children wanted a picnic to make

'One day two children wanted to make a picnic'

(26) a. L3 English:when they with the mum talk

b. L2 German:

dannach Geschister nahmen den Korb

later the siblings took the basket

'later the siblings took the basket'

(27) a. L3 English: when the dog the sandwiches eat

b. L2 German:

wenn sie mit seiner Mutter waren, der Hund sprang...

when they with their mother were, the dog jumped...

'when they were with their mother, the dog jumped...'

(28) a. L3 English: that the dog has all the lunch eating

b. L2 German:

... dann die Mutter gibt ihnen ein bisschen essen

...then the mother gives them a little bit of food

'...then the mother gives them a little bit of food'

(29) a. L3 English: because the dog have the food eat

b. L2 German:

Am Schluss die Kinder haben nichts zu essen

in.the end the children have nothing to eat

'In the end che children have nothing to eat'

Table 8.4 shows the different types of ILST encountered in the data, alongside their raw frequency and percentage of occurrence in the data. As the data in the table below show, ILST in main and embedded clauses occurred to nearly the same extent. However, in embedded clauses ILST patterned differently depending on whether it involved VFINAL in a simple verb phrase $(28.1 \%)$ or an 
overgeneralization of SEP in periphrastic constructions (22.1\%). In contrast, the occurrence of VFINAL in periphrastic constructions was only marginal $(0.7 \%)$, because the participants overgeneralized SEP instead.

Table 8.4: Types of ILST in the L3. Raw frequency and percentage

\begin{tabular}{lcr}
\hline \hline & \multicolumn{2}{c}{ Occurrences of ILST } \\
\cline { 2 - 3 } Structural property & Freq. & $\%$ \\
\hline SEP (main clauses) & 138 & 49.1 \\
VFINAL with simple VPs (embedded clauses) & 79 & 28.1 \\
VFINAL with periphrastic constructions (embedded clauses) & 2 & 0.7 \\
Overgeneralisation of SEP (embedded clauses) & 62 & 22.1 \\
\hline \hline
\end{tabular}

The rest of the section summarises the results from a quantitative perspective. Table 8.5 presents the descriptive statistics of the occurrence of ILST in the L3 at different levels of L2SP (raw frequency of occurrence, mean and standard deviation) in each structural property in the L2. A close inspection of the means reveals that ILST consistently occurred more frequently in low than in high levels of L2SP, and this is true regardless of the L2 structural property examined.

Table 8.5: Descriptive statistics of the occurrence of ILST in the L3 across different levels of L2SP in each property

\begin{tabular}{llrrrr}
\hline \hline & & & \multicolumn{3}{c}{ Occurrences of ILST } \\
\cline { 4 - 7 } \multicolumn{2}{l}{ Structural property } & \# of learners at each L2SP level & Freq. & $M$ & SD \\
\hline \multirow{2}{*}{ SEP } & Low & 4 & 7 & 1.75 & 0.5 \\
& High & 208 & 241 & 1.16 & 1.11 \\
\multirow{2}{*}{ VFINAL } & Low & 50 & 81 & 1.62 & 1.19 \\
& High & 167 & 179 & 1.07 & 1.06 \\
\multirow{2}{*}{ INV } & Low & 117 & 166 & 1.42 & 1.13 \\
& High & 121 & 115 & 0.95 & 1.02 \\
\hline \hline
\end{tabular}

For a more comprehensive view of the picture, a more exhaustive analysis of other aspects related to the occurrence of ILST is now offered. To gain further 


\section{Laura Sánchez}

insight into the relationship between L2SP and ILST (or lack thereof) in the L3, another way of looking at the data was to examine the non-occurrence of ILST in empirically-relevant contexts where it could occur and how this non-occurrence related to L2 proficiency levels in each structural property. Let us remind the reader that, as indicated in the background of the study, contexts where the targeted linguistic structures could be observed included simple verb phrases in embedded clauses, and periphrastic constructions in both main and embedded clauses. They constituted the empirically-relevant contexts for the analysis of ILST. Table 8.6 presents the distribution of participants who transferred ("transfer condition") and those who did not ("no transfer condition") in the L3 at different levels of L2SP in each structural property.

The information is to be read vertically and across conditions. The figures on VFINAL indicate that at low levels of L2SP, the vast majority of the participants transferred (82\%), whereas only $18 \%$ did not. A very similar pattern was observed for INV also at a low level of L2SP (80.3\% who transferred vs. $19.7 \%$ who did not). In turn, at high levels of L2SP the percentage of learners who do not transfer is somewhat higher than at low levels, both for VFINAL (35\%, against the $18 \%$ at low levels) and for INV (43\%, against the 19.7\% at low proficiency levels). The same distribution of participants across transfer conditions was found for SEP. However, because of the unbalanced distribution of participants in the low $(n=4)$ and high $(n=208)$ levels of L2SP in this structural property the percentages are not representative, and the means in Table 8.5 may be more informative.

Table 8.6: Distribution of participants across transfer conditions at different levels of L2SP in each property

\begin{tabular}{lrcrrrr}
\hline \hline & \multicolumn{2}{c}{ L2 SEP } & \multicolumn{2}{c}{ L2 VFINAL } & \multicolumn{2}{c}{ L2 INV } \\
Condition & Low & High & Low & High & Low & High \\
\hline Transfer & & & & & & \\
$n$ & 4 & 141 & 41 & 108 & 94 & 69 \\
$\%$ & 100 & 67.8 & 82 & 65 & 80.3 & 57 \\
No transfer & & & & & & \\
$n$ & 0 & 67 & 9 & 59 & 23 & 52 \\
$\%$ & 0 & 32.2 & 18 & 35 & 19.7 & 43 \\
\hline Total & 4 & 208 & 50 & 167 & 117 & 121 \\
\hline \hline
\end{tabular}

The information in Table 8.6 is complemented by Table 8.7 , which is to be read horizontally. Firstly, the "transfer condition" column shows the sum, percentage 
and mean occurrence of ILST per level of L2SP and OV structural property, calculated over the total number of empirically-relevant contexts (third column). Secondly, the "no transfer condition" shows the sum and mean of contexts where ILST did not occur. As the figures show, ILST in the L3 occurred much more frequently at low than at high levels of L2SP, which was true of the three structural properties. On the contrary, at high levels of L2SP the percentage of contexts where ILST could have occurred but did not is higher than at low proficiency levels.

Table 8.7: Distribution of empirically-relevant contexts across transfer conditions at different levels of L2SP

\begin{tabular}{lrrrrrrrrr}
\hline \hline & \multicolumn{3}{c}{ Transfer condition } & & \multicolumn{3}{c}{ No transfer condition } & \\
\cline { 2 - 3 } Structural property & Raw & $\%$ & $M$ & & Raw & $\%$ & $M$ & Total \\
\hline SEP & 7 & 77.8 & 1.75 & 2 & 22.2 & 0.5 & 9 \\
Low & 214 & 46.9 & 1.16 & 273 & 53.1 & 1.32 & 514 \\
High & & & & & & & \\
VFINAL & 81 & 61.4 & 1.62 & 51 & 38.6 & 1.04 & 132 \\
Low & 179 & 42.3 & 1.07 & 244 & 57.7 & 1.46 & 423 \\
High & & & & & & & \\
INV & 166 & 56.7 & 1.42 & 127 & 43.3 & 1.09 & 293 \\
Low & 115 & 38.3 & 0.95 & 185 & 61.7 & 1.53 & 300 \\
High & & & & & & & & \\
\hline \hline
\end{tabular}

Three series of ANCOVAs were run on the data, each using a different measure of L2SP, namely, one for each L2 structural property (SEP, VFINAL, INV). For all analyses, the cloze test scores that measured overall proficiency in the L3 English were used as a covariate, along with the age of the learners, which was added to the model as a second covariate. Not surprisingly, the ANCOVA testing the effect of L2SP in SEP was not statistically significant $(p=0.809)$, in all likelihood because of the ceiling effect in this independent variable. The ANCOVAs run using L2SP in the other two structural properties as independent variables turned out to be statistically significant. Specifically, there was a significant difference in the extent of ILST between different levels of L2SP whilst adjusting for L3 overall proficiency and age. This difference held for $\operatorname{VFINAL}(F(1,213)=4.047$, $p=0.046)$ and $\operatorname{INV}(F(1,238)=9.738, p=0.002)$. 


\section{Discussion and conclusions}

The research question guiding the study asked whether L2SP, operationalized in this study as the mastery of the OV structural properties in the source language of influence (L2 German), constrained the timing, extent, and type of ILST in the target language (L3 English). Based on the results, it may be confirmed that L2SP did constrain ILST in various ways. In addition to this, the analysis of analogous data in the L3 and the L2 (Jarvis 2000; Falk \& Bardel 2010) constituted a methodological advancement and a novel aspect of the study. The following paragraphs discuss the relationship between L2SP at a domain-specific level in the source language of influence and ILST in the target language.

In view of the results reported in the preceding section, the main finding is that a high level of L2SP in the structural property transferred was not a prerequisite for ILST to occur (as will be discussed below). That said, it was also true that, at least in some cases, a given structure was a more likely candidate for ILST if the corresponding level of L2SP was high, as in the case of SEP. As the figures in Table 8.3 show, virtually all participants exhibited a correct application of SEP in the L2 German (98.1\%), which suggests full mastery of the element transferred. The extent of ILST in the L3 was rather high, as suggested by the inspection of the means (mean: 1.16, Table 8.5). In contrast, the relationship between ILST and L2SP was different for VFINAL and INV, with the highest incidence of ILST being concentrated at low levels. In the case of VFINAL, this was true despite the somewhat unbalanced distribution of participants across low (23\%) and high (77\%) proficiency levels. Hence, the mean occurrence of ILST in the low level group was higher than in the high level group (1.62 vs. 1.07).

In the case of INV, the participants were more evenly distributed according to L2SP, with nearly half the sample in the high proficiency group (50.8\%) and the remaining $49.2 \%$ in the low group. Here again, the mean occurrence of ILST in the L3 was higher for participants with a low level of L2SP (1.42 vs. 1.07 in learners with a higher L2SP). This finding lends further support to Falk \& Bardel's (2010: 211) claim that what is known "at a low proficiency stage of L2 is easy to transfer into an L3 of the same character". It also supports claims that a high proficiency level in the L2 is not necessary for this L2 to become a source language of influence (De Angelis 2007; Rast 2010; Sánchez \& Bardel 2017), as anticipated in the opening of this section. To confirm the tendencies and patterns of ILST observed here, the design of future studies should target L3 learners with a lower level of L2SP in SEP and also L3 learners with a higher level in INV (not only in German, but also in other SOV languages). Such research would provide empirically pertinent contributions in order to obtain a deeper understanding of the interaction between L2 an L3 proficiency. 
The inverse relationship between level of L2SP and ILST in the L3 portrayed here was further corroborated when crosstabulating the occurrence or non-occurrence of ILST at different levels of L2SP (Table 8.6) in these two structural properties (i.e., VFINAL and INV). Likewise, it was also found that a higher L2SP in these properties was associated with an increase in the number of contexts where ILST did not occur (Table 8.7). Conversely, at low levels of L2SP in VFINAL, most participants were found to transfer $(82 \%)$, whereas only a $18 \%$ of them did not. In turn, the percentage of participants who transferred was lower at higher levels of L2SP (65\%). This tendency was nearly identical to the one of INV (Table 8.6). Here, at low levels of L2SP $80.3 \%$ of participants transfered, against $19.7 \%$ in the group of more proficient participants. In contrast, at higher levels barely $57 \%$ of the participants transferred, against the $80.3 \%$ of participants who transferred at low levels of L2SP. Of course, a $57 \%$ is still a high percentage but it is definitely smaller than at low levels of L2SP, and as pointed out above, further research should shed more light on this.

In light of the results here, what can be suggested is that low L2SP seemed to favour activation and transfer from the L2, and that participants would have a hard time blocking, that is, inhibiting the unintended activation of a previous interlanguage (Shanon 1991; Dewaele 2001; De Bot 2004; Sánchez 2011; Sánchez $\&$ Bardel 2017). The results also point to the competition of structures from the L2 German interlanguage with structures from the L3 English interlanguage. In fact, the number of participants who transferred and the high extent of ILST at low levels of L2 development lend support to the suggestion that the weakest language (L3 English) was processed (Abunuwara 1992) via another non-native language (L2 German). Certainly, in some clauses in the L3 exhibiting ILST, the thematic verb was a lexical invention where lexemes and morphemes from the two interlanguages had been blended (ex. geeat or willen) in the formation of various verbal forms such as present and past participles (Sánchez 2015b). The co-activation of information at the lexeme and the lemma levels was not systematically explored in the present study, but it would be worth being explored in forthcoming studies that examine the co-occurrence of (interlanguage) transfer at the interface between different linguistic levels.

A critical question of the present study was the concurrent acquisition of both the source language of influence and the target language, as the two were being studied at school at the time the data were collected. Yet, the development in the two was asynchronic, and for reasons explained in the description of the participants, the development of the L3 English lagged behind that of the L2 German. What is important here is that this asynchrony had a great impact on 


\section{Laura Sánchez}

the timing, extent and type of ILST (Montrul et al. 2011). The constraints imposed on ILST by L2SP in VFINAL and INV suggest a relationship between L2 and L3 development consistent with Cummins' (1979) developmental interdependence hypothesis. Thus, this interdependence would speak in favour of the extension of Cummins' hypothesis to L3 learning and multiligualism (Chumbow 1981; Thomas 1988; Abunuwara 1992; Cenoz 2000). Furthermore, such a relationship is bolstered by the strong interlanguage connections (Bartlet 1989; Dechert \& Raupach 1989; Dechert 2006; Hall et al. 2009) between the two interlanguages, both of which were still under development especially in relation to the structural properties investigated here.

Likewise, because the L2 was itself still an interlanguage under development, the process of learning where to place the verb in the L2 (a process that involved the acquisition of the cluster of structural properties) slowed down the pace of L3 learning. Therefore, it would be reasonable to argue that ILST was manifested here also as a proficiency constraint in the form of a delay in restructuring in the L3 (especially considering also the finding that ILST in the L3 occurred, above all, at low levels of L2SP in these two structural properties). Morever, due to concurrent acquisition of the two non-native languages and because the two of them were still underdeveloped, the participants had to cope with incompatible surface orders in their L2 and their L3. Having to cope with these incompatibilities and unlearning the syntactic regularities they had acquired (or were in the process of acquiring) for another non-native language (the L2) exacerbated this delay.

A collateral effect of the asynchronic development of the L2 and the L3, and another L2 proficiency constraint on the occurrence of ILST, was that gains in the development of VFINAL and INV in the L2 seemed to trigger a parallel development in the equivalent structures in the L3 and a decrease in the incidence of ILST. From this it follows that gains in the L2 would enhance the learners' sensitivity to notice the equivalent structures in the L3, in the same way as advances in the German of bilingual children sensitize them to corresponding structures in English (Tracy \& Gawlitzek-Maiwald 2005: 29; also Hammarberg 2001a). In this sense, the L2-L3 analogous data analyzed in this study indicate that once INV was acquired in the L2, the acquisition of verb placement in the L3 sped up as well. Furthermore, once INV was acquired in the L2, the extent of ILST was substantially reduced, as implied by the fact that the lowest incidence of ILST was found in data of participants at a high level of L2SP in INV. This was taken as evidence in favour of interpreting the acquisition of INV in the L2 German as a precursor or forerunner that accelerates the pace of acquisition of verb placement in L3 English. Thus, the evidence assembled apparently shows that development 
in the L3 lagged behind that of L2 German at least for a certain period of time that lasted until INV was acquired in the L2.

From a qualitative point of view, another constraint of the level L2SP on the occurrence of ILST in the data was the type of transfer. In previous studies it has been claimed that the occurrence of ILT is conditioned (Bouvy 2000), in particular, by "the linguistic development reached in one language" (De Angelis 2007: $115)$ or the "steady state" of another interlanguage, as Leung puts it (2003: 199). This has important implications for our understanding of the kind of structures that could be transferred from the L2 to the L3 considered in the present study. On the one hand, nearly half the occurrences of ILST in the L3 involved SEP in main clauses (49.1\%), a structural property that the learners could already apply to main clauses in their L2 without any problem. On the other hand, around half of the other occurrences were in embedded clauses but they did not necessarily involve VFINAL, as would have been the case in the L2 German. Instead, while VFINAL was transferred in L3 embedded clauses with simple verb phrases (representing $28.1 \%$ of the total amount of ILST occurrences), an overgeneralization of SEP $(22.1 \%)$ was found in virtually all embedded clauses with periphrastic constructions (62 out of 64). It is worth noting that the OV property overgeneralised the most by these L3 learners was SEP, of which they had full mastery in their L2 when used in main clauses. Equally, participants who were still at a low level of L2SP in VFINAL and still overgeneralized SEP in L2 embedded clauses with periphrastic constructions could only transfer this L2 developmental pattern to the L3. In other words, what these learners were transferring was a structural property that was still under development in their L2, and therefore at a higher risk of being influenced by another non-native language (Groseva 1998; Sánchez 2011). This lends further support to Sánchez \& Bardel's (2017: 241) claim that interlanguage underdevelopment might be "the driving force behind transfer". In addition to this, the comparison of L2-L3 analogous data revealed a clear intragroup congruity (Jarvis 2000) between the L2 and the L3 interlanguage performances, which made it possible to identify what it was in the L2 that motivated the L3 interlanguage behaviour.

\section{References}

Abraham, Werner. 1992. The base structure of the German clause under discourse functional weight: Contentful categories vs. Derivative functional categories. In Abraham Werner \& Elly Gelderen (eds.), German: Syntactic problemsproblematic syntax, 169-206. Tübingen: Max Niemeyer Verlag. 
Abunuwara, Ehab. 1992. The structure of the trilingual lexicon. European fournal of Cognitive Psychology 4(4). 311-322. DOI: 10.1080/09541449208406190.

Baker, Colin \& Sylvia Prys Jones. 1998. Encyclopedia of bilingualism and bilingual education. Clevedon: Multilingual Matters.

Bartlet, Guillermo. 1989. The interaction of multilingual constraints. In Hans Dechert \& Manfred Raupach (eds.), Interlingual processes, 151-177. Tübingen: Gunter Narr.

Beck, Maria-Louise. 1998. L2 acquisition and obligatory head movement. Englishspeaking learners of German and the local impairment hypothesis. Studies in Second Language Acquisition 20. 311-348.

Bouvy, Christine. 2000. Towards the construction of a theory of crosslinguistic transfer. In Jasone Cenoz \& Ulrike Jessner (eds.), English in Europe: The acquisition of a third language, 143-156. Clevedon: Multilingual matters.

Cenoz, Jasone. 2000. Research on multilingual acquisition. In Jasone Cenoz \& Ulrike Jessner (eds.), English in Europe: The acquisition of a third language, 3953. Clevedon: Multilingual Matters.

Chumbow, Beban Sammy. 1981. The mother tongue hypothesis in a multilingual setting. In Jean-Guy Savard \& Lorne Laforgue (eds.), Proceedings of the $5^{\text {th }}$ AILA congress, 42-55. Québec: Lawal University Press.

Cook, Vivian. 1992. Multicompetence and the learning of many languages. Language Culture and Curriculum 8. 93-98.

Council of Europe. 2001. Common European framework of reference for language: Learning, teaching, assessment.

Cummins, James. 1979. Linguistic interdependence and the educational development of bilingual children. Review of Educational Research 49. 222-251.

De Angelis, Gessica. 2007. Third or additional language acquisition. Clevedon: Multilingual Matters.

De Angelis, Gessica \& Larry Selinker. 2001. Interlanguage transfer and competing linguistic systems in the multilingual mind. In Jasone Cenoz, Britta Hufeisen \& Ulrike Jessner (eds.), Crosslinguistic influence in third language acquisition, 42-58. Clevedon: Multilingual Matters.

De Bot, Kees. 2004. The multilingual lexicon: Modelling selection and control. International fournal of Multilingualism 1. 17-32.

Dechert, Hans. 2006. On the ambiguity of the notion 'transfer'. In Janusz Arabski (ed.), Cross-linguistic influences in the second language lexicon, 3-11. Clevedon: Multilingual Matters.

Dechert, Hans \& Manfred Raupach. 1989. Interlingual processes. Tübingen: Gunter Narr. 
Dewaele, Jean-Marc. 1998. Lexical inventions: French interlanguage as L2 versus L3. Applied Linguistics 19(4). 471-490. DOI: 10.1093/applin/19.4.471.

Dewaele, Jean-Marc. 2001. Activation or inhibition? The interaction of L1, L2 and L3 on the language mode continuum. In Jasone Cenoz, Britta Hufeisen \& Ulrika Jessner (eds.), Cross-linguistic influence in third language acquisition: Psycholinguistic perspectives, 69-89. Clevedon: Multilingual Matters.

Falk, Ylva \& Camilla Bardel. 2010. The study of the role of the background languages in third language acquisition: The state of the art. International Review of Applied Linguistics in Language Teaching 48(2-3). 185-219. DOI: 10.1515/iral. 2010.009.

Gawlitzek-Maiwald, Ira \& Rosemarie Tracy. 2005. The multilingual potential in emerging grammars. International fournal of Bilingualism 9. 277-297.

Groseva, Maria. 1998. Dient das L2-System als ein Fremdsprachenlernmodell? In Beate Lindemann \& Britta Hufeisen (eds.), Tertiörsprachen: Theorien, Modelle, Methoden, 21-30. Tübingen: Stauffenburg Verlag.

Groseva, Maria. 2000. Deutsch und Englisch: Das gibt immer Krieg! In Beate Lindemann \& Britta Hufeisen (eds.), Tertiärsprachen: Theorien, Modelle, Methoden, 77-97. Tübingen: Stauffenburg Verlag.

Hall, Christopher, Denise Newbrand, Peter Ecke, Ulrike Sperr, Vanessa Marchand \& Lisa Hayes. 2009. Learners' implicit assumptions about syntactic frames in new L3 words: The role of cognates, typological proximity and L2 status. Language Learning 59. 153-203.

Hammarberg, Björn. 2001a. 'We goen shopping': Mixed utterances in bilingual children as a case of bilingual bootstrapping. In Katja Cantone \& Marc-Oliver Hinzelin (eds.), Proceedings of the colloquium on structure, acquisition, and change of grammars: Phonological and syntactic aspects, 73-78. Special Issue of Working Papers in Multilingualism, 26. Clevedon.

Hammarberg, Björn. 2001b. Roles of L1 and L2 in L3 production and acquisition. In Jasone Cenoz, Britta Hufeisen \& Ulrike Jessner (eds.), Cross-linguistic influence in third language acquisition: Psycholinguistic perspectives, 21-41. Clevedon: Multilingual Matters.

Hanzeli, Victor. 1977. The effectiveness of cloze tests in measuring the competence of students of French in an academic setting. The French Review 50. 865874.

Heaton, John Brian. 1966. Composition through pictures. London: Longman. Herdina, Philip \& Ulrike Jessner. 2002. A dynamic model of multilingualism: Perspectives of change in psycholinguistics. Clevedon: Multilingual Matters.

Jarvis, Scott. 2000. Methodological rigor in the study of transfer: Identifying L1 influence in the interlanguage lexicon. Language Learning 50. 245-309. 


\section{Laura Sánchez}

Katona, Lucy \& Zoltan Dörnyei. 1993. The C-Test: A teacher friendly way to test language proficiency. Forum 31. 34-35.

Leung, Yan-Kit Ingrid. 2003. Failed features versus full transfer full access in the acquisition of a third language: Evidence from tense and agreement. In Juana Liceras (ed.), Proceedings of the 6th generative approaches to second language acquisition conference (GASLA 2002), 199-207. Somerville, MA: Cascadilla Proceedings.

Leung, Yan-Kit Ingrid. 2005. L2 vs L3 initial state: A comparative study on the acquisition of French DPs by Vietnamese monolinguals and Cantonese-English bilinguals. Bilingualism: Language and Cognition 8. 39-61.

Montrul, Silvina, Rejanes Dias \& Hélade Santos. 2011. Structural similarity matters for transfer: Clitics and object expression in the L3 acquisition of Brazilian Portuguese. Second Language Research 27. 21-58.

Muñoz, Carmen (ed.). 2006. Age and the rate of foreign language learning. Clevedon: Multilingual Matters.

North, Brian. 1997. Perspectives on language proficiency and aspects of competence. Language Teaching 30. 93-100.

Odlin, Terence. 1990. Word order transfer, metalinguistic awareness, and constraints on foreign language learning. In Bill van Patten \& James Lee (eds.), Second language acquisition-foreign language learning, 95-117. Clevedon: Multilingual Matters.

Rast, Rebekah. 2010. The use of prior linguistic knowledge in the early stages of 13 acquisition. International fournal of Applied Linguistics 48(2-3). 159-183. DOI: 10.1515/iral.2010.008.

Ringbom, Håkan. 2001. Lexical transfer in L3 production. In Jasone Cenoz, Britta Hufeisen \& Ulrike Jessner (eds.), Cross-linguistic influence in third language acquisition, 59-68. Clevedon: Multilingual Matters.

Ringbom, Håkan. 2007. Cross-linguistic similarity in foreign language learning. Clevedon: Multilingual Matters.

Sánchez, Laura. 2010. Against "canonical word order": Evidence of basic word order transfer at the initial state. Newcastle Working Papers in Linguistics 17. $220-236$.

Sánchez, Laura. 2011. Crosslinguistic influence in third language acquisition: English after German in Spanish Catalan learners in an instructed setting. Barcelona: University of Barcelona. (Doctoral dissertation).

Sánchez, Laura. 2012. 'Luisa and Pedrito's dog will the breakfast eat': Interlanguage transfer and the role of the second language factor. In Gessica De Angelis \& Jean-Marc Dewaele (eds.), New trends in crosslinguistic influence and multilingualism research, 86-104. Clevedon: Multilingual Matters. DOI: 10/d9md. 
Sánchez, Laura. 2014. An inquiry into the role of L3 proficiency on crosslinguistic influence in third language acquisition. Odisea: Revista de Estudios Ingleses 15. 169-188. DOI: 10.25115/odisea.v0i15.282.

Sánchez, Laura. 2015a. Can a background language alter the path of acquisition of verb placement in a multilingual context? Evidence from a longitudinal study. In Gessica De Angelis, Ulrike Jessner \& Marijana Kresić (eds.), Crosslinguistic influence and crosslinguistic interaction in multilingual language learning, 7194. London: Bloomsbury.

Sánchez, Laura. 2015b. L2 activation and blending in third language acquisition: Evidence of crosslinguistic influence from the L2 in a longitudinal study on the acquisition of L3 English. Bilingualism: Language and Cognition 18. 252-269.

Sánchez, Laura. 2016. Transfer in English as an L3: Empirical evidence from school-age learners in Catalonia. In Camilla Bardel, Ylva Falk \& Christina Lindqvist (eds.), Tredjespråkinlärning, 185-206. Lund: Studentlitteratur.

Sánchez, Laura \& Camilla Bardel. 2016. Cognitive factors, perceptions and transfer in third language acquisition. Revue Française de Linguistique Appliqué 21(2016-2). 123-138. DOI: 10.3917/rfla.212.0123.

Sánchez, Laura \& Camilla Bardel. 2017. Transfer from an L2 in third language learning: A study on L2 proficiency. In Tanja Angelovska \& Angela Hahn (eds.), L3 syntactic transfer: Models, new developments and implications, 223250. Amsterdam: John Benjamins.

Sánchez, Laura \& Scott Jarvis. 2008. The use of picture stories in the investigation of crosslinguistic influence. TESOL Quarterly 42(2). 329-333.

Shanon, Benny. 1991. Faulty language selection in polyglots. Language and Cognitive Processes 6. 339-350.

Stratilaki, Sofia. 2006. Representations of plurilingual competence and language use in dynamic trilingual education. Zeitschrift für interkulturellen Fremdsprachenunterricht 11(1). https://tujournals.ulb.tu-darmstadt.de/index.php/zif/ article/view/356.

Thomas, Jacqueline. 1988. The role played by metalinguistic awareness in second and third language learning. Journal of Multilingual and Multicultural Development 9. 235-246.

Tracy, Rosemarie \& Ira Gawlitzek-Maiwald. 2005. The strength of the weak: Asynchronies in the simultaneous acquisition of German and English. Zeitschrift fur Literaturwissenschaft und Linguistik 35. 28-53.

Williams, Sarah \& Björn Hammarberg. 1998. Language switches in L3 production: Implications for a polyglot speaking model. Applied Linguistics 19(3). 259-333. DOI: 10.1093/applin/19.3.295. 



\title{
Chapter 9
}

\section{L1 Dutch vs L2 English and the initial stages of L3 French acquisition}

\author{
Rosalinde Stadt
}

University of Amsterdam

Aafke Hulk

University of Amsterdam

\section{Petra Sleeman}

University of Amsterdam

In this paper, we attempt to define the role of background languages in third language (L3) acquisition in the classroom by focusing on the influence of first language (L1) Dutch and second language (L2) English verb placement in L3 French amongst Dutch secondary school pupils (aged 11-13) who are in the initial stages of L3 acquisition of French $(N=23)$. To detect possible transfer from Dutch, we count errors based on $\mathrm{V} 2$ surface structures in sentences containing a sentence-initial adverb, and in order to detect transfer from English, we count errors based on the Adv- $\mathrm{V}$ word order in the middle field of the clause. We collected data from a grammaticality judgement task to account for receptive knowledge and a gap-filling task to measure learners' guided production. We found a considerable amount of transfer from the L1 in the initial stages, in both the grammaticality judgement task and the gap-filling task.

\section{Introduction}

Foreign language learning plays an important role in today's Dutch secondary school curriculum. English is mandatory throughout the whole duration of the secondary school programme and two other foreign languages (usually French, 
German or Spanish) besides English are mandatory in the first three years of secondary education. In this paper, we investigate to what extent the background languages - in this case, first language (L1) Dutch and second language (L2) English - play a role in third language (L3) acquisition of French among secondary school pupils. ${ }^{1}$ We especially concentrate on pupils who have just entered secondary school and who are therefore in the initial stages of learning French, but who already started learning English in primary school.

In previous studies conducted in the same secondary school as in this study (Stadt et al. 2016; 2018c), we tested the L2 status factor hypothesis - according to which the L2 takes on a stronger role than the L1 in L3 acquisition (L3A) on four groups of Dutch secondary school pupils (L2 English, L3 French): thirdand fourth-year pupils who had either been enrolled in an L2 English bilingual stream programme or in a mainstream Dutch secondary school curriculum (Stadt et al. 2016; 2018c). We only found partial support for the L2 status factor (Bardel \& Falk 2007; Falk \& Bardel 2011), as explained in more detail in §2.3. In both bilingual groups, where pupils had received more daily L2 exposure than the mainstream groups, and in the fourth-year mainstream group, where pupils had received more L2 exposure than the third-year mainstream group, we found significantly more possible transfer from English than from Dutch (supporting the L2 status factor hypothesis). However, in the third-year mainstream group, where pupils had received less exposure to English, the L1 and L2 were equally important sources of transfer. Hence, the smaller amount of L2 exposure the pupils received on a daily basis and throughout the years affected L2 transfer in L3A (see Hammarberg 2001; 2009; Tremblay 2006).

The effect of L2 English exposure on L3 French learning that we found in our previous research led us to an interest in investigating pupils in the initial stages of L3A to learn more about the extent to which the L1 and the L2 play different roles in pupils who have just entered the bilingual stream education and are not yet exposed to the L2 in the daily school context. Therefore, the general aim of this study is to investigate L1/L2 transfer in L3 French in first-year pupils (aged 11-13). These pupils were in their second week of secondary school at the time of testing and thus in the initial stages of L3 French learning. ${ }^{2}$ The research

\footnotetext{
${ }^{1}$ In this paper we use the notions "L3 acquisition" and "L3 learning" interchangeably, although we acknowledge, with Bardel \& Falk (2012: fn 1, p.61), that the situation that we describe is strictly speaking "learning".

${ }^{2}$ In L3A literature, initial state and initial stages are both used to indicate learners at the onset of L3A. Since the first-year pupils relevant to this paper are in their second week of learning (L3) French (having received some L3 vocabulary input) and based on the distinction made by García Mayo \& Rothman (2012), we use the term "initial stages" to indicate the developmental stage these L3 French learners are in.
} 
question relevant to this paper is: How does L1 Dutch and L2 English word order affect L3 French learning in the initial stages of acquisition? We gathered data from 23 first-year pupils enrolled in the same Dutch secondary school as the third- and fourth-year pupils we studied in Stadt et al. (2016; 2018c). They had not yet started their L2 English bilingual stream education, and as a consequence, they were not yet surrounded by English in their daily school practice as their third- and fourth-year fellow pupils were. However, let us note that the first-year pupils were not at the onset of learning English. Although the quality and quantity of teaching and therefore proficiency differs (Unsworth et al. 2015), most primary schools in the Netherlands offer English as a subject from at least the penultimate year of primary school (ages 10-11) (Rose 2016). ${ }^{3}$ To investigate the linguistic behaviour of the first-year pupils and to be able to compare the results to previous results, we use the same constructions as in our previous studies: To detect possible influence from Dutch on French, we look at errors based on XVS(O) (V2) word order, in sentences containing a sentence-initial adverb: Vandaag eet fan een appel *'Today eats John an apple', 'Aujourd'hui mange fean une pomme, and to detect transfer from English into French, we look at errors based on $\mathrm{Adv}-\mathrm{V}$ word order in sentences containing a manner/frequency adverb or a floating quantifier: 'John often eats an apple' * Fean souvent mange une pomme. We collected data from a grammaticality judgement task (GJT) to account for receptive knowledge and a gap-filling task to measure the learners' guided production.

The paper is structured as follows. In $§ 2$, we (1) discuss some studies in the L3A field of research that also focus on the initial stages of L3A, (2) review some studies on verb placement, and (3) give a short overview of the background for this study, that is, a recap of the third- and fourth-year results published in Stadt et al. (2016; 2018c). We set out our design in $\S 3$, and in $\S 4$ we report the results. In $\S 5$, we discuss our results, and in $§ 6$ we present some concluding remarks.

\section{Theoretical background}

\subsection{L3 learning in the initial stages of acquisition}

García Mayo \& Rothman (2012: 15), following Schwartz \& Sprouse (1996), define the initial state of L3 acquisition as "the set of linguistic hypotheses with which

\footnotetext{
${ }^{3} 66 \%$ of the Dutch primary schools offer English in the last two years of primary school (when pupils are aged 10-12 years) A small number of schools (17\%) offer English before that (from the age of 8-9) or and in 17\% of the cases, even earlier, from the age of 4-7 (Thijs et al. 2011).
} 
the learner begins the acquisition process". L3 acquisition resembles L2 acquisition with respect to linguistic knowledge of (an)other language(s) in advance of L2/L3 input. However, it differs in the sense that the learner has already learned a foreign language, which makes him or her a more "advanced" language learner (Cenoz \& Valencia 1994; Jessner 2006) and the learner has two systems available instead of one to make predictions about the L3. García Mayo \& Rothman (2012: fn. 12) notice that in L3 acquisition models the initial state has also been defined as the "initial stages" of the acquisition process, which they consider a more liberal definition than "initial state", which includes the actual initial state as intended by Schwartz \& Sprouse (1996). Various studies have been conducted on the initial stages of acquisition, finding both transfer from the L1 and the L2. In what follows, we briefly discuss some studies that proposed L1 or L2 transfer in the initial stages and which are therefore relevant to this study.

According to the full access full transfer hypothesis (Schwartz \& Sprouse 1996), the L1 grammar is fully transferred to the L2 initial state grammar. Although the hypothesis was originally formulated for L2 acquisition, it could be extended to L3 learning. The cumulative enhancement model (Flynn et al. 2004) claims that transfer from both the L1 and the L2 can occur at the initial stages of acquisition, as long as it is facilitative. According to the typological primacy model (Rothman 2010; 2011; 2015), perceived typological resemblance with L3 determines transfer from either L1 or L2.

Evidence of L1 transfer has been found in studies such as Hermas (2014a,b), who found preferred transfer from the L1 (Arabic) rather than from the L2 (French) in L3 English in studies on the acquisition of the null subject parameter (Hermas 2014a) and of restrictive relative clauses (Hermas 2014b). Similarly, Falk et al. (2015) found transfer from both the L1 and the L2 depending on the degree of metalinguistic knowledge (MLK) in the L1. They investigated the oral production of adjectives in 40 participants who were in the initial stages of learning L3 French and who had different degrees of explicit MLK of the L1. They found L1 transfer in learners with a high MLK in the L1, whereas learners with a low MLK (incorrectly) transferred language related information from the L2.

In turn, evidence of L2 transfer has been found in, for example, Falk \& Bardel (2011). They tested 44 L3 German intermediate learners with either L1 French-L2 English $(n=22)$ or L1 English-L2 French $(n=22)$ on the acquisition of objectpronoun placement in main clauses ('je le vois', 'I see him', 'Ich sehe ihn' - L1/L2 French $\neq \mathrm{L} 1 / \mathrm{L} 2$ English $=\mathrm{L} 3$ German) and subordinate clauses ('You know that I see him', 'Tu sais que je le vois', 'Du weisst dass ich ihn sehe'- L1/L2 English ₹ L1/L2 French = L3 German) (Falk \& Bardel 2011: 60). Data were gathered with a grammaticality judgement and correction task. The results demonstrated that 
learners were more influenced by the L2 than by the L1. Further evidence of L2 transfer was obtained in various studies by Sánchez $(2012 ; 2015 ; 2016)$ that investigated the occurrence of word order transfer (OV/VO orders) in the L3 English of bilingual Spanish/Catalan learners with prior knowledge of L2 German. The findings showed a systematic transfer from the L2 German in the initial stages by learners of the same age as those investigated in this study.

Other empirical evidence for L1 and L2 transfer in the initial stages is presented in $\S 2.2$, in which we focus specifically on transfer of the XVS(O) and the Adv-V word orders.

\subsection{Studies on verb placement}

In what follows, we discuss a few studies that concentrated particularly on the acquisition of the two word order constructions that are under examination in this study: Adv-V word order (+English, -French) and XVS(O) word order (+Dutch, -French).

\subsubsection{Adv-V word order}

Verb placement has already been the object of investigation in L3A, and various studies have more specifically focused on the Adv-V word order in the middle field of the clause. In English, manner and frequency adverbs and floating quantifiers appear pre-verbally, such as in a clause like Manon sometimes goes to the zoo. In the field of L3A, Westergaard et al. (2016) found empirical evidence for the linguistic primacy model - according to which facilitative or non-facilitative property-by-property transfer from one or both previously acquired languages occurs in L3A when a linguistic property in the L3 input reveals abstract structural similarity with linguistic properties of the previously learned languages by investigating the acquisition of Adv-V word order in English (as an L2 and an L3). They studied Adv-V word order in monolingual Norwegian and monolingual Russian learners learning English as an L2, and in Norwegian-Russian bilinguals learning English as an L3. Russian and English share the Adv-V word order, whereas Norwegian has a V-Adv word order in the same type of sentences. In that study, in which data were gathered by means of a GJT, they found that Russian monolinguals and Norwegian-Russian bilinguals could benefit from the Russian Adv-V word order, resulting in a more target-like use in English (compared to the Norwegian monolinguals).

Falk (2010) found evidence for the L2 status factor hypothesis in intermediate learners. She studied (amongst other things) the influence of English Adv-V word 
order in declarative main clauses in L3 German by means of a grammaticality judgement and a correction task. She investigated 60 learners of German (L3): one group of 30 L1 English/L2 French learners and one group of 30 L1 French/L2 English learners. French and German share a V-Adv word order, whereas English has an Adv-V word order ('Il mange souvent du chocolat', 'Er isst oft Schokolade', *He eats often chocolate, 'He often eats chocolate'). Thus for the L1 English-L2 French-L3 German group, the L2 and L3 shared the same word order, whereas it was the L1 and the L3 that showed similarity in this structure for the L1 FrenchL2 English-L3 German group. The results of this study showed that the L2 was the default transfer source in the acquisition of an L3, regardless of whether the influence was facilitative or not.

Hermas (2010), on the other hand, found empirical evidence for L1 transfer in a study on the initial stages of L3 learning. He investigated the acquisition of Adv-V word order in L3 English by means of an acceptability judgement test and a preference test. He tested 20 native speakers of Arabic in the initial stages of L3 English (L2 French). In Arabic, both the Adv-V and V-Adv word order are used, whereas French (V-Adv) differs from English (Adv-V) in this respect. The results of this study showed that the L3 learners of English, who had Arabic as an L1 and French as an L2, reached a high rate of accuracy in judging the Adv-V word order in L3 English, which Hermas (2010) interpreted as facilitative transfer from the Adv-V Arabic (L1) word order. On the basis of the data, Hermas argued that transfer from L1 can also be non-facilitative.

\subsubsection{XVS(O) word order}

Most Germanic languages are so-called V2 languages (e.g. German, Norwegian, Swedish, Danish, and Dutch). In these languages, the finite verb occupies the second position of the declarative main clause, including after a sentence initial adverb, resulting in Dutch sentences such as the following:

(1) Vandaag gaat John naar Parijs.

today goes John to Paris

'Today John goes to Paris.'

In what follows, we will discuss the results of two studies that demonstrated that a non-V2 language (as an L2) negatively influenced the acquisition of the V2 property in the $(+\mathrm{V} 2) \mathrm{L} 3$. Although various studies in the field of second language acquisition claim that the V2 rule (XVS $(\mathrm{O})$ ) is difficult to learn since subject-verbobject (SVO) is the canonical word order (Klein \& Perdue 1997; Pienemann 2016; 
Wahlstrom McKay 2001; Bohnacker 2006), Bohnacker (2006) found V2 placement in two groups of Swedish (+V2) beginning learners of German (+V2), which she attributed to positive transfer of the V2 rule. In Bohnacker's study, one group was learning German as an L2, and the other as an L3 after English (-V2). The oral production data indicated that at least for the L2 German group the acquisition of the V2 rule was not at all complicated (100\% target-like after four months of study). The other group, however, experienced more difficulties, which was attributed by the researcher to the negative influence of the L2 (English).

Bardel \& Falk (2007) studied verb placement in various groups of L1 and L2 backgrounds in the initial stages of L3 Swedish/L3 Dutch (both + V2 languages). In the first group, the L1 was a + V2 language (Dutch when the L3 was Swedish or Swedish when the L3 was Dutch) and the L2 was a -V2 language (English). In the second group, the L1 was a -V2 language (English, Italian, Hungarian or Albanian) and the L2 a +V2 language (Dutch in the case of L3 Swedish or Swedish in the case of L3 Dutch). The results of this study clearly demonstrated positive transfer of the V2 property in L3 Swedish/L3 Dutch, but only when the L2 was a $+\mathrm{V} 2$ language. The participants in the $\mathrm{L} 1+\mathrm{V} 2$ group showed less transfer of the V2 rule in L3 Swedish or L3 Dutch. Bardel \& Falk (2007: 480) concluded that "in L3 learning, the L2 acts like a filter, making the L1 inaccessible”.

\subsection{Verb placement in Dutch secondary school pupils: The background of this study}

In two previous studies (Stadt et al. 2016; 2018c), we studied verb placement amongst four groups of third- and fourth-year secondary school pupils who were either enrolled in an international middle years programme (MYP, a DutchEnglish bilingual stream programme) or a mainstream Dutch curriculum. The MYP is a bilingual stream programme of the International Baccalaureate (IBO 2019). In this programme, pupils receive over $50 \%$ of their subjects in English, whereas in the Dutch curriculum, pupils receive three hours a week of English as a school subject. Table 9.1 presents a systematic description of the background of the pupils and the distribution across groups.

In these previous studies, we compared the extent to which the third- and fourth-year pupils made errors based on the V2 rule (+ Dutch, -English, -French) versus the Adv-V word order (-Dutch, +English, -French) by means of a GJT. ${ }^{4}$

\footnotetext{
${ }^{4}$ We only looked at negative transfer, i.e. errors, since it is difficult to distinguish positive transfer from L3 knowledge, i.e. the command of a structure in the L3. Neither construction had explicitly been part of the French curriculum.
} 
The results of these studies are summarised in Tables 9.2 and 9.3. The results demonstrated that the third-year bilingual stream pupils made significantly more errors based on the L2 English Adv-V word order than on the L1 Dutch XVS(O) word order in French. In both fourth-year groups, this was also the case. By contrast, the mainstream third-year pupils were influenced to the same degree by Dutch as by English.

The results of the same study also showed that the third-year mainstream pupils made significantly more XVS(O) word order errors (based on the Dutch word order) than the bilingual stream pupils. In the mainstream group, 65 out of 154 errors could be traced to Dutch (37\%) and in the bilingual stream group, 55 out of $224(24.6 \%)$ errors were attributed to Dutch XVS(O) word order $(p=0.033$, according to a non-parametric Mann-Whitney $U$ test). Although the difference between mainstream and bilingual stream education particularly concerns the amount of L2 exposure (and L2 use) in the school context, the role of L1 Dutch differs considerably across groups. We suggested in Stadt et al. $(2016 ; 2018 \mathrm{c})$ that the relatively stronger role of the L1 in the third-year mainstream group could be indirectly due to less L2 exposure in this particular group. In other words, these results show that the mainstream school environment affects the extent to which the L1 is suppressed by the L2 and that the special L2 status does not come into play when the L2 is not sufficiently activated to suppress the L1 (cf. Hammarberg 2001).

However, in the fourth-year mainstream group, where Dutch is also more present in the daily school context, pupils barely made any XVS(O) errors. We interpreted this as evidence that the learners had "unlearned" the V2 rule. ${ }^{5}$ The slight decrease in the role of the L2 might be due to the fact that the pupils had an increased overall L3 proficiency. Nevertheless, the role of the L2 remained statistically stable across both years and types of education, ${ }^{6}$ whereas acceptance of the Dutch word order decreased.

\footnotetext{
${ }^{5}$ For a more detailed overview of the results and the discussion, see Stadt et al. (2016; 2018c).

${ }^{6}$ Although we found a tendency, the fourth-year bilingual stream pupils did not make significantly fewer Adv-V errors than the third-year bilingual stream pupils (year 4: 55/168 $=32.7 \%$ and year 3: $95 / 224=42.4 \% ; p=0.099$ ) and the fourth-year mainstream pupils did not make significantly fewer Adv-V errors than the third-year mainstream pupils (year 4:39/154 $=25.3 \%$ and year 3: $53 / 154=34.4 \% ; p=0.272$ ).
} 
Table 9.1: Description of the background of the pupils

\begin{tabular}{lccr}
\hline \hline Pupils & Number of pupils & Age & Instruction in English $^{a}$ \\
\hline 3rd year bilingual & 16 & $13-15$ & $1,942 \mathrm{~h}$ \\
3rd year mainstream & 11 & $13-15$ & $236 \mathrm{~h}$ \\
4th year bilingual & 12 & $14-16$ & $2,572 \mathrm{~h}$ \\
4th year mainstream & 11 & $14-16$ & $315 \mathrm{~h}$ \\
\hline \hline
\end{tabular}

${ }^{a}$ A school year consists of approximately 35 weeks per school year and a class takes 45 minutes. The bilingual stream pupils have received 1,627 hours of instruction in English at the end of Y3 and 1,863 hours of instruction in English at the end of Y4: 17 classes per week (446 hours) in Y1, 21 classes per week ( 551 hours) in Y2, 24 classes per week ( 630 hours) in Y3 and 9 classes per week (236 hours) in Y4. Additionally, the 3rd year bilingual stream pupils also receive four 45-minute classes of English as a subject in Y1, Y2 and Y3 (315 hours by the end of Y3) and three 45-minute classes of English as a subject in Y4 (394 hours by the end of Y4). The regular stream pupils only receive three hours of English as a subject ( 236 hours by the end of Y3 and 315 hours by the end of Y4).

Table 9.2: Adv-V and V2 errors in third-year bilingual (B) stream and mainstream (M) group

\begin{tabular}{|c|c|c|c|c|c|c|c|c|c|c|c|}
\hline & \multirow[b]{2}{*}{ pupils } & \multirow[b]{2}{*}{ items } & \multicolumn{4}{|c|}{$A d v-V$ errors } & \multicolumn{4}{|c|}{ V2 errors } & \multirow[b]{2}{*}{$p$-value } \\
\hline & & & $\#$ & $\%$ & $M$ & $\mathrm{SD}$ & $\#$ & $\%$ & $M$ & $\mathrm{SD}$ & \\
\hline B & 16 & $224^{a}$ & $95 / 224$ & 42.4 & 5.94 & 2.24 & $55 / 224$ & 24.6 & 3.44 & 1.79 & 0.005 \\
\hline M & 11 & $154^{b}$ & $53 / 154$ & 34.4 & 4.82 & 2.82 & $65 / 154$ & 37 & 5.18 & 2.23 & 0.742 \\
\hline
\end{tabular}

${ }^{a}(14 \times 16)$

${ }^{b}(14 \times 11)$

Table 9.3: Adv-V and V2 errors in fourth-year bilingual (B) stream and mainstream (M) group

\begin{tabular}{|c|c|c|c|c|c|c|c|c|c|c|c|}
\hline & \multirow[b]{2}{*}{ pupils } & \multirow[b]{2}{*}{ items } & \multicolumn{4}{|c|}{$A d v-V$ errors } & \multicolumn{4}{|c|}{ V2 errors } & \multirow[b]{2}{*}{$p$-value } \\
\hline & & & $\#$ & $\%$ & $M$ & $\mathrm{SD}$ & $\#$ & $\%$ & $M$ & $\mathrm{SD}$ & \\
\hline B & 12 & $168^{a}$ & $55 / 168$ & 32.7 & 4.58 & 1.83 & $19 / 163$ & 11.3 & 1.58 & 1.98 & 0.005 \\
\hline M & 11 & $154^{b}$ & $39 / 154$ & 25.3 & 3.55 & 1.92 & $4 / 154$ & 2.6 & 0.36 & 0.5 & 0.005 \\
\hline
\end{tabular}




\section{The present study and research question}

Taking into consideration the results presented above, it is relevant to study to what extent L1 and L2 transfer occur in first-year secondary school pupils who have not yet started their bilingual L1 Dutch/L2 English education and who are at the onset of French learning, i.e. in the very first stages of L3 acquisition. We address the following research question: How does the word order of L1 Dutch and L2 English affect L3 French learning in the initial stages of acquisition?

\subsection{Hypothesis}

We hypothesise that the first-year pupils will show more XVS(O) errors (based on the Dutch word order) than Adv-V errors (based on the English word order) in the initial stages of acquisition. This hypothesis is based on our previous study (Stadt et al. 2016) in which we found that the mainstream third-year pupils - who were receiving less L2 exposure compared to the third-year bilingual stream - made significantly more errors based on L1 Dutch than the third-year bilingual stream pupils and Hermas (2010; 2014a,b), who found that the L1 plays a strong role at the onset of $\mathrm{L} 3$ acquisition. This prediction is also motivated by a hypothesis such as the full access full transfer hypothesis (Schwartz \& Sprouse 1996), see §2.1.

In the next section, we will concentrate on the background of the participants and set out the design.

\subsection{Participants}

We tested 118 first-year pupils, but we had to exclude the vast majority of the pupils because they did not meet all criteria. One criterion was that pupils had to be aware of the Adv-V word order in English. To transfer the Adv-V word order into the L3, it was necessary that the pupils be sufficiently familiar with this particular word order in English. We tested this by means of an English gap-filling task, more details of which are given in section §3.3.2. 43 (out of 118) pupils passed the English gap-filling task. Their overall proficiency was assessed using the standardised online Anglia placement test to make sure that all pupils had at least the Anglia "elementary" level in English. The Anglia test showed that all pupils had at least the required "elementary" level (most of them had even a higher level), so we did not exclude any pupil on the basis of this test. The reason for having at least the "elementary" level may be that most primary school pupils start learning English in the 7th grade (aged 9-11) according to the Dutch curriculum. Furthermore, English is quite ubiquitous in the Netherlands. 
Therefore, youngsters generally receive a great deal of English input via media such as music, films and the Internet (Verspoor et al. 2007; 2010), which may also explain why all pupils had at least the "elementary level" in the Anglia test.

\subsection{Instruments}

\subsubsection{Linguistic tasks}

The data collection for this study consisted of two linguistic tasks: a GJT and a guided production gap-filling task (GFT). The tasks were constructed in a way that should make them easy to perform and vocabulary training took place in the first week before the students participated in the actual linguistic tasks (see $\S 3.4$ for more detailed information on the vocabulary training). Simple sentences with many cognates known in all three languages (such as pizza, chocolate, film, banana, adore, visit) were used. Vocabulary items were repeated in several sentences in order to reduce the learning task. Instead of nouns, proper names familiar in the three languages were used, if possible. Since pupils had been trained on vocabulary during the preparation, they were familiar with all the vocabulary used in the tasks. In this way we tried to make sure that in all cases the pupils were able to understand the sentences and judge their grammaticality. The test sentences were presented in the same order to all pupils. Note that the first-year tests were simplified versions of the third- and fourth-year tests. Nevertheless, the types of sentences were similar.

The GJT consisted of 32 items: seven items testing the Adv-V word order of which four items were ungrammatical and three items were grammatical; seven items tested the V2 rule of which four items were ungrammatical and three items were grammatical and 18 fillers. Two example items are provided in (2) and (3).

(2) Manon aime vraiment les biscuits.

$\mathrm{c} / \mathrm{i}$

Manon loves really the biscuits

'Manon really loves biscuits.'

(3) Aujourd'hui mange Jean une pomme.

c/ i c / i today eats Jean an apple

'Today Jean is eating an apple.'

The GFT contained 24 items: eight testing the Adv-V word order (reflecting the English word order) and eight testing the V2 rule (reflecting the Dutch word order). The test contained 8 fillers. Two example items are provided in (4) and (5). 
(4) Les enfants tous un téléphone utilisent the children all a telephone

use 'The children all use a telephone.'

(5) Aujourd'hui Jean au cinéma. va today Jean to.the cinema goes 'Today Jean is going to the movies.'

\subsubsection{Other instruments}

To test whether the pupils were familiar with the English Adv-V word order, we used an English gap-filling task, see §3.2. This English gap-filling task contained 24 items of which eight controlled for Adv-V order. As mentioned in $\$ 3.2$, we also used a standardised online Anglia placement test, to make sure that all participating pupils had at least the Anglia "elementary" level.

The pupils also filled out a language background questionnaire. The background questionnaire was a standardised questionnaire taken from the University of Amsterdam that we used in adapted form for our study on third- and fourth-year pupils and that we adapted again for this study so that it was suitable for the first-year pupils. Based on this questionnaire, we excluded all simultaneous bilinguals (most of which were English-Dutch and Arabic-Dutch bilinguals) and put aside all pupils who had lived abroad or who had a French language background in their immediate family, to make sure that the learning conditions for L1 Dutch, L2 English and L3 French were the same for all pupils. Of the 43 pupils who showed familiarity with the Adv-V order on the English gap-filling task (see section 3.2), 20 additional pupils were excluded on these grounds. We used the data of the remaining 23 pupils.

In the next section, we first present the procedure, followed by the results of the experiments described above. Although we will mainly focus on the new firstyear results in the following section, we close the section by also comparing the results to the results of the third- and fourth-year pupils (see §2.3) in order to get a clearer idea of the cross-sectional developmental pattern with respect to the influence of the background languages.

\subsection{Procedure}

At the time of data collection, the first-year pupils (aged 11-13) were in the second week of secondary school because in the first school week, the students needed time to prepare for taking the test. Three 45-minute periods were dedicated to 
the study of the basic French vocabulary (verbs, nouns) that the pupils needed to be able to participate in the French test, of which many vocabulary items were cognates. They also studied the necessary vocabulary as a homework assignment. The pupils were also allowed to use their vocabulary list during the test. Since it was their first week at school and their first encounter with French, we aimed at making this first week as playful as possible. For instance, the pupils had to create a colour card on the computer, filling in the French colour terms, and to name animals, although this was not needed for the linguistic tasks. Besides the vocabulary items needed for the linguistic task, they also learned some small clarifying chunks that we used in the tests, such as À Paris, 'In Paris' or C'est un, 'It is a'. However, it was crucial that the pupils did not receive any L3 grammar instruction or L3 input of whole sentences to avoid feeding them any relevant information about French syntax. ${ }^{7}$

The L3 French linguistic tasks were followed by the L2 English proficiency tests. As mentioned in §3.3.2, the English gap-filling task contained 8 sentences that controlled for the knowledge of the English Adv-V order. All pupils with more than three errors were excluded from the test. ${ }^{8}$ As also mentioned in §3.2, the standardised online Anglia placement test ${ }^{9}$ was used to make sure that all pupils had at least the Anglia "elementary level" in English. When pupils do not have an elementary level, the online test indicates a level lower than elementary (preliminary, primary, junior or first step).

All in all, five L3 French first-year classes participated in the study, with which two 45-minute sessions were scheduled within the same week in order to collect the data. The L3 French linguistic tasks (i.e. the grammaticality judgement task and the gap-filling task), the L2 English proficiency tests and the background questionnaire were completed during these two 45-minute sessions hours. Since it was important to start with the French test (so as not to bias the pupils with respect to English influence before taking the French test), the learners filled out the L3 French linguistic tasks first, followed by the L2 English proficiency tests and finally the background questionnaire. To complete the GJT, pupils had to indicate for each sentence, whether they judged the sentence correct (c) or incorrect (i). In the GFT, we asked the pupils to fill in the verb in the correct gap.

\footnotetext{
${ }^{7}$ The first author (who is also a French teacher in this school) designed the classes for the first week.

${ }^{8}$ The accuracy minimum of $5 / 8$ was used to make sure that the pupils would have a minimal knowledge of the Adv-V word order to transfer into the L3.

${ }^{9}$ https://www.anglia.org
} 


\subsection{Data analysis}

In the GJT, possible transfer from the L2 English Adv-V word order was detected by coding answers as incorrect when the pupils marked ungrammatical sentences such as *Manon vraiment aime les biscuits as correct and grammatical sentences such as Manon aime vraiment les biscuits (example 2) as incorrect. Possible transfer from the L1 Dutch XVS(O) word order was investigated by marking answers as incorrect when pupils wrongly marked sentences such as *Aujourd'hui mange Jean une pomme (example 3) as correct or grammatical sentences such as Aujourd'hui Jean mange une pomme as incorrect. In the GFT, if the pupils placed the verb in the first gap in example (4) or in the second gap in example (5) we coded the answer as correct and if the pupils placed the verb in the second gap in example (4) or in the first gap in example (5) we coded the answer as incorrect.

To make a valid statistical comparison, we aimed at minimising the differences between the test pairs in both the GJT and the GFT. Therefore, we kept the variances between the items, such as vocabulary and number of words, as minimal as possible. We tested all data for normality of distribution with a Shapiro-Wilk test. Except for the XSV $(\mathrm{O}) / \mathrm{XVS}(\mathrm{O})$ construction in the GJT, the Shapiro-Wilk test was below 0.05 , and thus almost all data deviated significantly from a normal distribution. For this reason, and because the number of pupils was low, we used the non-parametric two-way paired samples test to make the results more reliable.

\section{Results}

In this section, we give an overview of the data. In Table 9.4, we present the Adv$\mathrm{V}$ word order errors and V2 errors from both the receptive knowledge task (GJT) and the guided production task (GFT). In the GJT, the percentages are calculated out of a total of 161 (seven items per condition x 23 pupils), both for the Adv$\mathrm{V}$ construction and the XVS(O) construction. In $33.5 \%$ of the cases, the pupils accepted ungrammatical Adv-V sentences based on the acceptable English word order, such as * Jean souvent mange une pomme, or rejected grammatical V-Adv sentences, such as fean mange souvent une pomme. For the sentences examining the potential transfer of the Dutch V2 rule, these pupils misjudged $64.6 \%$ of the relevant items, accepting sentences such as *Aujourd'hui mange fean une pomme or rejecting correct sentences such as Aujourd'hui fean mange une pomme. In the production task (GFT), the percentages were calculated out of a total of 184 (eight items per condition $\mathrm{x} 23$ pupils). We found the same tendency as in the 
GJT in both the Adv-V word order construction and the XVS(O) construction: In $72.3 \%$ of the cases concerning the V2 rule, the pupils filled in the wrong gap, creating sentences such as *Aujourd'hui mange fean une pomme (Dutch word order), whereas in only $10.9 \%$ of the items targeting the Adv-V construction did they use the ungrammatical English $\mathrm{Adv}-\mathrm{V}$ word order * Fean souvent mange une pomme (English word order). In both tests, the difference between the number of errors based on the XVS(O) word order and those on the Adv-V word order is statistically significant. In the GJT $(\mathrm{Z}=-3.05, p=0.002, r=0.64)$ and in the GFT $(\mathrm{Z}=-4.06, p<0.001, r=0.85)$. Note that the effect sizes of both the GJT and the GFT are large. ${ }^{10}$

Table 9.4: Adv-V and V2 errors in GJT and GFT in first-year pupils

\begin{tabular}{|c|c|c|c|c|c|c|c|c|c|c|}
\hline & \multirow[b]{2}{*}{ items } & \multicolumn{4}{|c|}{$A d v-V$ errors } & \multicolumn{4}{|c|}{ V2 errors } & \multirow[b]{2}{*}{$p$-value } \\
\hline & & \# & $\%$ & $M$ & SD & \# & $\%$ & $M$ & $\mathrm{SD}$ & \\
\hline GJT & 161 & $54 / 161$ & 33.5 & 2.35 & 1.82 & $104 / 161$ & 64.6 & 4.52 & 1.44 & 0.002 \\
\hline GFT & 184 & $20 / 184$ & $10.9^{a}$ & 0.87 & 1.52 & $133 / 184$ & 72.3 & 5.78 & 1.91 & $<0.001$ \\
\hline
\end{tabular}

${ }^{a}$ In the results of Adv-V errors in the GFT, two pupils fell below two standard deviations of the mean. Without these outliers, the mean falls to 0.48 and the SD falls to 0.75 . There are no consequences for the statistical analysis.

These results are visually presented in a diagram (Figure 9.1). What catches the eye is the considerable amount of transfer of the L1 Dutch V2 word order into L3 French at the initial stages of acquisition. Let us emphasise that although the first-year pupils make significantly more mistakes based on the Dutch word order than on the English word order, they still make a considerable number of Adv-V errors in the GJT. We will come back to these observations in the discussion.

\section{Discussion}

\subsection{Discussion of the results}

In this study, we investigated L1 Dutch and L2 English transfer in secondary school pupils in the initial stages of L3 French acquisition. We aimed at investigating the extent to which L1 and L2 transfer occurs in this specific group of

\footnotetext{
${ }^{10}$ In a previous study (Stadt et al. 2018a), we calculated the correlation between the first-year pupils' proficiency in English (using the standardised Meara vocabulary size test, Paradis 2010) and the number of Adv-V errors. We found no significant correlation $(p=0.663)$.
} 


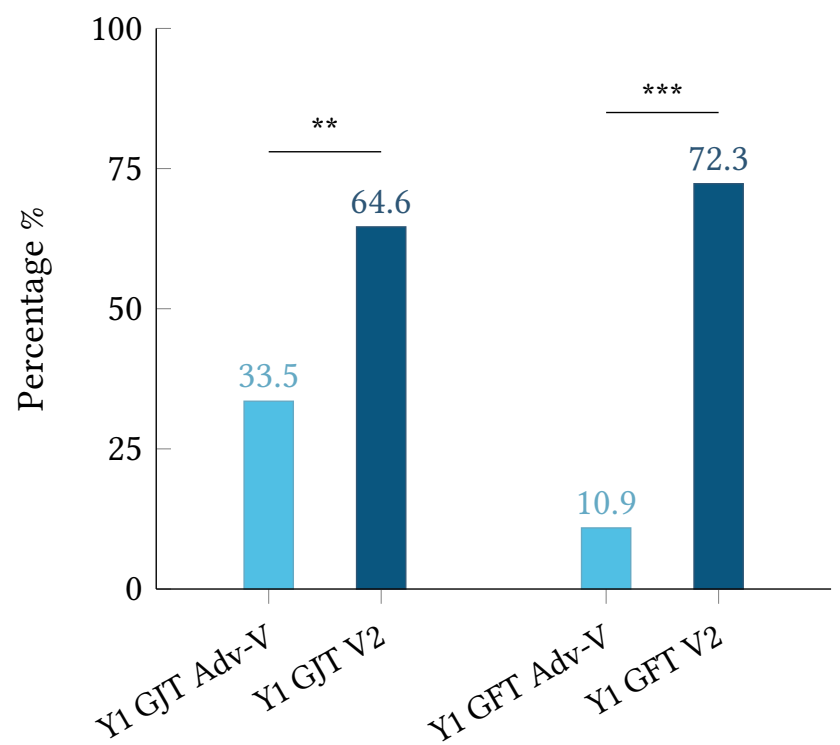

Figure 9.1: : Results of Adv-V errors and V2 errors in GJT and GFT for first-year pupils

learners. To this end, we investigated to what extent the L1 Dutch and L2 English word order affect L3 French learning in the initial stages of acquisition. We hypothesised that in the initial stages of L3 French acquisition, pupils would make more errors based on the Dutch word order than on the English word order. Our hypothesis is based on (1) our previous studies (Stadt et al. 2016; 2018c) in which we found that third-year mainstream pupils - who are less exposed to English in the daily school context than the third-year bilingual stream pupils - use their L1 significantly more often, on (2) Hermas (2010; 2014a,b), who found that the L1 plays a strong role at the onset of L3 learning, and (3) on an adaptation to L3 acquisition of Schwartz \& Sprouse's (1996) full access full transfer hypothesis.

To test transfer at the initial stages of acquisition, we examined to what extent first-year pupils accepted and produced the V2 property (from L1 Dutch) and Adv-V word order (from L2 English) in French. We found support for our hypothesis; that is, in the initial stages of acquisition, pupils do transfer the L1 to a high degree into the L3, which is in line with Hermas (2010; 2014a,b). Both in judgement (GJT) and in guided production (GFT), first-year pupils applied the L1 Dutch V2 rule in French (and possibly Dutch V-Adv word order, as well). The high amount of L1 transfer compared to the relatively low degree of L2 transfer in the initial stages could be due to the fact that the pupils had not yet received 
any L3 morphosyntactic input at the time of testing. Therefore, they were not able to make assumptions about word order in French in comparison with L1 or $\mathrm{L} 2$, so that they resorted to their L1 as a default language.

Regarding the comparison between transfer from the L1 and the L2, we found that the differences between possible negative transfer from L1 Dutch and possible negative transfer from L2 English are significant in both tests (GJT $p=0.002$ and GFT $p<0.001$ ). This finding can be interpreted as evidence against Bardel \& Falk (2007), who found a preferred role for the L2 in the L3A of absolute beginners, although the period of instruction in the L3 was longer in their study than in ours, which may explain the different results. However, we have to stress that in the GJT, pupils also made a considerable number of errors based on the English word order (in $33.5 \%$ of the cases, pupils accepted the English Adv-V word order, which is ungrammatical in L3 French, or rejected the grammatical V-Adv word order). The relatively high acceptance rate in the GJT could be due to the task. The judgement task may have been difficult for the first-year pupils to complete: Although the pupils were familiar with the vocabulary used in the task, a GJT demands reading skills, focus and morphosyntactic knowledge, which might be hard for first-year pupils who are in the initial stages of acquisition and who have only just learned some words in French. In general, the pupils found the GFT a much easier test to perform. ${ }^{11}$ In the GFT, the pupils almost never placed the verb after the adverb in French, hence making hardly any Adv-V errors. It could be that the activation and/or proficiency level of the L2 is so low that pupils in this stage of acquisition consider the L1 as the only possible language to transfer information from.

A factor that may have influenced the results is the pupils' proficiency level in English since they come from different primary school backgrounds. However, in a previous study (Stadt et al. 2018a), we calculated the correlation between the first-year pupils' proficiency in English (using the standardised Meara vocabulary size test; Paradis 2010) and the number of Adv-V errors. We found no significant correlation ( $p=0.663$, see fn. 10). Secondly, one may wonder whether the tasks were not too difficult for the learners. We do not think that this has been the case. We tried to make the linguistic tasks as easy as possible by including proper names and many cognates, by offering vocabulary lists to learn beforehand, and

\footnotetext{
${ }^{11}$ After completing all the tests, we always asked the pupils some questions about the tests. We often received the feedback that the GFT was easier than the GJT. Since the two tasks have the same type of sentences, testing the same constructions, the difference in experience could be due to the type of test: judging could be more difficult than completing a sentence with a given verb.
} 
by offering vocabulary lists during the tasks. A third point that may have influenced the results is that the test sentences were presented only in one order to all pupils, i.e. we did not use different versions of the tasks with different orders in which the sentences were presented. One could also wonder whether the fact that the vocabulary items were translated into Dutch may have influenced the results. However, in Stadt et al. (2016; 2018c) we also provided French-Dutch vocabulary lists, but in these studies, we saw predominantly influence from English. Future research should verify whether these points have influenced the results.

When we compare the results of the present study to the results of Stadt et al. (2016) with respect to the cross-sectional developmental pattern in the roles of L1 Dutch and L2 English in L3 French, we see an enormous decrease of XVS(O) errors from Y1 to Y3. Although the pupils had not received explicit instruction on L3 French verb placement in this case, the decrease in the number of V2 errors in later stages of L3 learning may also be due to increased L3 proficiency. Still, it is quite interesting to see that the increasing L3 proficiency has no effect on the number of L2 Adv-V errors: When we cross-sectionally compare the firstyear GJT data from this study to the third-year GJT data (Stadt et al. 2016), we see that the role of L2 English remains stable despite the fact that L3 proficiency increases (see Falk 2010, who found evidence for a substantial role for the L2 in intermediate learners). ${ }^{12}$

Another explanation for the changing role of the L1 could be that in the initial stages, the L1 plays the most important role and that in later stages of acquisition - once the pupils have received some L3 input and the L2 has begun to play a more prominent role in their everyday (school) lives - the L2 comes into play so that the L1 is to some extent suppressed by the L2 when the L2 is sufficiently activated. Westergaard et al. (2016) found positive transfer from L1/L2 Russian (+Adv-V word order) into L3 English (+Adv-V word order) in later stages of L3 English acquisition when learners received supporting evidence from the L1/L2. In our case, it seems possible that in later stages of L3 French acquisition, the learners received "misleading" evidence from the English Adv-V word order and therefore negatively transferred the Adv-V property into L3 French.

The idea that the learner needs a certain level of development and proficiency in the L2 to transfer syntactic structures from the L2 was found earlier by Bardel \& Falk (2007), Sánchez \& Bardel (2017) and Sánchez (2020 [this volume]). Moreover, the argumentation that the L2 suppresses the L1 when the L2 is sufficiently activated is also found in our previous study (Stadt et al. 2016), in which we

${ }^{12}$ Note that we did find an increase of $\mathrm{Adv}-\mathrm{V}$ errors from year 1 to year 3 in the guided production task (Stadt et al. 2018b). 
found that pupils with the same L3 proficiency showed a different use of the background languages in L3A: The mainstream pupils used the L1 significantly more often than the bilingual stream pupils, most likely because their curricular exposure to the L2 was much lower than in the bilingual stream pupils (in contrast to their more intense curricular exposure to the L1). Furthermore, in the comparison between L1 and L2 transfer, we found that the third-year mainstream pupils used the L1 and the L2 to the same extent, whereas the third-year bilingual stream pupils demonstrated significantly more influence from the L2 than from the L1, which suggests that learners who were not intensely exposed to the L1 at school transferred more from the L2.

For future research, it might also be interesting to look further into the interplay between an increasing L2 input/L2 proficiency and L3 proficiency (Bardel \& Lindqvist 2007; Sánchez \& Bardel 2017). It might also be relevant for a subsequent study to test L2 production in L3A such as writing and speaking skills as to get a more complete picture of the differences between receptive knowledge and production in L3A. Although the tasks that we used in this study are important in linguistic research because they provide evidence about the grammaticality of utterances that do not normally occur in natural language production (Schütze \& Sprouse 2014), it would be interesting to also focus on tasks that concentrate on fluency and meaning such as written or oral narrative tests (Ellis 2005; 2009).

\subsection{Interpretation of the results in light of other studies}

The results of this study show that the pupils transferred from the L1 in the initial stages of L3 acquisition in the constructions that we investigated. In the L3A field of research, some other studies found a strong effect from L1 in the initial stages of acquisition as well (although transfer from the L2 has also be found, as already mentioned in §2.1 and §2.2). Just as in studies conducted by, for example, Na Ranong \& Leung (2009) and Hermas (2010; 2014a,b), our results suggest L1 transfer in the initial stages. Subsequently, the role of the L2 becomes relatively more important. This may be due to the amount of L2 exposure, hence the degree of activation of the L2, and to awareness. Transfer from the L1 occurred regardless of the transfer being facilitative (or neutral) (contra the cumulative enhancement model, Flynn et al. 2004), and without the languages being typologically related, which is contra the typological primacy model (Rothman 2010; 2011; 2015). Moreover, transfer from the L1 occurred although the V2 rule is often recognised as difficult to transfer in the first stages of acquisition (e.g. Pienemann 2016). In a model recently introduced - the hierarchical inference framework (Pajak et al. 2016) -, development plays a central role. According to this 
model, the L3 learner slowly changes his or her implicit beliefs about the target language that are based on prior beliefs about other background languages. This is conventionally referred to as "interlanguage restructuring" and results from hypothesis testing. The hypotheses about language are adjusted as the learner receives more input from the L3. Pajak et al. (2016) would explain the decrease of transfer from the L1 by stating that, because of the L3 input in French in combination with an increasing knowledge of English, the learners' hypotheses about the usability of the background languages are adjusted. In the latest version of the L2 status factor hypothesis (Bardel \& Sánchez 2017), the particular status of the L2 is related to the degree of metalinguistic knowledge, meaning the extent to which the grammar (L2 and L3) is learned explicitly and thus stored in declarative memory. ${ }^{13}$ This may be related to our findings on the changing roles of L1 and L2: in later stages of L3A, when pupils have received language instruction (and gained more knowledge about languages) they may use their background languages differently. Future research might further explore the effect of metalinguistic knowledge on L1/L2 transfer in L3A in secondary school pupils (see Falk et al. 2015).

\section{Conclusion and future directions}

In this study, we examined to what extent first-year secondary school pupils transfer L1 Dutch and L2 English into L3 French in the case of two verb placement constructions: the V2 rule (L1 Dutch) and Adv-V word order (L2 English). Our aim was to further define under which circumstances L1/L2 transfer occurs in the initial stages of L3 learning. The results of this study demonstrate L1 transfer at the first encounter with the L3, arguably because the pupils think, before having received any L3 morphosyntactic input, that Dutch and French share the same word order. Hermas' (2010) hypothesis on L1 (Arabic) transfer in the initial stages of L3 (English) acquisition would therefore also hold for this particular group of secondary school pupils. A preferred role for the L2 over the L1, which we found in later stages of L3 development when pupils are exposed to L2 English to a greater extent (Stadt et al. 2016; 2018c) is not found in this group of learners at the onset of L3 French learning. We argued that this is due to the important L1 transfer in the initial stages but also to the fact that the L2 needs to be sufficiently activated for the L2 to "suppress" the L1.

\footnotetext{
${ }^{13}$ The L2 status factor hypothesis follows Paradis' (2004) distinction between procedural (implicit) and declarative (explicit) memory. In foreign language acquisition, information is assumed to be mainly stored in declarative memory. For a detailed discussion, see Bardel \& Sánchez (2017).
} 
In this study, we found task variation between the GJT and the GFT regarding the $\mathrm{Adv}-\mathrm{V}$ construction. It would be relevant for further work in the field to verify whether a GJT is a suitable task for (young) learners in the initial stages of L3 learning. A suggestion for future research could also be to examine other cases of syntactic transfer from L1 Dutch into L3 French to investigate whether the great amount of L1 transfer that we found in this study is typical for transfer of the V2 property or whether L1 transfer in the initial stages applies to other syntactic constructions as well. In future research, it would be interesting to also look at production data to learn more about L1 versus L2 transfer in the initial stages of acquisition in secondary school pupils (see Falk et al. 2015). Furthermore, it would be interesting to investigate the influence of L1 Dutch and L2 English in L3 French learning in other stages of L3 learning with a longitudinal study to learn more about the developmental patterns of L1/L2 influence in L3 French secondary school pupils.

\section{Acknowledgments}

We are very grateful to the reviewers for their valuable comments on an earlier version of this paper. Many thanks also go to the editors for their help in bringing the paper to its present form.

\section{References}

Bardel, Camilla \& Ylva Falk. 2007. The role of the second language in third language acquisition: The case of Germanic syntax. Second Language Research 23(4). 459-484. DOI: 10.1177/0267658307080557.

Bardel, Camilla \& Ylva Falk. 2012. The L2 status factor and the declarative/procedural distinction. In Jennifer Cabrelli Amaro, Suzanne Flynn \& Jason Rothman (eds.), Third language acquisition in adulthood, 61-78. Amsterdam: John Benjamins.

Bardel, Camilla \& Christina Lindqvist. 2007. The role of proficiency and psychotypology in lexical cross-linguistic influence: A study of a multilingual learner of Italian L3. In Marina Chini, Paola Desideri, Maria Elena Favilla \& Gabriele Pallotti (eds.), Atti del VI congresso internazionale dell'Associazione Italiana di Linguistica Applicata, 123-145. Perugia: Guerra Edizioni. 
Bardel, Camilla \& Laura Sánchez. 2017. The L2 status factor hypothesis revisited: The role of metalinguistic knowledge, working memory, attention and noticing in third language learning. In Tanja Angelovska \& Angela Hahn (eds.), L3 syntactic transfer: Models, new developments and implications, 85-101. Amsterdam: John Benjamins.

Bohnacker, Ute. 2006. When Swedes begin to learn German: From V2 to V2. Second Language Research 22(4). 443-486.

Cenoz, Jasone \& José F. Valencia. 1994. Additive trilingualism: Evidence from the Basque Country. Applied Psycholinguistics 15(2). 195-207. DOI: 10.1017 / S0142716400005324.

Ellis, Rod. 2005. Measuring implicit and explicit knowledge of a second language: A psychometric study. Studies in Second Language Acquisition 27(2). 141-172.

Ellis, Rod. 2009. Implicit and explicit learning, knowledge and instruction. In Rod Ellis, Shawn Loewen, Catherine Elder, Rosemary Erlam, Jenefer Philp \& Hayo Reinders (eds.), Implicit and explicit knowledge in second language learning, testing and teaching, 3-25. Clevedon: Multilingual Matters.

Falk, Ylva. 2010. Gingerly studied transfer phenomena in L3 Germanic syntax: The role of the second language in third language acquisition. Utrecht: LOT.

Falk, Ylva \& Camilla Bardel. 2011. Object pronouns in German L3 syntax: Evidence for the L2 status factor. Second Language Research 27(1). 59-82. DOI: 10.1177/0267658310386647.

Falk, Ylva, Christina Lindqvist \& Camilla Bardel. 2015. The role of L1 explicit metalinguistic knowledge in L3 oral production at the initial state. Bilingualism: Language and Cognition 18(2). 227-235. DOI: 10.1017/S1366728913000552.

Flynn, Suzanne, Claire Foley \& Inna Vinnitskaya. 2004. The cumulativeenhancement model for language acquisition: Comparing adults' and children's patterns of development in first, second and third language acquisition of relative clauses. International fournal of Multilingualism 1(1). 3-15. DOI: 10.1080/14790710408668175.

García Mayo, María del Pilar \& Jason Rothman. 2012. L3 morphosyntax in the generative tradition: The initial stages and beyond. In Jennifer Cabrelli Amaro, Suzanne Flynn \& Jason Rothman (eds.), Third language acquisition in adulthood, 9-32. Amsterdam: John Benjamins.

Hammarberg, Björn. 2001. Roles of L1 and L2 in L3 production and acquisition. In Jasone Cenoz, Britta Hufeisen \& Ulrike Jessner (eds.), Cross-linguistic influence in third language acquisition: Psycholinguistic perspectives, 21-41. Clevedon: Multilingual Matters.

Hammarberg, Björn. 2009. Processes in third language acquisition. Edinburgh: Edinburgh University Press. 
Hermas, Abdelkader. 2010. Language acquisition as computational resetting: Verb movement in L3 initial state. International fournal of Multilingualism 7(4). 343-362. DOI: 10.1080/14790718.2010.487941.

Hermas, Abdelkader. 2014a. Multilingual transfer: L1 morphosyntax in L3 English. International fournal of Language Studies 8(2). 1-24.

Hermas, Abdelkader. 2014b. Restrictive relatives in L3 English: L1 transfer and ultimate attainment convergence. Australian fournal of Linguistics 34(3). 361387.

IBO. 2019. http://www.ibo.org/programmes/middle-years-programme (9 June, 2019).

Jessner, Ulrike. 2006. Linguistic awareness in multilingualism: English as a third language. Edinburgh: Edinburgh University Press.

Klein, Wolfgang \& Clive Perdue. 1997. The basic variety (or: Couldn't natural languages be much simpler?). Second Language Research 13. 301-347.

Na Ranong, Sirita \& Yan-Kit Ingrid Leung. 2009. Null objects in L1 Thai-L2 English-L3 Chinese: An empiricist take on a theoretical problem. In Yan-Kit Ingrid Leung (ed.), Third language acquisition and universal grammar, 162-191. Clevedon: Multilingual Matters.

Pajak, Bozena, Alex B. Fine, Dave F. Kleinschmidt \& T. Florian Jaeger. 2016. Learning additional languages as hierarchical probabilistic inference: Insights from first language processing. Language Learning 66(4). 900-944.

Paradis, Michel. 2004. A neurolinguistic theory of bilingualism. Amsterdam: John Benjamins.

Paradis, Michel. 2010. EFL vocabulary level tests. 2nd edn. Swansea: University of Wales.

Pienemann, Manfred. 2016. Language processing and second language development: Processability theory. Amsterdam: John Benjamins.

Rose, Patricia. 2016. Engels in het basisonderwijs: Domeinbeschrijving ten behoeve van peilingsonderzoek. Enschede: SLO.

Rothman, Jason. 2010. On the typological economy of syntactic transfer: Word order and relative clause attachment preference in L3 Brazilian Portuguese. International Review of Applied Linguistics in Language Teaching 48(2-3). 245273.

Rothman, Jason. 2011. L3 syntactic transfer selectivity and typological determinacy: The typological primacy model. Second Language Research 27(1). 107-127. DOI: $10.1177 / 0267658310386439$.

Rothman, Jason. 2015. Linguistic and cognitive motivations for the typological primacy model of third language (L3) transfer: Timing of acquisition and pro- 
ficiency considered. Bilingualism: Language and Cognition 18(2). 179-190. DOI: 10.1017/S136672891300059X.

Sánchez, Laura. 2012. 'Luisa and Pedrito's dog will the breakfast eat': Interlanguage transfer and the role of the second language factor. In Gessica De Angelis \& Jean-Marc Dewaele (eds.), New trends in crosslinguistic influence and multilingualism research, 86-104. Clevedon: Multilingual Matters. DOI: 10/d9md.

Sánchez, Laura. 2015. L2 activation and blending in third language acquisition: Evidence of crosslinguistic influence from the L2 in a longitudinal study on the acquisition of L3 English. Bilingualism: Language and Cognition 18(2). 252269.

Sánchez, Laura. 2016. Transfer in English as an L3: Empirical evidence from school-age learners in Catalonia. In Camilla Bardel, Ylva Falk \& Christina Lindqvist (eds.), Tredjespråkinlärning, 185-206. Lund: Studentlitteratur.

Sánchez, Laura \& Camilla Bardel. 2017. Transfer from an L2 in third language learning: A study on L2 proficiency. In Tanja Angelovska \& Angela Hahn (eds.), L3 syntactic transfer: Models, new developments and implications, 223250. Amsterdam: John Benjamins.

Sánchez, Laura. 2020. From L2 to L3, verbs getting into place: A study on interlanguage transfer and L2 syntactic proficiency. In Camilla Bardel \& Laura Sánchez (eds.), Third language acquisition: Age, proficiency and multilingualism, 209-235. Berlin: Language Science Press. DOI: 10.5281/zenodo.4138747.

Schütze, Carson T. \& Jon Sprouse. 2014. Judgment data. In Robert Podesva \& Devyani Sharma (eds.), Research methods in linguistics, 27-50. Cambridge: Cambridge University Press.

Schwartz, Bonnie D. \& Rex A. Sprouse. 1996. L2 cognitive states and the Full Transfer/Full Access model. Second Language Research 12(1). 40-72. DOI: 10. 1177/026765839601200103.

Stadt, Rosalinde, Aafke Hulk \& Petra Sleeman. 2016. The influence of L2 English and immersion on L3 French in the Netherlands. In Jenny Audring \& Sander Lestrade (eds.), Linguistics in the Netherlands, 152-165. Amsterdam: John Benjamins.

Stadt, Rosalinde, Aafke Hulk \& Petra Sleeman. 2018a. The influence of L1 Dutch and L2 English on L3 French: A longitudinal study. Fournal of the European Second Language Association 1(1). 63-71.

Stadt, Rosalinde, Aafke Hulk \& Petra Sleeman. 2018b. The influence of L2 English on L3 French acquisition in bilingual education. In Tessa Mearns \& Rick de Graaff (eds.), CLIL and bilingual education in the Netherlands, 228-250. Special issue of the Dutch fournal of Applied Linguistics, 7(2). Amsterdam: John Benjamins. 
Stadt, Rosalinde, Aafke Hulk \& Petra Sleeman. 2018c. The role of L2 exposure in L3A: A comparative study between third- and fourth-year secondary school students in the Netherlands. In Janine Berns, Haike Jacobs \& Dominique Nouveau (eds.), Romance languages and linguistic theory 13: Selected papers from "Going Romance" 29, Nijmegen, 279-296. Amsterdam: John Benjamins.

Thijs, Annette, Bas Trimbos, Dirk Tuin, Marianne Bodde \& Rick de Graaff. 2011. Engels in het basisonderwijs: vakdossier. Enschede: SLO.

Tremblay, Marie-Claude. 2006. Cross-linguistic influence in third language acquisition: The role of L2 proficiency and L2 exposure. Cahiers Linguistiques d'Ottawa/Ottawa Papers in Linguistics 34. 109-119.

Unsworth, Sharon, Liv Persson, Tineke Prins \& Kees De Bot. 2015. An investigation of factors affecting early foreign language learning in the Netherlands. Applied Linguistics 36(5). 527-548.

Verspoor, Marjolijn, Kees De Bot \& Floor van der Heiden. 2007. Engels in het voortgezet onderwijs, de rol van buitenschools taalcontact. Levende Talen Tijdschrift 8(3). 3-10.

Verspoor, Marjolijn, Kees De Bot \& Eva van Rein. 2010. Binnen- en buitenschools taalcontact en het leren van Engels. Levende Talen Tijdschrift 11(4). 14-33.

Wahlstrom McKay, Louise. 2001. The acquisition and use of verb-second structures by second language learners of German. Iowa City: University of Iowa. (Doctoral dissertation).

Westergaard, Marit, Natalia Mitrofanova, Roksolana Mykhaylyk \& Yulia Rodina. 2016. Crosslinguistic influence in the acquisition of a third language: The linguistic proximity model. International fournal of Bilingualism 21(6). 666-682. 


\section{Name index}

Abraham, Werner, 210

Abunuwara, Ehab, 27, 73, 100, 215, 229, 230

Adesope, Olusola O., 171

Agresti, Alan, 87

Aitchison, Jean, 69, 95

Al-Thubaiti, Kholoud Abdullah, 169

Alibabaee, Ahmad, 77, 94

Andersen, Roger, 45

Anderson, John, 53

Angelovska, Tanja, 28

Aronin, Larissa, 16, 168

Athanasopoulos, Panos, 54, 55, 58, 60

August, Diane, 170, 193, 195

Baars, Bernard, 19

Baker, Colin, 219

Bardel, Camilla, 2, 17, 20, 23, 26, 29, $30,50,53,193,214-218,228$, $229,231,238,240,243,253-$ 256

Barkhuizen, Gary, 176

Barr, Dale J., 178

Bartlet, Guillermo, 230

Bates, Douglas, 178

Beaton, Alan, 7, 146

Beck, Maria-Louise, 210

Belletti, Adriana, 112, 117-120, 122, 135, 136, 138

Benmamoun, Elabbas, 22

Bennati, Elisa, 120, 124

Berkes, Éva, 2, 50-52
Berman, Ruth, 50

Bernardini, Petra, 120

Berretta, Monica, 117-120

Bialystok, Ellen, 123, 168, 171, 172, 192, 193, 195

Bild, Eva-Rebecca, 150

Binnick, Roger, 45, 46

Bird, Helen, 83

Bohnacker, Ute, 243

Bosma, Evelyn, 150, 159

Bottari, Piero, 118

Bouvy, Christine, 28, 215, 231

Brohy, Claudine, 21

Brones, Isabel, 147

Bruhn de Garavito, Joyce, 117

Brysbaert, Marc, 72

Buchholz, Barbara, 169

Burani, Cristina, 83

Bylund, Emanuel, 55, 58, 60

Cabrelli, Jennifer, 28

Cancila, Jessica, 117, 119, 120

Caramazza, Alfonso, 147

Casaponsa, Aina, 147, 161

Castro, Dina C., 172

Caudal, Patrick, 45

Cenoz, Jasone, 2, 16, 17, 21, 26-28, 68, $73,168,194,215,230,240$

Chen, Hsuan-Chin, 75

Cheung, Alan, 170

Chini, Marina, 118, 122

Chumbow, Beban Sammy, 215, 230 
Clenton, Jon, 77

Cobo-Lewis, Alan B., 175

Cohen, Jacob, 90

Collier, Virginia, 193

Coltheart, Max, 83

Comrie, Bernard, 44

Connors, Kathleen, 137

Cook, Vivian, 26, 215

Corino, Elisa, 120, 121, 135, 137

Costa, Albert, 70, 147

Coste, Daniel, 25, 27

Cremer, Marjolein, 76-78, 80, 97

Cummins, James, 215, 230

Cummins, Jim, 10, 22, 170, 193

Cunningham, Thomas. H., 149, 158

Curley, Janet, 71

D’Ydewalle, Géry, 150

Dahl, Östen, 44

Daller, Helmut, 97

De Angelis, Gessica, 16, 17, 25-30, 50, $68,70,72,171,210,214,217$, 228,231

De Bot, Kees, 168, 170, 214, 229

De Bruin, Angela, 171

De Groot, Annette M. B., 7, 70, 75, 77, 146,147

De Swart, Henriette, 47

Dechert, Hans, 230

Degani, Tamar, 21

DeKeyser, Robert M., 19, 54, 70

Dell, Gary S., 70

Dentler, Sigrid, 17

Depraetre, Ilsa, 45

Dewaele, Jean-Marc, 50, 214, 215, 229

Di Domenico, Elisa, 124

Diaubalick, Tim, 44, 56, 58, 59

Dijkstra, Jelske, 150

Dijkstra, Ton, 28, 70, 72, 73, 147, 148
Doiz, Aintzane, 46, 47, 176

Dörnyei, Zoltan, 220

Duffield, Nigel Gordon, 118

Dunn, Douglas M., 7, 145, 153

Dunn, Leota M., 148, 149

Dunn, Lloyd M., 7, 145, 148, 149, 153

Duyck, Wouter, 72, 75

Dyen, Isidore, 151, 153

Ellis, Nick C., 3, 7, 54, 95-97, 146

Ellis, Rod, 54, 123, 176, 255

Entwisle, Doris M., 76, 94

Erman, Britt, 96

Ervin, Susan M., 76, 94

Evangelou, Maria, 172

Evans, Michael, 19, 20

Falk, Ylva, 17, 20, 26, 29, 50, 53, 216, 228, 238, 240, 241, 243, 253, 254, 256, 257

Feng, Xiaojia, 168

Ferrari, Ida, 120, 137

Fessi, Inés, 56

Field, Andy, 90

Fitzpatrick, Tess, 4, 5, 67-69, 72, 75$80,94-96,99,100$

Flynn, Suzanne, 2, 30, 50-52, 240, 255

Foote, Rebecca, 44, 56, 57

Fouser, Robert, 20, 138

Franklin, Stan, 19

García Lecumberri, María Luisa, 21, 24,168

García Mayo, María del Pilar, 21, 24, $68,168,238-240$

García, Ofelia, 146

Gawlitzek-Maiwald, Ira, 220, 230

Genelot, Sophie, 169

Genesee, Fred, 169 
Giannini, Stefania, 112, 117-120, 122

Gibson, Martha, 17, 20

Gilhooly, Ken J., 83

Goldenberg, Claude, 195

Gollan, Tamar, 75

Goorhuis-Brouwer, Sieneke, 170

Gooskens, Charlotte, 83

Goral, Mira, 72, 74, 75, 100

Goriot, Claire, 7, 151, 159, 160, 194

Graham, C. Ray, 149, 158

Graham, Suzanne, 169

Grainger, Jonathan, 73

Granfeldt, Jonas, 119, 135

Green, David W., 72

Greenberg, Zachary I., 171

Grondin, Nathalie, 137

Groseva, Maria, 215, 231

Grosjean, François, 16, 17, 26, 72, 168

Guasti, Maria Teresa, 112, 118, 119

Gudmundson, Anna, 2-5, 20

Güell, Lourdes, 46

Guijarro-Fuentes, Pedro, 44, 56, 58, 59

Gundel, Jeanette K., 137

Gustafson-Capková, Sofia, 83

Haastrup, Kirsten, 69, 95

Hahn, Angela, 28

Hakuta, Kenji, 170, 193

Hall, Christopher, 230

Hamann, Cornelia, 119, 135, 136, 138

Hammarberg, Björn, 2, 16, 17, 28, 50,

53, 68, 112, 209, 215, 230, 238, 244

Hammill, Donald P., 150

Hanzeli, Victor, 220

Hartmann, Britt, 83

Hawkins, Roger, 137

Heaton, John Brian, 219
Henriksen, Birgit, 69, 95

Herdina, Philip, 26-28, 139, 215, 216

Hermas, Abdelkader, 29, 240, 242, 246, 252, 255, 256

Herschensohn, Julia, 135, 137

Herwig, Anna, 27, 74

Hiroshi, Zoya, 21

Ho, Connie, 75

Horst, Marlise, 146

Hufeisen, Britta, 2, 16-18, 168

Hulk, Aafke, 119, 137

Hulstijn, Jan, 69, 70

Izura, Cristina, 4, 5, 67-69, 72, 75-80, $94,95,99,100$

Jacobs, Holly L., 176

Jaekel, Nils, 169

Jaensch, Carol, 26, 27

Jarvis, Scott, 9, 216, 219, 228, 231

Jaspaert, Koen, 21

Jessner, Ulrike, 2, 18-20, 26-28, 139, $215,216,240$

Jin, Young S., 75

Juffs, Alan, 72

Karpava, Sviatlana, 56

Katona, Lucy, 220

Kecskes, Istvan, 29

Keijzer, Merel, 81

Kellerman, Eric, 50

Kelley, Alaina, 149, 158, 159

Kemp, Charlotte, 19, 20

Keppel, Geoffrey, 76

Khazaeenezhad, Bahareh, 77, 94

Kidd, Evan, 18

Klein, Elaine, 19

Klein, Wolfgang, 45, 242

Kohnert, Kathryn, 146, 149, 158, 159 
Kolde, Gottfried, 175

Kopečková, Romana, 21

Kovelman, Ioulia, 171

Kras, Tihana, 81

Krashen, Stephen, 24, 54

Kroll, Judith F., 68, 70-72, 75, 95, 147

Kruse, Heleen, 77

Krzeminska-Adamek, Malgorzata, 76

La Heij, Wido, 70

Langacker, Ronald, 47

Larson-Hall, Jenifer, 169

Lasagabaster, David, 171, 176

Laufer, Batia, 177

Lázaro Ibarrola, Amparo, 160

Lemhöfer, Kristin, 70, 73, 101, 148

Lemmens, Gertrude, 21

Leonini, Chiara, 117-120, 122

Leśniewska, Justyna, 160

Leung, Yan-Kit Ingrid, 28, 29, 215, 216, 231, 255

Levelt, Willem J. M., 70

Li, Li, 75, 99

Li, Xiaoqian, 171, 195

Lightbown, Patsy Martin, 170

Lin, Angel, 146

Linck, Jared A., 74

Lind, Marianne, 83

Lindemann, Beate, 17

Lindgren, Eva, 151

Lindqvist, Christina, 2, 26, 50, 255

Logie, Robert H., 83

Luk, Gigi, 171, 172

Maffei, Sabrina, 117, 119, 120, 122, 137

Malabonga, Valerie, 149, 159

Marian, Viorica, 74

Martin, Michelle, 172

Marx, Nicole, 17, 18
Matteini, Simona, 120

McLaughlin, Barry, 19, 20

Meara, Paul, 77, 94, 95

Meijer, Cor, 168

Meijers, Guust, 21

Méndez Pérez, Anita, 146, 149, 150, 154

Meyer, Antje S., 70

Michaelis, Laura, 43

Missler, Bettina, 19

Mitchell, Rosamond, 16, 17

Montrul, Silvina, 48, 117, 123, 214, 230

Morton, J. Bruce, 171

Müller, Natascha, 119, 137

Muñoz, Carmen, 1-3, 6-8, 20-25, 151, $154,159,161,168,169,171,220$

Murphy, Victoria A., 172

Myles, Florence, 16, 17

Na Ranong, Sirita, 29, 255

Nas, Gerard L. J., 75

Nation, Paul, 69, 95, 177

Nation, Robert, 20

Nayak, Nandini, 19, 20, 56

Newcomer, Phyllis L., 150

North, Brian, 215

Nuckle, Lucie, 137

O’Seaghdha, Padraig G., 70

Odlin, Terence, 50, 51, 215

Oller, D. Kimbrough, 149, 158

Otwinowska, Agnieszka, 7, 20, 146, 152

Paap, Kenneth R., 171

Paivio, Allan, 83

Pajak, Bozena, 255, 256

Papp, Tünde, 29

Paradis, Michel, 3, 19, 54, 251, 253, 256 
Parizzi, Francesca, 125

Pecher, Diane, 75

Pechmann, Thomas, 70

Pellicer-Sánchez, Ana, 69

Perdue, Clive, 242

Peukert, Hagen, 28

Pfenninger, Simone E., 1-3, 8, 10, 21, $22,24,25,169,174-177,179$, 180, 186, 188, 194

Pienemann, Manfred, 242, 255

Poarch, Gregory J., 148

Polinsky, Maria, 22

Politzer, Robert L., 77, 94

Postman, Léo, 76

Potapova, Irina, 148

Potter, Mary C., 71

Poulisse, Nanda, 70

Prys Jones, Sylvia, 219

Puig-Mayenco, Eloi, 30

Rash, Felicity, 175

Rast, Rebekah, 20, 214, 228

Rastle, Kathleen, 83

Rauch, Dominique Patrizia, 171

Raupach, Manfred, 230

Read, John, 69

Riegel, Klaus F., 77, 95

Ringbom, Håkan, 7, 20, 146, 214, 215

Rodríguez, Timothy A., 146

Rose, Patricia, 239

Rothman, Jason, 29, 50-52, 238-240, 255

Roussarie, Laurent, 45

Rutgers, Dieuwerke, 19, 20

Ryan, Ellen Bouchard, 123

Salaberry, Rafael, 3, 20, 44, 48, 56, 59

Sánchez Casas, Rosa M., 70, 73
Sánchez, Laura, 1-3, 9, 16, 20, 26, 29, $53,170,193,210-220,228,229$, $231,241,254-256$

Sanders, Marianne, 21

Santoro, Maurizio, 117, 118

Sanz, Cristina, 19, 21, 171, 172, 192, 193

Sasse, Hank, 44

Sayehli, Susan, 25

Schepens, Job, 151

Schlyter, Suzanne, 119, 135, 137

Schmiedtová, Barbara, 55, 60

Schmitt, Norbert, 69, 177

Scholes, Joseph, 48, 49

Schönpflug, Ute, 27

Schoonbaert, Sofie, 72, 75

Schoonen, Rob, 170

Schriefers, Herbert, 70

Schütze, Carson T., 255

Schwartz, Bonnie D., 52, 54, 239, 240, 246, 252

Schwieter, John W., 74

Sciutti, Sandro, 2-5, 9, 20

Segalowitz, Norman, 69, 70

Segalowitz, Sidney, 70

Selinker, Larry, 27, 29, 210, 214

Shanahan, Timothy, 195

Shanon, Benny, 214, 229

Sharwood Smith, Michael, 16, 17, 19

Sinclair, John, 96

Singleton, David, 16, 22, 24, 25, 72, 174, 177, 179, 180, 186, 194

Slabakova, Roumyana, 30, 48, 51, 52

Slavin, Robert Edward, 170

Slobin, Dan, 50

Smith, Carlota, 44

Soveri, Anna, 172

Sparks, Richard L., 170

Spinelli, Barbara, 125

Sprouse, Jon, 255 
Sprouse, Rex A., 52, 239, 240, 246, 252

Stadt, Rosalinde, 3, 10, 20, 238, 239, 243, 244, 246, 251-254, 256

Stadthagen-González, Hans, 154

Stafford, Catherine A., 172

Stewart, Erika, 68, 71, 72, 95, 147

Stolz, Walter S., 76

Stratilaki, Sofia, 27, 215

Sunderman, Gretchen, 74

Sundqvist, Pia, 25

Swain, Merrill, 20, 150, 171

Sylvén, Liss Kerstin, 25

Szewczyk, Jakub, 20

Szubko-Sitarek, Weronika, 68, 73, 100, 101, 148

Tagarelli, Kaitlyn, 19

Tarone, Elaine, 137

Thijs, Annette, 239

Thomas, Jacqueline, 19, 215, 230

Tiffany, Janice, 76

Timofte, Monica, 120

Tonkin, Humphrey, 15

Towell, Richard, 137

Tracy, Rosemarie, 220, 230

Tremblay, Marie-Claude, 238

Trévisiol, Pascale, 27

Tytus, Agniezska Ewa, 124

Ullman, Michael, 53, 54

Umbel, Vivian M., 148, 149, 158

Unsworth, Sharon, 150, 152, 153, 159, 169, 239

Valencia, José F., 21, 168, 240

Van de Poel, Marijke, 150

Van de Weijer, Joost, 120

Van Hell, Janet G., 7, 28, 77, 146-148

Van Heuven, Walter J. B., 70, 72, 73, 95
Vendler, Zeno, 45

Verspoor, Marjolijn, 77, 247

Vorberg, Dirk, 70

Wagenmakers, Eric-Jan, 75

Wagner, Daniel, 21

Wahlstrom McKay, Louise, 242

Weinreich, Uriel, 70, 71

Westergaard, Marit, 29, 50, 51, 241, 254

White, Joanna, 146

White, Lydia, 117-119, 137

Williams, Cen, 146

Williams, John, 53

Williams, Sarah, 2, 28, 50, 53, 209

Wilson, Michael D., 83

Wolfe-Quintero, Kate, 176

Wolter, Brent, 77

Wray, Alison, 96

Wu, Zhaohong, 72

Yow, Wei Quin, 171, 195

Zareva, Alla, 77

Zeelenberg, René, 75

Ziegeler, Debra, 44

Zivian, Irina W. M., 77, 95

Zobl, Helmut, 19, 137 




\section{Third language acquisition}

This book deals with the phenomenon of third language (L3) acquisition. As a research field, L3 acquisition is established as a branch of multilingualism that is concerned with how multilinguals learn additional languages and the role that their multilingual background plays in the process of language learning. The volume points out some current directions in this particular research area with a number of studies that reveal the complexity of multilingual language learning and its typical variation and dynamics.

ISBN $978-3-96110-280-8$

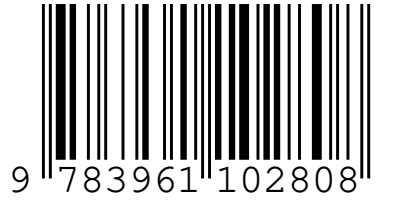

